\title{
Prenatal screening à la carte? Ethical reflection on the scope of testing for foetal anomalies
}

Citation for published version (APA):

de Jong, A. (2013). Prenatal screening à la carte? Ethical reflection on the scope of testing for foetal anomalies. [Doctoral Thesis, Maastricht University]. Maastricht University. https://doi.org/10.26481/dis.20131107aj

Document status and date:

Published: 01/01/2013

DOI:

10.26481/dis.20131107aj

Document Version:

Publisher's PDF, also known as Version of record

\section{Please check the document version of this publication:}

- A submitted manuscript is the version of the article upon submission and before peer-review. There can be important differences between the submitted version and the official published version of record.

People interested in the research are advised to contact the author for the final version of the publication, or visit the DOI to the publisher's website.

- The final author version and the galley proof are versions of the publication after peer review.

- The final published version features the final layout of the paper including the volume, issue and page numbers.

Link to publication

\footnotetext{
General rights rights.

- You may freely distribute the URL identifying the publication in the public portal. please follow below link for the End User Agreement:

www.umlib.nl/taverne-license

Take down policy

If you believe that this document breaches copyright please contact us at:

repository@maastrichtuniversity.nl

providing details and we will investigate your claim.
}

Copyright and moral rights for the publications made accessible in the public portal are retained by the authors and/or other copyright owners and it is a condition of accessing publications that users recognise and abide by the legal requirements associated with these

- Users may download and print one copy of any publication from the public portal for the purpose of private study or research.

- You may not further distribute the material or use it for any profit-making activity or commercial gain

If the publication is distributed under the terms of Article $25 \mathrm{fa}$ of the Dutch Copyright Act, indicated by the "Taverne" license above, 
Prenatal screening à la carte?

Ethical reflection on the scope of testing for foetal anomalies

Antina de Jong 
Prenatal screening à la carte?

Ethical reflection on the scope of testing for foetal anomalies

Thesis, Maastricht University, the Netherlands

ISBN: 978-90-5335-720-0

Author: Antina de Jong

Cover: Nikki Vermeulen, Ridderprint BV, Ridderkerk, the Netherlands

Lay-out: Simone Vinke, Ridderprint BV, Ridderkerk, the Netherlands

Printing: Ridderprint BV, Ridderkerk, the Netherlands

Copyright (C) 2013 by Antina de Jong

All rights reserved. No parts of this book may be reproduced, stored in a retrieval system, or transmitted in any form or by any means without prior permission of the author. 


\section{Prenatal screening à la carte?}

\section{Ethical reflection on the scope of testing for foetal anomalies}

\section{PROEFSCHRIFT}

ter verkrijging van de graad van doctor aan de Universiteit Maastricht, op gezag van de Rector Magnificus, Prof. dr. L.L.G. Soete volgens het besluit van het College van Decanen,

in het openbaar te verdedigen

op donderdag 7 november 2013 om 14.00 uur

door

Antina de Jong

Geboren op 8 mei 1967 te Gaast 


\section{Promotores:}

Prof. dr. G.M.W.R. de Wert

Prof. dr. C.E.M. de Die-Smulders

Prof. dr. J.M.M. van Lith (LUMC Leiden)

\section{Copromotor:}

Dr. W.J. Dondorp

\section{Beoordelingscommissie:}

Prof. dr. J.G. Nijhuis (chair)

Prof. dr. I.D. de Beaufort (Erasmus University Rotterdam)

Prof. dr. C. Stumpel

This thesis is the result of a research project of the CSG Centre for Society and the Life Sciences in The Netherlands, funded by the Netherlands Genomics Initiative (research project number: 70.1.061b). The research was conducted at the Faculty of Health, Medicine and Life Sciences, Department of Health, Ethics \& Society, School for Oncology and Developmental Biology (GROW), Maastricht University. 


\section{Contents}

$\begin{array}{ll}\text { Voorwoord } & 7\end{array}$

Chapter 1 General introduction 9

Chapter 2 Rapid aneuploidy detection or karyotyping? Ethical reflection 25

European Journal of Human Genetics 2011;19(10):1020-1025

Chapter 3 Non-invasive prenatal testing: ethical issues explored

European Journal of Human Genetics 2010;18(3):272-277

Chapter 4 Non-invasive prenatal diagnosis for aneuploidy: toward an integral

ethical assessment

Human Reproduction 2011;26(11):2915-2917

Chapter 5 Microarrays as a diagnostic tool in prenatal screening strategies.

Ethical reflection

Human Genetics (in press)

Chapter 6 Advances in prenatal screening: the ethical dimension

Nature Reviews Genetics 2011;12(9):657-663

Chapter 7 The scope of prenatal diagnosis for women at increased risk for aneuploidies: views and preferences of professionals and potential users Journal of Community Genetics 2013;4(1):125-135

Chapter 8 The new genetics and informed consent: differentiating choice to preserve autonomy

Bioethics 2013;27(6):348-355

Chapter 9 General discussion

PART I The normative framework for prenatal screening

PART II Dynamics of prenatal testing: challenging the normative framework

PART III Reproductive autonomy in context

Summary

Samenvatting

Curriculum Vitae 



\section{Voorwoord}

Dit proefschrift had ik alleen niet kunnen schrijven. Velen hebben, ieder op haar of zijn eigen wijze, bijgedragen aan de totstandkoming ervan. Het promoveren heeft mij vooral geduld gevraagd en geleerd. En dat geldt vast ook voor de mensen om mij heen. Een aantal personen wil ik in het bijzonder bedanken voor het zijn van metgezel tijdens dit promotieproces.

Prof.dr. G.M.W.R. de Wert, beste Guido, dank voor de gelegenheid die je me bood dit onderzoek te doen en je onverminderde vertrouwen in het welslagen ervan. Het gemak waarmee jij orde kan scheppen in een warboel van gedachten is evenzeer te bewonderen als te benijden. Je kritische vragen dreven mij soms tot wanhoop, maar brachten net zo vaak ons denken verder. En dat is waar een promotor voor is. Ik vond het fijn dat er ook ruimte was voor niet-werkgesprekken en dat we samen en met anderen 'zoals vanouds' plezier konden hebben.

Dr. W.J. Dondorp, beste Wybo, ogenschijnlijk onvermoeibaar heb jij versie na versie van alle hoofdstukken in dit proefschrift minutieus doorgenomen en voorzien van commentaar. Als jij je goedkeuring hebt gegeven weet ik zeker dat het goed is en dat stelt gerust. Dank dat ik nooit tevergeefs een beroep op je deed en dat ik van jouw grote expertise mocht profiteren. Je hebt niet alleen belangstelling voor 'de zaak' maar ook voor de mens daarachter. Met een goed gevoel herinner ik mij de keren dat we het werk even lieten voor wat het was en het overige wel en wee de revue lieten passeren.

Prof.dr. C.E.M. de Die-Smulders, beste Christine, dank voor je professionele en persoonlijke steun in de afgelopen jaren. Jouw jarenlange klinische ervaring en vakkennis hebben mijn onderzoek verrijkt. Het promotieproces viel mij soms zwaar, maar gelukkig kon ik altijd bij jou terecht. Met warme herinnering denk ik terug aan de keren dat ik bij jou en Jan thuis kwam om te eten en op te laden.

Prof.dr. J.J.M. van Lith, beste Jan, jouw grote ervaring en praktische inslag hebben ertoe bijgedragen dat ons academisch werk concreet genoeg werd om ook relevant voor de praktijk te zijn. Want dat is de plaats waar het uiteindelijk moet gebeuren. Dank voor het delen van je inzichten in de prettige en constructieve bijeenkomsten die we hadden.

Dr. S.G.M. Frints, beste Suzanne, jij zette ons tijdig op het spoor van NIPT en de manier waarop jij wetenschap en praktijk weet te combineren heeft een meerwaarde voor mijn project betekend. Dank voor je bereidheid in alle fasen van het proces mee te denken en mee te werken.

Dr. M.V.E. Macville, beste Merryn, voor mensen zoals ik blijft het moeilijk te doorgronden wat er nou precies in laboratoria gebeurt. Dank dat je me keer op keer wilde uitleggen hoe het werkte en dat ik me op jou kon verlaten voor het op juistheid checken van de technische details. 
Dr. A. Krumeich, beste Anja, dank voor je hulp bij de voorbereiding van het empirisch onderzoek en het verwerken van de data in een leesbaar artikel.

Hoewel ik niet zo vaak in Maastricht was, hebben de collega's van Metamedica mij altijd ontvangen als 'een van ons'. Het contact op afstand was daarbij net zo belangrijk als de ontmoeting op UNS40. In het bijzonder wil ik hier noemen: dr. Sandra van der Dam, Anna Wolters M.Phil., dr. Jenny Slatman, dr. Albine Moser en Angelique Heijnen. Beste Angelique, we konden ons contact gewoon weer oppakken waar het 7 jaar geleden bij het IGE was gebleven. Dank voor je veelzijdige raad en daad tijdens mijn tijd bij Metamedica en bij de praktische zaken van het promoveren.

En met weemoed noem ik hier onze veel te vroeg overleden collega dr. R.L.P. Berghmans. Beste Ron, dank voor je goede kamergenoot- en kameraadschap. Wat zouden we ook voor de promotie veel voorpret hebben gehad met het doornemen van alle waarschijnlijke en meest onwaarschijnlijke scenario's. Het deed me goed om samen met jou buiten de orde te denken en zo nieuwe ideeën en energie te krijgen.

Prof.dr. A.C.J.W. Janssens, beste Cecile, ik ken weinig wetenschappers die met zo veel passie en merkbaar plezier hun academische arbeid verrichten als jij. Het was voor ons beiden een verrassing toen we elkaar na 7 jaar weer tegenkwamen. Dit weerzien leidde tot een geslaagde samenwerking in het bestuur van de NACGG. Dank voor je adviezen en je inspiratie tijdens onze 'napraat-etentjes'.

Mijn trouwe ex-collega's van de Raad van State, mr.dr. E.O.H.P. Florijn, mr.dr. G.J.M. Evers en mr.dr. J. Luijendijk. Beste Erik, Guido en Hanneke, jullie belangstelling en steun tijdens dit promotieproces had ik niet kunnen missen. Jullie maanden mij tot bedaren als ik te opstandig werd en bemoedigden mij als het nodig was. Hoe mijn pet ook stond, ik wist mij altijd welkom in jullie gezelschap. Onze avonden rond Plein - die soms begonnen met een diepe zucht maar meestal eindigden vol frisse moed - hebben veel voor mij betekend.

Lieve Frank, Quirine en Sietze, ondertussen was ik gelukkig met jullie, die mij het dierbaarst zijn. Ik hoop dat in de afgelopen jaren altijd duidelijk is geweest dat jullie voor mij onvergelijkbaar veel meer betekenen dan enig artikel of boek dat ik schreef. En samen gaan wij gewoon verder. 


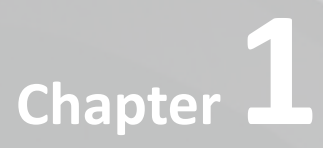

General introduction 



\subsection{Prenatal screening: traditional practice}

Soon after the first report in $1966^{1}$ on the possibility to karyotype the foetus in utero by using foetal cells obtained by amniocentesis, prenatal testing for the detection of foetal conditions in pregnancy found its way into clinical practice. From then on, prenatal screening as nowadays offered in most Western countries also gradually developed. Initially, screening was used as a public health tool, to reduce morbidity and mortality by preventing the birth of children with (severe) genetic disorders. ${ }^{2}$ Prenatal screening for Down's syndrome and some other major aneuploidies was offered to pregnant women of advanced maternal age only (first $\geq 38$ year, later $\geq 36$ years in most countries), because they have an a priori increased risk of having a child with aneuploidy. The methods used were amniocentesis ( $\geq 15-16$ weeks of gestation) and, since the mid-1980s, also chorionic villus sampling (CVS; $\geq 10-11$ week of gestation)..$^{3,4}$ At the time, these invasive methods were thought to entail an iatrogenic miscarriage risk of about $1,0 \%$ (more recent estimations are in the range of $0,3-0,5 \%)^{5}$ Because of this risk and given the relatively high costs of the invasive techniques, the offer was limited to pregnant women of advanced maternal age for reasons of proportionality and cost-effectiveness. This policy was based on weighing the relative benefits (number of affected foetuses found) and risk of the procedure (iatrogenic miscarriage): the so-called detection/miscarriage ratio. ${ }^{6}$

From the 1980s methods of risk-assessment for the most common trisomies (21, 18 and 13) were developed. These tests were based on maternal serum markers, and a decade later they were combined with first-trimester foetal nuchal translucency (NT-) measurement: together these are called the 'combined screening test'. ${ }^{3}$ This development has led to a twostep testing strategy: first, a risk-assessment test offered to (generally) all pregnant women -irrespective of age- and, second, invasive diagnostic testing to only those at increased risk (around > 1:200-250) for having a child with one of the trisomies.

Conventional karyotyping, identifying major numerical or structural chromosomal abnormalities that are visible by microscope, has been the gold standard of prenatal diagnostic testing for the past four decades. This meant that whereas the initial screen was usually set to establish the risk for trisomies 21,18 and 13 , the subsequent karyotyping provided insight into a wider range of possible defects, including sex-chromosomal abnormalities.

Besides the chromosomal abnormalities, testing for open neural tube defects (spina bifida and anencephaly) was performed in the second trimester, by means of measuring alphafetoprotein (AFP) in maternal serum. In case of a high AFP level, which is associated with neural tube defects, subsequent diagnostic testing followed. ${ }^{3}$ From the 1990 s onward, 
a second trimester foetal ultrasound scan was increasingly being offered to all pregnant women to detect neural tube defects and other major congenital anomalies.

The risk of testing (invasive procedures), the anxiety and burden caused by the test offer and the possible result of selective abortion were issues of discussion. However, the scope of prenatal screening and the techniques used were hardly debated, mainly due to a lack of alternatives. As a result, the testing techniques and the described scope remained rather constant for decades, and the screening strategy consisted of a limited set of standard test offers that pregnant women could either accept or decline.

Recent technological developments have challenged the obviousness of these standards and are reason to question what test to offer, to whom and why. ${ }^{7-10}$ As I will show, these are not only practical issues, but they bear moral relevance as well. In this thesis, I will focus on three recent developments in prenatal screening, that give reason for ethical reflection on former and current prenatal screening strategies: 1) a narrowing of the scope of testing, 2) a broadening of the scope of testing, and 3) an increase in the number and a diversification of the purpose of prenatal tests. These developments will be described in Section 1.4.

\subsection{The aim and scope of prenatal screening}

From the beginning, prenatal screening policies were debated because the aim of offering testing for foetal abnormalities was questioned. Whereas other population screening programmes offer opportunity for primary prevention or treatment, in the prenatal context treatment is only rarely an option, although foetal therapy may become more frequent in the future. ${ }^{11,12}$ Moreover, the only 'preventive measure' in this context would be selective abortion. To portray selective abortion as a means of prevention is ethically (as well as legally and politically) problematic, because it may send the message that women ought to have an abortion if they are pregnant with an affected foetus and that people with particular disorders are not welcome in society. ${ }^{13}$ The preventive goal of prenatal screening was therefore increasingly criticised and was replaced by a so-called 'autonomy view' ${ }^{14}$, that emphasised the personal character of reproductive choices. This focus on individual reproductive decision-making originated from the experience in clinical genetics and obstetric practice that the often unexpected birth of a handicapped child caused suffering and hardship to not only the child, but to the parents and often the family as well. Reproductive counselling of persons in families affected with severe genetic disabilities and disorders, running the risk of transmitting these to one's offspring, was a recognised need and well established practice in clinical genetics. This practice contributed to reformulating the purpose of offering prenatal screening: to equip prospective parents with health-related information about their foetus 
to offer opportunity for reproductive choice. Prospective parents were thus able to avoid, if wanted, the grief and suffering caused by the birth of a handicapped child. ${ }^{15}$ As a result, a transition "from chance to choice" ${ }^{16}$ could be achieved. To make clear that participation in screening was voluntary and aimed to allow pregnant women (and their partners) to make their own reproductive choices, the purpose of prenatal screening in Western policy documents was no longer worded in terms of prevention or health gain, but as giving those concerned worthwhile options from which to choose. ${ }^{6,17,18}$ This aim was briefly formulated as facilitating autonomous reproductive choice.

It was well recognized that prenatal screening also posed a burden on pregnant women. When confronted with the offer to test for foetal abnormalities, prospective parents are made aware of the possibility that their foetus might be affected with one of the disorders tested for. This knowledge in itself may raise uncertainty and anxiety. Moreover, the test offer imposes pregnant women with the responsibility to choose whether to be tested or not. In case of invasive testing, this also includes the decision whether they want to run the risk of an iatrogenic miscarriage. Those who choose to be tested and receive a reassuring test result, will eventually be relieved. However, if prospective parents are confronted with an adverse test result, they have to decide about continuing or terminating the pregnancy. To abort an initially wanted child is emotionally very burdening and stressful and may cause sorrow and grief over a longer period of time. This psychological and emotional impact of prenatal screening and its possible consequences, inspired the discussion whether offering prenatal testing could be seen as beneficial at all. Despite ongoing debate, the general opinion was and still is that prospective parents, being aware of the possible burdens, only themselves can decide what they are willing and able to handle and what suits their situation best. Therefore, emphasising the voluntary character of participating throughout the whole prenatal screening strategy is essential.

\subsection{The justification of abortion and selective abortion}

Because prenatal testing aims to detect foetal abnormalities in order to give prospective parents the opportunity to either terminate the pregnancy or prepare for a child with a serious disorder, a preliminary question is whether abortion, and more in particular selective abortion, can be justified at all. The answer to this question primarily depends on the moral status that is attributed to the foetus, and that determines whether foetal life has to be protected or not. ${ }^{19}$ If the embryo/foetus is considered a person right from the start (i.e. from the conception onwards), having the same moral status and rights as any other person (children, adults), then abortion has to be qualified as murder and is unjustifiable. This is the stance of the Roman Catholic Church and some other Christian communities. Others (some 
Jewish and Islamic movements) differentiate between various stages in foetal development and often assign a major importance to the cerebral development of the foetus at 40 days (8 weeks of gestation). This moment is associated with ensoulment, and from that moment the status of the foetus is thought to equal that of a person. ${ }^{20}$ In most Western countries, the 'gradualist view' is dominant. In this view, foetal development is also of major importance. The moral status of the embryo/foetus is seen as being initially relatively low but gradually increasing with its development. This means that abortion is never understood as a morally indifferent act, but that it is acknowledged that in certain situations abortion, all things considered, can be seen as a morally defensible act: the earlier in pregnancy, the easier to justify, until a certain point in foetal development. Legislation in many Western countries allows abortion until 20-24 weeks of gestation under certain conditions.

Selective abortion is morally even more complex, because then prospective parents do not want to avoid having any child, but want to avoid having this particular child. According to some commentators this selective character of abortion for foetal abnormalities means that the lives of people with the selected abnormality or disease are considered worth less than the lives of healthy people. ${ }^{13}$ This critique is known as the 'disability rights critique'. Moreover, according to the 'expressivist argument' the prenatal test offer itself is seen as contributing to such discrimination, because it offers opportunity for selective abortion and sends the tacit message that the lives of 'disabled' persons are worth less than the lives of persons without disabilities. ${ }^{21}$ This critique does however not hold given the morally different status of, on the one hand, an embryo/foetus and, on the other hand, a person. To accept that prospective parents may terminate a pregnancy because of a foetal abnormality is not the same as saying that the lives of persons with that abnormality are less worth living -or worse- should be terminated. Prenatal screening and selective abortion are in themselves not discriminatory acts. Whether they have a discriminatory effect very much depends on how the screening strategy is actually presented, how the possibility of selective abortion is portrayed, and on whether society is willing to take care of its disabled fellow citizens.

I therefore share the dominant view that both abortion and selective abortion can be justified under certain conditions. Offering prospective parents the opportunity to gather information about their foetus in order to enable them to make an autonomous choice with regard to either continuing or terminating the pregnancy in case of a foetal abnormality, is not discriminatory nor morally objectionable in itself. The conditions for and the scope of such a prenatal test offer will, however, be the major subjects discussed in this thesis. 


\subsection{Recent developments in prenatal screening}

In this section three recent developments in prenatal screening will be described. I will also shortly point out what ethical issues do arise due to these changes in prenatal screening practice.

\subsubsection{Narrow testing}

The availability of new molecular techniques has led to the option of faster and cheaper diagnostic testing aimed at selected chromosome regions (e.g. comprising the most common chromosome defects). These so-called rapid aneuploidy detection (RAD) tests have been introduced in a few West-European countries, including the Netherlands, as a replacement for or as an additional to conventional karyotyping offered to women at increased risk for trisomies 21, 18 and 13 . In some countries women are offered a choice between RAD and karyotyping. ${ }^{22}$ The possibility to offer a RAD test targeted at trisomies 21, 18 and 13 (and mostly chromosomes $X$ and $Y$ as well) instead of karyotyping, allows for earlier definite test results and avoids unexpected and unclear findings. At the same time, RAD reduces the range of possible outcomes that women may consider relevant for their reproductive decision-making. This raises the question what the aim of offering opportunity for autonomous reproductive choice actually means: offering choice with regard to a narrow range of conditions only, or for a broader scope of abnormalities too? This question also comes up in a totally different context. In the last few years the development of non-invasive prenatal testing (NIPT) ${ }^{1 *}$ has expanded and NIPT is about to be introduced in prenatal screening strategies. NIPT techniques enable testing on cell-free foetal DNA/RNA circulating in the blood of pregnant women. This can be done quite early in pregnancy $(\geq 7$ weeks of gestation) and the procedure is easy and safe to perform.

The application of NIPT as a second-tier screening test in the testing cascade for trisomies 21 , 18 and 13 is pending. ${ }^{23}$ This means that NIPT will serve as a (very reliable) second screening test between the combined screening test and follow-up invasive diagnostic testing. By that, the number of invasive procedures can be drastically reduced. Expectations are that onestep diagnostic NIPT will eventually replace current two-step testing, namely the combined screening test and invasive diagnostic testing. Either way, if NIPT is offered for trisomies 21, 18 and 13 only, this implies a limitation in the diagnostic scope and reproductive choice when compared to the traditional offer of conventional karyotyping. Unless additional testing is offered - I'll come to that in Section 1.4.3.

\footnotetext{
$1^{*}$ In the chapters 3, 4, and 6 the abbreviation NIPD (non-invasive prenatal diagnosis) is used, because these chapters consist of papers that were written and published some time ago. Recently, however, the terminology has internationally changed into NIPT (non-invasive prenatal testing). To be in keeping with this international usage, I also use this latter term in this chapter and in Chapter 9.
} 


\subsubsection{Broad testing}

An opposite development to that of narrowing the scope of testing, is the introduction of broad, genome-wide diagnostic tests performed on foetal material obtained by amniocentesis and CVS. Microarray-based techniques allow for detecting a much wider range of foetal defects than can be revealed by conventional karyotyping, and are increasingly applied if foetal abnormalities are found by ultrasound scans throughout the pregnancy. Suggestions to offer microarrays for more indications, such as an increased risk for the trisomies or to all pregnant women without a specific indication, can also be found in the literature. ${ }^{24}$

Another ongoing development is the ever advancing nature of foetal ultrasound scans, including NT-measurement. This enables identifying not only major abnormalities such as spina bifida and anencephaly, but also 'markers' for all kinds of other, possibly milder, abnormalities. The scope ranges from congenital heart defects to all kinds of structural defects and genetic syndromes. Currently, abnormal ultrasound findings are usually followed by an offer for invasive microarray testing. Whereas broader testing allows for the detection of more clinically relevant abnormalities, it also increases the amount of unclear and possibly unwanted findings that are difficult to handle in the prenatal situation. Moreover, how can adequate informed consent for either the ultrasound scans or the broad diagnostic tests be reached? It is impossible to inform prospective parents beforehand about all the findings possibly generated and if tried, this can easily result in information overload. What does offering reproductive choice in such a context actually mean? And to what range does or should prenatal screening actually extend in the first place? If, eventually, a genome-wide NIPT may be feasible too ${ }^{25,26}$ this will make risky invasive procedures redundant and then all these questions will become even more urgent. This is not to say that prenatal screening for foetal disorders should be extended to include testing for more conditions, but if they will be included, the question arises: who is to decide about that and on what grounds? ?,9,10 $^{7,10}$

\subsubsection{Increased number of testing}

In Section 1.4.1 I touched upon the issue of additional testing after a narrow test has been offered. This not only relates to the case of RAD, but also applies to a (future) narrow, one-step NIPT. The current combined screening test not only indicates the risk for having a child with trisomy 21,18 or 13 . NT-measurement, although initially offered to increase the accuracy of the risk-assessment for these trisomies, has in practice developed into a test that also indicates other abnormalities. An increased NT $\geq 3.5 \mathrm{~mm}$ in itself is reason to offer follow-up diagnostic testing by microarray. If NIPT for trisomies 21,18 and 13 would substitute the combined screening test, this would result in a loss of findings identified by NT-measurement and follow-up diagnostic testing. Unless, of course, NT-measurement would be offered additionally. However, complementary tests would complicate the testing 
trajectory and come down to a fragmentation and increase in the number of tests offered to pregnant women. What does this extended number and extended period of testing mean for prospective parents in terms of emotional, psychological and cognitive burdens? And what range has to be covered exactly by additional tests?

Another tendency is that one and the same test or test moment will be used for testing both pregnancy-related problems that can be treated and foetal abnormalities. How to deal with tests that have such a two-fold scope and aim? Testing for reason of pregnancy management may require a more directive attitude of professionals, whereas testing for untreatable foetal abnormalities explicitly does not. It should be ensured that the offer of prenatal tests with these different aims meets, respectively, the conditions of adequate clinical care and the requirements of the normative framework for prenatal screening. Can these different aims and conditions clearly be separated in the test offer, and if not, what conclusions should be drawn?

All in all, the scope of prenatal screening becomes increasingly indistinct, because the various techniques allow both a narrowing and a broadening of the traditional scope, and because an increase in the number of prenatal tests becomes apparent. This development may ultimately challenge the very aim of prenatal screening: is reproductive autonomy promoted by offering more options or is meaningful choice impracticable when offering more and heterogeneous tests?

\subsection{Objectives of this study}

These three developments in the prenatal screening strategies present a challenge for the 'reproductive autonomy' account of the aim of prenatal screening. Until recently autonomous choice in prenatal screening meant being given the opportunity to autonomously decide about whether or not to accept a standard offer of prenatal screening. Only in the margin of this there has been some debate about whether the possibility of 'unexpected' findings as a result of karyotyping would require the accommodation of a 'right not to know' 6,27,28 Every account of what to test for in prenatal screening either implicitly or explicitly presupposes an answer as to why such screening is being offered in the first place. Without explicitly addressing this ' $w$ hy', a reasoned debate about the pros and cons of wider or more limited testing will therefore be impossible.

The main objective of this thesis is to map out the moral landscape of prenatal screening, more specifically to identify and systematically evaluate the moral pros and cons of the main developments in current prenatal screening strategies. This evaluation will be performed in 
relation to two normative accounts of the aim of prenatal screening, namely prevention and reproductive autonomy.

The secondary goal of this thesis is to explore whether the notion of autonomous reproductive choice, as meant in the dominant moral framework for prenatal screening, can be given the wider interpretation of offering pregnant women the opportunity to individually decide about what conditions to test for or not. This is called the concept of 'individualised choice' ${ }^{22,29}$ And if the scope of prenatal screening would become more individualised, what -if any- lines should be drawn from a moral point of view?

With this analysis, I hope to contribute to developing an adequate normative framework for ethical guidance and policy making regarding prenatal screening.

\subsection{Method}

This study combines theoretical and empirical methods, namely ethical analysis of relevant literature and empirical research.

The ethical method used is the so-called wide reflective equilibrium, which searches for coherence between different sets of beliefs, intuitions, general ethical principles, judgements, and practical experience, arrived at by processes of deliberation. ${ }^{30,31}$ This method best fits the complexity of the issues involved and has a proven value for the normative analysis of bioethical problems. The term 'reflective equilibrium' (RE) has been introduced by John Rawls in his book 'A Theory of Justice'. ${ }^{32}$ In his view, justification is a reflective process in which moral beliefs, ethical principles and theoretical rules are considered in order to make them as coherent as possible. ${ }^{33}$

In the context of applied ethics, RE is used as a method to relate two opposite accounts of moral reasoning. ${ }^{33}$ On the one hand, a model that holds that justified moral judgements can be reached through a deductive method of reasoning according to general principles and rules. However, these rules and principles are often unable to solve an ethical problem as it arises in daily practice, because they are mostly too abstract to come to one particular conclusion and to determine what should be done and not be done. The other model, based on casuistry and analogy in actual moral decision-making, uses an inductive method of reasoning. This model holds that general norms can be derived from analysing social practice and paradigmatic cases and by comparison of cases, and that these norms can then again be used for other individual cases. However, interpretations, analogies and moral decisions in practice may conflict and by that make justification impossible to reach. ${ }^{33} \mathrm{RE}$ combines elements of both accounts, by using moral intuitions, actual practice, and relevant ethical principles to come to moral judgements. The wide RE also includes background theories, such as a theory of the person, specific thinking formats or concepts, in order 
to reach "coherence among the widest set of moral and non-moral beliefs by revising and refining them at all levels." 30

The search for a justifiable moral practice can be described as an iterative process between theory and practice. In this thesis, concepts as they appear in theories regarding population screening and public health/public health genetics were considered explicitly. ${ }^{16,34,35}$ Furthermore, the ethical values as articulated in the basic principles of health-care ethics were of major importance in our ethical assessment. These include the principles of respect for persons, of beneficence and non-maleficence, and of justice. Experiences with prenatal testing in the daily practice of clinical genetics and obstetrics were included by explicitly including professionals in these fields and pregnant women in the actual process of deliberation. The empirical part of in this study has a qualitative character. Opinions, views and preferences of stakeholders, more in particular professionals involved in prenatal screening and potential users of this screening (pregnant women and parents), were generated in various focus groups. The results of this qualitative research are reported in Chapter 7, and are also integrated in the ethical analysis as it appears in the other chapters of this thesis.

\subsection{Outline of this thesis}

This thesis consists of seven articles that have been published, and a general discussion. The discussion in this thesis is based on the developments in the field of prenatal screening until 1 May 2013. Furthermore, since the articles have been published in various journals requiring the spelling to be in either British or American English, the spelling throughout this thesis is not always consistent.

Chapters 2, 3, 4, 5 and 6 address the ethical implications of three different developments in prenatal screening, namely the introduction of RAD, NIPT and microarray-based testing techniques.

In Chapter 2 the ethical pros and cons of a narrow diagnostic test (RAD) versus conventional karyotyping are addressed. Do the advantages of RAD (fast, targeted and cheap) clearly outweigh the disadvantages of conventional karyotyping (slower and generating unclear findings)? Or is the broader yield of karyotyping preferable? This also depends on what one thinks prenatal screening is or should be about: a test for trisomies 21,18 and 13 only? Or should prenatal testing offer the opportunity for testing for a wider range of abnormalities? There is no agreement amongst professionals and prospective parents in this regard. The question then is what option would best accord with the overall aim to give opportunity for autonomous reproductive choice. 
Chapter 3 explores the ethical implications of NIPT in prenatal screening strategies. Will the fact that NIPT can be performed easily, early and safely, lead to an uninformed and thoughtless uptake and to normalisation of testing and abortion? Or do these challenges appear, if at all, only if NIPT is used for identifying a much broader range of abnormalities? The possible ethical relevance of the timing of testing for the possible selective abortion, will also be considered.

Chapter 4 also deals with NIPT and discusses what the introduction of NIPT for trisomies 21, 18 and 13 means for the screening strategy as a whole. A decision has to be made whether complementary (invasive) tests will be offered, to avoid a loss of information as compared with current practice. But what does the accumulation of tests mean for the requirements of informed consent and proportionality?

In Chapter 5, genomic microarray analysis will be discussed. This technique is increasingly being applied as a prenatal diagnostic tool, but as yet no clear guidelines exist when microarrays should be applied prenatally, and whether a targeted or genome-wide array has to be favoured. Given the aim of prenatal screening for foetal abnormalities, to facilitate autonomous reproductive choice, the question arises what a 'suitable test' actually means, and how adequate information about the heterogeneous findings possibly generated by microarrays can be provided to pregnant women in the context of informed consent. Other genome-wide testing techniques, like whole genome/exome sequencing and analysis, may in the future be used prenatally as well. These techniques do not only generate information about congenital disorders, but may also reveal that the future child will have a high risk of developing a late(r)-onset disease. Are there reasons to limit the scope beforehand, for example to protect future children's right not to know? Suggestions of how to tackle this problem are provided.

Chapter 6 gives an overview of all the developments discussed in this thesis and shows how these together raise important ethical questions concerning meaningful reproductive choice, the autonomy rights of future children, equity of access and the proportionality of testing. A main challenge is to decide about the range of conditions for which testing should be offered and the reasons to do so.

Chapter 7 presents the results of the qualitative research. How do professionals and prospective parents evaluate various test options and what would they prefer? Four different test options are discussed: a standard test offer of RAD, karyotyping and microarrays, and the option of individualised choice. It appears that respondents greatly differ in how they assess the pros and cons and the feasibility of the different test options in practice. Does this mean that a single standard test offer is inadequate and that more differentiation is needed? 
Prenatal screening is not the only area where ethical issues regarding informed consent in genetic testing come up. Chapter 8 shows that similar problems arise in other areas where genetic tests are being used, specifically in neonatal screening and direct-to-consumer testing. It will become clear that the ways to address the ethical issues need to be attuned to the different contexts.

The final Chapter 9 gives an overview of the normative framework for prenatal screening and shows how the various developments affect and challenge this framework. Should this lead to a change in the normative framework or in prenatal screening practice? Some general conclusions and suggestions are provided.

\subsection{Screening and diagnosis: some clarifications}

Before moving on to the ethical discussion, I will clarify how the notions of screening and diagnosis are used in this thesis

First, in the normative and regulatory discourse it is customary to use the term 'screening' for any systematic and unsolicited test offer, initiated by a public health service or professional, that aims at the systematic early detection or exclusion of (a risk for) a specific condition, regardless of the type of test being offered. The distinguishing feature is its unsolicited character: the test is provided to (a specific group of) persons -in this context pregnant women- who do not yet have any symptoms of illness nor another reason to seek medical help for the condition in question. In that regard, it is fundamentally different from (diagnostic) testing based on a specific indication. ${ }^{36}$ In medical discourse, the term screening is mainly used for qualifying the character of the test itself. As such, it refers to a test for riskassessment and differs from a diagnostic test that allows to make a definitive diagnosis and that explains the health problems or clarifies abnormal screening test results. In this thesis, the term screening is primarily used in the first sense.

Second, I conceive prenatal screening as referring to the whole of the testing trajectory offered to pregnant women, including both risk-assessment (screening) and follow-up testing (diagnosis). This view is not self-evident. Despite fairly standard methods of risk-assessment, practice and opinions differ regarding what kind of follow-up testing is and should be offered to pregnant women at increased risk for either aneuploidies or abnormalities indicated by results of foetal ultrasound scans. The procedure of the first step (risk-assessment) is generally regulated, for example in the Dutch Draaiboek Prenatale Screening ${ }^{37}$, but national policy-documents do not always record how the subsequent diagnostic test should be performed. Apparently, there is a different approach to the first and second step in the testing strategy, in the sense that the first tends to be uniformly regulated, whereas the interpretation of the latter tends to be left to professionals' own discretion. Thus, individual 
professionals and centres may, and actually do, differ in what diagnostic procedure they offer to pregnant women. If the requirement of equal access, that applies to all screening strategies, also refers to the quality of testing ${ }^{38}$, differences in the (national) provision of test offers to women having an identical indication, are problematic. Beyond this consideration, I advance three reasons to conceive follow-up testing as part of the screening strategy. First, the ultimate decision to terminate or continue a pregnancy cannot be based on a riskassessment alone: in that regard the aim to provide reproductive options and to guarantee a valid and reliable test instrument in this scenario is only met with the current two-step procedure - until, of course, a one-step diagnostic NIPT-test becomes available. Second, the diagnostic test is consequential to the indication 'increased risk' that results from the first-step screening-test: pregnant women would not be confronted with a subsequent diagnostic offer without being screened first. In this regard, the two tests are inextricably related. Third, participation in screening should be based on information about not only the initial decision regarding risk-assessment, but also about other decisions that possibly have to be made in the successive trajectory. ${ }^{6}$ If one does consider, as I do, both test phases to be an intrinsic part of the screening strategy, this means that the aim and requirements of prenatal screening do apply to both the initial and the follow-up testing phase. 


\section{References}

1. Steele M, Breg WJ: Chromosome analysis of human amniotic-fluid cells. Lancet 1966;1:383-385.

2. van El C, Pieters T, Cornel M: Genetic screening and democracy: lessons from debating genetic screening criteria in the Netherlands. J Comm Genet 2012;3:79-89.

3. Bui T-H, Meiner V: State of the art in prenatal diagnosis. In: Leuzinger-Bohleber M, Engels E-M, Tsiantis J (eds): The Janus Face of Prenatal Diagnostics. A European Study Bridging Ethics, Psycholanalysis, and Medicine. London: Karnac Books, 2008, pp 61-86.

4. Bobrow M: Prenatal diagnosis and medical genetics - past and future. In: Galjaard H, Noor LHW (eds): Prenatal Testing: New Developments and Ethical Dilemmas. Amsterdam: Royal Netherlands Academy of Arts and Sciences, 2004, pp 16-19.

5. Mujezinovic F, Alfirevic Z: Procedure-related complications of amniocentesis and chorionic villous sampling: a systematic review. Obstet Gynecol 2007;110:687-694.

6. Health Council of the Netherlands. Prenatal Screening: Down's syndrome, neural tube defects, routineultrasonography. Publication no. 2001/11. The Hague: Health Council of the Netherlands, 2001.

7. Shuster E: Microarray genetic screening: a prenatal roadblock for life? Lancet 2007;369:526-529.

8. Ogilvie CM, Yaron Y, Beaudet AL: Current controversies in prenatal diagnosis 3: For prenatal diagnosis, should we offer less or more than metaphase karyotyping? Prenat Diagn 2009;29:11-14.

9. Bui T-H, Vetro A, Zuffardi O, Shaffer LG: Current controversies in prenatal diagnosis 3: is conventional chromosome analysis necessary in the post-array CGH era? Prenat Diagn 2011;31:235-243.

10. de Wert G: Ethiek van voortplantingsgeneeskunde. In: Heineman $\mathrm{M}$ (ed): Obstetrie en gynaecologie. Maarssen: Elsevier gezondheidszorg, 2007, pp 21-60.

11. Gezondheidsraad, Centrum voor ethiek en gezondheid: Zorg voor het ongeboren kind. Publicatienummer 2009/01. Den Haag: Gezondheidsraad, 2009.

12. Bianchi D: From prenatal genomic diagnosis to fetal personalized medicine: progress and challenges. Nat Med 2012;18:1041-1051.

13. Parens $\mathrm{E}, \mathrm{Asch} \mathrm{A}$ : The disability rights critique of prenatal genetic testing. Reflections and Recommendations. Hastings Cent Rep 1999;29:S1-22.

14. de Wert G, de Wachter M: Mag ik uw genenpaspoort? Ethische aspecten van dragerschapsonderzoek bij de voortplanting. Baarn: Ambo, 1990.

15. van El C, Krijgsman L, Pieters T, Cornel M: Genetische screening en preventie van erfelijke en aangeboren aandoeningen: een problematische combinatie. TGE 2007;17:105-111.

16. Buchanan A, Brock D, Daniels N, Wikler D: From chance to choice. Genetics and justice. Cambridge: Cambridge University Press, 2000.

17. Nuffield Council on Bioethics: Genetic screening. Ethical Issues. London: Nuffield Council on Bioethics, 1993.

18. UK National Screening Committee. Criteria for appraising the viability, effectiveness and appropriateness of a screening programme. Available at: http://www.screening.nhs.uk/criteria

19. de Jong A, Dondorp W, De Wert G: Ethische reflectie. In: Wildschut H, van Goudoever J, den Hollander N, Keirse $\mathrm{E}$, De Wert G (eds): Foetale en neonatale screening op aangeboren afwijkingen. Leidraad voor besluitvorming. Amsterdam: Reed Business, 2011, pp 405-437.

20. Mackler AL: Introduction to Jewish and Catholic bioethics: a comparative analysis, Georgetown: Georgtown University Press, 2003.

21. Parens E, Asch A (eds): Prenatal testing and disability rights. Georgetown: Georgetown University Press, 2000.

22. Boormans E, Birnie E, Oepkes D, Boekkooi PF, Bonsel GJ, van Lith JM, on behalf of the MAKE study groupMembers: Individualized choice in prenatal diagnosis: the impact of karyotyping and standalone rapid aneuploidy detection on quality of life. Prenat Diagn 2010;30:928-936. 
23. Nicolaides K, Syngelaki A, Ashoor G, Birdir C, Touzet G: Noninvasive prenatal testing for fetal trisomies in a routinely screened first-trimester population AJOG 2012:207:374.e1-6.

24. Fiorentino F, Napoletano S, Caiazzo F, Sessa M, Bono S, Spizzichino L, Gordon A, Nuccitelli A, Rizzo G, Baldi M: Chromosomal microarray analysis as a first-line test in pregnancies with a priori low risk for the detection of submicroscopic chromosomal abnormalities. Eur J Hum Genet 2013;21:725-30.

25. Lo YMD, Chan KCA, Sun H, Chen EZ, Jiang P, Lun FM, Zheng YW, Leung TY, Lau TK, Cantor CR, Chiu RWK: Maternal plasma DNA sequencing reveals the genome-wide genetic and mutational profile of the fetus. Sc Transl Med 2010;2:61ra91.

26. Kitzman JO, Snyder MW, Ventura M, Lewis AP, Qiu R, Simmons LE, Gammill HS, Rubens CE, Santillan DA, Murray JC, Tabor HK, Bamshad MJ, Eichler EE, Shendure J: Noninvasive Whole-Genome Sequencing of a Human Fetus. Sci Transl Med 2012;4:137ra176.

27. Leung WC, Lao TT: Rapid aneuploidy testing, traditional karyotyping, or both? Lancet 2005;366:97-98.

28. van Zwieten M: The target of testing. Dealing with 'unexpected' findings in prenatal diagnosis. Amsterdam: Uitgeverij Buijten \& Schipperheijn, 2006.

29. de Jong A, Dondorp WJ, Timmermans DR, van Lith JM, de Wert GM: Rapid aneuploidy detection or karyotyping? Ethical reflection. Eur J Hum Genet 2011;19:1020-1025.

30. van den Burg W, van Willigenburg $T$ (eds): Reflective equilibrium. Essays in Honour of Robert Heeger. Dordrecht: Kluwer Academic Publishers, 1998.

31. Daniels N: Justice and justification. Cambridge: Cambridge University Press, 1996.

32. Rawls J: A Theory of Justice. Cambridge: Harvard University Press, 1971.

33. Beauchamp TL, Childress JF: Principles of Biomedical Ethics. New York/Oxford: Oxford University Press Inc, 2009.

34. Health Council of the Netherlands: Genetic Screening. The Hague: Health Council of the Netherlands, 1994.

35. Khoury M, Burke W, Thomson E (eds): Genetics and Public Health in the 21st Century: Using Genetic Information to Improve Health and Prevent Disease. Oxford: Oxford University Press, 2000.

36. Gezondheidsraad: Prenatale screening: Down Syndroom, neuralebuisdefecten, routine-echoscopie. Den Haag: Gezondheidsraad, 2001.

37. RIVM: Draaiboek Prenatale Screening. Downsyndroom en Structureel Echoscopisch Onderzoek. Versie 2.0. RIVM - Centrum voor bevolkingsonderzoek, 2011.

38. Favre R, Moutel G, Duchange N, Vayssière C, Kohler M, Bouffet N, Hunsinger MC, Kohler A, Mager C, Neumann M, Vayssière C, Viville B, Hervé C, Nisand I: What about Informed Consent in First-Trimester Ultrasound Screening for Down Syndrome? Fetal Diagn Ther 2008;23:173-184. 


\section{Chapter 2}

\section{Rapid aneuploidy detection or karyotyping?}

Ethical reflection

de Jong A, Dondorp WJ, Timmermans DRM, van Lith JMM, de Wert GMWR

European Journal of Human Genetics 2011;19(10):1020-1025 


\begin{abstract}
No consensus exists whether women at increased risk for trisomy 21, 18 and 13 should be offered stand-alone rapid aneuploidy detection (RAD) or karyotyping. In this paper, the ethical implications of a fast, relatively cheap and targeted RAD are examined. The advantages of RAD seem less robust than its proponents suggest. Fast test results only give a short-term psychological benefit. The cost advantage of RAD is apparent, but must be weighed against consequences like missed abnormalities, which are evaluated differently by professionals and pregnant women. Since pre-test information about RAD will have to include telling women about karyotyping as a possible alternative, the advantage of RAD in terms of the quantity of information that needs to be given may also be smaller than suggested. We conclude that none of the supposed arguments in favour of RAD is decisive in itself. Whether the case for RAD may still be regarded as convincing when taking these arguments together seems to depend on one's implicit view of what prenatal screening is about. Are we basically dealing with a test for trisomy 21 and a few conditions more? Or are there good grounds for also testing for the wider range of abnormalities that karyotyping can detect? As professionals and pregnant women may have different views about this, we suggest that the best approach is to offer women a choice between RAD and karyotyping. This approach is most in line with the general aim of prenatal screening: providing opportunities for autonomous reproductive choice.
\end{abstract}




\subsection{Introduction}

Prenatal screening strategies for chromosomal abnormalities consist of two steps. ${ }^{1,2}$ First, a risk assessment for the most common trisomies (21 and generally also 18 and 13 ) is carried out. This is based on a combination of maternal serum testing and foetal nuchal translucency measurement. ${ }^{3}$ Second, a diagnostic test is offered to women found to be at an increased risk of having a child with one of those trisomies. The diagnosis (usually karyotyping) is performed on foetal material obtained through either chorionic villus sampling (CVS; at 1114 weeks' gestation) or amniocentesis (at 15-18 weeks' gestation). These are invasive tests that hold a small but significant risk (0.3-1.0\%) of iatrogenic miscarriage. ${ }^{4,5}$ Karyotyping has been the gold standard for prenatal diagnostic testing for nearly half a century. It has a high reliability in diagnosing numeric chromosome aberrations, as well as (major) structural abnormalities. These include unbalanced translocations, balanced translocations (familial and de novo), mosaicism, supernumerary chromosomes, triploidy, and sex chromosome abnormalities. Down's syndrome (trisomy 21 ) is the most common aneuploidy causing intellectual and developmental disability. ${ }^{6}$ Other chromosomal abnormalities are less frequent and highly variable. Some of those are lethal (eg, trisomy 13 and trisomy 18), others are asymptomatic, relatively mild (eg, XXY (Klinefelter's syndrome), XXX, XYY), or are of uncertain clinical significance. ${ }^{7,8}$

Karyotyping is a labour intensive and thus a rather expensive technique, which takes an average time of 14 days before the test results can be reported. As karyotyping reveals all chromosomal abnormalities that can be microscopically detected, it may lead to other findings than the aneuploidies targeted in prenatal screening. Among those 'incidental' (or with a misnomer: 'unexpected') findings, there can be severe but also mild abnormalities or abnormalities of which the impact on the health of the child is unsure. ${ }^{7,9-11}$ The development of techniques for rapid aneuploidy detection (RAD) allows cheaper and rapid diagnosis of some selected chromosomal anomalies. A 'narrow' RAD targets the chromosomes 21,18 and 13, whereas a 'broad' RAD also includes the sex chromosomes. This development has led to an increased discussion as to whether a full karyotype is always indicated. RAD has already been introduced in several countries, but the question whether and if so, how, RAD should be offered is still under debate., ${ }^{7,811-14}$ Four prenatal diagnostic test options for women at increased risk can be distinguished: karyotyping as stand-alone; RAD with subsequent karyotyping; ;5,16 offering women a choice between RAD and karyotyping ${ }^{14,17,18}$ and a stand-alone RAD. Because a stand-alone RAD has been recommended by the UK National Screening Committee and several individual commentators, ${ }^{11,19,20}$ the discussion in this paper focuses on this approach. We will do so by exploring the main arguments in favour of RAD as stand-alone that can be found in the literature: (a) RAD detects the most important abnormalities; (b) RAD enables fast test results and reduces anxiety; (c) RAD is 
cheaper than karyotyping; (d) the limited scope of RAD simplifies pre-test counselling and enables adequate informed consent; (e) RAD produces only clear test results and eases post-test counselling and decision-making; and (f) RAD guarantees a consistent scope of testing throughout the screening strategy. Although these arguments may appear to be only 'technical', they actually are morally charged arguments as well. Therefore, an ethical reflection is needed. The insights gained will be of use to professionals and policymakers in deciding what prenatal diagnostic test offer is to be preferred in the screening context.

\subsection{Normative framework for prenatal screening}

To clarify the perspective of our reflection, we first briefly address the normative framework for prenatal screening. This framework is based on the four central principles of health-care ethics.

First, the principle of respect for autonomy not only requires that the woman concerned should give her adequate informed consent for screening but is also at the basis of the classical account of the aim of prenatal screening. There is a strong consensus, at least in Western countries, that prenatal screening for foetal abnormalities should have the purpose of facilitating autonomous reproductive choice for pregnant women and their partners. ${ }^{20,21}$ The alternative aim of maximising the prevention of the birth of children with congenital abnormalities is regarded as morally problematic for two reasons. It not only sends the implied message that persons with the relevant handicaps are not welcome in society, but it may also lead to pressure upon pregnant women to undergo screening and decide to abort in the case of a foetal abnormality. That would run counter to the principle of autonomy.

Second, the twin principles of beneficence and non-maleficence require that the benefits to pregnant women from participating should clearly outweigh the disadvantages that all screening programmes do have. Finally, the principle of justice requires equity of access and cost-effective use of financial means, especially when programmes are collectively or publicly funded. ${ }^{4,22,23}$

\subsection{Arguments in favour of RAD as stand-alone: an evaluation}

\subsubsection{RAD detects the most important abnormalities}

The debate about RAD and karyotyping is very much about the scope of prenatal testing. Although both diagnostic tests are offered as a follow-up to screening for a fairly limited set of abnormalities, RAD leads to narrowing the range of possible findings as compared with karyotyping. In the debate about this, karyotyping is often presented as the obvious reference point, meaning that the onus of justification rests with those arguing in favour of 
more limited testing. ${ }^{24}$ The incidence of clinically relevant abnormalities missed by RAD is estimated to be 1:1000-1:1659, whereas missed abnormalities of mild or uncertain clinical significance are more frequent.,14,19 Proponents of RAD estimate these residual risks to be of limited relevance. ${ }^{25,26}$ This is however not obvious, because both the quantity and quality (or seriousness) of chromosomal abnormalities missed by RAD can be evaluated differently. A difference in appreciation already manifests itself in the decision to offer either a 'broad' or a 'narrow' RAD, which respectively identifies or misses the $X$ and $Y$ chromosomes. The clinical significance of sex chromosomal abnormalities is not always clear and may vary from a relatively mild to an asymptomatic phenotype. An example is XYY, which has been associated with intellectual and behavioural problems but does often not actually lead to any problems at all. To avoid complex pre-test counselling about the possible outcome of findings of limited or uncertain clinical significance and to spare women difficult decisions based on such findings, some professionals want to avoid detecting sex chromosomal abnormalities. Others find it important not to miss them, just to offer parents maximum information and maximum autonomy. ${ }^{27}$

Both a broad and a narrow RAD miss clinically relevant and unclear autosomal abnormalities that karyotyping does identify. A recent study including 24 prenatal experts suggests that professionals largely prefer to detect abnormalities with severe consequences and would rather not detect chromosomal abnormalities without clinical consequences. ${ }^{28}$ Dissensus exists with regard to abnormalities with mild or uncertain outcomes. Interestingly, neither RAD nor karyotyping corresponds with these wishes of professionals, because RAD covers only some of the more severe abnormalities, while karyotyping also detects abnormalities without clinical consequences. ${ }^{28}$ Proponents of RAD seem to value the fact that it misses abnormalities as 'acceptable, in view of their limited or uncertain clinical relevance', ${ }^{25}$ whereas proponents of karyotyping favour access to these findings because they have potential (ranging from uncertain to major) clinical significance. ${ }^{7}$ Pregnant women themselves have different attitudes towards these findings as well. This is shown by their preference for either RAD or karyotyping ${ }^{12,14,29}$ and by the different reproductive choices they make in case of test results with uncertain clinical significance: most decide to continue with the pregnancy, but some decide for abortion. ${ }^{7}$ Different views have been found in the general public and between countries as well. ${ }^{30,31}$ In short, no consensus exists about the relevance of the abnormalities missed by RAD. A preference for a narrow RAD, a broad RAD, or karyotyping reflects various views on what delineation of the scope of diagnostic testing is most in line with facilitating autonomous reproductive choice as the aim of prenatal screening. 


\subsubsection{Fast test results}

A second reason to prefer RAD is that it generates test results within 1-4 days. This is considerably faster than karyotyping, which takes $\geq 14$ days in Europe, although results can be ready as early as from 7 days in the United States. ${ }^{8}$ This reduced waiting time for RAD is clearly advantageous, if it diminishes anxiety for women. ${ }^{19,31,32}$ Still, three qualifying remarks need to be made.

First, the striking contrast between the speed of karyotyping in the United States and Europe in itself bears moral relevance. The difference between fast ( 7 days) and slow (21 days) karyotyping is 2 weeks. This substantial difference raises the question whether RAD is the only way to shorten the lengthy waiting period that is indeed hard to justify in view of maternal anxiety, the time left for decision making, and the emotional burden of (later) termination of the pregnancy. Furthermore, the difference between fast karyotyping (7 days) and a slow RAD (4 days) is only 3 days, which diminishes the advantage of reduced maternal anxiety that a choice for RAD would entail. The absence of a substantial extra waiting time for more comprehensive information may also motivate women to choose a broad test instead of a narrow test. ${ }^{29}$

Second, in the face of the existing rather large difference in reporting time between karyotyping and RAD, the consequences of a fast or slow test result should be accounted for. Waiting for test results of karyotyping can place a significant emotional burden on women and their partners, ${ }^{26,31}$ but studies also suggest that RAD has no overall psychological benefit compared with karyotyping despite reduced anxiety and stress in the short term. ${ }^{33,34}$

Moreover, a recent study, including 103 pregnant women considering amniocentesis, suggests that anxiety and length of waiting time have some effect on women's preferences, but that the clinical consequences of detected abnormalities appear to have the greatest influence on the test that these women would choose. ${ }^{12}$

Third, part of the clinically relevant abnormalities missed by RAD will be found by the routine ultrasound scan that most pregnant women undergo in the second trimester. ${ }^{35,36}$ If so, test results will be delayed by 2-10 weeks, compared with, respectively, a late amniocentesis and an early CVS. This leaves little time for the emotionally burdening decision about continuing or terminating the pregnancy, as abortion is legally prohibited after 20-24 weeks of gestation in many countries. In case of adverse findings that could have been detected earlier, it will be difficult for professionals to explain that they chose a rapid but limited test for the sake of the woman's well-being. Restricting and postponing autonomous choice for this reason is clearly paternalistic. Besides, there is an inconsistency in saying that findings not detected by RAD are of limited value while at the same time presenting the later ultrasound scan as a safety net where at least part of the missed abnormalities will still be found. 
To conclude, the ability to produce test results within only a few days counts in favour of RAD, but this advantage is not unchallenged and does not seem to provide a decisive reason to offer a stand-alone RAD.

\subsubsection{Financial costs}

In the third place, RAD is favoured because it is relatively cheap to perform. Expenses per trisomy 21 case detected ('detection/cost' ratio) are less for RAD when compared with karyotyping. ${ }^{31,37}$ Furthermore, a recent study suggests that both short- and long-term costs, including incremental cost for a live-born child having a chromosomal abnormality missed by a broad RAD, are lower for a stand-alone RAD than for standard karyotyping. ${ }^{12}$ According to the same study, allowing women a choice between karyotyping and RAD reduces costs compared with standard karyotyping. If confirmed in further research, these data would seem to suggest that, from a purely economic perspective, a stand-alone RAD is the preferred diagnostic test. Of course, financial considerations are relevant in the ethical assessment of what test to offer. It is a requirement of distributive justice that publicly or collectively funded programmes for prenatal screening should be cost-effective. But that does not amount to saying that the least costly option is always the best choice. Even though it should be acknowledged that budgetary constraints may in practice limit the range of alternative tests available, the challenge is indeed to offer the test that best serves the aim of prenatal screening, while being proportional in the sense that the costs involved can be justified from a health-care economic point of view.

\subsubsection{Pre-test counselling: informed consent}

Proponents of RAD assert that the limited amount of abnormalities targeted by RAD ensures that prospective parents can be better informed about the test and that adequate informed consent can be obtained more easily. To inform prospective parents about karyotyping is more complicated, because this test may also generate a much wider range of findings, including abnormalities of which the clinical significance is limited or unclear. ${ }^{11,38} \mathrm{~A}$ real concern is indeed that an offer of karyotyping is not always preceded by adequate counselling and informed consent and may therefore lead to outcomes that are 'unexpected'. Not, of course, for the professional, but for the woman and her partner who were not informed beforehand about the possibility of such outcomes. RAD would avoid this. Still, 'easy' pretest counselling for RAD may be challenged by two factors.

First, a narrow RAD includes the chromosomes 21, 18 and 13, and a broad RAD the chromosomes $\mathrm{X}$ and $\mathrm{Y}$ as well. This means that proper counselling and informed consent for RAD can still not be limited to Down's syndrome, but will also have to include the differences between trisomies 21,18 and 13 and the sex chromosomal abnormalities. In order to enable 
deliberate choices based on sufficient and relevant information and consistent with the decision maker's values, ${ }^{39}$ pre-test counselling requires an adequate amount of information, adjusted to the patient's knowledge and capabilities. ${ }^{40}$ In the context of RAD, a distinction can be made between three categories of abnormalities: (1) lethal conditions (trisomies 18 and 13); (2) serious conditions implying lifelong intensive (medical) aid (Down's syndrome); and (3) conditions implying hardly any infirmities (most sex chromosomal abnormalities). A narrow RAD may detect abnormalities of categories (1) and (2), whereas a broad RAD will also find category (3) abnormalities. Karyotyping can detect the same categories of abnormalities, but will also lead to (4) abnormal findings of which the clinical implications are unknown. Given this overlap in types of abnormalities possibly detected by RAD and karyotyping, the pre-test counselling advantage of RAD may be limited, at least where a broad RAD is concerned.

Second, it is reasonable to assume that at least some pregnant women are well acquainted with karyotyping, which has for decades been the accepted diagnostic test. To prevent that women agree to a test on the basis of false assumptions, information about the more limited scope of RAD as compared with karyotyping should be available. An important aspect of women's decision making that will also have to be addressed is their views about whether the narrow focus of RAD provides sufficient justification for undergoing risky invasive testing. ${ }^{41,42}$ Because RAD thus requires more extensive counselling than generally accounted for by its proponents, the pre-test counselling advantage of RAD compared with karytoyping may be less than is often assumed.

The different views on RAD suggest an underlying controversy on the interpretation of reproductive autonomy and on how pregnant women's autonomy could best be served. Should the emphasis be on optimising and easing the process of decision making for them, or on maximising the amount of information and reproductive options that they will be provided with? With regard to decision making, a pro-RAD assumption would be that information related to karyotyping is too complicated. However, research among pregnant women has shown that they differ in their preference for either a limited or more extensive amount of information. ${ }^{38,43}$ The challenge will be to adapt the information accordingly, while ensuring it is not too much but yet enough information to facilitate adequate informed consent. To restrain information and to limit choices, based on evaluations by professionals, may indeed make counselling more easy, but these evaluations do not necessarily correspond with those of future parents themselves.

From a moral point of view, the question is which approach is most in line with the principles underlying the normative framework. On the one hand, it can be argued that restricting the 
scope of diagnostic testing violates the principle of respect for autonomy and falls short of the requirement of beneficence. On the other hand, respect for autonomy need not mean that pregnant women should be provided with as much information about the foetus as possible, as that might have the adverse effect of undermining rather than furthering their ability of making autonomous choices and perhaps even lead to harming the women in question. Indeed, more choice is not necessarily better than less. But the question here is about restricting the scope of testing prior to any evidence that women would otherwise be burdened with information that they cannot handle. Pregnant women are found to have different information needs regarding the health of the foetus and also tend to evaluate the features of RAD differently. ${ }^{12,14}$ It is therefore not evident that the balance of benefits and burdens is more favourable in case of a stand-alone RAD as compared with karyotyping.

\subsubsection{Post-test counselling: burden of choice and anxiety}

Another contended advantage is that by avoiding findings of limited and unclear clinical significance, RAD does not confront prospective parents with difficult and unwanted reproductive choices. ${ }^{25,38}$ Some professionals are especially uneasy about reporting unclear or mild abnormalities, because of the dilemmas stemming from it. ${ }^{7}$ Where test results are ambivalent or uncertain, prospective parents will have to decide whether to terminate a wanted pregnancy while the chances of having a healthy child are quite large, or to continue the pregnancy with the implication of continued worries even until after the child's birth, through its childhood or further. Therefore, some conclude that generating these findings is not always in the best interest of the woman or the couple. ${ }^{11,44}$

However, pregnant women also show interest in findings with clinically mild consequences and in practice some choose to terminate a pregnancy in case of unclear or mild findings, as they cannot accept the uncertainty of the clinical outcome. ${ }^{7,12}$ Although the possibility of an 'unnecessary abortion' is a burdening prospect for both professionals and pregnant women, the potential benefit of information about the foetus possibly being affected should be accounted for as well. Clearly, decisions regarding testing and termination of pregnancy should explicitly be left to pregnant women's own views and values in order to respect their autonomous reproductive decision making.

The argument that RAD avoids difficult decisions with regard to terminating or continuing the pregnancy, does not apply to a broad RAD, which also includes $\mathrm{X}$ and $\mathrm{Y}$. To target these abnormalities undermines this purpose and supposed advantage of RAD, because most of the sex chromosomal abnormalities are associated with a relatively mild or asymptomatic phenotype, thus being exactly the findings that RAD intends to avoid. 


\subsubsection{The logic of the prenatal screening strategy}

In prenatal screening strategies, a positive risk assessment for trisomy 21 (18 and 13) generally functions as the 'gateway' to subsequent diagnostic testing. Because RAD targets these same abnormalities, the screening strategy itself remains consistent in scope throughout its subsequent steps. For this reason, RAD is argued to be the most adequate diagnostic test: test what you screen for. However, to really avoid any breach in this 'logic of the screening strategy', RAD should only target those abnormalities for which screening is offered in the first place. If pregnant women are offered prenatal screening for trisomies 21, 18 and 13, the thrust of the argument would be that subsequent testing should not also include $X$ and $Y{ }^{13}$ Or, for that matter, RAD should only include trisomy 21 if women are offered screening for Down's syndrome only.

An as yet overlooked consequence of standard karyotyping is that it implies unequal access to diagnostic testing. Pregnant women at an increased risk for trisomies 21, 18 and 13 are given the possibility of having the foetus tested for a range of other abnormalities as well, whereas testing for those 'further' abnormalities is unavailable for other pregnant women. Are we to conclude that in order to end this inequality, justice requires a choice between either offering a narrow RAD to the increased risk group, or offering karyotyping to all pregnant women (as is the case in the United States) ${ }^{16}$ Not necessarily. Although the inequality in access may be unfortunate, it is not unfair. Both RAD and karyotyping are performed on foetal material obtained by risky invasive procedures, although this may change within the years to come as soon as non-invasive prenatal diagnostic techniques become widely available..$^{45,46}$

Until then the miscarriage risk adhered to current invasive procedures has to be reckoned with, which raises the issue of proportionality. Central to this assessment is the detection/ miscarriage ratio. Since women in the group with an increased risk for the few conditions screened for will already be offered invasive testing for RAD, this ratio will become more favourable for them if karyotyping is performed. This ratio will a priori be less favourable for pregnant women without an increased risk for those conditions. Furthermore, the principles of non-maleficence and respect for autonomy are at stake when women are denied the possibility of getting additional information from foetal material obtained through a procedure with a miscarriage risk. ${ }^{13,47}$ For this reason, some argue in favour of further expanding the range of abnormalities to be included in diagnostic testing offered to those having CVS or amniocentesis in the context of prenatal screening, for example, by including relatively common heritable diseases like cystic fibrosis and hemoglobinopathies. ${ }^{11}$ However, the problem of unequal access will make itself even more clearly felt when such a broader test is offered only to those with a positive test for a limited number of chromosomal abnormalities. 
Although unequal access to the 'surplus' findings of karyotyping may not be a decisive reason to offer a stand-alone RAD, it does constitute a moral reason to reconsider current access to karyotyping.

\subsection{Conclusion}

There is no consensus whether women at increased risk for trisomy 21 (18 and 13) should be offered RAD or karyotyping. RAD has some advantageous features: it is fast, relatively cheap, and produces clear test results. Assessment of these aspects, however, shows that the advantages ascribed to RAD are not conclusive. Fast test results have a short term but not an overall psychological benefit over later results. Therefore, the time gain is of minor importance when weighing a fast but limited test (RAD) against a slower but more extensive test (karyotyping). The relevance of abnormalities missed by RAD are evaluated differently between and among professionals and women, and the counselling advantages due to the targeted scope of RAD in the pre-test and post-test situation are relative. RAD is cheaper than karyotyping, but this cannot settle the issue.

We conclude that, from a moral point of view, the case for RAD is less strong than it may at first seem. It is not immediately obvious that RAD is more in line with the requirement of respect for autonomy than karyotyping. Nor is it clear that the balance of advantages and disadvantages is more favourable for the women concerned in the case of RAD. Neither does the fact that women with a prior risk for common aneuploidies are offered wider testing to which others have no access amount to a serious injustice. However, even if a separate assessment of the alleged advantages of RAD does not show any of them to be decisive, it can still be asked whether their cumulative effect might not decide the argument in favour of RAD. The answer to this will depend mainly on what one thinks the scope of prenatal screening and testing should be. The moral framework of prenatal screening itself is not decisive in this regard. For those who think that testing for trisomy 21 or perhaps for common aneuploidies is what prenatal screening is really about, the arguments for limiting the test offer to a narrow or broader RAD may sound convincing. However, others may find that there are good grounds for wanting prenatal screening to at least include the wider range of conditions that karyotyping might detect. Given that there is no objective perspective from whence to decide between these views, leaving the choice to the women concerned would at least have the benefit of being in line with the general aim of offering opportunities for autonomous reproductive choice.

This approach would also have the more practical advantage of being open towards future debates that are most likely about broadening rather than limiting the scope of prenatal screening. The dynamics of the field points in the opposite direction from that proposed 
by those arguing for RAD. New techniques that can identify an even broader scope of heterogeneous abnormalities than karyotyping are already on the horizon. ${ }^{48,49}$ Broader diagnostic testing may even become possible on cell-free foetal DNA that is present in the plasma of pregnant women. ${ }^{45} \mathrm{~A}$ part from the advantage of allowing testing early in pregnancy and without the miscarriage risk adhered to current invasive techniques, the possibility of broad non-invasive diagnostic testing raises further ethical issues. ${ }^{50}$ Without wanting to preempt the debate about whether these developments should lead to further broadening the scope of prenatal screening, we suggest that offering RAD as a stand-alone sends the wrong message. Is protecting pregnant women from difficult choices the best way of preparing for the challenges ahead? Instead of assuming that anything beyond RAD is too difficult for them, it may be better to invest in finding approaches to counselling and informed consent that are adjusted to broader kinds of testing without compromising central moral principles.

\section{Acknowledgements}

We thank professor Bartha Knoppers for her helpful comments on an earlier draft of this paper. 


\section{References}

1. Boyd PA, Devigan C, Khoshnood B, Loane M, Garne E, Dolk H; EUROCAT Working Group: Survey of prenatal screening policies in Europe for structural malformations and chromosome anomalies, and their impact on detection and termination rates for neural tube defects and Down's syndrome. BJOG 2008;115:689-696.

2. Tapon D: Prenatal testing for Down syndrome: comparison of screening practices in the UK and USA. J Genet Couns 2010;19:112-130.

3. Saller DN, Canick JA: Current methods of prenatal screening for down syndrome and other fetal abnormalities. Clin Obstetr Gynecol 2008;51:24-36.

4. Health Council of the Netherlands: Prenatal Screening. Down's syndrome, neural tube defects, routineultrasonography. Publication no. 2001/11. The Hague, Health Council of the Netherlands, 2001.

5. Mujezinovic F, Alfirevic Z: Procedure-related complications of amniocentesis and chorionic villous sampling; a systematic review. Obstetr Gynecol 2007;110:687-694.

6. Bui T-H, Meiner V: State of the art in prenatal diagnosis. In: Leuzinger-Bohleber M, Engels E-M, Tsiantis J (eds): The Janus Face of Prenatal Diagnostics. A European Study Bridging Ethics, Psycholanalysis, and Medicine. London: Karnac Books, 2008, pp 61-86.

7. Leung WC, Lau ET, Lau WL, Tang R, Wong SF, Lau TK, Tse KT, Wong SF, To WK, Ng LK, Lao TT, Tang MH: Rapid aneuploidy testing (knowing less) versus traditional karyotyping (knowing more) for advanced maternal age: what would be missed, who should decide? Hong Kong Med J 2008;14:6-13.

8. Caine A, Maltby AE, Parkin CA, Waters JJ, Crolla JA: Prenatal detection of Down's syndrome by rapid aneuploidy without a full karyotype: a cytogenetic risk assessment. Lancet 2005;366:123-128.

9. Bui T-H, Blennow E, Nordenskjöld M: Prenatal diagnosis: molecular genetics and cytogenetics. Best Practice Res Clin Obstetr Gynaecol 2002;16:629-643.

10. Mann K, Fox SP, Abbs SJ, Yau SC, Scriven PN, Docherty Z, Ogilvie CM: Development and implementation of a new rapid aneuploidy diagnostic service within the UK National Health Service and implications for the future of prenatal diagnosis. Lancet 2001;358:1057-1061.

11. Ogilvie CM, Yaron Y, Beaudet AL: Current controversies in prenatal diagnosis 3: For prenatal diagnosis, should we offer less or more than metaphase karyotyping? Prenat Diagn 2009;29:11-14.

12. Boormans EA: Rapid Aneuploidy Detection in Prenatal Diagnosis. The Clinical use of Multiplex LigationDependent Probe Amplification. Thesis, Amsterdam: Buijten \& Schipperheijn, 2010.

13. de Jong A, Dondorp W, de Wert G: The scope of prenatal diagnostic testing for chromosomal aberrations: broad or narrow? Ethical considerations on the choice of tests. Ned Tijdschr Geneeskd 2009; 153: A1060.

14. Bui T-H: Prenatal cytogenetic diagnosis: gone FISHing, BAC soon! Ultrasound Obstet Gynecol 2007;30:247-251.

15. Cirigliano V, Voglino G, Ordoñez E, Marongiu A, Paz Cañadas M, Ejarque M, Rueda L, Lloveras E, Fuster C, Adinolfi M: Rapid prenatal diagnosis of common chromosome aneuploidies by QF-PCR, results of 9 years of clinical experience. Prenat Diagn 2009;29:40-49.

16. ACOG: ACOG Practice Bulletin No. 88: invasive prenatal testing for aneuploidy. Obestetr Gyneco/2007;110:145914567.

17. Boormans EM, Birnie E, Oepkes D, Boekkooi PF, Bonsel GJ, van Lith JM; MAKE study groupMembers of the MAKE study group: Individualized choice in prenatal diagnosis: the impact of karyotyping and standalone rapid aneuploidy detection on quality of life. Prenat Diagn 2010;30:928-936.

18. The Swedish Council on Technology Assessment in Health Care (SBU): Methods of Early Prenatal Diagnosis. Report no: 182, 2006.

19. Mann K, Donaghue C, Fox S, Docherty Z, Ogilvie C: Strategies for the rapid prenatal diagnosis of chromosome aneuploidy. Eur J Hum Genet 2004;12:907-915.

20. UK National Screening Committee: NHS Fetal Anomaly Screening Programme - Screening for Down's syndrome: UK NSC Policy recommendations 2007-2010: Model of Best Practice, 2008.

21. Health Council of the Netherlands: Screening: Between Hope and Hype. Publication no. 2008/05. The Hague: Health Council of the Netherlands, 2008.

22. Beauchamp TL, Childress JF: Principles of Biomedical Ethics. 6th edn. New York/Oxford: Oxford University Press Inc., 2008.

23. Nuffield Council on Bioethics: Genetic Screening, Ethical Issues. London: Nuffield Council on Bioethics, 1993. 
24. Dudarewicz L, Holzgreve W, Jeziorowska A, Jakubowski L, Zimmermann B: Molecular methods for rapid detection of aneuploidy. J Appl Genet 2005;46:207-215.

25. Nicolini U, Lalatta F, Natacci F, Curcio C, Bui T-H: The introduction of QF-PCR in prenatal diagnosis of fetal aneuploidies: time for reconsideration. Hum Reprod Update 2004;10:541-548.

26. Ogilvie CM: Prenatal diagnosis for chromosome abnormalities: past, present and future. Pathol Biol 2003;51:156-160.

27. Leung TN: Rapid aneuploidy testing versus traditional karyotyping: is it better to know more? Hong Kong Med J 2008;14:4-5.

28. Boormans E, Birnie E, Knegt A, Schuring-Blom G, Bonsel G, van Lith J: Aiming at multidisciplinary consensus: what should be detected in prenatal diagnosis? Prenat Diagn 2010;30:1049-1056.

29. Ryan M, Diack J, Watson V, Smith N: Rapid prenatal diagnostic testing for Down syndrome only or longer wait for full karyotype: the views of pregnant women. Prenat Diagn 2005;25:1206-1211.

30. Chan Y, Sahota D, Leung T, Choy K, Chan O, Lau T: Chinese women's preferences for prenatal diagnostic procedure and their willingness to trade between procedures. Prenat Diagn 2009;29:1270-1276.

31. Grimshaw GM, Szczepura A, Hultén M, MacDonald F, Nevin NC, Sutton F, Dhanjal S: Evaluation of molecular tests for prenatal diagnosis of chromosome abnormalities. Health Technol Assess 2003;7:1-146.

32. Ogilvie C, Lashwood A, Chitty L, Waters J, Scriven P, Flinter F: The future of prenatal diagnosis: rapid testing or full karyotype? An audit of chromosome abnormalities and pregnancy outcomes for women referred for Down's syndrome testing. BJOG 2005;112:1369-1375.

33. Boormans EM, Birnie E, Oepkes D, Bilardo CM, Wildschut HI, Creemers J, Bonsel GJ, van Lith JM; M.A.K.E.study group: The impact of rapid aneuploidy detection (RAD) in addition to karyotyping versus karyotyping on maternal quality of life. Prenat Diagn 2010;30:425-433.

34. Mujezinovic F, Prosnik A, Alfirevic Z: Different communication strategies for disclosing results of diagnostic prenatal testing. Cochrane Database Syst Rev 2010;11:CD007750.

35. Kagan K, Chitty L, Cicero S, Eleftheriades M, Nicolaides K: Ultrasound findings before amniocentesis in selecting the method of analysing the sample. Prenat Diagn 2007;27:34-39.

36. Leung W, Waters J, Chitty L: Prenatal diagnosis by rapid aneuploidy detection and karyotyping: a prospective study of the role of ultrasound in 1589 second-trimester amniocenteses. Prenat Diagn 2004;24:790-795.

37. Gekas J, van den Berg DG, Durand A, Vallée M, Wildschut HI, Bujold E, Forest JC, Rousseau F, Reinharz D. Rapid testing versus karyotyping in Down's syndrome screening: cost-effectiveness and detection of clinically significant chromosome abnormalities. Eur J Hum Genet 2011;19:3-9.

38. van Zwieten M: The Target of Testing. Dealing with 'Unexpected' Findings in Prenatal Diagnosis. Amsterdam: Uitgeverij Buijten \& Schipperheijn, 2006.

39. van den Berg M, Timmermans D, Ten Kate L, van Vugt J, van der Wal G: Are pregnant women making informed choices about prenatal screening? Genet Med 2005;7:332-338.

40. Chervenak FA, McCullough LB, Sharma G, Davis J, Gross S: Enhancing patient autonomy with risk assessment and invasive diagnosis: an ethical solution to a clinical challenge. Am J Obstet Gynecol 2008;199:19.e11-19.e14.

41. Dickinson J, Harcourt E, Murch A: The selective use of rapid aneuploidy screening in prenatal diagnosis. Aust $N$ Z J Obstet Gynaecol 2009;49:28-33.

42. Wenstrom KD: Aneuploidy screening: the changing scene. Obstet Gynaecol 2003;101:840-842.

43. Ormond KE, Iris M, Banuvar S, Minogue J, Annas GJ, Elias S: What do patients prefer: informed consent models for genetic carrier testing. J Genet Counsel 2007;16:539-550.

44. Donaghue C, Roberts A, Mann K, Ogilvie CM: Development and targeted application of a rapid QF-PCR test for sex chromosome imbalance. Prenat Diagn 2003; 23:201-210.

45. Lo YMD, Chan KCA, Sun $\mathrm{H}$ et al: Maternal plasma DNA sequencing reveals the genome-wide genetic and mutational profile of the fetus. Sci Transl Med 2010;2:61ra91.

46. Chiu RW, Akolekar R, Zheng YW, Leung TY, Sun H, Chan KC, Lun FM, Go AT, Lau ET, To WW, Leung WC, Tang RY, Au-Yeung SK, Lam H, Kung YY, Zhang X, van Vugt JM, Minekawa R, Tang MH, Wang J, Oudejans CB, Lau TK, Nicolaides KH, Lo YM: Non-invasive prenatal assessment of trisomy 21 by multiplexed maternal plasma DNA sequencing: large scale validity study. BMJ 2011;342:c7401. 
47. Lim AS, Lim TH, Hess MM, Kee SK, Lau YY, Gilbert R, Hempel TE, Anderson KJ, Zaleski DH, Tien SL, Chia P, Subramaniam R, Tan HK, Tan AS, Sanger WG: Screening with fluorescence in-situ hybridisation: is it a sufficiently robust stand-alone test for prenatal diagnosis? Hong Kong Med J 2010;16: 427-433.

48. Zuffardi O, Vetro A, Brady P, Vermeesch J: Array technology in prenatal diagnosis. Semin Fetal Neonatal Med 2011;16:94-98.

49. Hillman SC, Pretlove S, Coomarasamy A, McMullan DJ, Davison EV, Maher ER, Kilby MD: Additional information from array comparative genomic hybridization technology over conventional karyotyping in prenatal diagnosis: a systematic review and meta-analysis. Ultrasound Obstet Gynecol 2011;37:6-14.

50. de Jong A, Dondorp W, de Die-Smulders C, Frints S, de Wert G: Non-invasive prenatal testing: ethical issues explored. Eur J Hum Genet 2010;18:272-277. 



\section{Chapter}

Non-invasive prenatal testing: ethical issues explored

de Jong A, Dondorp WJ, de Die-Smulders CEM, Frints SG, de Wert GMWR European Journal of Human Genetics 2010;18(3):272-277 


\begin{abstract}
This paper explores the ethical implications of introducing non-invasive prenatal diagnostic tests (NIPD tests) in prenatal screening for foetal abnormalities. NIPD tests are easy and safe and can be performed early in pregnancy. Precisely because of these features, it is feared that informed consent may become more difficult, that both testing and selective abortion will become 'normalised', and that there will be a trend towards accepting testing for minor abnormalities and non-medical traits as well. In our view, however, the real moral challenge of NIPD testing consists in the possibility of linking up a technique with these features (easy, safe and early) with new genomic technologies that allow prenatal diagnostic testing for a much broader range of abnormalities than is the case in current procedures. An increase in uptake and more selective abortions need not in itself be taken to signal a thoughtless acceptance of these procedures. However, combining this with considerably enlarging the scope of NIPD testing will indeed make informed consent more difficult and challenge the notion of prenatal screening as serving reproductive autonomy. If broad NIPD testing includes later-onset diseases, the 'right not to know' of the future child will become a new issue in the debate about prenatal screening. With regard to the controversial issue of selective abortion, it may make a morally relevant difference that after NIPD testing, abortion can be done early. A lower moral status may be attributed to the foetus at that moment, given the dominant opinion that the moral status of the foetus progressively increases with its development.
\end{abstract}




\subsection{Introduction}

Since the discovery of cell-free foetal DNA/RNA (cffDNA/RNA) in maternal plasma in 1997,1 the possibility to use this cffDNA/RNA for non-invasive prenatal diagnosis (NIPD) has been investigated many times. ${ }^{2-6}$ cffDNA/RNA can be obtained from a maternal blood sample, as early as 4 weeks of gestation, ${ }^{7}$ but currently only reliably so from 7 weeks of gestation. ${ }^{4}$ This development holds the promise of NIPD testing early in pregnancy and without the small, but significant risk of foetal loss that the current invasive procedures of chorionic villus sampling (CVS) and amniocentesis (AP) carry. NIPD testing for the determination of a Y-signal for pregnancies at risk of X-linked disorders and for diagnosis of Rhesus factor status in RhD-negative women is now being translated into clinical practice. ${ }^{4}$ In many European countries, discussion about broader applications of NIPD testing can be expected in the coming years. 8,9 The feasibility of NIPD for trisomy 21,13 and 18 has already been shown, ${ }^{2}$ but large-scale independent studies are still needed. Sex-chromosomal abnormalities (eg, Turner syndrome (X0) and triple $X$ syndrome $(X X X))$ could in principle be diagnosed by NIPD testing as well, ${ }^{4}$ if reliable quantitative tests become available in the future and the maternal 'background' can be excluded from testing. Even if accurate NIPD testing for the mentioned abnormalities becomes possible, the clinical utility of the test remains to be assessed. This includes balancing the benefits to the harms also with regard to its psychological, ethical, legal, social and economic implications. ${ }^{10,11}$ The possible ethical implications of NIPD as a new approach to prenatal testing have so far been reviewed in a few publications. ${ }^{4,8,9}$,

${ }^{12-17}$ Apart from clear benefits related to avoiding the miscarriage risk of present invasive methods, important potential drawbacks have been mentioned as well. For one thing, proper counselling and informed consent is argued to become more challenging when offering NIPD testing. Moreover, there is a concern that the ease and safety of NIPD may lead to prenatal screening being increasingly conceived as a matter of course, both by those making the offer and by the women undergoing the test. Related to this is the concern that selective abortion of foetuses with minor abnormalities, the wrong sex or unwanted paternity, will become normalised.

This paper aims to expand and refine these ethical evaluations and will add some new ethical perspectives with regard to possible implications of NIPD at present and in the future.

In our view, it is not so much the fact that foetal material used for prenatal testing can be obtained early and non-invasively (allowing easy and safe testing) that would lead to moral challenges. Rather, it is the fact that a technology with these features would be open to being used for testing a potentially much broader range of abnormalities than those included in the presently used method of microscopic chromosome analysis (karyotyping). 
Although NIPD testing can also be applied in high genetic-risk families and for the management of pregnancy, the focus of this paper will primarily be on the application of NIPD testing in the screening context. The reason for this focus on prenatal screening is that in the near future, the question if, and if so, in what way NIPD testing is to be applied within prenatal screening strategies should be considered and discussed by policy makers, health care professionals and society at large.

To avoid confusion, a preliminary remark is needed on terminology. In medicine, 'screening' is often used as referring to a kind of test for risk assessment or disease discovery. However, after the convention in normative and regulatory discourse, we will use 'screening' as referring to any systematic and unsolicited offer of predictive testing (using whatever types of test) involving individuals who themselves have no reason (yet) to seek medical help for the condition in question. ${ }^{18}$ In this broader sense, screening stands in contrast to 'diagnosis' as testing on indication.

\subsection{Current practice of prenatal screening}

Prenatal screening is widely accepted and is considered to be important to enable women and their partners to make informed reproductive choices. ${ }^{19}$ In many countries, prenatal screening strategies consist of two elements. ${ }^{20,21}$

First, screening for Down's syndrome (trisomy 21) and other aneuploidies by means of a risk-assessment test and, in case of a positive initial result, a diagnostic invasive prenatal test is offered for further diagnosis such as CVS at 11-13 weeks of gestation or amniocentesis at 15 -18 weeks of gestation. These invasive procedures may induce a miscarriage in $0.3-$ $1.0 \%$ of the pregnancies investigated. ${ }^{20,22,23}$ The risk-assessment test generally combines biochemical markers in maternal serum and ultrasound markers (nuchal translucency measurement) to determine whether there is a higher risk of having a child with DS or other aneuploidies. If so, a diagnostic test, such as conventional karyotyping (cytogenetic analysis) or rapid aneuploidy detection (DNA analysis), is offered to confirm or exclude the presence of a chromosomal abnormality in the foetus. ${ }^{20,22-24}$

Second, an ultrasound investigation is offered at week 18-20 of gestation to identify major structural, congenital malformations and also to look for so-called 'soft' markers that increase the risk for chromosomal or genetic syndromes. When there is an increased risk, a more detailed ultrasound scan and/or invasive prenatal or postnatal diagnostic tests are needed for further diagnosis. ${ }^{20}$ 


\subsection{Possible dynamics of NIPD testing}

\subsubsection{NIPD testing in the context of prenatal screening}

Research into NIPD testing has mainly focused on those chromosomal abnormalities currently diagnosed with karyotyping as part of the prenatal screening strategies. Wright distinguishes five possible applications of NIPD testing in this context: as an additional test to improve overall risk assessment, as an intermediate test between risk assessment and invasive diagnostic testing for high-risk pregnancies, as a replacement for current riskassessment tests, as a replacement for current invasive diagnostic tests or as a replacement for both risk-assessment and diagnostic tests. ${ }^{8}$ As structural abnormalities per se are not identified through NIPD testing, its possible introduction would not affect current ultrasound screening.

In the ethical discussions thus far, NIPD testing as a substitution for the present combination of risk assessment and invasive diagnostic testing seems generally to be regarded as ultimately the most likely scenario. ${ }^{4,8,12,14,16}$ Indeed, if NIPD tests can easily, safely, reliably and cheaply diagnose chromosomal abnormalities such as trisomy 21 in early pregnancy, this will entail abolishment of the current two-step-testing process.

\subsubsection{Increasing number of prenatal diagnostic tests}

An important implication of NIPD testing as a one-step approach to prenatal screening is that prenatal diagnostic tests will be offered to all pregnant women, instead of to a limited high-risk group. This increase in the number of diagnostic tests does not mean an increase in the extent of the actual group that is approached with an unsolicited prenatal test offer: only the nature of this offer will change. Direct access to diagnostic testing has the advantage of avoiding false positive and false negative outcomes of risk assessment. This means that all pregnant women can profit from the more certain diagnostic test results for reproductive decision making, which enhances their reproductive autonomy. ${ }^{25}$ However, a morally relevant aspect is also that a diagnosis early in pregnancy may have the drawback of increasing the burden of knowledge and choice for the women concerned. As chances of an affected pregnancy ending in miscarriage decrease with gestational age, early testing will more often burden women with 'unnecessary' decision making concerning pregnancies that may spontaneously miscarry. . $^{826}$

\subsection{Informed consent for NIPD testing: the nature of the test}

Concern has been expressed that offering NIPD testing on a wide scale would undermine informed consent. ${ }^{8,12-15}$ If current two-step testing is substituted by a single diagnostic test, it is supposed to be more difficult to provide all pregnant women with adequate information and pre-test counselling, 'despite being conceptually easier'. ${ }^{8}$ The quote refers to the fact 
that one-step screening can do without the concept of risk, which most people find difficult to handle. But why would informed consent in such an approach still be more difficult? The idea behind this concern may be that in two-step screening information about the challenges and possible outcomes of further testing need only be given to the small subset of women with a positive screen result, whereas all necessary information must be given at once in one-step screening. However, this view is morally problematic, as it ignores that risk assessment is potentially a first step in a sequence of testing with exactly the same possible implications as one-step screening. As the information to be given before risk assessment should not be limited to this first 'innocent' step, it is unclear why one-step screening as such would make information and pre-test counselling more difficult. However, a further assumption behind the concern about informed consent may be that introducing NIPD testing will be combined with enlarging the scope of prenatal screening. As we will argue later on in this article that would indeed make informed consent more challenging. But the point we want to make here is that there is nothing in the nature of the NIPD test itself (its one-step character) that would lead to this greater challenge. Of course, this is not to deny that in current practice information, counselling and consent are often inadequately dealt with $^{27-30}$ and this may also be the case with regard to NIPD testing. However, as long as NIPD testing will be offered for the same range of abnormalities as in the present two-step approach to prenatal screening, there is no reason to assume that these problems will be larger than they already are.

\subsection{Normalisation of NIPD testing}

A further concern that has been raised is that the introduction of NIPD as a risk-free procedure may lead to 'normalisation' of prenatal testing. In addition to what has more generally been referred to as a 'technological imperative', the mechanism behind this would be driven by the specific features of NIPD testing. ${ }^{4,8,12-14,31}$ A distinction can be made between normalisation of the offer and of the uptake, although these aspects are of course related.

Normalisation of the offer means that NIPD tests will be portrayed by clinicians and experienced by pregnant women as part of routine antenatal care, because, due to its ease and safety, it seems to be a rather trivial test to offer and take. This may lead to normalisation of uptake, ranging from a rather thoughtless uptake to women feeling socially pressurised to be tested. . $^{8,3,32}$ If this implies testing without informed consent, uptake cannot be said to be the result of nor to be promoting autonomous reproductive decision making. Of course, an increase in uptake does not necessarily indicate its normalisation, as it might also reflect a conscious positive reception of the new possibilities of NIPD testing by pregnant women, ${ }^{33}$ and thus signify the achievement of the aim to 'facilitate parental reproductive choice'. ${ }^{8}$ 
However, as it has often been observed that in current prenatal screening programmes, test uptake is not always on the basis of adequate understanding, ${ }^{32}$ there is indeed reason for concern that the ease and safety of NIPD testing will make this even more difficult to achieve. This concern is reinforced by the finding that health care professionals seem inclined to the view that a less stringent standard of informed consent would suffice for NIPD testing. ${ }^{34}$ We find this problematic because, iatrogenic risks aside, the possible outcomes and consequences of invasive and non-invasive diagnostic testing remain the same. We, therefore, agree that introducing NIPD testing should not be regarded as a reason for loosening present guidelines for informed consent. ${ }^{34}$

\subsection{Normalisation and trivialisation of early selective abortion}

Easy, safe and early NIPD testing might lead to an increase in the number of affected foetuses aborted. ${ }^{13}$ In addition to this possible quantitative implication, concern has been expressed about a qualitative change in selective abortion procedures as well. As Hall et al. ${ }^{13}$ comment: 'More generalised use of non-invasive testing could facilitate selective terminations of pregnancy in a range of conditions hitherto not diagnosed prenatally and where the arguments for and against termination may not have received sufficiently scrutiny'. We will consider this possible 'trivialisation of abortion' in relationship to the possible earlier timing of selective abortion because of NIPD testing.

NIPD testing early in pregnancy may on balance offer important benefits for the women involved. It enables earlier reassurance and, therefore, allows for 'better opportunities for prenatal bonding ${ }^{14}$ for those women who might experience their pregnancy being 'tentative' during the testing period. At the same time, early testing enables a longer period for the decision-making process after a positive test result, which may be valued positively by some women as well. In addition, if a positive test result leads to a choice for selective abortion, this termination might be physically and psychologically less burdening when carried out earlier in pregnancy. ${ }^{13}$ These implications for women may support the view and the experience that early testing and abortion, even if performed for abnormalities hitherto not prenatally diagnosed, may be less problematic. Empirical research is needed to illuminate women's attitudes and preferences in this regard.

The early timing of abortion is also ethically relevant because of different opinions about the moral status of the embryo or early foetus. ${ }^{35,36}$ The timing of abortion is only ethically insignificant if an absolute or high moral status is assigned to the embryo right from the start, or, conversely, when there is no independent status attributed to the embryo/foetus at all. However, the dominant opinion in most Western countries, often also reflected in legislation, is that the moral status of the embryo/foetus progressively increases with its 
development (the gradualist view). ${ }^{26} \mathrm{~A}$ variant of this view refers to transitional moments at specific stages in embryonic or foetal development. As cffDNA/RNA can currently reliably be obtained from a maternal blood sample from 7 weeks of gestation ( 5 weeks of development), the beginning of cerebral development at 6 weeks ( 40 days) ( 8 weeks of gestation) is of special importance in this connection. In some religions, this developmental stage is associated with ensoulment. ${ }^{37,38}$ Adherents of this ' 40 days position' would presumably have no or less moral objections to selective abortion before that specific point in time, because of the lower or absent moral status of the foetus before that moment. More generally, adherents of a gradualist view will favour the possibility of earlier selective abortions after NIPD testing. It is conceivable that this time factor might as well be relevant for the scope of the conditions for which NIPD testing will be applied.

To summarise, the lower moral status of the embryo and the possibly less traumatic psychological and emotional implications of early abortion might influence and to some extent justify a certain broadening of the scope of NIPD testing.

\subsection{Changing the scope of prenatal testing}

\subsubsection{Narrow or broad?}

NIPD testing is feared to be applied for more and also for increasingly minor abnormalities, without adequate justification: the so-called 'specification creep' ${ }^{8,13}$ The reasoning behind this concern seems to be that the invasiveness of current diagnostic testing prevents expansion of its scope. Supposedly, one would not take the risk of losing a healthy child with invasive testing, but for the detection of (a high risk for) a really serious disease. In this view, the ease, safety and early moment of NIPD testing could be an incentive to apply NIPD testing for more and less serious conditions in the future. One could, however, also reason the other way around: the effort and the risk of the invasive procedure may be an incentive to test for as much abnormalities as possible, just to make this risk more proportional and to provide a more firm justification..$^{39,40}$

Karyotyping has been the 'Gold Standard' for diagnostic testing in the screening context for almost half a century now and also seems to be the reference point for the scope of NIPD testing. ${ }^{8}$ When NIPD testing implies abolishment of the current risk assessment, a limitation of the scope of NIPD testing to the chromosomal abnormalities diagnosed by karyotyping seems no longer evident. Furthermore, the issue whether the scope of invasive diagnostic testing should be narrower or broader than the current scope has already been under discussion for some years now. ${ }^{41-43}$ Limitation to some well-defined anomalies, such as trisomy 21,13 and 18 , has been proposed, as well as an expansion of the scope by, for example, array-based comparative genomic hybridisation. ${ }^{44,45}$ One of the main reasons 
to offer narrow testing is to reduce the probability of unexpected and clinically unclear findings. These can lead to difficult pre- and post-test counselling situations, impair informed decision making and make decisions regarding selective abortion emotionally more difficult and morally controversial. A broader scope is mainly supported by the argument that prenatal testing should focus on detecting any possible (severe) disability, irrespective of its cause and depending on the woman's or couple's choice. If people prefer to have maximum information, withholding information would deprive them of their autonomous reproductive choice. ${ }^{42}$

The above shows that the features of NIPD testing in itself do not necessitate a specific scope of testing: it could be narrow as well as broad.

\subsubsection{NIPD testing for heterogeneous abnormalities}

Although not feasible in the near future, a possible future expansion of the scope of NIPD testing has been brought up several times. ${ }^{4,8,12}$ If it might indeed become possible to include a kind of total genome sequencing in NIPD testing, the scope of NIPD testing in the context of common prenatal screening could exceed that of karyotyping. Then its scope might not only include (mono)genetic and/or congenital disorders, but also complex and late-onset disorders. ${ }^{4,8,12}$ Such an increase in scope is assumed to be 'more ethically problematic'. ${ }^{8}$ It has proven to be next to impossible to reach consensus about the definition of a list of diseases that are serious enough to test prenatally and to justify selective abortion - even if performed early. Partly because of variable expression, changes over time because of evolving treatment and personal situation, the severity of diseases is perceived differently. Still, broad ethically relevant categories of diseases and genotypes may be discerned: causative genetic traits for congenital disorders with clear clinical consequences, causative genetic traits for late-onset diseases, genetic variants associated with increased susceptibility to disease and carriership of recessive disorders. Inclusion of all these categories in an NIPDtesting array will lead to different ethical challenges, which will be discussed below.

\subsection{Informed consent for NIPD testing: the scope of the test}

\subsubsection{Generic consent}

If an NIPD test will be aimed at detection of different categories of disorders simultaneously, this would complicate informed consent, counselling and decision-making. Testing for (many) heterogeneous abnormalities at once would require more, more elaborate and detailed information. In addition, findings of unclear significance, which are always present in complex testing, would require special attention. Altogether, this could lead to an 'information overload', which could impair the decision-making process. ${ }^{46}$ More intensive counselling would be needed, which might be too time consuming and expensive if offered 
on a wide scale. Therefore, the requirement of extensive informed consent for broad NIPD testing may be really problematic to comply with.

As regards this subject, the alternative of generic consent has been proposed. ${ }^{47}$ This concept 'would emphasize broader concepts and common-denominator issues in genetic screening' by providing 'general information to obtain consent for the screening and much more detailed information on specific conditions only after they have been detected' ${ }^{47}$

A conceivable way of obtaining generic consent for an NIPD test with a broader scope would be to inform women in more general terms about categories of abnormalities included. On the basis of this information, women might be given the opportunity to indicate what kinds of abnormalities they would prefer to be told about. ${ }^{26}$ This approach has already been discussed with regard to current karyotyping. ${ }^{22}$ Some kind of generic consent seems to be inevitable when offering a broad NIPD test. The question is whether this is a justifiable way of executing the principle of respecting reproductive autonomy, because it endangers the feasibility of truly informed choices. ${ }^{26}$

In this respect, offering broad NIPD testing to all pregnant women may be seen as the molecular equivalent of the second trimester ultrasound scan. As the prenatal ultrasound scan may also detect a broad range of foetal defects, informed consent would at least require informing women before the scan about the variety of test results they could possibly encounter and have to deal with. Although a lack of proper informed consent has been reported in this context as well, ${ }^{48,49}$ this has been a remarkably less debated subject than with regard to risk-assessment and invasive prenatal diagnostic tests. ${ }^{27-30,50}$ The implementation of informed consent for these latter two prenatal tests has been proven to be inadequate several times, showing a discrepancy between theory and practice in this regard. Hence, there is a need to discuss the model and the implementation of informed consent for any present and future prenatal screening offer. The question will ultimately be to what extent the condition of informed consent is really valued: if the features, scope and implementation of prenatal testing are adjusted to the requirements of proper informed consent, the value of this condition will be reinforced. If it is the other way around, a declared adherence to the value of informed consent may well be deluding. ${ }^{51}$

\subsubsection{Decision-making process and the right not to know}

NIPD testing for a broad and heterogeneous range of abnormalities would generate a large amount of information and inevitably include findings the significance of which would be difficult, if at all, to interpret and explain. Unclear findings might lead to extensive diagnostic follow-up and even to the testing of parents to establish inheritance of unusual results, which may confront parents with unexpected findings about themselves as well. This leads 
to the question whether such knowledge would be harmful or beneficial for the parents and the future child. Unclear findings regarding the foetus could lead to confusion and unnecessary anxiety for parents, which is likely to persist throughout the pregnancy and into the postnatal period if the pregnancy is continued. A decision to terminate a wanted pregnancy on a basis of unclear testing results may be associated with 'particular feelings of guilt'. ${ }^{42}$ On the one hand, patient autonomy may still be an important consideration for providing women with more information about their foetus, if they prefer so. ${ }^{52}$ On the other hand, it has been asserted that prenatal screening for 1000 genetic variations with 99.9\% accuracy for true positives at once may lead to the consequence that 'every foetus will be identified as abnormal', thereby undermining the aim of this screening. ${ }^{43}$ These different views again underline the necessity of empirical research into women's attitudes, preferences and expected burdens regarding (broad) NIPD testing to assess the requirement of proportionality.

The issue of the right not to know of the future child might become a relevant issue in case of testing for monogenetic late-onset diseases and for increased susceptibility to diseases. Unsolicited knowledge of these traits would be an invasion of the autonomy of future children who have prenatally been diagnosed. If NIPD testing included these different kinds of disorders and the pregnancy was continued, it would resemble the possible future scenario of whole genome profiling of newborns, which would not be directed at any particular disease, but would reveal information about many and heterogeneous abnormalities, including late-onset diseases. ${ }^{53}$ As such, the resemblance of broad NIPD testing with newborn profiling indicates a blurring of the distinction between reproductive and non-reproductive screening. Testing foetuses would de facto amount to testing (future) children. Disclosure of findings about late-onset diseases in the neonatal screening context is considered to be incompatible with the widely, but not universally, endorsed maxim that predictive genetic testing should in principle be avoided in minors to protect their autonomy and privacy. ${ }^{53,54}$ The only accepted exception is if medical interventions are available to alter the course of the disease..$^{53,54}$

\subsection{NIPD testing for non-medical reasons}

NIPD testing for establishing sex or paternity, which is currently commercially offered, and subsequent selective abortion if the foetus is of the 'wrong' sex or from the 'wrong' biological father are generally thought to be problematic. , $14,55-57^{-57}$

With regard to gender testing, one concern is the preference in some societies of having a boy over a girl, which could have disrupting effects on those societies if selective abortion of female foetuses would be performed on a large scale. In that case, society could have 
good reason to restrict individual choice, because it undermines a public good..$^{58}$ Indeed, in some countries, sex selection is prohibited for exactly this reason. ${ }^{59}$ If sex selection would reflect a discrimination against women and systematically reinforce that bias, this could constitute a moral and legal injustice to be prevented. ${ }^{60}$ However, sex selection itself does not necessarily entail a discriminatory act. It could as well be an act of responsibility for a future girl's interest (eg, to guard it from being treated unjustly) even if this motive would arise against the background of a discriminatory society. ${ }^{36,61}$ Furthermore, couples can have personal motives for sex selection, such as family balancing. Some reject this as showing that children are increasingly seen as 'commodities'. However, sex selection for family balancing can also be valued as an opportunity for reproductive autonomy. ${ }^{62}$

With regard to prenatal paternity testing, there are hardly any medical applications, except in case of inherited diseases in which the underlying gene defect is not known and prenatal diagnostic tests cannot, therefore, be used. ${ }^{16}$ Non-medical reasons include ambiguous paternity in case of women with more than one sexual partner who are unsure of the actual father, and women who may be pregnant as the result of rape. In the latter case, paternity testing is not disputed, whereas in the former case paternity testing has been criticised. ${ }^{8,13}$, ${ }^{14}$ It has been suggested to counsel the women involved about the relative significance of biological kinship. ${ }^{14}$ To the extent that this is carried out with the aim of reducing the number of prenatal paternity tests, this approach strikes us as morally problematic. Counselling should be respectful of how the woman herself perceives the emergency situation leading to her request; counsellors should not try to defuse the problem by defining it away. We also suspect that reluctance to provide prenatal paternity testing may be prompted by an implicit condemnation of a promiscuous life. This would clearly be moralistic and unprofessional.

One should also realise that without paternity testing, women could feel compelled to terminate the pregnancy anyhow. Or women could feel compelled to continue the pregnancy, with the consequence of having a child fathered by the wrong man. Prenatal paternity testing may, therefore, lead to the least harm for the woman involved and be morally justified. ${ }^{63}$

Although personal motives for sex selection and paternity testing may be ethically controversial, abortion is allowed under various legal rules regarding social termination. ${ }^{16,61}$ In the case of NIPD testing, views regarding the moral status of the early embryo will be of relevance with regard to both reasons for selective abortion. 


\subsection{Conclusion}

On the one hand, women taking part in prenatal screening can profit from the ease, safety and early moment of NIPD testing. The introduction of a test with these features has ethically favourable consequences: absence of iatrogenic miscarriage because of the test, earlier reassurance, a longer period for decision-making and the possibility of an early abortion, which may be physically and psychologically less burdening and ethically less problematic because of presumed lower moral foetal status. On the other hand, should NIPD testing for a broader scope of abnormalities become possible in the future, this will complicate the ethical issues regarding NIPD testing. Informed consent will become far more challenging - if attainable at all. Moreover, should NIPD testing become available for a wide range of disorders including late-onset diseases, this may lead to the same ethical difficulties as with regard to wide range testing of newborns, in which the dominant view is that the child's right not to know should be respected. It is difficult to see how this respect can be upheld when, after broadening prenatal testing, children will be born with a positive test result for a serious late-onset disease. The debate about the ethical challenges of broad genetic testing is currently conducted in the contexts of neonatal screening and invasive prenatal testing. In this article, we have shown that the same issues will present themselves even more forcefully should broad NIPD testing become possible. A proactive further analysis of these issues is urgently needed. As we have stressed, this also requires empirical research into pregnant women's attitudes, needs and preferences concerning different modalities of prenatal testing. 


\section{References}

1 Lo YM, Corbetta N, Chamberlain PF, Rai V, Sargent IL, Redman CW, Wainscoat JS: Presence of fetal DNA in maternal plasma and serum. Lancet 1997;350:485-487.

2. Fan HC, Blumenfeld YJ, Chitkara U, Hudgins L, Quake SR: Noninvasive diagnosis of fetal aneuploidy by shotgun sequencing DNA from maternal blood. PNAS 2008;105:16266-16271.

3. Lo YMD, Chiu RWK: Prenatal diagnosis: progress through plasma nucleic acids. Nat Rev Genet 2007;8:71-77.

4. Wright $\mathrm{CF}$, Burton $\mathrm{H}$ : The use of cell-free fetal nucleic acids in maternal blood for non-invasive prenatal diagnosis. Hum Reprod Update 2009;15:139-151.

5. Geifman-Holtzman O, Berman JO: Prenatal diagnosis: update on invasive versus noninvasive fetal diagnostic testing from maternal blood. Expert Rev Mol Diagn 2008;8:727-751.

6. Maron JL, Bianchi DW: Prenatal diagnosis using cell-free nucleic acids in maternal body fluids: a decade of progress. Am J Med Genet 2007;145C:5-17.

7. Illanes S, Denbow M, Kailasam C, Finning K, Soothill P: Early detection of cell-free fetal DNA in maternal plasma. Early Hum Dev 2007;83:563-566.

8. Wright C: Cell-free fetal nucleic acids for non-invasive prenatal diagnosis Report of the UK expert working group, PHG Foundation, 2009.

9. Wright CF, Chitty LS: Cell-free fetal DNA and RNA in maternal blood: implications for safer antenatal testing. BMJ 2009;339:b2451.

10. Grosse SD, Khoury MJ: What is the clinical utility of genetic testing. Genet Med 2006;8:448-450.

11. Sanderson S, Zimmern R, Kroese M, Higgins J, Patch C, Emery J: How can the evaluation of genetic tests be enhanced? Lessons learned from the ACCE framework and evaluating genetic tests in the United Kingdom. Genet Med 2005;7:495-500.

12. Benn PA, Chapman AR: Practical and ethical considerations of noninvasive prenatal diagnosis. JAMA 2009;301:2154-2156.

13. Hall A, Bostanci A, John S: Ethical, legal and social issues arising form cell-free fetal DNA technologiesAppendix III to the report: Cell-free fetal nucleic acids for non-invasive prenatal diagnosis, PHG Foundation, 2009.

14. Newson AJ: Ethical aspects arising from non-invasive fetal diagnosis. Sem Fetal Neonat Med 2008;13:103-108.

15. Schmitz D, Netzer C, Henn W: An offer you can't refuse? Ethical implications of non-invasive prenatal diagnosis. Nat Rev Genet 2009;10:515.

16. Smith RP, Lombaard H, Soothill PW: The obstetrician's view: ethical and societal implications of non-invasive prenatal diagnosis. Prenat Diagn 2006;26:631-634.

17. Schmitz D, Henn W, Netzer C: Commentary: no risk, no objections? Ethical pitfalls of cell-free fetal DNA and RNA testing. BMJ 2009;339:b2690.

18. Health Council of the Netherlands: Genetic Screening. Publication no. 1994/22. The Hague: Health Council; 1994.

19. Health Council of the Netherlands: Prenatal Screening (2); Down's Syndrome, Neural Tube Defects. Publication no. 2004/06. The Hague: Health Council of the Netherlands, 2004.

20. Bui T-H, Meiner V: State of the art in prenatal diagnosis. In: Leuzinger-Bohleber M, Engels E-M, Tsiantis J (eds):The Janus Face of Prenatal Diagnostics. A European Study Bridging Ethics, Psycholanalysis, and Medicine. London: Karnac Books, 2008, pp 61-86.

21. Saller DN, Canick JA: Current methods of prenatal screening for Down Syndrome and other fetal abnormalities. Clin Obstet Gynecol 2008;51:24-36.

22. Health Council of the Netherlands: Prenatal Screening: Down's Syndrome, Neural Tube Defects, RoutineUltrasonography. Publication no 2001/11E. The Hague: Health Council of the Netherlands, 2001. 
23. Mujezinovic F, Alfirevic Z: Procedure-related complications of amniocentesis and chorionic villous sampling: a systematic review. Obstet Gynecol 2007;110:687-694.

24. ACOG ACOG: Practice Bulletin No. 88 (2007) Invasive prenatal testing for aneuploidy. Obestet Gynecol 2007;110:1459-1467.

25. Lo DYM, Chiu RWK: Noninvasive prenatal diagnosis of fetal chromosomal aneuploidies by maternal plasma nucleic acid analysis. Clin Chem 2008;54:461-466.

26. de Wert G: Looking ahead. Reproductive technologies, genetics and ethics. Amsterdam: Thela Thesis, 1999.

27. van den Berg M: Decision Making on Prenatal Screening. Wageningen: Ponsen \& Looijen B.V., 2006.

28. Marteau TM, Dormandy E: Facilitating informed choice in prenatal testing: how well are we doing. Am J Med Genet 2001;106:185-190.

29. Seavilleklein V: Challenging the rhetoric of choice in prenatal screening. Bioethics 2009;23:68-77.

30. van Zwieten M: The Target of Testing. Dealing with 'Unexpected' Findings in Prenatal Diagnosis. Amsterdam: Uitgeverij Buijten \& Schipperheijn, 2006.

31. van den Heuvel A, Chitty L, Dormandy E, Newson A, Deans Z, Marteau TM: Informed choice in prenatal testing: a survey among obstetricians and gynaecologists in Europe and Asia. Prenat Diagn 2008;28:1238-1244.

32. Green J, Hewison J, Bekker H, Bryant L, Cuckle H: Psychosocial aspects of genetic screening of pregnant women and newborns: a systematic review. Health Technol Assess 2004;8:iii,ix-x,1-109.

33. Kooij L, Tymstra T, van den Berg P: The attitude of women toward current and future possibilities of diagnostic testing in maternal blood using fetal DNA. Prenat Diagn 2009;29:164-168.

34. van den Heuvel A, Chitty L, Dormandy E, Newson A, Deans Z, Attwood S, Haynes S, Marteau TM: Will the introduction of non-invasive prenatal diagnostic testing erode informed choices? An experimental study of health care professionals. Patient Educ Couns 2009;78:24-8.

35. Gillon R: Is there a 'new ethics of abortion'. J Med Ethics 2001;27:ii5-ii9.

36 Pennings G, de Wert G: Evolving ethics in medically assisted reproduction. Hum Reprod Update 2003;9:397404.

37. Aramesh K: Abortion: an Islamic ethical view. Iran J Allergy Asthma Immunol 2007;5:29-33.

38. Mackler AL: Introduction to Jewish and Catholic Bioethics: A Comparative Analysis. Georgetown: Georgtown University Press, 2003.

39. ten Kate LP. Snelle prenatale diagnostiek van chromosomale fwijkingen;beperkingen en mogelijkheden. Ned Tijdschr Geneesk 2006;150:1608-1612.

40. van den Veyver I, Beaudet AL: Comparative genomic hybridization and prenatal diagnosis. Curr Opin Obstet Gynecol 2006;18:185-191.

41. Bui T-H: Prenatal cytogenetic diagnosis: gone FISHing, BAC soon! Ultrasound Obstet Gynecol 2007;30:247251.

42. Ogilvie CM, Yaron Y, Beaudet AL: Current controversies in prenatal diagnosis 3: for prenatal diagnosis, should we offer less or more than metaphase karyotyping? Prenat Diagn 2008;29:11-14.

43. Shuster E: Microarray genetic screening: a prenatal roadblock for life. Lancet 2007;369:526-529.

44. Sahoo T, Cheung SW, Ward P, Darilek S, Patel A, del Gaudio D, Kang SH, Lalani SR, Li J, McAdoo S, Burke A, Shaw CA, Stankiewicz P, Chinault AC, Van den Veyver IB, Roa BB, Beaudet AL, Eng CM: Prenatal diagnosis of chromosomal abnormalities using array-based comparative genomic hybridization. Genet Med 2006;8:719727.

45. Shaffer LG, Coppinger J, Alliman S, Torchia BA, Theisen A, Ballif BC, Bejjani BA: Comparison of microarray-based detection rates for cytogenetic abnormalities in prenatal and neonatal specimens. Prenat Diagn 2008;28:789795.

46. de Wert G, Dondorp W: Ethical issues. In: van Vugt M, Shulman K (eds): Prenatal Medicine. New York/London: Taylor \& Francis, 2006. pp 575-604. 
47. Elias S, Annas GJ: Generic consent for genetic screening. N Engl J Med 1994;330:1611-1613.

48. de Kort S: Verkeerde routine. 20-wekenecho is zoektocht naar alle mogelijk afwijkingen geworden. Medisch Contact 2008:63563.

49. Laror J, Begley C:Fetal anomaly screening: what do women want to know. J Adv Nurs 2006;55:11-19.

50. Favre R, Moutel G, Duchange N, Vayssière C, Kohler M, Bouffet N, Hunsinger MC, Kohler A, Mager C, Neumann $M$, Vayssière $C$, Viville $B$, Hervé $C$, Nisand I: What about informed consent in first-trimester ultrasound screening for down syndrome. Fetal Diagn Ther 2008;23:173-184.

51. Clarke AJ: Prenatal genetic screening: paradigms and perspectives. In: Harper PS, Clarke AJ (eds): Genetics, Society and Clinical Practice. Oxford: BIOS Scientific Publishers, 1997, pp 119-140

52. Friedman JM: High-resolution array genomic hybridization in prenatal diagnosis. Prenat Diagn 2009;29:20-28.

53. Human Genetics Commission and the UK National Screening Committee (Joint Working Group): Profiling the newborn: a prospective gene technology? London: Human Genetics Commission, 2005.

54. Hayeems RZ, Bytautas JP, Miller FA: A systematic review of the effects of disclosing carrier results generated through newborn screening. J Genet Counsel 2008;17:538-549.

55. Bianchi DW: At-home fetal DNA gender testing: caveat emptor. Obstet Gynecol 2006;107:216-218.

56. Hall S, Reid E, Marteau TM: Attitudes towards sex selection for non-medical reasons: a review. Prenat Diagn 2006;26:619-626.

57. Rogers W, Ballantyne A, Draper H: Is sex-selective abortions morally justified and should it be prohibited. Bioethics 2007; 21:520-524.

58. Buchanan A, Brock D, Daniels N, Wikler D: From Chance to Choice. Genetics and Justice. Cambridge: Cambridge University Press; 2000.

59. Zhu WX, Lu L, Hesketh T: China's excess males, sex selective abortion, and one child policy: analysis of data from 2005 national intercensus survey. BMJ 2009;338:b1211.

60. Toebes B: Sex selection under international human rights law. Med Law Internat 2008;9:197-225.

61. Health Council of the Netherlands: Sex-selection for non-medical reasons. Publication no. 1995/11E. The Hague: Health Council of the Netherlands, 1995.

62. Moazam F: Feminist discourse on sex screening and selective abortion of female foetuses. Bioethics 2004;18:269-9702.

63. Bayertz K: Pränatale Vaterschaftsdiagnostik und selective Abtreibung. Ethische Überlegungen zu einem schwierigen Fall aus der genetischen Beratungspraxis. 9 Jahrbuch für Recht und Ethik 2001;9119-129. 


\section{Chapter 4}

Non-invasive prenatal diagnosis for aneuploidy: toward an integral ethical assessment

de Jong A, Dondorp WJ, Frints SGM, de Die-Smulders CEM, de Wert GMWR

Human Reproduction 2011;26(11):2915-2917 


\begin{abstract}
The great promise of the pending introduction of non-invasive prenatal diagnosis (NIPD) for trisomy 21 (18 and 13) is that it enables one-step, early and safe testing for these abnormalities. The ethical debate so far has been limited to possible drawbacks of routine access to this type of testing: normalization of testing and abortion and adverse effects on autonomous decision-making. We address the ethical implications of the fact that routine NIPD affects the scope and strategy of current prenatal screening cascades. A decision is needed whether complementary (invasive) testing remains in place in order to avoid a loss of information as compared with current practice. If so, the supposed advantages of NIPD may be less significant than generally assumed. Accumulation of tests challenges informed consent and proportionality. Therefore, an ethical evaluation of the implications of NIPD for the prenatal screening strategy as a whole is needed.
\end{abstract}




\subsection{Introduction}

Screening for aneuploidies in the developed, primarily Western, world generally consists of two stages: (i) a risk assessment for trisomies 21 (Down's syndrome), 18 (Edward's syndrome) and 13 (Patau's syndrome), based on the combination of maternal serum testing, fetal nuchal translucency (NT) measurement and/or maternal age; (ii) a diagnostic follow-up test in case of an increased risk, performed on material obtained through invasive procedures: amniocentesis (AC) or chorionic villus sampling (CVS). ${ }^{1,2}$ Trials with non-invasive prenatal diagnosis (NIPD) using cell-free fetal DNA and RNA in maternal blood are currently performed worldwide and focus primarily on NIPD for trisomy 21, although trisomies 18 and 13 may follow. ${ }^{3-5}$ As a result, the current two-step testing may be replaced by a one-step diagnostic test targeted at these specific abnormalities. ${ }^{6}$

Although there has been some ethical debate about this prospect, the discussion has concentrated mainly on NIPD itself and on possible implications of routine access to onestep, early, easy and risk-free prenatal diagnosis. The issues discussed include the perceived risk of normalization of testing and abortion, the fact that non-medical applications such as testing for fetal sex and paternity will become more easily available, and a possible negative effect on autonomous decision-making. ${ }^{7,8}$ Although these issues need to be addressed as well, we assert that the expected introduction of routine NIPD testing for trisomy 21 (and 18 and 13) urgently calls for ethical reflection on the overall scope and strategy of prenatal screening. A decision is needed whether complementary (invasive) testing remains in place in order to avoid a loss of information as compared with current practice. We discuss the practical and ethical implications of routine NIPD testing either for trisomy 21 only or for trisomies 21,18 and 13 .

\subsection{Timing of NIPD-testing}

Fetal DNA can be detected from 5 weeks of gestation and reliable NIPD may be feasible from 7 to 9 weeks of gestation. ${ }^{9}$ Therefore, it has been assumed in the literature that NIPD will take place rather early in the first trimester. This would have the advantage that test results are received early, leaving more time for decision-making. Furthermore, possible termination of pregnancy in case of an adverse test result at this stage of pregnancy may be emotionally less burdensome than in the current approach, where diagnostic results are available after 1114 weeks (CVS) or 16-20 weeks (AC) of gestation. Early testing is favourable from an ethical point of view as well. According to the dominant account, the moral status of the embryo/ fetus is relatively low at the start and increases with further stages of development (the gradualist view). ${ }^{10}$ This notion of a gradually increasing moral status implies that selective abortion early in pregnancy is morally different from termination of affected pregnancies later in the first trimester or in the second trimester. 
However, a serious disadvantage of early NIPD is that it may increase the burden of choice for women, since abnormal fetuses will be identified that would have miscarried spontaneously later in pregnancy. ${ }^{11}$ Moreover, the timing of an NIPD test offer will depend on how NIPD can best be integrated in the overall screening strategy.

\subsection{Complementary testing: trisomies 18,13 and NT measurement?}

A possible scenario is that NIPD will initially be introduced for diagnosing trisomy 21 only and replace current two-step testing for this abnormality. This would maximize the benefits of NIPD at an early stage of its development: the drawbacks of false-positive and falsenegative results generated by current risk assessment and the miscarriage risk attached to current invasive diagnostic methods would thereby be..$^{6,12} \mathrm{~A}$ recent study by Susman et al. suggests that this procedure would lead to $84 \%$ fewer invasive procedures, while diagnosing an additional $7 \%$ of trisomy 21 cases (corresponding with the false negatives in current risk assessment). However, this procedure would also imply that about $50 \%$ of chromosomal abnormalities other than trisomy 21, including trisomies 18 and 13 , would be missed even when follow-up detection by the mid-trimester fetal anomaly scan is included. ${ }^{13,14}$ So to prevent testing being less informative than current practice, a solution would be to leave risk assessment and invasive diagnostic testing in place as a complementary screening trajectory for trisomies 18 and 13. Of course, the need for this does not arise as soon as these trisomies can be included in the NIPD array.

Abolishing current risk assessment raises a similar question with regard to NT measurement. Although offered as part of risk assessment for common aneuploidies, this procedure may concurrently lead to the early identification of pregnancies at a high risk of both chromosomal and non-chromosomal disorders, such as congenital heart defects and Mendelian disorders such as Noonan syndrome. ${ }^{15,16}$ Assuming that this information has added value in terms of reproductive options, the question arises what to do with NT measurement when introducing NIPD for the three trisomies. Should NT measurement be left in place as a separate screening test, complementary to NIPD? That would have the benefit of avoiding a reduction of the scope of prenatal screening and of the reproductive options that it is meant to provide. It would then only be logical to also offer this separate NT measurement to women who are currently not having risk assessment testing for common aneuploidies or who do not opt for NIPD in the future. However, separate NT testing must also be in line with the requirements of proportionality and informed consent. 


\subsection{Proportionality and informed consent}

First, offering complementary testing comes at the price of confronting women with additional test offers shortly after NIPD has been performed. This may add to the burden of testing, because screening will increasingly become fragmented, leading to a series of moments of choice for women and possibly to a prolonged period of anxiety. To avoid this possible drawback of successive testing, NIPD and complementary tests could be offered simultaneously at weeks $11-12$ of gestation, which is the usual period for risk assessment and gives the best performance for the NT measurement. ${ }^{15}$ From a logistic point of view, such a combination would also be advantageous. However, it may be challenging to adequately inform women about those simultaneous, but very different test offers. A targeted diagnostic test for trisomy 21, a risk assessment test for trisomies 18 and 13, and NT measurement for a broad range of abnormalities are very dissimilar in kind and scope. They also differ with regard to the kind of test outcomes (risk versus diagnosis) and decisionmaking consequences (follow-up testing versus termination/continuation of pregnancy). Furthermore, this 3-fold combination of tests would diminish the advantages of a 'standalone' NIPD as the moment of testing would be delayed. In contrast to the promise of more simple counselling as a result of the conceptually easy character of NIPD ${ }^{11}$, counselling would in fact become more complicated because of the heterogeneity of this compound test offer. Although NIPD would still have the advantage of being safe to perform, the other supposed advantages (early, easy) would, in this scheme, be less significant than generally assumed.

Second, since prenatal screening also requires the just use of scarce financial resources (distributive justice), the detection/cost ratio of NIPD for trisomy 21 or for trisomies 21, 18 and 13 with or without specific complementary testing has to be considered as well. A costeffectiveness analysis should take into account all the relevant aspects of the test options, including costs for counselling, for follow-up testing and for the lifetime provision of care for people with abnormalities undetected by a stand-alone NIPD.

Third, the advantages of possible additional invasive testing for trisomies 18 and 13 may not evidently outweigh the disadvantages for participants, because its very limited target would negatively affect the detection/miscarriage ratio. ${ }^{17}$

Fourth, separate NT measurement would amount to turning current 'incidental' findings into a screening target and require that informed consent be adapted accordingly. Presently, the possibility of those 'incidental' (non-aneuploidy-related) findings is not always included in pre-test information. ${ }^{15}$ As a consequence, pregnant women may be confronted with findings that they were not prepared for and that they might otherwise have indicated that they did not want to receive. ${ }^{18}$ It is evident that pre-test information will have to cover these 
findings should NT measurement become a separate test. But given that an enlarged NT ( $\geq 3.5 \mathrm{~mm}$ ) may indicate a risk for a wide range of abnormalities, this will not be possible on the level of specific abnormalities. As a form of more 'generic consent ${ }^{19}$ seems unavoidable here, the challenge is to offer not too much but yet enough information to enable women's informed decision-making with regard to this testing.

\subsection{Conclusion}

The general opinion is that NIPD holds great promise to enable prenatal diagnostic testing earlier in pregnancy and in a one-step, easy and safe manner. However, as our ethical considerations of the pending introduction of NIPD for trisomy 21 (and then 18 and 13) suggest these expectations may well reflect a one-sided view that overlooks the broader context of prenatal screening in which NIPD has to be implemented. A decision is needed whether only NIPD or NIPD and complementary testing will be offered. This requires a proactive ethical evaluation to find out which approach is most in line with the principles of respect for autonomy and of beneficence, underlying the normative framework for prenatal screening. 


\section{References}

1. Bui T-H, Meiner V: State of the art in prenatal diagnosis. In: Leuzinger-Bohleber M, Engels E-M, Tsiantis J (eds): The Janus Face of Prenatal Diagnostics. A European Study Bridging Ethics, Psycholanalysis, and Medicine. London: Karnac Books, 2008, pp 61-86.

2. Saller D, Canick J: Current Methods of Prenatal Screening for Down Syndrome and Other Fetal Abnormalities. Clin Obstet Gynecol 2008;51:24-36.

3. Chiu RW, Akolekar R, Zheng YW, Leung TY, Sun H, Chan KC, Lun FM, Go AT, Lau ET, To WW, Leung WC, Tang RY, Au-Yeung SK, Lam H, Kung YY, Zhang X, van Vugt JM, Minekawa R, Tang MH, Wang J, Oudejans CB, Lau TK, Nicolaides KH, Lo YM: Non-invasive prenatal assessment of trisomy 21 by multiplexed maternal plasma DNA sequencing: large scale validity study. BMJ 2011;342:c7401.

4. Ehrich M, Deciu C, Zwiefelhofer T, Tynan JA, Cagasan L, Tim R, Lu V, McCullough R, McCarthy E, Nygren AO, Dean J, Tang L, Hutchison D, Lu T, Wang H, Angkachatchai V, Oeth P, Cantor CR, Bombard A, van den Boom D: Noninvasive detection of fetal trisomy 21 by sequencing of DNA in maternal blood: a study in a clinical setting. Am J Obstet Gynecol 2011;204:205.e201-211.

5. Papageorgiou EA, Karagrigoriou A, Tsaliki E, Velissariou V, Carter NP, Patsalis PC: Fetal-specific DNA methylation ratio permits noninvasive prenatal diagnosis of trisomy 21. Nat Med 2011;17:510-513.

6. Go ATJL, van Vugt JMG, Oudejans CBM: Non-invasive aneuploidy detection using free fetal DNA and RNA in maternal plasma: recent progress and future possibilities. Hum Reprod Update 2011;17:372-382.

7. Benn PA, Chapman AR: Practical and Ethical Considerations of Noninvasive Prenatal Diagnosis. JAMA 2009;301:154-2156.

8. Schmitz D, Netzer C, Henn W: An offer you can't refuse? Ethical implications of non-invasive prenatal diagnosis. Nat Rev Genet;2009;10:515.

9. Wright $\mathrm{CF}$, Burton $\mathrm{H}$ : The use of cell-free fetal nucleic acids in maternal blood for non-invasive prenatal diagnosis. Hum Reprod Update 2009;15:139-151.

10. de Wert G: Looking ahead. Reproductive technologies, genetics and ethics. Amsterdam: Thela Thesis, 1999.

11. Wright C: Cell-free fetal nucleic acids for non-invasive prenatal diagnosis. Report of the UK expert working group. PHG Foundation, 2009.

12. de Jong A, Dondorp W, de Die-Smulders C, Frints S, de Wert G: Non-invasive prenatal testing: ethical issues explored. Eur J Hum Genet 2010;18:272-277.

13. Susman M, Amor D, Muggli E, Jaques A, Halliday J: Using population-based data to predict the impact of introducing noninvasive prenatal diagnosis for Down syndrome. Genet Med 2010;12:298-303.

14. Benn P, Chapman A: Ethical challenges in providing noninvasive prenatal diagnosis. Curr Opin Obstetr Gynecol;2010;22:128-34.

15. Bilardo C, Timmerman E, Pajkrt E, van Maarle M: Increased nuchal translucency in euploid fetuses-what should we be telling the parents? Prenat Diagn 2010;30:93-102.

16. Sonek J: First trimester ultrasonography in screening and detection of fetal anomalies. Am J Med Genet C Semin Med Genet 2007;145C:45-61.

17. Health Council of the Netherlands: Prenatal Screening: Down's syndrome, neural tube defects, routineultrasonography. Publication no. 2001/11. The Hague: Health Council of the Netherlands, 2001.

18. de Wert G, Dondorp W: Ethical issues. In: van Vugt M, Shulman K (eds): Prenatal medicine. New York/London: Taylor \& Francis, 2006, pp 575-604.

19. Elias S, Annas G: Generic Consent for Genetic Screening. New Engl J Med;1994;330:1611-1613. 



\section{Chapter}

Microarrays as a diagnostic tool in prenatal screening strategies.

Ethical reflection

de Jong A, Dondorp WJ, Macville MVE, de Die-Smulders CEM, van Lith JMM, de Wert GMWR

Human Genetics (in press) 


\begin{abstract}
Genomic microarray analysis is increasingly being applied as a prenatal diagnostic tool. Microarrays enable searching the genome at a higher resolution and with higher sensitivity than conventional karyotyping for identifying clinically significant chromosomal abnormalities. As yet, no clear guidelines exist on whether microarrays should be applied prenatally for all indications or only in selected cases such as ultrasound abnormalities, whether a targeted or genome-wide array should be used, and what these should include exactly. In this paper we present some ethical considerations on the prenatal use of microarrays. There is a strong consensus, at least in Western countries, that the aim of prenatal screening for foetal abnormalities should be understood as facilitating autonomous reproductive choice for prospective parents. The tests offered should be valid and useful to reach that purpose. Against this background we address several ethical issues raised by the prenatal application of microarrays. First we argue that the general distinction between a targeted and a genome-wide microarray needs to be scrutinised. Then we examine whether microarrays are 'suitable tests' to serve either a screening or a diagnostic purpose. Given the wide range of findings possibly generated by microarrays, the question arises whether microarrays actually promote or interfere with autonomous reproductive decision making. Moreover, if variants of unknown clinical significance are identified, this adds to the burden and complexity of reproductive decision making. We suggest a qualified use of microarrays in the prenatal context.
\end{abstract}




\subsection{Introduction}

Array-based molecular cytogenetic techniques (in short: microarrays) have for quite some time been routinely used in the postnatal setting, in particular to evaluate children with mental retardation or other abnormal phenotypes with unknown cause. ${ }^{1-3}$ Microarrays enable searching the entire genome for copy number variants (CNVs) at a higher resolution and with higher sensitivity than conventional karyotyping, and can detect more clinically relevant abnormalities. ${ }^{4-7}$ Because of this increased yield, microarrays are increasingly applied as a prenatal diagnostic tool. For the moment, microarray analysis will be performed on invasively obtained foetal material, although considerable effort is being put in methods for genome-wide diagnostics by means of non-invasive prenatal testing (NIPT). ${ }^{8,9}$

So far, no clear guidelines exist if and when to use microarrays prenatally. In 2010, the International Standards for Cytogenomic Arrays (ISCA) Consortium published a consensus statement in which the evidence at that time was thought to be insufficient to allow recommendations regarding prenatal applications. ${ }^{10}$ The ISCA proposed to use traditional cytogenetic methods instead. Earlier, in 2009, the American College of Obstetrics and Gynecology (ACOG) recommended to use conventional karyotyping as the principal cytogenetic tool in prenatal diagnosis, although a targeted array that focuses on detecting chromosomal abnormalities for known genetic syndromes was proposed as an adjunct tool in case of a combination of abnormal ultrasound findings and a normal conventional karyoype. ${ }^{11}$ The Italian Society of Human Genetics (SIGU) has in 2012 recommended a genome-wide array instead of a targeted array in this situation. ${ }^{12}$ Some expect or recommend microarray analysis to become the 'first-tier test' for all pregnancies because of its increased yield, irrespective of the indication. ${ }^{5,13-15}$ Others are more reticent about introducing this test prenatally. This reticence is mainly due to the fact that microarrays identify CNVs that can be categorised as being likely benign, likely pathogenic or a variant of unknown clinical significance (VOUS) ${ }^{16}$, and that arrays generate more VOUS than karyotyping., ${ }^{4,17,18}$ Thus, finding more clinically relevant abnormalities comes at the price of finding more VOUS: estimations of the percentage of VOUS in all prenatal samples vary from $0,3-1 \%$, depending on the population tested and the platform used. .,19,20 $^{4}$

Despite the differing opinions about the prenatal application of microarrays, they are already used for several indications, and mostly applied in case of foetal abnormalities shown by foetal ultrasound scans. ${ }^{5,21-23}$ Most pregnancies with ultrasound anomalies show a normal karyotype and remain without an aetiological diagnosis if only conventional karyotyping is applied. Testing by microarrays at a higher resolution and for more abnormalities is therefore

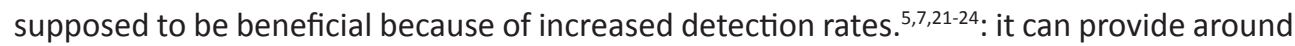
$6 \%$ extra diagnoses in this situation. ${ }^{4,6,21}$ Another indication to perform microarray testing 
is to interpret chromosome rearrangements detected by conventional karyotyping of which the clinical consequences are unsure. Microarrays allow for determining the size of the imbalance and the gene content, which may help to distinguish between pathogenic versus benign findings and to shed some light on the associated phenotype. ${ }^{4,6,21}$ Moreover, microarray testing can be offered to women with an increased risk for trisomies 21,18 and 13 , either based on risk-assessment outcomes or advanced maternal age. This will improve the overall detection rate of clinically significant chromosomal abnormalities compared to conventional karyotyping, since microarray may reveal around $1,7 \%$ more cases in this group. ${ }^{6,15,25}$ For this same reason it has also been proposed to offer microarray as a first-tier test to all pregnant women. ${ }^{4,14,15}$

To address the question what kind of microarray testing should be offered and to whom, it is morally important to assess whether this would be done for the purpose of finding a diagnosis or for screening and whether a targeted or a genome-wide microarray is a 'suitable test' for these purposes. In this paper, we will first briefly elucidate the notion of a suitable test and show how this relates to the normative framework for medical testing (diagnosis and screening). We will then go on to scrutinise the distinction between a targeted and a genome-wide microarray, and show that these notions are in need of a conceptual clarification to allow insight into the ethical implications of both. Next, we assess whether microarrays serve a diagnostic or a screening purpose, and whether they can be seen and justified as 'suitable' tests.

\subsection{A suitable test}

One of the well known Wilson \& Jungner criteria for population screening is that there must be a suitable test. ${ }^{26}$ This notion refers to the quality of a test in relation to its aim. The quality of a genetic test can be determined on different levels: analytical validity, clinical validity and clinical utility. Analytical validity is the ability of the test to accurately determine the genotype of interest. Clinical validity is the accuracy with which the test can predict a phenotype. This comprises both formal test characteristics as well as predictive value in a specific population. A diagnostic test is a test with $\sim 100 \%$ positive and negative predictive value. A screening test may have a somewhat lower score in this respect and still be suitable, if a positive result can be followed up by a test of diagnostic quality. Finally, clinical utility refers to quality in the wider sense of the ability of a genetic test to generate information that is relevant and important given the specific aim of the testing procedure. ${ }^{27}$ Taken in this wider sense, a 'suitable test' is one that would show a positive balance of aim-related advantages and unavoidable disadvantages (drawbacks and costs) of testing. 
At this level, the notion of a suitable test connects with ethical acceptability, more specifically with the conditions of 'appropriateness' and 'proportionality'. ${ }^{28}$ To be appropriate, a medical activity must lead (or contribute) to achieving a legitimate aim of medicine. With regard to genetic testing, a distinction must at this point be made between the aims of diagnosis and screening. In clinical care the aim of testing is to clarify the medical problem with which the patient presents, in order to allow treatment or secondary prevention. Prenatal diagnosis (indicated either in view of a genetic risk that was known prior to conception or as diagnostic follow-up testing in a prenatal screening context) is a special case, as the aim of testing in this context is to clarify the situation in order to either reassure the prospective parents, or to allow them to make a decision about whether or not to continue the pregnancy to term. The aim of screening programmes generally is the early detection of disease or risk factors in persons without clinical symptoms or complaints, so as to allow timely intervention (treatment or primary prevention) expected to lead to a significant health gain on a population level. Prenatal screening, however, is a special case here. There is a strong consensus, at least in Western countries, that the aim of prenatal screening for foetal abnormalities should be understood as facilitating autonomous reproductive choice for pregnant women (and their partners), rather than to achieve a population health gain by trying to prevent the birth of children with congenital abnormalities. ${ }^{29}$

Assuming that medical testing is appropriate in view of a legitimate aim, the further condition of 'proportionality' requires that any drawbacks, burdens and costs are proportional to the importance of achieving that end. For instance, a costly and burdensome test which is known beforehand only to have a limited impact on clinical management, may well be disproportional. Moreover, if there is a choice between different ways to reach the same end, the least risky, burdensome, costly, etc alternative should in principle be chosen (this is often referred to as the condition of 'subsidiarity'). ${ }^{30}$

In addition to requiring a legitimate aim and a suitable test (in the sense just given), the ethical acceptability of medical testing requires that the person to be tested (or this person's representative) has given his or her informed consent. This presumes a professional duty to provide him or her with the information needed for making a well-considered decision, including information about the aim and nature of the procedure, but also about implications of possible outcomes for the testee and any other stakeholders.

As we will show, the implementation of microarray testing in the prenatal testing cascade challenges some of these conditions of what, from the perspective of ethical acceptability, would be a suitable test. 


\subsection{Genome-wide versus targeted microarray: a moot distinction}

Generally, a distinction is made between a genome-wide and a targeted microarray, but the meaning of the adjectives 'genome-wide' and 'targeted' is not as clear as it may seem at first sight.

First, both kinds of tests are genome-wide in the sense that both search throughout the entire genome for possible sub-microscopic deletions and duplications. A targeted microarray, however, is designed to only cover genomic regions across the genome that are known to be associated with phenotypic abnormalities: thus, it can focus on various regions throughout the whole genome and include as many or as few microdeletion and duplication syndromes as thought to be needed. ${ }^{5}$ Moreover, the density of probes in both targeted and genome-wide arrays can vary. Whereas karyotyping can only detect anomalies to a resolution of 5-10 $\mathrm{Mb}$, bacterial artificial chromosomes (BAC) arrays and high-resolution oligonucleotide arrays are capable of detecting changes at a much higher resolution - up to 50-100 Kb. ${ }^{31,32}$ Microarrays can also be designed to have a different resolution for specific parts across the genome. For example, 'critical regions' that are known for being associated with specific abnormalities, may be searched at a higher resolution (thus detecting smaller deletions and duplications), whereas the remaining regions (so-called backbone regions) are searched for deletions and duplications of a greater size only. ${ }^{5,731}$ Since every microarray is biased in the sense that its design is based on a decision of what size and kind of deletions and duplications are to be detected, a so-called "unbiased whole-genome array-CGH"33 does not exist. It is therefore important to know what particular design an array has (resolution for critical and backbone region).

Second, the main feature of targeted prenatal microarrays, that they only cover genomic regions known to be associated with phenotypic abnormalities, has the advantage (and purpose) to minimise the number of VOUS, in order to equally minimise the emotional burden and counselling difficulties associated with VOUS. ${ }^{11,33-37}$ Still, their design means that the 'target' is not per se related to the initial indication. The microarray is mostly used for a diagnostic purpose, namely to explain a specific unclear (mostly foetal ultrasound scan) abnormality, but a targeted array targets all known genomic regions, whatever the indication. In that regard, it clearly differs from targeted testing by molecular methods for rapid aneuploidy detection (RAD) ${ }^{38}$ : whereas the scope of RAD is explicitly limited to the few abnormalities for which the pregnant woman is found to be at increased risk, the scope of a targeted microarray is not limited to a few indication-related specific genomic regions only. We therefore conclude that 'targeted' in the prenatal context is not a clear concept, but has two different meanings. On the one hand, targeted indicates that the scope of the technique is explicitly limited to the diagnostic question, i.e. to the purpose of identifying one or only a limited number of well-described disorders indicated by a specific symptom or 
risk-assessment. This meaning applies to the narrow RAD test. On the other hand, targeted indicates that the scope of a test is limited in that it does reveal all known clinically relevant abnormalities and does not -or at least as little as possible- generate unclear findings. In the case of prenatal microarrays, this second meaning of targeted de facto applies: although there is a specific reason to perform an array -a diagnostic indication- the design of the array itself is not specifically tailored to this indication. This is not only a terminological issue, but bears ethical relevance too. From a normative perspective, the scope of a diagnostic test should be adjusted as much as possible to the initial diagnostic question. This basic conceptual clarification is an essential part of the justification for doing that specific test (criteria of appropriateness, proportionality and subsidiarity). In the case of prenatal microarrays this does not evidently hold.

As our analysis shows, the terms 'genome-wide' and 'targeted' are equivocal and in our view therefore not suitable for indicating the ethically relevant characteristics of the two kinds of microarrays. To avoid any confusion about what 'genome-wide' and 'targeted' in the prenatal context mean when indicating diagnostic tests, we propose to use the terms 'undirected' and 'directed' for describing the arrays instead. 'Undirected' arrays search the whole genome, or part(s) of it, for all CNVs, both those that are associated with a known phenotype and those of uncertain clinical significance. 'Directed' microarrays aim to provide maximum detection of all clinically significant CNVs. The term 'targeted' will be reserved for tests whose scope is attuned to the diagnostic question (See: Table 1).

\section{Table 1 | Ideal types of testing}

$\begin{array}{ll}\text { Denotation } & \text { Characteristic of test } \\ \text { Undirected } & \text { The test seeks all, both clear and unclear, aberrations (known and unknown CNVs) } \\ \text { Directed } & \text { The test seeks all known and clear aberrations (known CNVs) } \\ \text { Targeted } & \text { The test only seeks the aberrations indicated by the diagnostic question }\end{array}$

From this classification it follows that an undirected microarray can never be targeted. A directed array can sometimes be understood as targeted, namely if and insofar the diagnostic question is totally undefined, as may be the case when unclear foetal ultrasound markers are found. If the direction of the diagnostic search cannot be derived from the markers, it may be necessary to look for all known and clear aberrations (directed microarray) to enlarge the chance of finding a clarification. However, a specific ultrasound finding, for example a foetal heart defect, indicates that the diagnostic search by microarray can focus on regions associated with cardiogenetic diseases only. 


\subsection{The use of microarrays: between prenatal diagnosis, screening and research}

\subsubsection{The case for targeted arrays}

Microarrays are increasingly used as a follow-up test in a prenatal diagnosis context. One application is to clarify chromosome rearrangements detected by conventional karyotyping. In that case, the focus and aim are rather straightforward: to give more clarity about the nature and the phenotypical consequences of a specific chromosomal abnormality. Such information is important for pregnant women to make a well-informed decision about whether to terminate or continue the pregnancy. In this situation a targeted microarray, focusing on the specific region that needs clarifying only, should ideally be applied to answer the diagnostic question. An array that focuses on more regions would exceed the scope of the question and would in that sense not be appropriate but amount to excessive testing. The most frequent application of microarrays in prenatal diagnosis is to clarify foetal ultrasound abnormalities, and in this situation the focus is less clear-cut. First- and second trimester ultrasound scans may show major structural anomalies as well as markers that may indicate heterogeneous abnormalities and syndromes. In the latter case, as will be discussed below, a targeted array will often not be possible. However, the cause of (some) major and isolated structural abnormalities may be relatively easy to identify. ${ }^{39}$ Whenever this is the case, it would seem that an array meant to clarify the findings need not look beyond the particular genomic region(s) associated with them.

But even in cases where it would be possible to target the design of the array itself or to target the analysis of the data obtained by an (un)directed microarray ${ }^{1,40}$, to the best of our knowledge not a targeted but a directed or an undirected array is generally used. Directed arrays as described in the literature and as used at various institutions cover around 75-200 genomic disorders ${ }^{7}$ and most of these "known deletion and duplication syndromes would not present with any specific prenatal risk factors or characteristic ultrasound findings". ${ }^{41}$ This suggests that in practice, the indication or diagnostic question does not determine the decision of what test platform to use or what analysis to perform. The same arrays are used for pre- and postnatal samples and for different indications, mainly for practical and/ or financial reasons. Since directed (and targeted) arrays necessitate frequent updating to include new relevant CNVs, some commentators insist that such arrays are simply not costeffective and impractical from a laboratory point of view. ${ }^{24,42} \mathrm{~A}$ similar argument is made by Rehm with regard to next-generation sequencing (NGS). She remarks that "although disease-targeted testing is likely to remain useful for the short term, laboratories are faced with the never-ending incremental costs to develop and to validate each new diseasetargeted panel, as well as to update constantly the content of existing panels as new genes are identified. This burden is causing laboratories to consider more efficient approaches than targeted testing." ${ }^{43}$ 
However, these considerations cannot conceal that in situations where a targeted test would suffice to clarify the karyotyping or ultrasound findings, the use of wider tests marks a step from prenatal diagnosis to a wider prenatal screening paradigm, where (un)directed microarrays serve as a tool to identify any foetal abnormality detectable by microarray, rather than just answer the clinical question. The same shift is behind offering (un)directed microarrays to pregnant women at increased risk for common aneuploidies (trisomies 21, 18 and 13$) \cdot{ }^{4,14}$

Excessive testing is ethically problematic, as it adds to the unavoidable drawbacks of testing without a possible justification in terms of aim-related advantages for the testee(s). From a proportionality perspective, a test with such implications can hardly be suitable for prenatal diagnosis. This problem may seem to disappear with the implicit shift from prenatal diagnosis to prenatal screening, where the aim of testing for foetal abnormalities is no longer bound by an indication. If prenatal screening is aimed at providing women or couples with whatever information about the foetus they may find relevant in view of autonomous reproductive decision-making, there may seem to be no such thing as 'excessive testing'. Some have followed this path towards proposing that all pregnant women should be offered an (un)directed microarray. ${ }^{14}$ However, even if it could be argued that a 'maximum yield approach' would be appropriate given the aim of prenatal screening, more is needed to speak of a suitable test, especially in view of what this would entail for the testees in terms of the balance of benefits and drawbacks ('proportionality').

\subsubsection{The place for directed arrays}

If multiple ultrasound abnormalities are found, this indicates that the pregnancy could be 'at-risk', but the question at risk for what can mostly not be answered exactly. An enlarged nuchal translucency (NT) thickening (at 11-12 weeks of gestation), usually defined as $\geq 3.0$ - $3.5 \mathrm{~mm}$, is associated with an increased risk of congenital cardiac disorders and a number of genetic and non-genetic disorders, thus giving reason for follow-up testing. ${ }^{44}$ The midtrimester ultrasound scan examines over-all basic foetal anatomy including, amongst other things, head, heart, abdomen, spine, limbs and extremities ${ }^{45}$ and is used to identify a broad range of aberrations indicating heterogeneous abnormalities and syndromes. The broad and unselective character of these ultrasound scans brings about that if foetal anomalies are found, it will not always be possible to specify the diagnostic question and thus also to limit the scope of the follow-up diagnostic test to specific parts of the genome.

If the aim of a directed array is to clarify unspecific ultrasound findings by identifying their possible cause, such an array would in so far be 'targeted': a directed microarray may identify $6 \%$ more clinically significant CNVs than conventional karyotyping would do. Indeed, it can 
be argued that offering an ultrasound screen involves a duty to as much as possible clarify any unclear findings in order to either provide reassurance to pregnant women or to allow them to make a meaningful decision about whether or not to continue the pregnancy. But even if answering to an obvious indication for follow-up testing, the use of a directed array in such cases blurs the distinction between diagnosis and screening: while giving a better chance of clarifying the earlier findings for the prospective parents, at the same time the test will detect any other submicroscopic chromosomal abnormalities known to be relevant for the health prospects of the future child.

In the literature, an undirected array has regularly been referred to as a "diagnostic screen" 33 or as "genome wide screening". 24,46 However, as our analysis suggests, this qualification also applies to the use of directed arrays, even where this approach would be appropriate (rather than excessive) follow-up testing. De facto, the use of such arrays comes down to scanning the foetal genome for any possible abnormality, related or unrelated to the ultrasound findings. As a result, prenatal microarrays have an ambiguous character, which tends to obscure their purpose as a follow-up test. This may explain why publications about prenatal microarrays do not usually specify the percentage of results that actually answers the diagnostic question raised by ultrasound abnormalities. Neither is the classical distinction made between intended and incidental findings when indicating the yield of microarrays; this distinction seems to be fading with the shift towards screening for any (known) genetic abnormality. With this implicit shift, it also becomes less obvious why one would use a directed instead of an undirected array in case of unspecific ultrasound abnormalities.

\subsubsection{The problem with undirected arrays}

Proponents of an undirected array want to optimise the identification of all possibly clinically relevant CNVs. To detect these, both known and unknown regions are included in the testing array. A directed approach is seen as disadvantageous in that it will miss yet unknown clinically important aberrations..$^{24,47,48}$ But it is far from evident that the extra yield of an undirected array gives a better chance of clarifying unspecific ultrasound findings. In most cases, what it adds is not a more adequate diagnosis, but VOUS and the hope that through further classification and research, VOUS may be turned into meaningful findings. ${ }^{6,49}$ This entails assessing "clinical findings, literature, available databases, and gene content and size to determine whether there (is) sufficient information on which to base the prediction of phenotype and, if so, whether the phenotype (is) of sufficient clinical relevance to be reported." ${ }^{\prime \prime}$ In other words: if VOUS are classified, this will to a large extent be based on estimation and subjective evaluation of its possible meaning. ${ }^{50}$ This may explain why, next to the differences in the array design, estimations on the number of VOUS vary from around $0.4 \%$ to $12 \%{ }^{49,51}$ The conclusion must be that for lack of clinical validity, undirected microarrays 
are a research tool rather than an instrument of clinical care. This is also apparent from regular remarks in the literature saying that the number of VOUS will decrease as 'genomewide' arrays will be applied more often, and more novel clinically relevant CNVs will be detected. ${ }^{21,52}$ Or, as de Wit et al. state: "To allow the discovery of new pathogenic CNVs, whole genome array platforms should be recommended in the prenatal setting (...)." ${ }^{39}$ From an ethical point of view, there is a clear danger here that ignoring the distinction between research and care will lead to turning pregnant women into research subjects without their knowledge and consent. Bassem et al. ${ }^{53}$ have remarked "(...) whole-genome arrays are explorative by design and by purpose." They therefore want to reserve undirected arrays for research purposes only, and propose to use directed arrays in diagnostic laboratories in order to protect patients against possible wrong interpretations. "After all", they say, "we serve patients, not study subjects." 53

Why indeed burden pregnant women with VOUS if this will not lead to a better diagnosis? The implicit 'shift towards screening' provides proponents of undirected arrays with a simple argument: because any information that something may be wrong with the foetus can be relevant for the decision to continue or abort the pregnancy. For instance, according to McGillivray et al. ${ }^{54}$ it would be paternalistic of professionals to withhold information about VOUS, because "(a) result of uncertain significance is still information" and "(i)f it is all about choice, then, no option or information potentially relevant to a woman's choice and her decision-making processes should be withheld." They add that professionals should not be held responsible for women's decisions to terminate a pregnancy in case of unclear findings. But from an ethical point of view, this equation of a 'maximum yield approach' to microarray testing with 'facilitating autonomous reproductive choice' as the accepted aim of prenatal screening is too simple. It ignores the crucial question how generating (further) unclarities would possibly serve this purpose. The message "we have found something in your foetus, but we do not know what it means" cannot reasonably be seen as relevant and helpful for prospective parents' reproductive decision-making. Choices must be meaningful to be worthwhile. If they are not, the problem is not just that reproductive autonomy becomes an empty concept, but also that its pursuit comes at a price that is no longer proportional, given the added burdens of anxiety and stress and the possible long-term impact of a decision to terminate a wanted pregnancy for what may have been false alarm. In terms of the ethical framework set out earlier in this paper, the conclusion must be that undirected arrays are not a suitable test, neither for the purpose of prenatal diagnosis, nor for that of prenatal screening.

Of course, the issue of unclear test results is not new and unclear findings are difficult to completely avoid in prenatal testing. Conventional karyotyping may also generate results of which the clinical significance is unclear and even a directed microarray may incidentally 
reveal unclear findings. The same holds for the use of prenatal ultrasound. Analysts and clinicians are used to deal with these situations and especially clinicians may be expected to act prudently and take into account the principle of non-maleficence when reporting test results to their patients. Still, these latter situations have to be distinguished from the scenario that unclear findings are deliberately generated - as is the case with undirected microarrays.

In our view, professionals who want to offer undirected arrays to their patients, should make clear that the main purpose of doing so is research: to contribute to the steadily growing knowledge about genotype-fenotype relations and thereby to reduce the amount of VOUS. But it may well be that in some cases individual patients would directly benefit from participating in this research, as some unclear findings may be clarified swiftly and sufficiently enough to provide them with relevant information (even though still ahead of formal proof of validity). This possibility may be a reason why well informed patients may find it worthwhile to consent to participating in such research, while accepting that this comes at a price of being confronted with more unclear or ambiguous outcomes than would otherwise be the case. Still we think that, as part of the pre-test and consent procedure, professionals offering such 'experimental diagnosis' should make clear to the woman or the couple that 'true VOUS' will not be reported to them.

\subsection{Informed choice and counselling for microarray testing}

Ganesamoorthy et al. have recently suggested that "the issue of balancing the use of the highest resolution arrays to maximise detection against the drawbacks of novel or uncertain findings may best be managed by giving parents the option of high-resolution or low-resolution, targeted, prenatal analysis." 55 We do not agree. If undirected arrays are unsuitable precisely because they undermine rather than serve autonomous decision making by pregnant women and their partners, offering this choice in the name of that ideal is a non-starter. It seems a thin disguise for the attempt to preserve the option of using genome-wide arrays while relegating the responsibility to the patient. However, leaving the decision to the woman or the couple may well be an option where there would be a choice between a targeted and a directed array. In cases where a targeted array would be an appropriate follow-up test for karyotyping or ultrasound findings, opting for a directed array would reflect the shift from diagnosis to screening. If only the prospective parents are aware of this, there seems nothing wrong with allowing them to choose this option, assuming that a directed array can more easily be justified as a suitable test for prenatal screening purposes, than an undirected one. Allowing this choice between a targeted follow-up test and a wider screening test is similar to the 'individualised choice' between a targeted RADtest and karyotyping. ${ }^{56}$ 
This still raises the question how to provide prospective parents with adequate information in order to facilitate them to make an informed choice whether to be tested or not, and what outcomes to receive or not. The traditional interpretation of meaningful informed consent is that testees are in the pre-test situation informed about all conditions tested for, so that they can indicate what results they want to receive or not. It is clear that in case a of microarray test, this traditional interpretation of informed consent is untenable. It is impossible to extensively inform prospective parents about all the possible findings, including their clinical consequences. To do so would probably result in such an overload of information, that parents will in fact be incapacitated to give their informed consent. Categorising findings may be the best and in fact the only feasible option in the case of microarrays. ${ }^{57}$

To ensure that prospective parents' views and preferences are taken into account, pre- and post-test counselling has to satisfy more than the requirements of adequate information and non-directiveness alone. The 'interpretive model' of the professional-patient relationship as introduced by Emanuel and Emanuel ${ }^{58}$ seems to comply best with what is needed in this situation. This model allows for a collaboration of the professional and the pregnant woman to choose the test option that suits the woman's situation and preferences best. To reach that, the professional informs her about the available options and helps the woman to clarify her own wants and values to reach the decision that best fits her.

\subsection{Late-onset diseases: include or exclude?}

Apart from the overall suitability of microarray(s) for diagnostic testing, an important question is whether there is reason to explicitly exclude specific results from testing beforehand. A prenatal microarray may not only generate information about congenital disorders but may as well reveal, amongst other things, (predispositions for) late( $r$ )-onset diseases and the already mentioned VOUS. In that regard it can be seen as a precursor of the possible future prenatal application of whole exome sequencing (WES), whole genome sequencing (WGS) and broad or narrow analyses of these sequences that are likely to be introduced in prenatal screening strategies as well. ${ }^{59-61}$ Donley et al. have identified six different types of information that may be identified when analysing data of WGS and asked whether these suit the purpose of informed reproductive decision making: congenital disorders, non-medical traits, susceptibility genes, carrier status, VOUS, and late-onset diseases (highly penetrant genetic conditions that cause symptoms only later in life). ${ }^{60}$ Here, we will shortly address the last type of information since this raises the most urgent ethical issues that necessitate a decision to either include such outcomes in a testing platform or not. Elsewhere, this issue has been discussed in more detail. ${ }^{59}$ 
Classic examples of untreatable, severe late(r)-onset diseases are Huntington disease (HD) and hereditary early-onset Alzheimer disease. If these findings are included in a broad test, and if the pregnant woman has indicated that she wants to receive these test results, then she will be informed about them in case of a positive result. If the woman then decides to continue the pregnancy, this would mean that the child will be born with burdening knowledge about future conditions: one would de facto be screening the future child. ${ }^{18,57,59,60}$ In that regard, the distinction between prenatal and postnatal testing becomes blurred. Screening newborns and children for late(r)-onset conditions that are untreatable is generally considered to be morally unjustified in view of the children's anticipatory autonomy rights and the principle of non-maleficence. Children have the right to decide themselves, when competent to do so, to be tested for these conditions or not. To test them either in childhood, neonatally or prenatally, would deprive them of this right and amount to an infringement of the principle of respect for persons. ${ }^{18,62,63}$ This means that a conflict arises between the (prospective) parents' right to know because and insofar this is linked with their reproductive decision-making, and the future child's right not to know.

The question here is which of the two should prevail in the prenatal context. Are prospective parents entitled to all health-related information about their foetus because, based on their reproductive autonomy, they should be enabled to make well-informed reproductive decisions on the basis of such information? Not without limitation. As it may be necessary in the neonatal context to override parental autonomy to receive certain information "to prevent harm and to preserve a minor's future autonomy"64, so it may also be needed in the prenatal setting to limit reproductive autonomy, if a clear reproductive interest is absent and a future minor's future autonomy has to be protected. However, insofar pregnant women want to use this information to make a well-informed decision to terminate the pregnancy, there is indeed a reproductive interest to receive this information and in principle there will not be a future child to be harmed. Therefore, it has been suggested to only give conditional access ${ }^{18,59}$, namely "to only provide this information if the woman has indicated in pre-test counselling that she indeed intends to ask for a termination if confronted with this type of finding." 18 This stance is opposed by several commentators. For instance, in an earlier debate about prenatal testing for HD, the Canadian Royal Commission on New Reproductive Technologies rejected the idea of conditional access for several reasons. ${ }^{65}$ They claim that prospective parents who do not consider selective abortion for HD would not ask for the test, that people do not know in advance what they will actually do, that it is morally and legally unacceptable to enforce abortion, and that the problem will seldom occur. De Wert (2002) has argued that these objections are not decisive for declining conditional access to prenatal testing for late-onset diseases, given the possible violation of the rights and interests of the future child. Therefore he argues that conditional access to such testing is "morally justified, or even morally imperative." ${ }^{66}$ We agree with this latter view and 
moreover point out that with the increase of genome-wide testing, possibly revealing a predisposition for late-onset diseases, the issue is likely to occur more often if no measures are taken against including this type of finding in a testing platform. We of course agree that women can never be forced to actually proceed in accordance with their expressed intention to abort in case of an adverse test result. Still, they will then be aware of the possibly destructive implications of burdening their future child with such knowledge - and they have to take the responsibility for that.

\subsection{Conclusion}

Microarrays enable identifying more clinically significant abnormalities in the prenatal context than conventional karyotyping and this is usually seen as a benefit, also in the prenatal context. Although we acknowledge the advantages of microarrays, we have also shown the drawbacks of the fact that the phenotypical consequences of many CNVs are uncertain. We noted a tendency to use broader arrays than would be needed for clarifying karyotyping or ultrasound outcomes and an implicit shift from a prenatal diagnosis to a prenatal screening paradigm. This causes microarrays to have an ambiguous character. A clear distinction should be made between targeted, directed and undirected microarrays. If the indication pregnant women present with is clear, diagnostic testing should be done by what we have defined as a targeted microarray, ideally focussing on regions that are associated with the specific type or category of earlier findings. If, for instance, former outcomes point to cardiac problems, a targeted array would not look for CNVs associated with neurogenetic abnormalities. If such an array is not available, or cannot be made available at a reasonable cost, or if there are other justified reasons to apply a broader microarray, a directed microarray may be a suitable test. With regard to undirected arrays, we have suggested that generating VOUS serves a research purpose and does not contribute to the aim of autonomous reproductive decision making.

Even in case of a directed microarray, autonomous decision making and adequate informed consent are complicated by the heterogeneous amount of findings that a microarray can generate. Prospective parents should be made aware of the intrinsic uncertainty of possible findings by microarrays in pre- and post-test counselling. The complexity of the information at hand may even ask for moving up the moment of the provision of prenatal testing possibilities to the preconceptional period, in order to leave enough time for adequate and autonomous parental deliberation. Furthermore, post-test information about late-onset diseases should only be made conditionally accessible in order to protect future children's anticipatory autonomy rights 
More in general, the current prenatal application of microarrays seems to be complicated by the fact that the development of this technique and the gain of knowledge about its outcomes are still in progress: the application is therefore taking place in the intermediate phase between research and implementation. As a result, decisions have still to be made about what possible findings to include in a testing array or not. In that regard, the prenatal use of microarrays may reflect a so-called 'extemporaneous' ${ }^{67}$ translation of research into clinical care, instead of a well-balanced introduction of this technique after a profound evaluation of clinical, empirical and normative issues. With increasing knowledge, it may be possible to differentiate microarrays per diagnostic question in order to offer a suitable test and a clear answer to the medical question at hand.

For now, prospective parents will be confronted with the question whether they want to terminate or continue the pregnancy affected with any of the CNVs found. Since selective abortion is an emotionally and ethically charged decision, providers of prenatal tests have the obligation to carefully decide what findings they will confront prospective parents with and where the line between beneficial and maleficent provision of information will be passed. Allowing pregnant women an 'individualised choice' between a targeted follow-up test and a wider screening test (directed microarray), may be an alternative. This option is in line with the aim of prenatal screening and offers women or couples the opportunity to choose the test that best fits their individual wants and needs. 


\section{References}

1. Bejjani B, Shaffer L: Application of array-based comparative genomic hybridization to clinical diagnostics. Mol Diagn 2006;8:528-533.

2. Shaffer LG, Kashork CD, Saleki R, Rorem E, Sundin K, Ballif BC, Bejjani BA: Targeted genomic microarray analysis for identification of chromosome abnormalities in 1500 consecutive clinical cases. J Pediatrics 2006;149:98102.

3. Stankiewicz P, Beaudet A: Use of array CGH in the evaluation of dysmorphology, malformations, developmental delay, and idiopathic mental retardation. Curr Opin Genet Dev 2007;17:182-192.

4. Armengol L, Nevado J, Serra-Juhé C, Plaja A, Mediano C, García-Santiago FA, García-Aragonés M, Villa O, Mansilla E, Preciado C, Fernández L, Ángeles Mori M, García-Pérez L, Lapunzina PD, Pérez-Jurado LA: Clinical utility of chromosomal microarray analysis in invasive prenatal diagnosis. Hum Genet 2012;131:513-523.

5. Savage M, Mourad M, Wapner R: Evolving applications of microarray analysis in prenatal diagnosis. Curr Opinion Obstet Gynecol 2011;23:103-108.

6. Wapner RJ, Martin CL, Levy B, Ballif BC, Eng CM, Zachary JM, Savage M, Platt LD, Saltzman D, Grobman WA, Klugman S, Scholl T, Simpson JL, McCall K, Aggarwal VS, Bunke B, Nahum O, Patel A, Lamb AN, Thom EA, Beaudet AL, Ledbetter DH, Shaffer LG, Jackson L: Chromosomal microarray versus karyotyping for prenatal diagnosis. N Engl J Med 2012;367: 2175-2184.

7. Zuffardi O, Vetro A, Brady P, Vermeesch J: Array technology in prenatal diagnosis. Semin Fetal Neonatal Med 2011;16:94-98.

8. Kitzman JO, Snyder MW, Ventura M, Lewis AP, Qiu R, Simmons LE, Gammill HS, Rubens CE, Santillan DA, Murray JC, Tabor HK, Bamshad MJ, Eichler EE, Shendure J: Noninvasive Whole-Genome Sequencing of a Human Fetus. Sci Transl Med 2012;4:137ra176.

9. Srinivasan A, Bianchi D, Huang $H$, Sehnert A, Rava R: Noninvasive detection of fetal subchromosome abnormalities via deep sequencing of maternal plasma. Am J Hum Genet 2013;92:167-176.

10. Miller DT, Adam MP, Aradhya S, Biesecker LG, Brothman AR, Carter NP, Church DM, Crolla JA, Eichler EE, Epstein CJ, Faucett WA, Feuk L, Friedman JM, Hamosh A, Jackson L, Kaminsky EB, Kok K, Krantz ID, Kuhn RM, Lee C, Ostell JM, Rosenberg C, Scherer SW, Spinner NB, Stavropoulos DJ, Tepperberg JH, Thorland EC, Vermeesch JR, Waggoner DJ, Watson MS, Martin CL, Ledbetter DH: Consensus statement: chromosomal microarray is a first-tier clinical diagnostic test for individuals with developmental disabilities or congenital anomalies. Am J Hum Genet 2010;14:749-764.

11. American College of Obstetrics and Gynecology: Array comparative genomic hybridization in prenatal diagnosis. Committee Opinion Number 446, November 2009. Obstet Gynecol 2009;114:1161-1163.

12. Novelli A, Grati FR, Ballarati L, Bernardini L, Bizzoco D, Camurri L, Casalone R, Cardarelli L, Cavalli P, Ciccone R, Clementi M, Dalprà L, Gentile M, Gelli G, Grammatico P, Malacarne M, Nardone AM, Pecile V, Simoni G, Zuffardi O, Giardino D: Microarray application in prenatal diagnosis: a position statement from the cytogenetics working group of the Italian Society of Human Genetics (SIGU). Ultrasound Obstet Gynecol 2012;39:384-388.

13. Bernhardt B, Soucier D, Hanson K, Savage M, Jackson L, Wapner R: Women's experiences receiving abnormal prenatal chromosomal microarray testing results. Genet Med 2013;15:139-145.

14. Fiorentino F, Napoletano S, Caiazzo F, Sessa M, Bono S, Spizzichino L, Gordon A, Nuccitelli A, Rizzo G, Baldi M: Chromosomal microarray analysis as a first-line test in pregnancies with a priori low risk for the detection of submicroscopic chromosomal abnormalities. Eur J Hum Genet 2013;21:725-730.

15. Maya I, Davidov B, Gershovitz L, Zalzstein Y, Taub E, Coppinger J, Shaffer LG, Shohat M: Diagnostic utility of array-based comparative genomic hybridization (aCGH) in a prenatal setting. Prenat Diagn 2010;30;1131 $-1137$.

16. Hillman SC, Pretlove S, Coomarasamy A, McMullan DJ, Davison EV, Maher ER, Kilby MD: Additional information from array comparative genomic hybridization technology over conventional karyotyping in prenatal diagnosis: a systematic review and meta-analysis. Ultrasound Obstet Gynecol 2011;37:6-14. 
17. Cavalli P, Cavallari U, Novelli A: Array CGH in routine prenatal diagnosis practice. Prenat Diagn 2012;32:708709.

18. Dondorp W, Sikkema-Raddatz B, de Die-Smulders C, de Wert G: Arrays in postnatal and prenatal diagnosis: An exploration of the ethics of consent. Hum Mutat 2012;33:916-922.

19. Coppinger J, Alliman S, Lamb A, Torchia B, Bejjani B, Shaffer L: Whole-genome microarray analysis in prenatal specimens identifies clinically significant chromosome alterations without increase in results of unclear significance compared to targeted microarray. Prenat Diagn 2009;29:1156-1166.

20. Wapner R, Driscoll D, Simpson J: Integration of microarray technology into prenatal diagnosis: counselling issues generated during the NICHD clinical trial. Prenat Diagn 2012;32:396-400.

21. Hillman S, McMullan D, Maher E, Kilby M: Clinical utility of array comparative genomic hybridisation for prenatal diagnosis: a cohort study of 3171 pregnancies. BJOG 2012;119: 281-1282.

22. Leung TY, Vogel I, Lau TK, Chong W, Hyett JA, Petersen OB, Choy KW: Identification of submicroscopic chromosomal aberrations in fetuses with increased nuchal translucency and apparently normal karyotype. Ultrasound Obstet Gynecol 2011;38:314-319.

23. Van den Veyver IB, Patel A, Shaw CA, Pursley AN, Kang SH, Simovich MJ, Ward PA, Darilek S, Johnson A, Neill SE, Bi W, White LD, Eng CM, Lupski JR, Cheung SW, Beaudet AL: Clinical use of array comparative genomic hybridization (aCGH) for prenatal diagnosis in 300 cases. Prenat Diagn 2009;29:29-39.

24. Faas BH, van der Burgt I, Kooper AJ, Pfundt R, Hehir-Kwa JY, Smits AP, de Leeuw N: Identification of clinically significant, submicroscopic chromosome alterations and UPD in fetuses with ultrasound anomalies using genome-wide 250k SNP array analysis. J Med Genet 2010;47:586-594.

25. Park JH, Woo JH, Shim SH, Yang SJ, Choi YM, Yang KS, Cha DH: Application of a target array comparative genomic hybridization to prenatal diagnosis. BMC Medical Genetics 2010;11:102.

26. Wilson J, Jungner G: Principles and practice of screening for disease. Geneve, World Health Organisation, 1968.

27. Javaher P, Schmidtke J: Clinical Validity and Utility of Genetic Testing in Heritable Disorders. In: Kristofferson U, Schmidtke J, Cassiman J-J (eds): Quality Issues in Clinical Genetic Services. Dordrecht: Springer, 2010:147-156.

28. Beauchamp TL, Childress JF: Principles of Biomedical Ethics. New York/Oxford: Oxford University Press Inc, 2009.

29. UK National Screening Comittee: NHS Fetal Anomaly Screening Programme - Screening for Down's syndrome. Policy recommendations 2007-2010: Model of Best Practice.

30. American College of Medical Quality (ACMQ): Professional and Ethical Policies of the ACMQ. Policy 3. Standard of Care; Policy 8. Definition and Application of Medical Necessity. Available at: http://www.acmq.org/policies.

31. Edelmann L, Hirschhorn K: Clinical Utility of Array CGH for the Detection of Chromosomal Imbalances Associated with Mental Retardation and Multiple Congenital Anomalies. NY Acad Sci 2009;1151:157-166.

32. F. Scott, K. Murphy, L. Carey, W. Greville, N. Mansfield, P. Barahona, R. Robertson and A. McLennan: Prenatal diagnosis using combined qf-PCR and array CGH analysis as a first line test: results from over 1000 consecutive cases. Ultrasound Obstet Gynecol 2013;41:500-507.

33. Veltman J, de Vries B: Diagnostic Genome Profiling: Unbiased Whole Genome or Targeted Analysis? J Mol Diagn 2006;8:534-537.

34. Kleeman L, Bianchi DW, Shaffer LG, Rorem E, Cowan J, Craigo SD, Tighiouart H, Wilkins-Haug LE: Use of array comparative genomic hybridization for prenatal diagnosis of fetuses with sonographic anomalies and normal metaphase karyotype. Prenat Diagn 2009;29:1213-1217.

35. Le Caignec C, Boceno M, Saugier-Veber P, Jacquemont S, Joubert M, David A, Frebourg T, Rival JM: Detection of genomic imbalances by array based comparative genomic hybridisation in fetuses with multiple malformations. J Med Genet 2005; 42: 121-128.

36. Reiff M, Ross K, Mulchandani S, Propert KJ, Pyeritz RE, Spinner NB, Bernhardt BA: Physicians' perspectives on the uncertainties and implications of chromosomal microarray testing of children and families. Clin Genet 2012;83:23-30. 
37. Shaffer LG, Coppinger J, Alliman S Torchia BA, Theisen A, Ballif BC, Bejjani BA: Comparison of microarray-based detection rates for cytogenetic abnormalities in prenatal and neonatal specimens. Prenat Diagn 2008;28:789795.

38. Faas BHW, Cirigliano V, Bui T-H: Rapid methods for targeted prenatal diagnosis of common chromosome aneuploidies. Sem Fet Neonal Med 2011;16:81e87.

39. de Wit M, Srebniak M, Govaerts L, Van Opstal D, Galjaard R, Go A: The additional value of prenatal genomic array testing in fetuses with (isolated) structural ultrasound abnormalities and a normal karyotype: a systematic review of the literature. Ultrasound Obstet Gynecol 2013; doi: 101002/uog12575 2013.

40. Vermeesch JR, Fiegler H, de Leeuw N, Szuhai K, Schoumans J, Ciccone R, Speleman F, Rauch A, Clayton-Smith J, Van Ravenswaaij C, Sanlaville D, Patsalis PC, Firth H, Devriendt K, Zuffardi O: Guidelines for molecular karyotyping in constitutional genetic diagnosis. Eur J Hum Genet 2007;15:1105-1114.

41. Fruhman G, van den Veyver I: Applications of Array Comparative Genomic Hybridization in Obstetrics. Obstet Gynecol Clin North Am 2010;37:71-85.

42. Vetro A, Bouman K, Hastings R McMullan DJ, Vermeesch JR, Miller K, Sikkema-Raddatz B, Ledbetter DH, Zuffardi O, van Ravenswaaij-Arts CM: The introduction of arrays in prenatal diagnosis: a special challenge. Hum Mutat 2012;33:923-929.

43. Rehm H: Disease-targeted sequencing: a cornerstone in the clinic. Nat Rev Genet 2013;14:295-300.

44. Sonek J: First trimester ultrasonography in screening and detection of fetal anomalies. Am J Med Genet $\mathrm{C}$ Semin Med Genet 2007;145C:45-61.

45. Salomon LJ, Alfirevic Z, Berghella V, Bilardo C, Hernandez-Andrade E, Johnsen SL, Kalache K, Leung KY, Malinger G, Munoz H, Prefumo F, Toi A, Lee W; ISUOG Clinical Standards Committee: Practice guidelines for performance of the routine mid-trimester fetal ultrasound scan. Ultrasound Obstet Gynecol 2011;37:116-126.

46. Srebniak M, Boter M, Oudesluijs G et al: Genomic SNP array as a gold standard for prenatal diagnosis of foetal ultrasound abnormalities. Mol Cytogenet 2012;5:14.

47. Choy K, Setlur S, Lee C, Lau T: The impact of human copy number variation on a new era of genetic testing. BJOG 2010; 117:391-398.

48. Tyreman M, Abbott KM, Willatt LR, Nash R, Lees C, Whittaker J, Simonic I: High resolution array analysis: diagnosing pregnancies with abnormal ultrasound findings. J Med Genet 2009;46:531-541.

49. Shaffer LG, Dabell MP, Fisher AJ, Coppinger J, Bandholz AM, Ellison JW, Ravnan JB, Torchia BS, Ballif BC, Rosenfeld JA: Experience with microarray-based comparative genomic hybridization for prenatal diagnosis in over 5000 pregnancies. Prenat Diagn 2012;32:976-985.

50. Alesi V, Bertoli M, Sinibaldi L, Novelli A: The clinical utility and indications of chromosomal microarray analysis in prenatal diagnosis. BJOG 2013;120:119-120.

51. D’Amours G, Kibar Z, Mathonnet G, Fetni R, Tihy F, Désilets V, Nizard S, Michaud JL, Lemyre E: Whole-genome array $\mathrm{CGH}$ identifies pathogenic copy number variations in fetuses with major malformations and a normal karyotype. Clin Genet 2012;81:128-141.

52. Park SJ, Jung EH, Ryu RS, Kang HW, Ko JM, Kim HJ, Cheon CK, Hwang SH, Kang HY: Clinical implementation of whole-genome array CGH as a first-tier test in 5080 pre and postnatal cases. Mol Cytogenet 2011;4:12.

53. Bassem A, Bejjani B, Shaffer L: Targeted Array CGH. J Mol Diagn 2006;8:537-539.

54. McGillivray G, Rosenfield J, McKinlay Gardner R, Dillam L: Genetic counselling and ethical issues with chromosome microarray analysis in prenatal testing. Prenat Diagn 2012;32: 389-395.

55. Ganesamoorthy D, Bruno D, McGillivray G, Norris F, White SM, Adroub S, Amor DJ, Yeung A, Oertel R, Pertile MD, Ngo C, Arvaj AR, Walker S, Charan P, Palma-Dias R, Woodrow N, Slater HR: Meeting the challenge of interpreting high-resolution single nucleotide polymorphism array data in prenatal diagnosis: does increased diagnostic power outweigh the dilemma of rare variants? BJOG 2013;120:594-606.

56. de Jong A, Dondorp W, Timmermans D, van Lith J, de Wert G: Rapid aneuploidy detection or karyotyping? Ethical reflection. Eur J Hum Genet 2011;19:1020-1025. 
57. de Jong A, Dondorp W, Frints S, de Die-Smulders C, de Wert G: Advances in prenatal screening: the ethical dimension. Nat Rev Genet 2011;12:657-663.

58. Emanuel E, Emanuel L: Four models of the physician-patient relationship. JAMA 1992;267:2221-2226.

59. Dondorp W, de Wert G: The 'thousand-dollar genome': an ethical exploration. The Hague: Health Council of the Netherlands, 2010.

60. Donley G, Hull S, Berkman B: Prenatal whole genome sequencing. Just because we can, should we? Hastings Cent Rep 2012;42:28-40.

61. Health Council of the Netherlands. Screening: between hope and hype. Publication no. 2008/05. The Hague: Health Council of the Netherlands, 2008.

62. Borry P, Evers-Kiebooms G, Cornel M, Clarke A, Dierickx K, on behalf of the Public and Professional Policy Committee (PPPC) of the European Society of Human Genetics (ESHG): Genetic testing in asymptomatic minors: background considerations towards ESHG Recommendations. Eur J Hum Genet 2009;17:711-719.

63. Human Genetics Commission and the UK National Screening Committee (Joint Working Group) Profiling the newborn: a prospective gene technology? London, UKNSC, 2005.

64. Wertz D, Fletcher J, Berg K, On behalf of the World Health Organization: Review of Ethical Issues in Medical Genetics. Geneva: World Health Organization, 2003.

65. Royal Commission on New Reproductive Technologies. Proceed with Care. Volume I. Ottowa: Minister of Government Services, 1993.

66. de Wert G: Ethical aspects of prenatal testing and preimplantation genetic diagnosis for late onset neurogenetic disease: the case of Huntington's disease. In: Evers-Kiebooms G, Zoetewij M, Harper P (eds): Prenatal Testing for Late-Onset Neurogenetic Diseases. Oxford: Bios Scientific Publishers, 2002, pp 129-157.

67. Wilfond B, Nolan K: National policy development for the clinical application of genetic diagnostic technologies. Lessons from cystic fibrosis. JAMA 1993;270:2948-2954. 


\section{Chapter}

Advances in prenatal screening: the ethical dimension

de Jong A, Dondorp WJ, Frints SGM, de Die-Smulders CEM, de Wert GMWR

Nature Reviews Genetics 2011;12(9):657-663 


\section{Abstract}

Prenatal screening strategies are undergoing rapid changes owing to the introduction of new testing techniques. The overall tendency is towards broadening the scope of prenatal testing through increasingly sensitive ultrasound scans and genome-wide molecular tests. In addition, non-invasive prenatal diagnosis is likely to be introduced in the near future. These developments raise important ethical questions concerning meaningful reproductive choice, the autonomy rights of future children, equity of access and the proportionality of testing. 


\subsection{Introduction}

Current prenatal screening cascades in the developed (primarily Western) world consist of similar testing methods. ${ }^{1,2}$ These include a first-trimester risk assessment for the most common aneuploidies and a second-trimester fetal ultrasound scan to identify fetal anomalies. ${ }^{3}$ In the case of a positive risk assessment, invasive procedures (amniocentesis or chorionic villus sampling) are offered to allow diagnostic follow-up testing. For decades, conventional karyotyping has been the gold standard for this form of prenatal diagnosis. However, it is now being replaced by molecular techniques that will allow narrowing or broadening of the scope of diagnostic testing (See: Figure 6.1). This raises questions about the range of conditions for which such testing should be offered and why. A distinct development is the pending introduction of non-invasive prenatal diagnosis (NIPD). This promises to make prenatal screening easier and safe but again raises the question about its scope. As we discuss here, there is an important ethical dimension to the developments and choices that the field is currently facing.

Most of the ethical questions discussed in this paper are relevant for shaping future prenatal screening practices both in settings where services are largely offered as a marketdriven commodity (as in the United States) and in countries where they are part of public health care (as in most European countries, Canada and Australia). Standard-setting and debate about guiding principles have contributed to the formation of an internationally acknowledged normative framework for the provision of prenatal screening (See: Box 6.1). On a general level, this framework builds on the basic principles of biomedical ethics: respect for persons, beneficence, non-maleficence and justice. More specific norms for population screening include proportionality, equity of access and informed consent. ${ }^{4} \mathrm{~A}$ core element of the normative framework for prenatal screening is that informed consent as a mere precondition is not enough. Enabling meaningful reproductive choice with regard to parenting or avoiding a child with a serious disorder or disability is (or should be) the very aim of offering testing for fetal abnormalities. ${ }^{5,6}$ This is in order to ensure that abortion decisions remain personal and are not turned into instruments of societal goals, such as prevention and cost-reduction by bringing down the number of people requiring life-long and costly care.

Here we provide an overview of current developments in prenatal screening, showing how each of these relates to the normative framework and what ethical challenges they entail. We then address some ethical issues in more detail and make suggestions about how specific challenges might be addressed. Although we take the current normative framework as our point of departure, our message in this paper is that the dynamics of the field may also put the framework to the test. 


\section{Box 6.1 | Key ethics terminology}

The 'normative framework' regarding prenatal screening for fetal anomalies refers to the set of ethical (and/or legal) norms that together provide the context of justification for professional practice and public policy making with regard to prenatal screening. This framework can be regarded as a context-specific articulation of the basic principles of health-care ethics. ${ }^{4}$

- The principle of respect for persons reflects the notion that, as autonomous agents, human beings deserve to be treated as moral subjects. In the context of screening, this requires that decision making about participation and all further steps in the screening process must be based on adequate information and voluntary choice ('informed consent').

- The twin principles of beneficence and non-maleficence stem from the Hippocratic roots of medical ethics. As screening is offered on the initiative of the health-care system, it is essential that the possible benefits for participants clearly outweigh the disadvantages (burdens and risks) that such programmes always also have - for instance, as a consequence of false-positive or falsenegative outcomes.

- The principle of justice requires that equity of access to screening programmes is ensured and that they are provided on the basis of a fair distribution of benefits, burdens and financial resources.

Building on these ethical norms, the framework for prenatal screening fits in with the more general set of principles for population screening, as initially formulated by Wilson and Jungner. ${ }^{49}$

But prenatal screening has a different aim than most other forms of population screening. ${ }^{6,50}$ Instead of providing options for treatment or prevention of disease, prenatal screening aims at providing pregnant women and their partners with information that they may want to use as a basis for decision making about whether to continue the pregnancy. The 'clinical utility' of prenatal screening depends on the extent to which it allows participants to make well-informed and autonomous reproductive choices. However, (prenatal) screening programmes must also be proportional. This cannot be decided merely in terms of the balance of benefits and drawbacks for participants. One should also look at possible consequences for other individuals and groups and to societal implications, including costs. ${ }^{51}$

Because selective abortion is a major issue of moral sensitivity in debates about prenatal screening, it seems appropriate to make the following preliminary remarks. A first debate concerns the moral status of the fetus. The prevailing view, also reflected in legislation allowing abortion up to a certain limit, is that the status of the fetus is relatively low and increases with its development. Those who take this view usually accept that abortion may be justified if the parents want to avoid having a child with a serious disease or disability. ${ }^{7}$ Although it is sometimes proposed that society should come up with a list of diseases serious enough to warrant prenatal testing, it is widely accepted that this is unrealistic and undesirable, given that many disorders have a variable expression and that the impact of a disease is, to a large extent, context-dependent. ${ }^{8} \mathrm{~A}$ second debate concerns the selective nature of abortion for fetal abnormalities. According to the 'disability rights critique', prenatal screening sends the 
message that it would have been better if those living with the targeted conditions had not been born. ${ }^{9}$ However, the claim that this is true by implication does not hold. Whether prenatal screening has discriminatory effects depends on how the programme is presented and implemented in practice. If informed decisions rather than abortion rates are taken as a measure of success, the disability rights critique is less convincing. ${ }^{7}$

A final remark on terminology: we use the term prenatal screening to refer to the whole of the testing trajectory offered to low-risk pregnant women. Prenatal diagnosis refers to follow-up testing as a part of this trajectory. Prenatal testing is used as a generic term.

Figure 6.1 | Prenatal screening cascade: current and possible future test-routes

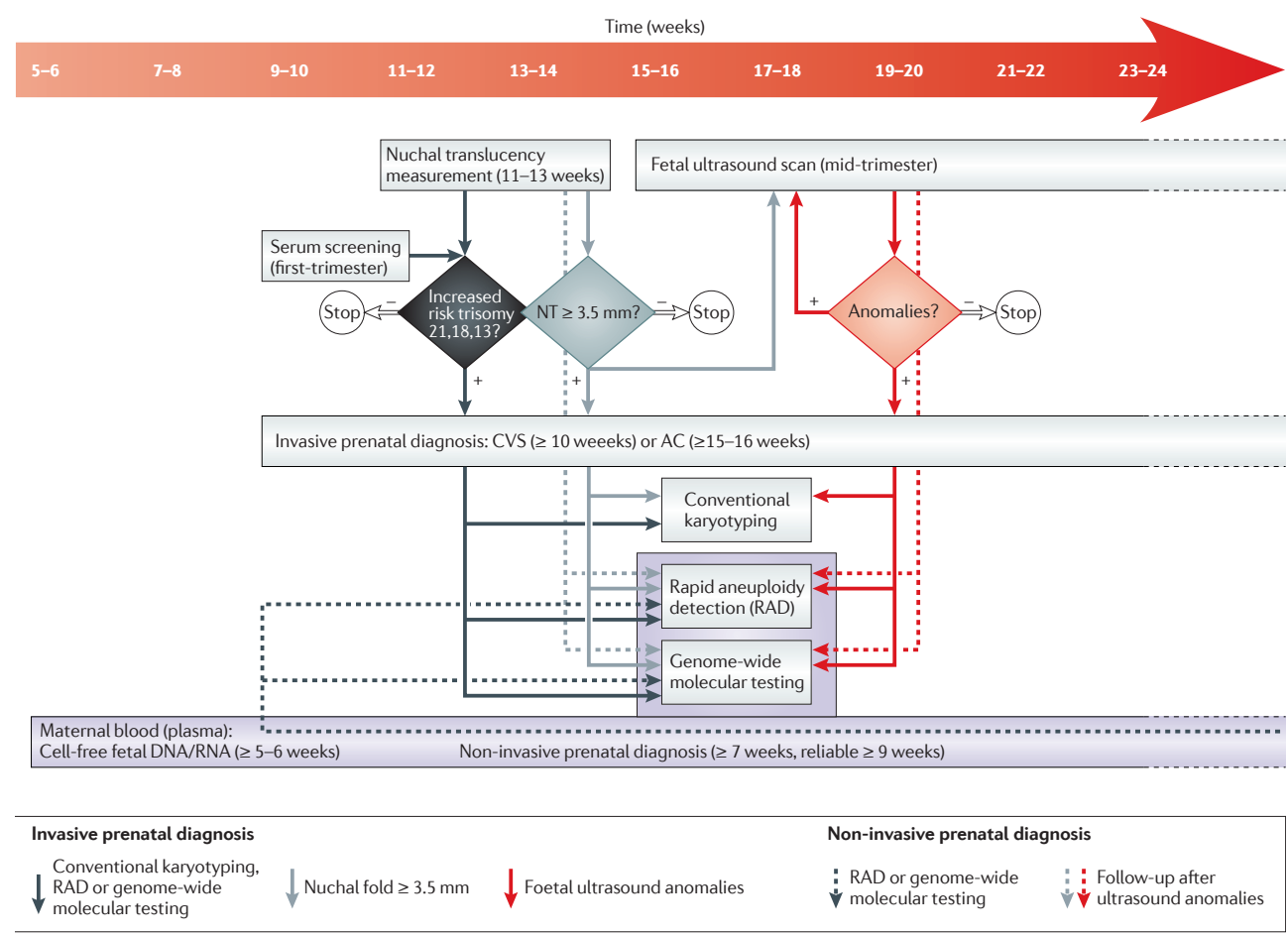

Test routes in current and possible future prenatal screening cascades. The horizontal arrow at the top denotes the gestational age. In the case of an increased risk of trisomies 21, 18 or 13, invasive prenatal diagnosis is offered: conventional karyotyping, rapid aneuploidy detection (RAD) or genome-wide molecular testing. A nuchal translucency $\geq 3.5 \mathrm{~mm}$ or fetal ultrasound anomalies may lead to either follow-up ultrasound testing or invasive prenatal diagnosis. Non-invasive prenatal diagnosis (NIPD) using cell-free fetal DNA or RNA that is obtained from maternal blood (plasma) may, in the near future, be implemented clinically as a one-step diagnostic test for trisomy 21 (and possibly also trisomies 18 and 13) using RAD or genome-wide molecular testing, including next-generation sequencing, for the detection of paternal mutations that underlie monogenic disorders. NIPD could also be offered as a follow-up test after ultrasound anomalies. See: Table 6.1 for more details about each type of test. 


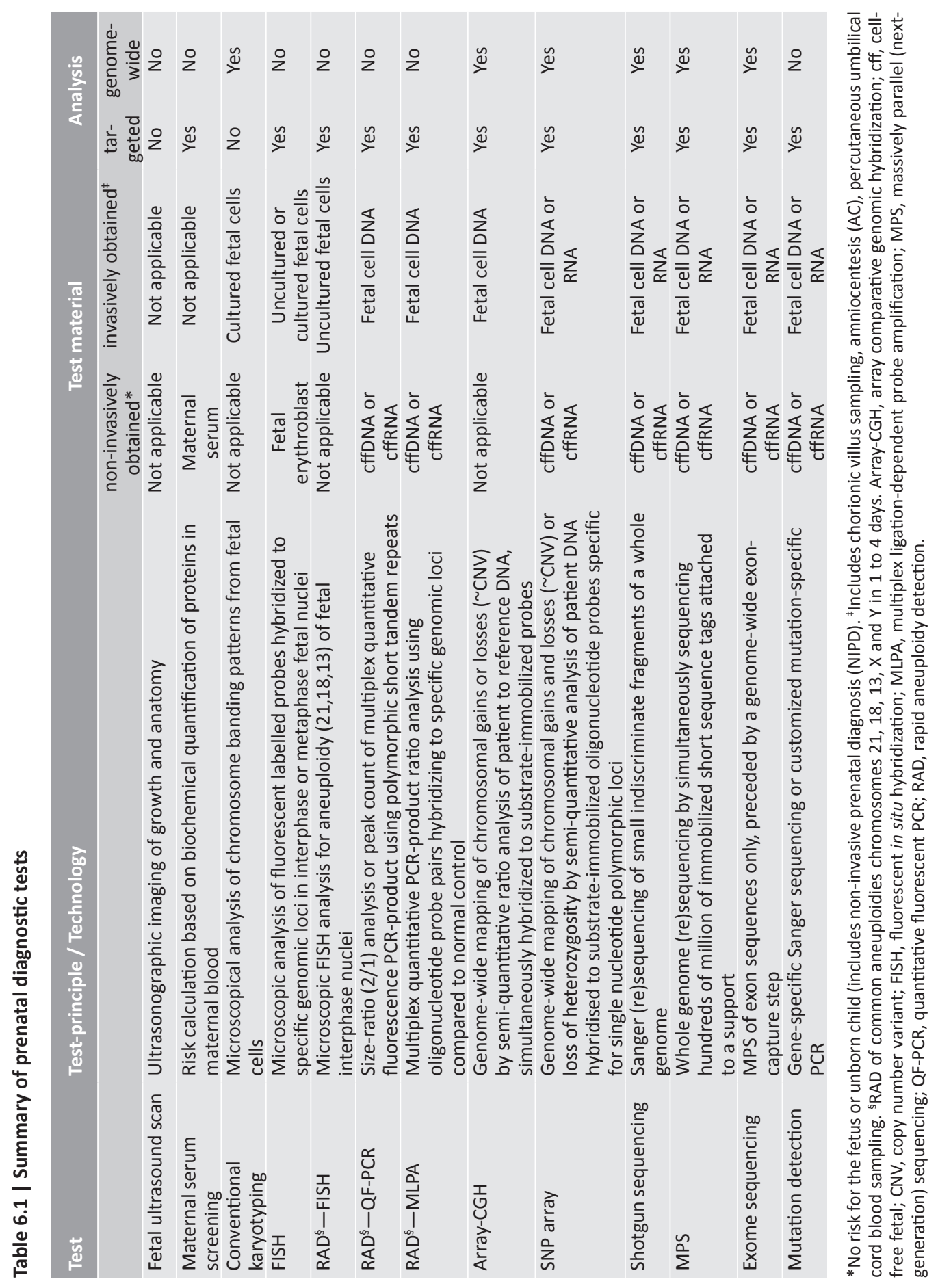




\subsection{Developments in prenatal screening}

\subsubsection{Rapid aneuploidy detection}

In most developed countries, the diagnostic test after a positive risk assessment for trisomies 21,18 and 13 is still conventional karyotyping. ${ }^{1,10}$ This method detects all microscopically visible chromosome aberrations, including rare numerical or structural abnormalities that may have serious clinical consequences but also deletions, duplications or other chromosomal anomalies that can have mild, uncertain or even no clinical consequences. ${ }^{11,12}$ As a result, women may be confronted with other findings than those for which they were offered risk assessment and follow-up testing. This is one of the reasons why, particularly in northern European countries, some have advocated to replace conventional karyotyping with a targeted molecular 'rapid aneuploidy detection' (RAD) test. ${ }^{13,14}$ Three common RAD techniques are currently being used: interphase fluorescence in situ hybridization (FISH), quantitative fluorescent PCR (QF-PCR) and multiplex ligation-dependent probe amplification (MLPA) ${ }^{15}$ (See: Table 6.1). These tests generate reliable results within 3 days, which is much faster than karyotyping, and are used to diagnose only trisomies 21,18 and 13 , although probes often also include the sex chromosomes. In terms of the normative framework, the question arises whether avoiding additional findings that may complicate decision making render RAD a better approach to diagnostic follow-up testing than karyotyping. ${ }^{16}$ Or is the opposite the case, given that RAD reduces the range of possible outcomes that women may find relevant for reproductive choice ${ }^{11}$ Does the miscarriage risk attached to current invasive procedures require that testing should be maximally informative? ${ }^{17}$ While this debate is still going on ${ }^{18}$, both karyotyping and RAD are currently offered, either as standalone tests or as options between which pregnant women may choose. ${ }^{19-21}$

\subsubsection{Prenatal ultrasound}

Whereas the framework for prenatal screening was developed at a time when a limited number of fetal abnormalities were screened for, the introduction of fetal ultrasound screening has effectively changed this. The second-trimester fetal ultrasound scan has a wide range of possible outcomes. Apart from various structural defects (with severe, mild or unknown clinical consequences), these screens increasingly reveal so-called 'soft markers' that indicate a risk of a wide range of genetic disorders, which require further diagnosis to confirm. Although 'controversial' soft markers may sometimes be discarded ${ }^{22,23}$, the trend seems to be towards more detailed screening. ${ }^{3}$ Remarkably, the question of how women can be properly prepared and give informed consent for this complex form of prenatal screening has, until now, received only scant attention. ${ }^{24}$

Nuchal translucency measurement at around 11 weeks of gestation was introduced as part of the risk assessment for common trisomies but has developed into a de facto screening 
test for other defects as well. An enlarged nuchal translucency of $\geq 3.5 \mathrm{~mm}$ is associated with an increased risk of intra-uterine fetal death, congenital heart defects and many other structural defects and genetic syndromes. This finding generally leads to follow-up diagnostic testing by using further ultrasound scans, karyotyping or genome-wide molecular tests. ${ }^{25,26}$ However, pre-test information does not usually cover this possible further trajectory. This means that women may be confronted with outcomes they were not prepared for and may find difficult to handle.

\subsubsection{Genome-wide molecular testing}

The debate about RAD can be expected soon to give way to the question of whether the scope of diagnostic testing should be broader than karyotyping. That, at least, seems to be the thrust of technological developments. ${ }^{27}$ Molecular genetic tests with a higher resolution than conventional karyotyping include several array-based platforms and shotgun or parallel sequencing that can be used for genome-wide analysis ${ }^{29,30}$ (and perhaps, in the future, even whole-genome analysis ${ }^{28}$ ) (See: Table 6.1).

Abnormalities that such tests might detect include small interstitial or telomeric deletions or duplications and partial or uniparental disomies that may, in addition to identifying childhood-onset disorders, also lead to the detection of genetic risk factors for late-onset disorders such as hereditary cancers. In some centres in Europe and the United States, genome-wide tests are offered to women at an increased risk of chromosomal abnormalities or in cases of ultrasound anomalies. ${ }^{31,32}$ Some propose targeted testing by using arrays that are designed to detect clinically significant abnormalities while minimizing the detection of unclear findings. ${ }^{32,33}$ However, others favour wider arrays in order to identify more aberrations. ${ }^{34}$ Although more comprehensive testing may have benefits in terms of clinically relevant findings that would otherwise be missed, a serious challenge is that, with the present state of knowledge, many of the results of such testing are impossible to interpret. This leads to a lack of clarity about what women should be told and, more generally, to concerns about the feasibility of well-informed decision making for comprehensive testing. For example, copy number variants (CNVs) that are detected by array comparative genome hybridization (array-CGH) or SNP analysis can be categorized as likely to be pathogenic, likely to be benign or of unknown clinical significance ${ }^{35}$ (See: Table 6.1). The balance of benefits and burdens will also be affected if unnecessary anxiety is caused by such outcomes. Further questions relating to genome-wide molecular testing are whether the autonomy rights of future children may be violated and whether justice would require offering such testing to all pregnant women. 


\subsubsection{Non-invasive prenatal diagnosis}

In the next 2 to 5 years, it is expected that NIPD performed on cell-free fetal DNA (cffDNA) and cffRNA in maternal blood will be introduced as a routine screening test for aneuploidies (See: Box 6.2; Figure 6.1). In high-risk families, NIPD will also possibly serve as a routine diagnostic test for autosomal-dominant and autosomal-recessive traits, such as Huntington's disease and cystic fibrosis, respectively. ${ }^{36-38}$ In the short-term, this may be limited to the detection of paternally inherited traits owing to difficulties in distinguishing between maternal and fetal DNA.

\section{Box 6.2 | Non-invasive prenatal diagnosis}

In 1997, Lo et al. ${ }^{52}$ discovered circulating cell-free fetal DNA (cffDNA) and cffRNA in maternal plasma, creating possibilities for non-invasive prenatal diagnosis (NIPD). The main advantage of this is that the procedure-related miscarriages of current invasive techniques (namely, chorionic villus sampling and amniocentesis) are avoided, as NIPD requires only blood samples, which are taken from the mother as well as the father. The cffDNA and cffRNA appear the maternal blood circulation from early placenta formation (from 5 to 6 weeks of gestation - the trophoblast stage), which makes reliable NIPD possible from 9 weeks of gestation. NIPD is already implemented in clinical practice for fetal Y-chromosome detection in case of X-linked disorders and for fetal Rhesus $\mathrm{D}(\mathrm{RhD})$ determination. ${ }^{53}$

Many research groups are now trying to detect the most common trisomies, 21,18 and 13 , through NIPD. These trisomies can be detected either by shotgun sequencing or massively parallel genomic sequencing. ${ }^{54,55}$ Recently, the first large-scale validation study for trisomy 21 has been published ${ }^{56}$, and clinical implementation is expected within 2 to 5 years. Targeted NIPD for combined testing of trisomies 21, 18 and 13 remains more challenging. The number of known trophoblast-expressed genes is still limited, and as long as the use of epigenetic signatures that offer potential for detecting trisomies - for example, DNA methylation - has not become routine, it is difficult to develop a targeted, robust and cheap aneuploidy test. ${ }^{57,58}$

As the benefits of an early and safe one-step approach to prenatal diagnosis are clear, it would seem that current risk-assessment practices for common trisomies can be abandoned in the screening context. However, if nuchal translucency measurement -which is currently a part of this risk assessment-were also to be dropped, a much smaller range of abnormalities will be identified. Introducing NIPD may thus lead to a reduction in the scope for autonomous reproductive decision making by pregnant women. Although this loss can be averted by offering stand-alone nuchal translucency measurement as a complement to NIPD, that would make the testing trajectory more costly, complicated and burdensome. In terms of the aim of prenatal screening, piling up additional tests may have the adverse effect of undermining autonomous choice. 
Some commentators expect that, eventually, genome-wide NIPD testing will become possible. ${ }^{39}$ Although this would reduce the need for complementary tests, concerns about the feasibility of adequate informed consent and decision making are heightened when broad genetic testing takes the form of a safe and simple blood test to be performed as early, perhaps, as 7 weeks of pregnancy. ${ }^{40}$ As NIPD will take away the 'gatekeeper' effect of the current risk of miscarriage that comes with amniocentesis and chorionic villus sampling, concerns have also been raised that it will contribute to testing for minor abnormalities or non-health related conditions and to a corresponding 'trivialization' of abortion. ${ }^{38}$

\subsection{Specific ethical issues}

\subsubsection{Meaningful reproductive choice}

Given that prenatal screening should be aimed at providing pregnant women with opportunities for meaningful reproductive choice, a crucial issue is whether new tests expand or undermine these opportunities. ${ }^{18}$ The classic interpretation of informed consent is that a decision to be tested or not must be well-informed for every condition included in the test panel. Ideally, the woman undergoing the testing should also be given the opportunity to indicate which specific outcomes she does not want to be informed about ('the right not to know'). But the clear tendency towards ever-broader testing makes this model appear increasingly out of touch with reality. Broad prenatal testing may generate findings that vary from severe conditions, such as Duchenne muscular dystrophy, to predispositions for a wide range of early- or late-onset diseases and to CNVs for which the clinical consequences are unclear. To give detailed pre-test information on the level of all such outcomes is not realistic. It would lead to 'information overload' and would frustrate rather than serve the aim of autonomous choice. ${ }^{7}$

How can this problem be solved? One option is to look for an alternative approach to informed consent, avoiding information overload but still allowing well-informed decision making. A possible model proposed in the context of multiplex neonatal screening is that of 'generic consent'. ${ }^{41}$ This involves presenting pre-test information in general categories of types of outcomes. ${ }^{7}$ In the context of prenatal testing, relevant categories include: congenital lethal disorders; early- or late-onset disorders requiring intensive medical care; early- or late-onset disorders requiring limited medical care; susceptibilities for complex disorders; conditions involving only minor health problems; and abnormal findings of which the clinical implications are unknown.

A key question is whether this still facilitates well-informed decision making. One problem is that the different categories may fail to capture the variable expression of many disorders. 
Moreover, the severity of different diseases is perceived differently among both health-care professionals and pregnant women. The practical feasibility of such alternative models of informed consent needs to be tested in empirical studies.

A second option is the use of filters to minimize findings that may be unclear or otherwise difficult to handle. This would allow counselling and decision making to be limited either to a few selected serious conditions or (in the context of broader testing and linked with a form of 'generic consent') to a smaller or wider subset of the six categories mentioned above. This approach has the advantage of avoiding the problem of whether pregnant women's interests are really served by being offered the choice to receive information about all possible outcomes of genome-wide molecular testing. If, as we think, the answer to this is 'no', it is inevitable that professionals and other stakeholders must find a balance between allowing women to decide for themselves as much as possible and helping them to do so by defining the range of meaningful choices.

\subsubsection{The autonomy rights of the future child}

A second issue that arises in the scenario of genome-wide molecular testing is that of the future child's 'anticipatory autonomy rights'. ${ }^{42}$ These rights may be violated when prenatal testing has revealed a predisposition for a late-onset disease that is not amenable to treatment or prevention starting in childhood and the woman decides to continue the pregnancy. Testing children for such conditions is generally regarded as unacceptable, not just because benefits for the child that might outweigh any burdens are absent but also because it deprives the individual of his or her right to self-determination. This includes determining whether to be tested once mature enough to do so. ${ }^{43,44}$ But then, clearly, it is also problematic to perform such tests in fetuses that may well grow into children. There are two possible solutions here. One solution is to limit the scope of testing by using targeted arrays or algorithms, avoiding as much as possible the detection of predispositions for late-onset diseases. The drawback of this is that women who might have chosen to terminate the pregnancy in case of such a finding are effectively deprived of what for them would be a meaningful reproductive option. The alternative solution is to allow women to undergo genome-wide analysis but only after they have expressed, in pre-test counselling, the clear intention to choose abortion if a predisposition for a late-onset disease is found. Although women cannot, of course, be forced to stick to this intention, this approach may provide the optimal balance of respecting the autonomy rights of the woman and those of her possible future child. ${ }^{28}$ The same approach is used in the context of prenatal diagnosis for Huntington's disease..$^{45}$ Empirical studies are needed to see whether this would also be feasible in the different context of prenatal screening. 


\subsubsection{Equity of access}

What about the justice of offering genome-wide prenatal tests only to women with a positive risk assessment for common trisomies? Other pregnant women may rightly complain that they have the same a priori risk for all other outcomes of such tests. This issue already arises with karyotyping as a diagnostic follow-up, but it becomes more prominent with genome-wide molecular testing, in which more abnormalities may be found and the detection/miscarriage ratio will be more favourable. This problem of formal justice can be theoretically eliminated in two ways. One is to only offer RAD as a follow-up test. The other is to offer invasive testing to all pregnant women, as is the case in the United States. ${ }^{10}$ The former solution amounts to a form of 'levelling down justice': denying possible benefits to some because others cannot have them. Problems of capacity aside, the latter solution (access for all) seems to be most in line with the general aim of offering opportunities for autonomous reproductive choice. ${ }^{18,46}$ Although concerns about exposing women to the risk of miscarriage without good reason are certainly relevant for counselling, denying access to invasive procedures on these grounds is paternalistic. This seems difficult to justify, given that the relevant tests may reveal serious fetal abnormalities. Of course, it does not follow that testing for whatever conditions women find important should be covered by public or collective funding. This is an issue of distributive justice and proportionality that we will briefly comment upon in the next section.

\subsubsection{Overall proportionality}

A crucial element in the moral evaluation of screening programmes is their proportionality, meaning that the moral importance of what the programme will achieve must outweigh any disadvantages. On the level of the benefits and burdens for individual women and their partners, the developments outlined above raise the question of how the tendency towards broader screening will affect this balance. To answer this question, data are needed about the psychosocial aspects and decision-making dynamics of wide-scope prenatal testing, including the possible implications for family members. As follows from our discussion of the expected introduction of NIPD-based prenatal screening, proportionality may also be challenged when new and better tests do not replace what was offered before but instead lead to additional testing. Moreover, the consequences of new developments for different social groups and society at large should also be taken into account. Testing for only some abnormalities (as is the case in using RAD) may reinforce the criticism that prenatal screening contains the message that certain groups of people are not welcome in society. ${ }^{9}$ However, this argument loses much of its sting with the further broadening of the scope of prenatal testing. ${ }^{47}$ If prenatal screening is used for a broad range of conditions, no groups need to find themselves specifically targeted. 
On a societal level, the proportionality of prenatal screening is also a matter of costeffectiveness. ${ }^{48}$ With ever-broader testing, this becomes more complicated than when prenatal screening was still directed at a few serious abnormalities, such as Down's syndrome - the costs of which for society are high, and the detection of which leads to, in most cases, a termination of pregnancy. It seems reasonable that public funding must cover prenatal testing for disorders that have a considerable impact on the lives of children and families but not necessarily more than that. Inevitably, this will refuel the debate about which conditions are serious enough to warrant prenatal testing, although it will do so from the different perspective of access and funding. Indeed, this may well lead to a shift towards giving more emphasis to considerations that are relevant from a public health perspective.

\subsection{Concluding remarks}

We have discussed four developments that challenge the current normative framework for prenatal screening. Our conclusion regarding RAD is that offering women the choice between conventional karyotyping and narrower testing is most in line with the aim of prenatal screening. With regard to ultrasound screening and genome-wide diagnostic testing (based on current invasive procedures or in the context of NIPD), we think there is a clear need to explore the feasibility of alternative models of informed consent. As it seems inevitable that filters will have to be used, debate is needed about how these should be defined. Genomewide prenatal testing will have the effect of blurring the distinction between prenatal testing and predictive testing of minors. Until now, these were different worlds with their own normative frameworks, focusing, respectively, on reproductive choice for pregnant women and on the interests (including future autonomy rights) of the child. We have argued that, in the light of these interests, the right of the pregnant woman to obtain information about the genetic make-up of her future child is not unlimited, nor unconditional. Finally, the clear tendency towards ever-broader testing in the context of prenatal screening raises morally relevant questions about access, funding and proportionality. As this article has shown, the choices are as much about ethics as they are about technology.

\section{Acknowledgements}

We thank M. Macville for his valuable comments on this paper. This research was supported by the Centre for Society and Genomics, funded by the Netherlands Genomics Initiative (project number: 70.1.061b) and the Dutch Research Prevention Fund project, Netherlands Organisation for Scientific Research (NWO) (project number: 200320009). 


\section{References}

1. Bui T-H, Meiner V: The Janus Face of Prenatal Diagnostics. In: Leuzinger-Bohleber M, Engels E-M, Tsiantis J (eds): A European Study Bridging Ethics, Psycholanalysis, and Medicine. London: Karnac Books, 2008, pp 6186.

2. Tapon D: Prenatal testing for Down syndrome: comparison of screening practices in the UK and USA. J Genet Couns 2010;19:112-130.

3. Salomon LJ, Alfirevic Z, Berghella V, Bilardo C, Hernandez-Andrade E, Johnsen SL, Kalache K, Leung KY, Malinger G, Munoz H, Prefumo F, Toi A, Lee W; ISUOG Clinical Standards Committee: Practice guidelines for performance of the routine mid-trimester fetal ultrasound scan. Ultrasound Obstet Gynecol 2011;37:116-126.

4. Beauchamp TL, Childress JF. Principles of Biomedical Ethics. New York/Oxford: Oxford Univiversity Press, 2009.

5. Health Council of the Netherlands: Screening: between hope and hype. The Hague, Health Council of the Netherlands, 2008.

6. Nuffield Council on Bioethics: Genetic screening: a Supplement to the 1993 Report by the Nuffield Council on Bioethics. Nuffield Council on Bioethics, 2006.

7. de Wert G, Dondorp W: Ethical issues. In: van Vugt M, Shulman K (eds): Prenatal medicine. New York/London: Taylor, Francis, 2006, pp 575-604.

8. Wertz D, Knoppers B: Serious genetic disorders: can or should they be defined? Am J Med Genet 2002;108:2935.

9. Parens E, Asch A (eds): Prenatal Testing And Disability Rights. Georgetown: Georgetown University Press, 2000.

10. American College of Obstetricians and Gynecologists: ACOG Practice Bulletin No. 88, December 2007. Invasive prenatal testing for aneuploidy. Obestet Gynecol 2007;110:1459-1467.

11. Caine A, Maltby AE, Parkin CA, Waters JJ, Crolla JA: Prenatal detection of Down's syndrome by rapid aneuploidy without a full karyotype: a cytogenetic risk assessment. Lancet 2005;366 ;123-128.

12. Leung WC, Lau ET, Lau WL, Tang R, Wong SF, Lau TK, Tse KT, Wong SF, To WK, Ng LK, Lao TT, Tang MH; Working Group on Prenatal Diagnosis and Counselling, Hospital Authority. Rapid aneuploidy testing (knowing less) versus traditional karyotyping (knowing more) for advanced maternal age: what would be missed, who should decide? Hong Kong Med J 2008;14:6-13.

13. Ogilvie CM, Yaron Y, Beaudet AL: Current controversies in prenatal diagnosis 3: for prenatal diagnosis, should we offer less or more than metaphase karyotyping? Prenat Diagn 2009;29:11-14.

14. UK National Screening Committee: Fetal anomaly screening programme - screening for down's syndrome: UK NSC policy recommendations 2007-2010: model of best practice. Department of Health, 2008.

15. Faas BHW, Cirigliano V, Bui T-H: Rapid methods for targeted prenatal diagnosis of common chromosome aneuploidies. Semin. Fetal Neonatal Med 2011;16:81-87.

16. van Zwieten M: The target of testing. Dealing with 'unexpected' findings in prenatal diagnosis. Amsterdam: Uitgeverij Buijten, Schipperheijn, 2006.

17. Lim AS, Lim TH, Hess MM, Kee SK, Lau YY, Gilbert R, Hempel TE, Anderson KJ, Zaleski DH, Tien SL, Chia P, Subramaniam R, Tan HK, Tan AS, Sanger WG: Rapid aneuploidy screening with fluorescence in-situ hybridisation: is it a sufficiently robust stand-alone test for prenatal diagnosis? Hong Kong Med J 2010;6:427433.

18. de Jong A, Dondorp W, Timmermans D, van Lith J, de Wert G: Rapid aneuploidy detection or karyotyping? Ethical reflection. Eur J Hum Genet 2011;19:1020-1025.

19. Boormans EM, Birnie E, Oepkes D, Boekkooi PF, Bonsel GJ, van Lith JM: Individualized choice in prenatal diagnosis: the impact of karyotyping and standalone rapid aneuploidy detection on quality of life. Prenat Diagn 2010;30:928-936.

20. Bui T-H: Prenatal cytogenetic diagnosis: gone FISHing, BAC soon! Ultrasound Obstet Gynecol 2007;30:247251. 
21. Cirigliano V, Voglino G, Ordoñez E, Marongiu A, Paz Cañadas M, Ejarque M, Rueda L, Lloveras E, Fuster C, Adinolfi M: Rapid prenatal diagnosis of common chromosome aneuploidies by QF-PCR, results of 9 years of clinical experience. Prenat Diagn 2009;29:40-49.

22. Rochon M, Eddleman K: Controversial ultrasound findings. Obstet Gynecol Clin North Am 2004;31:61-99.

23. Bethune M: Time to reconsider our approach to echogenic intracardiac focus and choroid plexus cysts. Aust NZ J Obstet Gynaecol 2008;48:137-141.

24. Schoonen HM, Essink-Bot ML, Van Agt HM, Wildschut HI, Steegers EA, De Koning HJ: Informed decisionmaking about the fetal anomaly scan: what knowledge is relevant? Ultrasound Obstet Gynecol 2010;37:649657.

25. Bilardo C, Timmerman E, Pajkrt E, van Maarle M: Increased nuchal translucency in euploid fetuses - what should we be telling the parents? Prenat Diagn 2010;30:93-102.

26. Sonek J: First trimester ultrasonography in screening and detection of fetal anomalies. Am J Med Genet $C$ Semin Med Genet 2007;145C:145-161.

27. Bui T-H, Vetro A, Zuffardi O, Shaffer LG: Current controversies in prenatal diagnosis 3: is conventional chromosome analysis necessary in the post-array CGH era? Prenat Diagn 2011;31:235-243.

28. Dondorp W, de Wert G: The 'thousand-dollar genome': an ethical exploration. Publication no. 2010/15. The Hague: Health Council of the Netherlands, 2010.

29. Savage M. Mourad M, Wapner R: Evolving applications of microarray analysis in prenatal diagnosis. Cur. Opin Obstet Gynecol 2011;23:103-108.

30. de Ravel T, Devriendt K, Fryns J, Vermeesch J: What's new in karyotyping? The move towards array comparative genomic hybridisation (CGH). Eur J Pediatr 2007;166:637-643.

31. Maya I, Davidov B, Gershovitz L, Zalzstein Y, Taub E, Coppinger J, Shaffer LG, Shohat M: Diagnostic utility of array-based comparative genomic hybridization (aCGH) in a prenatal setting. Prenat Diagn 2010;30:11311137.

32. Van den Veyver IB, Patel A, Shaw CA, Pursley AN, Kang SH, Simovich MJ, Ward PA, Darilek S, Johnson A, Neill SE, Bi W, White LD, Eng CM, Lupski JR, Cheung SW, Beaudet AL: Clinical use of array comparative genomic hybridization (aCGH) for prenatal diagnosis in 300 cases. Prenat Diagn 2009;29:29-39.

33. American Committee of Obstetricians and Gynecologists: ACOG Committee Opinion No. 446. Array comparative genomic hybridization in prenatal diagnosis. Obstet Gynecol 2009;114:1161-1163.

34. Faas BH, van der Burgt I, Kooper AJ, Pfundt R, Hehir-Kwa JY, Smits AP, de Leeuw N: Identification of clinically significant, submicroscopic chromosome alterations and UPD in fetuses with ultrasound anomalies using genome-wide 250k SNP array analysis. J Med Genet 2010;47:586-594.

35. Hillman SC, Pretlove S, Coomarasamy A, McMullan DJ, Davison EV, Maher ER, Kilby MD: Additional information from array comparative genomic hybridization technology over conventional karyotyping in prenatal diagnosis: a systematic review and meta-analysis. Ultrasound Obstet Gynecol 2011;37:6-14.

36. Avent N, Madgett T, Maddocks D, Soothill P: Cell-free fetal DNA in the maternal serum and plasma: current and evolving applications. Curr Opin Obstet Gynecol 2009;21:175-179.

37. Lo Y: Noninvasive prenatal detection of fetal chromosomal aneuploidies by maternal plasma nucleic acid analysis: a review of the current state of the art. BJOG 2009;116:152-157.

38. Wright C: Cell-free fetal nucleic acids for non-invasive prenatal diagnosis. Report of the UK expert working group. PHG Foundation, 2009.

39. Lo YM, Chan KC, Sun H, Chen EZ, Jiang P, Lun FM, Zheng YW, Leung TY, Lau TK, Cantor CR, Chiu RW: Maternal plasma DNA sequencing reveals the genome-wide genetic and mutational profile of the fetus. Sci Transl Med 2010;2:61ra91.

40. de Jong A, Dondorp W, de Die-Smulders C, Frints S, de Wert G: Non-invasive prenatal testing: ethical issues explored. Eur J Hum Genet 2010;18:272-277.

41. Elias S, Annas G. Generic consent for genetic screening. N Engl J Med 1994;330:1611-1613. 
42. Feinberg J: The Child's Right to an Open Future. In: Aiken W, Lafollette H (eds): Whose Child? Children's Rights, Parental Autonomy, and State Power. New Jersey: Littlefield, Adams, Co, 1980, pp 124-153.

43. Human Genetics Commission and the UK National Screening Committee. Joint Working Group: Profiling the Newborn: A Prospective Gene Technology? London: UKNSC, 2005.

44. Borry P, Evers-Kiebooms G, Cornel MC, Clarke A, Dierickx K; Public and Professional Policy Committee (PPPC) of the European Society of Human Genetics (ESHG). Public and Professional Policy Committee (PPPC) of the European Society of Human Genetics (ESHG): Genetic testing in asymptomatic minors: recommendations of the European Society of Human Genetics. Eur J Hum Genet 2009;17:720-721.

45. de Wert G: Ethical aspects of prenatal testing and preimplantation genetic diagnosis for late-onset neurogenetic disease: the case of Huntington's disease. In: Evers-Kiebooms G, Zoetewij M, Harper P (eds): Prenatal Testing for Late-Onset Neurogenetic Diseases. Oxford: Bios Scientific Publishers, 2002, pp 129-157.

46. Kuppermann M, Norton M: Prenatal testing guidelines: time for a new approach. Gynecol Obstet Invest 2005;60:6-10

47. Boyle R, Savulescu J: Prenatal diagnosis for "minor" genetic abnormalities is ethical. Am J Bioeth 2003;3:W60-W65.

48. Stewart A, Brice P, Burton H, Pharoah P, Sanderson S, Zimmern R: Genetics, Health Care and Public Policy. Cambridge: Cambridge University Press, 2007.

49. Wilson J, Jungner G: Principles and practice of screening for disease. Geneva, World Health Organization, 1968.

50. Health Council of the Netherlands: Genetic screening. The Hague: Health Council of the Netherlands, 1994.

51. Haddow J, Palomaki G: ACCE: a model process for evaluating data on emerging genetic test. In: Khoury M, Little J, Burke W (eds): Human genome epidemiology. A scientific foundation for using genetic information to improve health and prevent disease. Oxford: Oxford University Press, 2004, pp 217-233.

52. Lo YMD, Corbetta N, Chamberlain PF, Rai V, Sargent IL, Redman CW, Wainscoat JS: DNA in maternal plasma and serum. Lancet 1997;350:485-487.

53. Wright $\mathrm{CF}$, Burton $\mathrm{H}$ : The use of cell-free fetal nucleic acids in maternal blood for non-invasive prenatal diagnosis. Hum Reprod Update 2009;15:139-151.

54. Chiu RW, Chan KC, Gao Y, Lau VY, Zheng W, Leung TY, Foo CH, Xie B, Tsui NB, Lun FM, Zee BC, Lau TK, Cantor CR, Lo YM: Noninvasive prenatal diagnosis of fetal chromosomal aneuploidy by massively parallel genomic sequencing of DNA in maternal plasma. Proc Natl Acad Sci USA 2008;105:20458-20463.

55. Fan H, Blumenfeld Y, Chitkara U, Hudgins L, Quake S: Noninvasive diagnosis of fetal aneuploidy by shotgun sequencing DNA from maternal blood. Proc Natl Acad Sci USA 2008;105:16266-16271.

56. Chiu RW, Akolekar R, Zheng YW, Leung TY, Sun H, Chan KC, Lun FM, Go AT, Lau ET, To WW, Leung WC, Tang RY, Au-Yeung SK, Lam H, Kung YY, Zhang X, van Vugt JM, Minekawa R, Tang MH, Wang J, Oudejans CB, Lau TK, Nicolaides KH, Lo YM: Non-invasive prenatal assessment of trisomy 21 by multiplexed maternal plasma DNA sequencing: large scale validity study. BMJ 2011;342:c7401.

57. Chiu R, Lo Y: Non-invasive prenatal diagnosis by fetal nucleic acid analysis in maternal plasma: the coming of age. Semin Fetal Neonatal Med 2010;16:88-93.

58. Papageorgiou EA, Karagrigoriou A, Tsaliki E, Velissariou V, Carter NP, Patsalis PC: Fetal-specific DNA methylation ratio permits noninvasive prenatal diagnosis of trisomy 21. Nature Med 2011;17:510-513. 


\section{Chapter}

\section{The scope of prenatal diagnosis for women}

at increased risk for aneuploidies: views and preferences of professionals and potential users

de Jong A, Dondorp WJ, Krumeich A, Boonekamp J, van Lith JMM, de Wert GMWR Journal of Community Genetics 2013;4(1):125-135 


\begin{abstract}
The increasing number of prenatal diagnostic tests in prenatal screening strategies, raises the question what tests to offer and why. This qualitative study investigated the views and preferences of professionals and potential users regarding four diagnostic test options for women at increased risk for common aneuploidies. Seven focus group sessions were conducted in The Netherlands between October 2009 and June 2010, with various categories of participants $(n=55)$ : professionals engaged in prenatal testing and potential users of this testing (meaning pregnant women and parents of young children). Participants were invited to mention all pros and cons and their preferences regarding four hypothetical diagnostic test options, presented on vignettes: a standard offer of rapid aneuploidy detection, karyotyping or array comparative genomic hybridization, representing a narrow, traditional and broad test, respectively, and the option of individualised choice. Then, a semi-structured group interview was conducted. The data were analysed by the constant comparative method. Participants identified similar test-specific pros and cons but showed different preferences. Users' opinion on what test to offer as a general policy differed from what they would choose themselves. All participants agreed that in theory, users should be enabled to make an informed choice about what test to apply, but they disagreed about the feasibility of this ideal. Standard narrow testing was favoured for its limiting effects on emotional and organisational burdens; individualised choice was preferred for assuring women's decisive influence. The varying opinions reflect different views on what autonomy in the prenatal screening context means, suggest that a single standard test offer is inadequate and that differentiation will be needed.
\end{abstract}




\subsection{Introduction}

Current prenatal screening cascades include a first-trimester risk assessment for common trisomies and mid-trimester foetal anomaly scans. Invasive diagnostic testing is offered to women at an increased risk of chromosomal or genetic abnormalities. ${ }^{1,2}$ Conventional karyotyping, that can reliably diagnose numeric chromosome aberrations and (major) structural abnormalities, has long been the standard diagnostic test. But alternative techniques, that allow testing for either a more limited or broader scope, are increasingly being introduced instead. Techniques for rapid aneuploidy detection (RAD) target only trisomies 13, 18 and 21 and mostly sex chromosomal abnormalities. ${ }^{3}$ Other techniques, such as microarray-based comparative genomic hybridisation (array $\mathrm{CGH}$ ), are used to detect a broader range of heterogeneous abnormalities. ${ }^{4,5}$ Whereas some favour targeted arrays to detect selected abnormalities and avoid unclear or troublesome test results ${ }^{6-8}$, others prefer genome-wide, non-targeted arrays to maximally identify all kinds of clinically relevant aberrations..$^{9,10}$ The implementation of these different techniques has led to debate about what diagnostic test should be offered to pregnant women and why. ${ }^{11,12}$ There is no consensus among professionals about what specific test to offer in the prenatal testing cascade and pregnant women themselves have different preferences regarding the scope of testing as well. ${ }^{13-15}$

Empirical studies on the preferences of professionals and 'users' (pregnant women, prospective parents and consumers) regarding the scope of prenatal testing have mainly focused on determining the differences with regard to choice outcomes amongst and between these two categories of respondents and on identifying the correlation between preferences on the one hand and characteristics of the tests and/or of the respondents on the other hand. Studies included a limited number of tests only. Boormans et al. and Grimshaw et al. introduced three test options: a test targeted on Down's syndrome only, RAD and karyotyping. ${ }^{16,17}$ These studies showed that testing for Down's syndrome only was hardly chosen, that professionals mostly wanted to offer RAD, and that opinions differed among pregnant women and between professionals and women. 'Individualised choice' was suggested as a solution for these differences. ${ }^{16}$ Pieters et al. studied pregnant women's attitudes towards 'microarray-based genomic profiling technologies', which they referred to as 'prenatal full-scale testing for genetic disorders'. ${ }^{18}$ They found that this kind of test was not readily accepted, but that women with a low educational level were more likely to be interested in full-scale testing. More research into the factors that influence pregnant women's decisions was thought to be needed. When studying consumers' opinions toward reproductive testing, Hathaway et al. found a wish to have prenatal testing for more conditions than generally offered. ${ }^{19}$ These further conditions included for example mental retardation, deafness and cancer. The studies mentioned give a good overview of 
what test would be preferred by whom. We however wanted to know on the basis of what considerations professionals and users come to a certain choice. Therefore, we aimed to explore the spectrum of underlying views that play a part in the evaluation of prenatal tests and influence decision making. Given the current broad range of available techniques, we studied these views with regard to four prenatal test options: three diagnostic tests that are actually offered in current prenatal testing cascades: conventional karyotyping, a narrow test (RAD), and a broad test for heterogenous abnormalities (array CGH). Offering women an 'individualised choice' ${ }^{13}$ between these three tests was introduced as a fourth option. Although in current north-west European practice this option is limited to a choice between RAD and karyotyping ${ }^{3,13,14}$, we included array CGH into this alternative as well, because this test is increasingly applied. To explore the underlying views of professionals and potential users, we aimed to address three main questions: (1) how do Dutch professionals and potential users (meaning pregnant women and parents) evaluate the pros and cons of the four different test options; (2) what test options do they think should be offered to women in general and for what reasons; and (3) what test options do users prefer for themselves and why?

\subsection{Materials and methods}

\subsubsection{Data collection}

This study was undertaken in The Netherlands, between October 2009 and June 2010. Focus groups were conducted with potential users of prenatal testing and professionals who are involved in prenatal testing. We preferred a group-based approach over individual interviews, because groups are an effective source for eliciting views, for stimulating people to share and debate these, and for generating new ideas. ${ }^{20}$ We composed homogenous groups, to effect that participants could speak freely among their peers and to reduce the risk that some participants would dominate the discussion based on their professional background or experience, or that others would feel uncomfortable or inhibited to contribute. ${ }^{20,21}$ Informed consent was obtained at the beginning of each session. Users were offered a monetary incentive; all participants were offered a reimbursement for travel expenses. This study was cleared for approval by the Medical Ethics Committee of the Maastricht University Medical Centre+, azM, Maastricht, The Netherlands.

The focus groups were moderated by WD, ADJ or GDW and co-moderated by ADJ or JB. The group sessions all lasted $2 \mathrm{~h}$. All focus groups started with a brief plenary introduction of the aim of the study and of the session, namely to explore all views of participants and explicitly not to reach consensus. Then vignettes containing four test options were distributed (Box 7.1). The four options involved three standard test offers: (A) conventional karyotyping, 
(B) RAD and (C) a non-targeted array CGH. The fourth option (D) entailed asking pregnant women to choose themselves between (A), (B) and (C). We used vignettes to make sure that all participants had the same picture and a basic understanding of the four options. We described these test options in general terms and did not distinguish between different types of RAD or variants of array CGH. Instead, we focused on the common factors to avoid that participants, and especially professionals who actually offer these tests, would start to discuss the facts and details of different test techniques. The users and midwives had also been e-mailed this vignette the week before the group session, to make them already familiar with the subject to be discussed.

\section{Box 7.1 | Vignette with four test options}

\section{Option A - current}

Pregnant women are offered a standard test: karyotyping

This test can identify all chromosomal abnormalities, including Down syndrome.

Some of these abnormalities have severe and others have mild clinical consequences

Generally, clear information can be provided about abnormalities found

Sometimes, the clinical consequences of abnormalities are unknown

Test results: 2 - 3 weeks

\section{Option B - narrow}

Pregnant women are offered a standard test: RAD

This test can identify a few most severe chromosomal abnormalities, including Down syndrome.

Clear information can always be provided about abnormalities found

Test results: 2 - 3 days

\section{Option C - broad}

Pregnant women are offered a standard test: array-CGH

This test can identify all chromosomal abnormalities, including Down syndrome

This test can also indentify other kinds of abnormalities, such as the hereditary disease cystic fybrosis

Often, clear information can be provided about abnormalities found

Sometimes, the clinical consequences of abnormalities are unknown

Test results: 2 - 3 weeks

\section{Option D - choice}

Pregnant women are offered all three tests: A, B and C

They may choose themselves which test they prefer

We sketched the scenario that women at increased risk for trisomies 13, 18 and 21 were offered a diagnostic test performed on material obtained by an invasive procedure (either amniocentesis or chorionic villus sampling). We chose this scenario because it resembles current practice that participants were likely to be familiar with, in order to avoid that it would be experienced as too hypothetical. After briefly explaining the content of the vignettes 
and answering informative questions, participants were asked to write down individually all pros and cons of the four test options and to give their opinion on what option should be offered to pregnant women. Users had to indicate as well what they would choose for themselves. Subsequently, they were asked to mention and explain the arguments and preferences they had written down. By following this procedure we wanted to ensure that all participants' initial thoughts were mentioned, and to prevent that the discussion would too soon strike out on a certain course. All arguments and preferences were listed on a flip-chart, to guarantee that they were all covered and rightly understood. To explore the considerations more in depth, a semi-structured group interview was conducted, guided by both a predetermined topic guide and the flip-chart notes. This qualitative design enabled to bring forward the individual views and to profit from the dynamics of a group discussion. All group sessions were digitally recorded and transcribed.

\subsubsection{Sampling and recruitment}

As potential users we included pregnant women and parents (both male and female) of young children (0-3 years). The assumption was that these persons had been offered testing and would possibly have to deliberate about testing in a next pregnancy. We included fathers in the latter group, because of their partaking in the reproductive decision-making. ${ }^{22,23} \mathrm{We}$ included three categories of professionals, whose professional involvement in prenatal diagnostic testing differs: midwives have mainly initial involvement in counselling and reference to specialist care; gynaecologists from regional and urban hospitals are involved in the standard-test procedures; experts from academic centres actually perform specialised (follow-up) testing on a daily basis. By selecting these categories of participants, representing different perspectives, we aimed to collect a broad range of relevant views from persons directly concerned with prenatal testing. ${ }^{21}$

The users were recruited in the south-west of The Netherlands by advertisements in local newspapers and by distributing an information leaflet to pregnant women who visited the obstetric outpatient clinic at Leiden University Medical Centre. We recruited the midwives and academic experts from across the country by sending a digital general invitation trough their national professional societies. To reach relevant gynaecologists across the country, we asked the academic experts for possible referrals.

\subsubsection{The sample}

Seven focus groups were conducted that included 55 participants. Of these, 25 potential users were divided over four group sessions: two groups with in all 15 pregnant women (user pregnant $=$ UP) and two groups with in all ten parentsof young children (user male and female = UM and UF, respectively). We included 30 professionals who were divided per profession over three group sessions: one group with nine midwives (professional 
midwife $=\mathrm{PM})$, one group with ten gynaecologists from regional and municipal hospitals (professional gynaecologist $=$ PG), and one group with 11 experts from academic medical centres (professional academic $=$ PA). The latter consisted of gynaecologists $(n=4)$, clinical geneticists $(n=3)$, cytogeneticists $(n=2)$ and clinical cytogeneticists $(n=2)$. Because in the course of the group sessions no new information was obtained and redundancy occurred, data saturation was achieved ${ }^{24}$ and no further participants were included.

\subsubsection{Analysis}

Analysis was conducted on the content of participants' notes, the flip-charts and the transcripts to identify major themes and sub-themes. The coding process started on the content of the notes and flip-charts, and followed the constant comparative method. ${ }^{25}$ To reduce the chance of bias and ensure consistency, two members of the research team (ADJ and WD) independently coded the content systematically and iteratively, with guidance from an experienced qualitative researcher (AK). In this first phase of the analysis, we did a descriptive coding to label the various topics in the text. These open codes differed minimally and were adjusted slightly. The resulting scheme was used for subsequently analysing the text content of the transcripts, using the $\mathrm{NVivo} 8^{\circledR}$ software program. Here, the same method was applied: ADJ coded the full content and WD checked for consistency by coding and comparing segments across the transcripts. In the second phase, we grouped the topics into sub-themes and found the same patterns in all three sources of data by means of an inductive reasoning method. The text belonging to these sub-themes were found to differ with regard to the 'level' of discussion: the test features as such were mentioned and classified, but the concepts of informed choice and autonomy elicited a more reflective discussion. This led to the distinction between the themes of 'evaluation of test features' and 'informed choice' as presented in the 'Results' and 'Discussion'. Participants' and users' preferences were approached as separate subjects, in order to give insight in how users differentiate between themselves and 'the public'. All researchers contributed to the discussion in the analysis process with regard to the formulation of the major conclusions. Thus, investigator triangulation was achieved.

\subsection{Results}

\subsubsection{Themes and preferences}

Two major themes emerged in the focus groups. Participants first focused on features of the test options, such as test outcomes, wait for results and costs and classified these as pros and cons. Secondly, a more reflective discussion started about the meaning of informed choice and autonomy in the prenatal screening context. The results caused us to distinguish between two groups of professionals, namely midwives and physicians (gynaecologists 
and experts from academic medical centres); we will refer to them accordingly. Pregnant women and parents together are called users. We talk about participants if we mean both professionals and users. The most important sub-themes are elaborated in the sections below and are often illustrated by representative quotes. Sometimes, citations are slightly adjusted for reasons of readability. Whenever an aspect relates to a specific test option, the denominator (A, B, C or D) is added between brackets. Participants' choices and reasons to choose a particular test option and users' preferences for themselves are presented subsequently.

\subsubsection{Evaluation of test features}

\section{Test outcomes}

Considerations regarding the amount and type of abnormalities possibly generated by the tests were mentioned by all participants. In general, more extensive information about the foetus was favoured. Users tended to associate broad testing (C) with certainty and narrow testing (B) with 'fake certainty'. UP13: '(...) test C (...) is the most comprehensive test, with complete clarity, because you know everything possible. (...) The disadvantage of $B$ is that you don't have complete clarity and you can be falsely reassured as there may be other abnormalities'. Although professionals thought that more information could also 'falsely reassure' women, they stressed that a broad test could identify relevant abnormalities that would otherwise be missed. Yet, all realised that the profit of possibly generating more abnormalities would come at the price of an increase in (unclear) findings that would complicate counselling and decision making and aggravate the dilemma whether to terminate the pregnancy or not. A pregnant woman (UP2) commented: 'One has to take in a large amount of information and the spectrum of findings will become very large, so it will be really difficult to make a choice'. And a professional (PG2) stated: 'Some of the test results, such as deletions and translocations, are complicated and we hardly know what to do with them (...). It is not always clear what it all means to the foetus and this makes it difficult for the layman. And for us as well'. Some professionals mentioned that C could also generate unexpected findings about the parents and predispositions, which would be problematic if couples had not been adequately counselled beforehand. PA10: 'In addition to what has been said about C: an array does not only generate information about the foetus or causal mutations. It can indirectly also generate genetic information about the parents and about risk factors, such as a BRCA mutation (...).'

Participants agreed that a narrow test (B) would avoid these problems while still identifying some severe abnormalities. Still, testing for all kinds of serious disorders (C) was found important. Users were particularly interested in hereditary diseases and limitation to some specific abnormalities (A and B) was debated. UP2: '(...) it started with Down's syndrome, 
because one could easily test this, when naturally there are other disorders that are even more serious. This is positive with $\mathrm{C}$, that you can also find those other abnormalities and take them into account.' However, all recognised that differentiation between serious, mild and marginal abnormalities was difficult. Because of that, some participants feared that broader testing (C) would lead to the pursuit of a genetically perfect child and that abortion would increasingly be performed for minor abnormalities. UP5: 'Where does it stop? I think that the danger is that if there are possibilities to know more, that people increasingly will want to know more, and then it becomes the norm, a slippery slope. This frightens me.'

Finally, some found that less information would make the miscarriage risk of invasive testing disproportionate. PG3: 'It is dangerous to do an amniocentesis. So the moment that choices about the scope have to be made, my approach would be do it to the best of the possibilities available.'

These considerations about broad and narrow testing show that participants struggled to find the balance between their wish to test for all kinds of severe abnormalities and the drawbacks of too much findings.

\section{Wait for results, costs and familiarity}

Tests differ with regard to throughput time. Participants favoured quick test results (B) for three reasons. First, the period of stress and anxiety while waiting for test results would be minimised. PG5: 'I think that speed will reduce fear. There is a big difference between waiting for results for 3 weeks or 3 days.' Second, if test results were generated earlier in pregnancy, this would leave more time for the decision to terminate or continue the pregnancy. UP1: 'One might have more time to make that decision in peace and quiet. And surely with the second test (amniocentesis, ADJ) you have to decide rather quickly whether you want an abortion or not. This decision that you have to make within 2 to 3 weeks will be decisive for your life.' Third, earlier results would enable a possible earlier abortion, which was thought to be emotionally less traumatic. PM8: 'The pregnancy progresses too. So if women choose an abortion, then they of course rather have the termination of pregnancy at 16 weeks than at 18 weeks. Or at 9.'

The financial costs of the tests were approached from different perspectives. Most professionals asserted that costs, including time and personnel needed for counselling and logistics, would be high for $C$ and $D$, and they considered this problematic from a public policy point of view. This problem was recognised by some users but 'solved' differently. They proposed public funding for a minimum set of tests ( $A$ and $B$ ) and (income related) out-of-pocket payment in case of more expensive testing ( $C$ and $D$ ) to ensure availability of all options. Other users, taking the individual user's perspective, found it unseemly to talk about financial costs of prenatal testing, because it would complicate the already precarious situation of prospective parents who were offered testing. 
Finally, nearly all users appeared to only be superficially familiar with the organisation of current testing cascades and unaware of the fact that women are generally offered conventional karyotyping (A). This led to a striking contrast between professionals and users in how they evaluated $A$. While the longstanding experience with and reliability of $A$ was considered a great asset by professionals, users thought that this test did not have any advantage at all. UM2: 'A is neither here nor there. So if you have A, B, or C, than I would go for $B$ or $C$. I think $A$ is a compromise and combines the disadvantages only.'

The discussion about these aspects shows that only a short waiting time is unanimously favoured, but that participants differ in their evaluation of financial costs and testing experience.

\subsubsection{Informed choice}

\section{Individualised choice: ideal and feasibility}

In theory, all participants favoured an 'individualised choice' as presented in D. Terms mentioned were: promotion of autonomy, ideal informed choice, and control over own pregnancy. At the same time, they realised that the scenario presented in D would encounter practical drawbacks, because it would be difficult to adequately inform and counsel women and such a complex choice could overtax women and throw them off balance. UP10: 'With regard to $D$, the choices can be overwhelming and then you are not competent to make a rational assessment. So where do parents base their choices on, then?' Despite agreement on these both sides of $D$, participants reached opposite conclusions when discussing the feasibility of $D$ in practice. Two groups could be discerned: (1) those who were sceptical about the feasibility of $D$, and (2) those in favour of $D$ being dedicated to achieve it.

The first group, including most physicians and some users, considered it as good as impossible to provide women with adequate information and ensure adequate counselling. Especially physicians were sceptical about women's capacity to make the choice presented in D. PG4: 'It's a lot to ask of your patients. And the question is also if people are really waiting for all that information and all those choices. Mostly they'll be at a loss.' It was called a 'spurious option' (PG3), because it would provide women with a sense of control which would not correspond with the actual situation. PG7: 'And D, hmm, how is a layman going to make this choice. (...) except the advantage that men and woman have a feeling of control concerning their lives, there is no other real advantage in giving them the possibility to choose.' Users in this group stressed the emotional burden of choice and doubted whether women actually wanted to make it. UF4: 'I can imagine that as a pregnant woman you might find it scary to make that decision, and that it would be a lot easier if one test was simply offered.' Thus, the overall conclusion of this group was that $D$ might provide for autonomous choice in theory but not in practice. 
Participants in the second group, consisting of most midwives and most users, found that women's reproductive options should not be constrained by others. They considered the choice for a specific test to be an essential part of women's autonomy and especially midwives felt uncomfortable with an intrusion upon it. PM6: 'People have to make this choice themselves. Especially if various test alternatives are available, who do I think I am to withhold this information from them?' This view was placed in the societal context of an increasing individual freedom and availability of choices in many fields of personal life, including health care, and was reinforced by the awareness that women very much differed in their views and preferences. UP7: 'That you have a choice what type of test you would want, just gives you more freedom. Some want all available information even if the consequences are not clear, others do not. Personally, I would only want to know the information that is a hundred percent certain and if I can understand what it means. But that is me, I think that is different for each individual.' Still, there were ambivalent feelings toward the choice scenario.

Midwives sensed that professionals devolved their responsibility (to choose the right test) unto pregnant women. PM1: 'You are putting the responsibility with the parents. But the feeling that you are passing the buck, makes me feel uncomfortable and reluctant.' The users in this group expressed worries regarding the responsibility and emotional impact of such a choice. They feared making the wrong choice and subsequent regret, particularly if the test chosen would miss an abnormality that would make the child suffer after birth. UP3: 'The moment that you have decided against these tests... can you forgive yourself if your child is born with an abnormality and dies after three pain-filled and dreadful years. How well can you look at yourself in the mirror with the knowledge that you could have known. There is no going back, that is what I find difficult about these tests.' The midwives and users in this group also thought that the complexity of such a choice could have the effect that women would (want to) rely more on professionals. Therefore, they emphasised that great effort should be put in informing and counselling women to enable them to make the choice offered in D. Since a standard approach would probably not meet women's individual needs, it was thought essential to tailor both the test offer and the counselling to women's different capacities and wishes. UF2: 'Just give the woman what she needs. I think that a 16-year old pregnant girl will be frightened by all these options. But a 40-year old woman is going to think more realistically, yes, there are risks. Well, I'm going to dwell upon all these options.'

These considerations show that the difficulties and possible drawbacks of individualised choice are acknowledged, but that this group wants and expects to overcome these with adequate counselling in order to respect women's autonomy. 


\section{Choice: consistency and fairness}

Related to participants' different views on individualised choice itself, they dissented on how the testing cascade should be evaluated. The scenario in our study was that diagnostic testing was offered to women whose risk-assessment showed an increased risk for trisomies 13,18 or 21 . This led to discussion about the relation between the two successive tests. Those who were sceptical about $C$ and $D$, took the risk-assessment as their point of departure and argued that the scope of subsequent diagnostic testing should be consistent with that (B). Possible additional findings of A and C were labelled as 'excessive' diagnostics by some physicians. PG2: 'In my opinion, it is an advantage that the results are the same as what the patients have undergone the screening for; that was the reason to do this. The results of the diagnosis would be equivalent to what you are screened for and nothing else.' Some users agreed that if the first test was for Down syndrome, one should not be troubled with avoidable other findings later on. Furthermore, it was thought 'unfair' if only women at increased could test for more abnormalities, while others, having the same risk for these surplus findings, had no access to this test.

The midwives and users who placed great importance on women's own choice, exactly reasoned the other way around and argued that access should be attuned to the favoured scope of diagnostic testing. They criticised the current focus on the trisomies and thought it unfair that women who were not at risk for these particular abnormalities had no access to broader testing. UP6: 'I don't think this is logical. I am forced to be tested for chromosome abnormalities for which you need to be at high risk and only after that am I allowed to test for hereditary disorders, whereas I might only want the foetus to be tested for hereditary abnormalities.' Therefore, they proposed to adjust the policy of admittance in order to enable access to broader testing for those women who wanted it.

\subsubsection{Views and preferences}

When asked what specific test options should be offered to pregnant women and why (research question 2), a majority of participants tended to choose between two extremes: either D or B (See: Table 7.1). Most users and midwives chose D, because it allowed women (and their partners) to make their own choice on what test would best suit their personal situation. Most physicians and the other users chose B for various reasons. Feasibility in terms of women's competence, counselling and costs, and consistency with women's indication (increased risk for trisomies) were mentioned most by the physicians. The emotional impact was decisive for users: B would only produce information about severe and clear abnormalities and therefore avoid difficult decision making and emotional burden. Only a few participants chose options in between: long-standing familiarity with A caused some professionals to chose this test, whereas $C$ was seen as the best alternative between $\mathrm{D}$ (too complex) and A and $\mathrm{B}$ (too restricted). 
Table 7.1 | Test option that should be offered to women according to participants

\begin{tabular}{|c|c|c|c|c|c|}
\hline Preference & A & B & C & D & No \\
\hline Pregnant women $(n=15)$ & & 4 & & 11 & \\
\hline Parents $(n=10)$ & & 4 & 1 & 5 & \\
\hline Midwives ( $n=9)$ & 1 & 1 & & 6 & 1 \\
\hline Academics $(n=11)$ & 2 & 8 & & 1 & \\
\hline Gynaecologists ( $n=10)$ & & 9 & 1 & & \\
\hline
\end{tabular}

The picture changed when users indicated what test option they would prefer for themselves (research question 3) (See: Table 7.2). Their preferences were spread over four options: B, C, D or no testing at all. Reasons for B and D were the wish to limit the emotional burden of unclear findings and decision making, and to have the opportunity to make one's own choice, respectively. In this respect, there was no difference with the reasons mentioned for their 'general' preference. But some users who preferred D in general, did not want to bear the responsibility in this option themselves. The accumulation of decision-making moments throughout the pregnancy was experienced as an additional burden. UP8: 'The largest disadvantage for me would be that there has been an offer of choice in asking if the mother to be is willing to take part in the risk-assessment and in the high risk amniocentesis. And to make a further choice once more then between 3 different tests would be really difficult for me. So, one option would be enough for me.' Therefore, they chose the test that was most comprehensive (C) but still not too burdensome.

Table 7.2 | Test option that users prefer for themselves

\begin{tabular}{|c|c|c|c|c|c|}
\hline Preference & $\mathbf{A}$ & B & C & D & No \\
\hline Pregnant women $(n=15)$ & & 4 & 5 & 6 & \\
\hline Parents $(n=10)$ & & 3 & 1 & 1 & 5 \\
\hline
\end{tabular}

Finally, part of the users indicated that they would choose no testing at all, either because they were opposed to abortion or would not want to risk losing the pregnancy because of iatrogenic miscarriage, whatever the possible benefit of testing.

\subsection{Discussion}

This qualitative study on professionals' and users' views and preferences regarding four prenatal test options showed two levels of deliberation: classification of test features and reflection on the concepts of informed choice and autonomy. The latter seemed to have the 
largest influence on participants' preferences. Furthermore, personal bearing capacity led some users to give a different answer with regard to what they would choose for themselves and to what choices should be offered to pregnant women in general.

\subsubsection{Features of testing: pros and cons}

Initial observations regarded the features of tests, including test outcomes, wait for results and financial costs. Since other studies have shown the relevance of these 'test attributes'13 in the evaluation of prenatal diagnostic tests ${ }^{16-18}$, we expected these issues to arise in our focus groups as well. Users and professionals identified similar test-specific aspects, but their evaluation did not coincide in all respects. The same inventory of aspects however suggests that users in our study realised both the beneficial and adverse aspects of various tests - despite existing doubts whether they have adequate understanding of the drawbacks of particularly broad testing. ${ }^{18}$ Although users understood that, compared with karyotyping (A) and RAD (B), more and different abnormalities could be identified by broad testing (C), it was not clear whether they realised that the incidence of these other findings is considerably lower. Remarkably, this lower incidence was not a major issue for the professionals either when evaluating the various test options. However, pre-test information should include a distinction between common findings and possible but rare findings ${ }^{26}$ and may differ in both quantity and detail. But the question remains how to provide complex information in the actual counselling situation without confronting users with either a deficit or an overload of information. In either case users would not be adequately equipped to make an informed choice to either participate or not engage in testing. Moreover, user's individual comprehension and the time-pressure in the prenatal context should be taken into account. Although we observed that users and professionals identified the same set of test-specific features, these appeared not to be decisive for choosing a specific test option.

\subsubsection{Reproductive autonomy: limiting burdens or maximising options}

Although all participants agreed that reproductive autonomy was in theory best served by leaving the decision for a specific test to pregnant women themselves, the feasibility of such an informed choice in practice was evaluated differently.

The view that an informed choice as intended in option $D$ and needed in option $C$ is too complicated and that optimal decision making and limitation of burdens should prevail over maximising information, may be seen as paternalistic. ${ }^{27,28}$ However, adherents of a narrow test seemed to assume that limiting choices better accords with the aim of prenatal screening to enable autonomous reproductive choice, given the requirements of, amongst other things, adequate counselling, informed consent and proportionality (benefits for participants outweigh the burdens). ${ }^{29}$ This view also leaves room for what we have earlier 
called the 'logic of the screening strategy' argument ${ }^{30}$, holding that the limited scope of the preceding risk-assessment justifies and requires offering a corresponding diagnostic test to ensure consistency throughout the testing phases. In this view, a broader test is not rejected per se but may be offered for specific indications. Indeed, broader testing (C) has already been introduced and was favoured by professionals in our study in case of foetal ultrasound abnormalities. ${ }^{5,10}$ Although it seems only logical that problems regarding comprehension and counselling will also arise in this situation -albeit on a smaller scale- these were hardly discussed for this context. In this regard, the justification for limiting the scope of testing and reproductive options was contextualised: physicians tended to reason from an organisational point of view, taking the existing screening system as their point of departure.

Participants preferring D reasoned primarily from a users' perspective. They asserted that reproductive autonomy required enabling an individualised choice: allowing pregnant women themselves to determine whether they would benefit more from a comprehensive or a limited test. In this view, the scope of and access to diagnostic testing should not be limited by others but valuable options should be available to all. Still, the possible disadvantages of such a choice was acknowledged. Users' fear for making a wrong decision and regret afterwards -the so-called anticipated decision regret ${ }^{31}$ - and midwives' concern about professionals' failure to take their responsibility reflect the anticipation of a so-called decisional conflict. Such a conflict may arise when people are faced with an inherent difficult choice and other complicating factors ${ }^{32}$ such as -in this case- lack of knowledge and time pressure. To obviate these drawbacks, extensive counselling was thought to be crucial.

Although counselling models as such were not discussed, it was obvious that participants thought that a situation in which professionals only provide 'objective' information and subsequently leave the decision making to the testee alone, would have serious shortcomings. This so-called information mode ${ }^{33}$ has formerly been criticised for being too simplistic and inaccurate, for the misconception that a strict distinction between facts and values can be achieved, and for ignoring professionals' duty to help patients handle information in order to reach an autonomous choice. ${ }^{33-35}$ Precisely this latter aspect of responsibility to support is well addressed in the 'interpretive model', in which the professional not only provides the patient with adequate information but also acts as a counsellor who engages in patient's autonomous decision making. The interaction between professional and patient thus aims to 'elucidate the patient's values and what he or she actually wants and help the patient select the available medical interventions that realise these values' ${ }^{\prime 33}$. Because the agenda of the user is directive in this process, the interpretive model may also meet the ambivalent feelings that users expressed with regard to extensive counselling: that women presumably want to be supported by professional guidance when facing a difficult choice, that such 
support can make women depend on and be influenced by professionals, which may both contrast with autonomous choice. If the counselee herself determines the direction and content of counselling, these possible drawbacks can be countered. This would also enable to meet the different interpretations that women may have of informed choice and the specific support they expect from the professional. ${ }^{36}$ Nevertheless, in view of the doubts expressed about the feasibility and desirability of more extensive counselling, there is a need for further ethical reflection and empirical research on what counselling model would be appropriate in prenatal testing scenarios to ensure that women are really enabled to make an autonomous reproductive choice.

\subsubsection{Users' preferences: general policy versus private choice}

A majority of the users expressed similar considerations and preferences for themselves as for women in general. However, a large minority mentioned new arguments and different preferences when deliberating about what option they would choose for themselves as opposed to what should be offered to women in general.

First, some declined all forms of testing because either abortion as such or the procedureinduced miscarriage risk was unacceptable to them. Importantly, these users emphasised that they did not want to impose their personal choice on others: every woman should make up her own mind what option best suited her personal situation and whether she would terminate a pregnancy or run the risk of losing a healthy foetus. Therefore, they still approved of the general offer of testing. As for their personal preferences, a correlation between declining prenatal testing and abortion is consistent with other studies. ${ }^{37,38}$ The iatrogenic miscarriage risk is also a known reason for rejecting prenatal testing. ${ }^{39}$ It is likely but as yet unclear whether the introduction of non-invasive prenatal testing ${ }^{40}$ means that these particular users will accept testing if the miscarriage risk is absent or at least the number of unnecessary invasive procedures will be reduced. ${ }^{41}$ If so, the question remains if they would test for either a narrow or broad range of conditions, as soon as the latter becomes possible. ${ }^{42,43}$

Second, half of the users who appreciated $\mathrm{D}$ in general chose $\mathrm{C}$ for themselves. This alternative of a standard broad test enables maximising information, albeit at the cost of possible difficult test-outcomes and decision making, but avoids the burden and responsibility to choose the 'right test'. This dilemma between wanting a choice and experiencing ambivalence about subsequent decision making in the prenatal setting has been described before ${ }^{44}$ and reflects awareness of the chance of a decisional conflict. These considerations reinforce the need for giving adequate support to individual women in their decision-making process. 


\subsubsection{Concluding remarks}

The controversy shown by the views and preferences in our study reflects one of the central ethical questions in current prenatal screening, namely how reproductive autonomy in this context has to be interpreted. Does it mean that the amount of reproductive options for women should be maximised and individualised choice be offered to all? Or should the burdens be limited, the decision-making process be optimised and a standard narrow test be offered in order to ensure a real autonomous choice? Our results confirm the finding in other studies that the question what test option best complies with the aim of prenatal screening is answered differently by both professionals and users, and suggests that a 'one-size fits-all' approach fails to take into account the different views and preferences of pregnant women and their partners. ${ }^{45}$ Since both a broad and a small standard test offer may interfere with women's autonomy, differentiation may be needed. The ethical and practical conditions for such a differentiated test offer are still to be defined. Whatever the test offer may include, our findings suggest that not only adequate information and non-directivity are crucial in counselling, but that there is also a need for reflection on counselees' values and for support to realise these. The interpretive model may be helpful in this regard.

\subsubsection{Limitations}

This study has several limitations. First, the sample size was limited and our sampling method cannot rule out that participants might have been biased and may not be representative of the Dutch professionals and users. This means that findings cannot be generalised without caution. Second, in this study participants reflected on a hypothetical situation and persons' hypothetical responses may not match actual behaviour. These limitations did however not hamper the aim of this study to explore views and preferences of potential users and professionals. The general criticism of qualitative research, that it is too subjective and that researchers' beliefs contribute too much to the findings ${ }^{46,47}$, we refute as follows: the data collected were rich in content as all participants could among their peers express their views and give comprehensive explanations, and the analysis was conducted independently by various researchers. The strength of this study is that various categories of participants, who can be considered stakeholders of prenatal testing policies, were enrolled and that they provided a broad range of considerations that can inform further reflection on the scope of prenatal screening.

\section{Acknowledgements}

The authors wish to thank all pregnant women, parents, midwives and clinicians who were willing to participate and share their views with us. We also thank the personnel of the Obstetrics Department at the Leiden University Medical Centre for their help in recruiting pregnant women. 


\section{References}

1. Salomon LJ, Alfirevic Z, Berghella V, Bilardo C, Hernandez-Andrade E, Johnsen SL, Kalache K, Leung KY, Malinger G, Munoz H, Prefumo F, Toi A, Lee W; ISUOG Clinical Standards Committee: Practice guidelines for performance of the routine mid-trimester fetal ultrasound scan. Ultrasound Obstet Gynecol 2011; 37:116-126.

2. Tapon D: Prenatal testing for Down syndrome: comparison of screening practices in the UK and USA. J Genet Couns 2010;19:112-130.

3. Faas B, Cirigliano V, Bui T: Rapid methods for targeted prenatal diagnosis of common chromosome aneuploidies. Semin Fetal Neonatal Med 2011;16:81-87.

4. Hillman SC, Pretlove S, Coomarasamy A, McMullan DJ, Davison EV, Maher ER, Kilby MD: Additional information from array comparative genomic hybridization technology over conventional karyotyping in prenatal diagnosis: a systematic review and meta-analysis. Ultrasound Obstet Gynecol 2011;37:6-14.

5. Savage M, Mourad M, Wapner R: Evolving applications of microarray analysis in prenatal diagnosis. Curr Opin Obstet Gynecol 2011;23:103-108.

6. American Committe of Obstetricians and Gynecologists. ACOG Committee Opinion Number 446: Array comparative genomic hybridization in prenatal diagnosis. Obstet Gynecol 2009;114:1161-1163.

7. Shaffer LG, Coppinger J, Alliman S, Torchia BA, Theisen A, Ballif BC, Bejjani BA: Comparison of microarray-based detection rates for cytogenetic abnormalities in prenatal and neonatal specimens. Prenat Diagn 2008;28:789795.

8. Van den Veyver IB, Patel A, Shaw CA, Pursley AN, Kang SH, Simovich MJ, Ward PA, Darilek S, Johnson A, Neill SE, Bi W, White LD, Eng CM, Lupski JR, Cheung SW, Beaudet AL: Clinical use of array comparative genomic hybridization (aCGH) for prenatal diagnosis in 300 cases. Prenat Diagn 2009;29:29-39.

9. Choy K, Setlur S, Lee C, Lau T: The impact of human copy number variation on a new era of genetic testing. BJOG 2010;117:391-398.

10. Faas BH, van der Burgt I, Kooper AJ, Pfundt R, Hehir-Kwa JY, Smits AP, de Leeuw N: Identification of clinically significant, submicroscopic chromosome alterations and UPD in fetuses with ultrasound anomalies using genome-wide 250k SNP array analysis. J Med Genet 2010;47:586-594.

11. de Jong A, Dondorp W, Timmermans D, van Lith J, de Wert G: Rapid aneuploidy detection or karyotyping? Ethical reflection. Eur J Hum Genet 2011;19:1020-1025.

12. Shuster E: Microarray genetic screening: a prenatal roadblock for life? Lancet 2007;369:526-529.

13. Boormans EM, Birnie E, Oepkes D, Boekkooi PF, Bonsel GJ, van Lith JM; MAKE study groupMembers of the MAKE study group: Individualized choice in prenatal diagnosis: the impact of karyotyping and standalone rapid aneuploidy detection on quality of life. Prenat Diagn 2010;30:928-936.

14. Bui T-H, Vetro A, Zuffardi O, Shaffer LG: Current controversies in prenatal diagnosis 3: is conventional chromosome analysis necessary in the post-array CGH era? Prenat Diagn 2011;31:235-243.

15. Schmitz D, Henn W, Netzer C: Commentary: No risk, no objections? Ethical pitfalls of cell-free fetal DNA and RNA testing. BMJ 2009;339:b2690.

16. Boormans E, Birnie E, Bilardo C, Oepkes D, Bonsel G, van Lith J: Karyotyping or rapid aneuploidy detection in prenatal diagnosis? The different views of users and providers of prenatal care. BJOG 2009; 116:1396-1399.

17. Grimshaw G, Szczepura A, Hultén M MacDonald F, Nevin NC, Sutton F, Dhanjal S: Evaluation of molecular tests for prenatal diagnosis of chromosome abnormalities. Health Technol Assess 2003;7:1-146.

18. Pieters J, Kooper A, Smits A, de Vries J: Parent's attitudes towards full-scale prenatal testing for genetic disorders. J Psychosom Obstet Gynaecol 2009;30:42-47.

19. Hathaway F, Burns E, Ostrer H: Consumers' desire towards current and prospective reproductive genetic testing. J Genet Couns 2009;18:137-146.

20. Ulin PR, Robinson ET, Tolley EE: Qualitative Methods in Public Health. A Field Guide for Applied Research. San Francisco: Jossey-Bass, 2005.

21. Polit D, Beck C: Nursing research: principles and methods. Philadelphia: Lippincott Williams \& Wilkins, 2004.

22. Locock L, Alexander J: Just a bystander? Men's place in the process of fetal screening and diagnosis. Soc Sci Med 2006;62:1349-1359. 
23. Williams R, Dheensa S, Metcalfe A: Men's involvement in antenatal screening: A qualitative pilot study using e-mail. Midwifery 2011;27:861-866.

24. Morse J: Determining sample size. Qual Health Res 2000;10:3-5.

25. Strauss A, Corbin J: Basics of qualitative research: techniques and procedures for developing grounded theory. London: Sage Publications, 1998.

26. Wertz D, Fletcher J, Berg K, On behalf of the World Health Organization. Review of Ethical Issues in Medical Genetics. Geneva: World Health Organization, 2003.

27. Beauchamp TL, Childress JF: Principles of Biomedical Ethics. New York/Oxford: Oxford University Press Inc, 2009.

28. Dworkin G: The theory and practice of autonomy. Cambridge: Cambridge University Press, 1988.

29. Health Council of the Netherlands. Screening: between hope and hype. Publication no. 2008/05. The Hague, Health Council of the Netherlands, 2008

30. de Jong A, Dondorp W, de Wert G: The scope of prenatal diagnostic testing for chromosomal aberrations: broad or narrow? Ethical considerations on the choice of tests. Ned Tijdschr Geneeskd 2009;153:A1060.

31. Tymstra T: 'At least we tried everything': about binary thinking, anticipated decision regret, and the imperative character of medical technology. J Psychosom Obstet Gynaecol 2007;28:131.

32. O'Connor A, Jacobsen M, Stacey D: An Evidence-Based Approach to Managing Women's Decisional Conflict. J Obstet Gynecol Neonatal Nurs 2002;31:570-581.

33. Emanuel E, Emanuel L: Four models of the physician-patient relationship. JAMA 1992; 267: 2221-2226.

34. García E, Timmermans D, van Leeuwen E: Reconsidering prenatal screening: an empirical-ethical approach to understand moral dilemmas as a question of personal preferences. J Med Ethics 2009;35:410-414.

35. Marteau TM, Dormandy E: Facilitating Informed Choice in Prenatal Testing:How Well Are We Doing? Am J Med Genet 2001;106:185-190.

36. Ahmed S, Bryant LD, Tizro Z, Shickle D: Interpretations of informed choice in antenatal screening: A crosscultural, Q-methodology study. Soc Sci Med 2012;74:997-1004.

37. Lumley M, Zamerowski S, Jackson L, Dukes K, Sullivan L: Psychosocial correlates of pregnant womens attitudes toward prenatal maternal serum screening and invasive diagnostic testing: beyond traditional risk status. Genet Test 2006;10:131-138.

38. Potter B, O’Reilly N, Etchegary H Howley H, Graham ID, Walker M, Coyle D, Chorny Y, Cappelli M, Boland I, Wilson $\mathrm{BJ}$ : Exploring informed choice in the context of prenatal testing: findings from a qualitative study. Health Expect 2008;11:355-365.

39. Caughey A, Washington A, Kuppermann M: Perceived risk of prenatal diagnostic procedure-related miscarriage and Down syndrome among pregnant women. Am J Obstet Gynecol 2008 198: 333.e1-8.

40. Chiu RW, Akolekar R, Zheng YW, Leung TY, Sun H, Chan KC, Lun FM, Go AT, Lau ET, To WW, Leung WC, Tang RY, AuYeung SK, Lam H, Kung YY, Zhang X, van Vugt JM, Minekawa R, Tang MH, Wang J, Oudejans CB, Lau TK, Nicolaides $\mathrm{KH}$, Lo YM: Non-invasive prenatal assessment of trisomy 21 by multiplexed maternal plasma DNA sequencing: large scale validity study BMJ 2011:342:c7401.

41. Bianchi D, Platt L, JD G, Abuhamad A, Sehnert A, Rava R: Genome-Wide Fetal Aneuploidy Detection by Maternal Plasma DNA Sequencing. Obstet Gynecol 2012;119:890-901.

42. Lo YM, Chan KC, Sun H, Chen EZ, Jiang P, Lun FM, Zheng YW, Leung TY, Lau TK, Cantor CR, Chiu RW. : Maternal plasma DNA sequencing reveals the genome-wide genetic and mutational profile of the fetus. Sc Transl Med 2010;2:61ra91.

43. Fan H, Gu W, Wang J, Blumenfeld Y, El-Sayed Y, Quake S: Non-invasive prenatal measurement of the fetal genome. Nature 2012; 487: 320-324.

44. Aune I, Möller A: 'I want a choice, but I don't want to decide' -A qualitative study of pregnant women's experiences regarding early ultrasound risk assessment for chromosomal anomalies. Midwifery 2012;28:14-23.

45. Kuppermann M, Norton M: Prenatal testing guidelines: time for a new approach. Gynecol Obstet Invest 2005; 60 6-10.

46. Mays N, Pope C: Qualitative research: rigour and qualitative research. BMJ 1995;311:109-112.

47. Press N: Qualitative research: Thoughts on how to do it; how to judge it; when to use it. Genet Med 2005;7:155158. 



\section{Chapter 8}

The new genetics and informed consent: differentiating choice to preserve autonomy

Bunnik EM, de Jong A, Nijsingh $\mathrm{N}$, de Wert GMWR

Bioethics 2013;27(6):348-355 


\begin{abstract}
The advent of new genetic and genomic technologies may cause friction with the principle of respect for autonomy and demands a rethinking of traditional interpretations of the concept of informed consent. Technologies such as whole-genome sequencing and microarray based analysis enable genome-wide testing for many and heterogeneous abnormalities and predispositions simultaneously. This may challenge the feasibility of providing adequate pre-test information and achieving autonomous decision-making. These challenges are presented for three different areas in which these so-called 'new genetics' technologies are increasingly being applied: newborn screening, prenatal screening strategies and commercial personal genome testing. In this paper, the discussion will build upon the existing ethical framework for a responsible set-up of testing and screening offers and some of its criteria will be reinterpreted in the light of the new genetics. It will be argued that the scope of a responsible testing or screening offer should align with the purpose(s) of testing and with the principle of respect for autonomy for all stakeholders involved, including (future) children. Informed consent is a prerequisite but requires a new approach. Preliminary and general directions will be presented for an individualised or differentiated set-up of the testing offer and for the informed consent process. The discussion in this paper may contribute to the formation of new ideas on how to tackle the issues of autonomy and informed consent for (public) healthcare and direct-to-consumer applications of the new genetics.
\end{abstract}




\subsection{Introduction}

Since the completion of the Human Genome Project in the early 2000s, worldwide research in human genetics has included the study of both specific genes (genetics) and genomes in their entirety (genomics), and has led to the development of increasingly rapid, simple and financially attractive technologies for the mapping and the scrutinising of (parts of) the human genome, which are called the 'new genetics'. The most frequently used and promising techniques are micro-array based analysis and whole-genome/whole-exome sequencing (referred to as WGS and WES, respectively) (See: Box: 8.1). In the practice of (public) healthcare, these new technologies are increasingly replacing traditional test procedures. WGS is expected to be broadly implemented within the next couple of years. ${ }^{1}$ In prenatal screening, conventional karyotyping (See: Box 8.1) is being replaced by genomewide array-based techniques ${ }^{2}$, and the dropping costs of the new genetics may also bring about their application in newborn screening programmes. ${ }^{3,4}$ Some commentators even claim that in the near future every individual child will be 'profiled', leading to enhanced options for treatment and prevention later in life. ${ }^{5}$ Moreover, the new genetics has found its way to the public outside of healthcare systems, through direct-to-consumer (DTC) marketing, often without the involvement of healthcare professionals. ${ }^{6}$

The new genetics significantly increase the chance of identifying relevant disorders, but also of revealing 'incidental' and possibly unwanted findings. In fact, whole-genome tests routinely reveal such findings, not only about the testee but possibly about his or her close relatives as well. Generating all this information may be welcomed insofar testees are able to understand it and willing to use it for preventive strategies or reproductive decisionmaking. However, this information will not merely be beneficial, but may cause harm as well. If testees become confused and anxious due to test outcomes, or if they are wrongly reassured by false-negative test results, this may adversely impact their health. Therefore, decisions regarding what information (not) to generate through a genome-wide test and (not) to report back to testees should be made carefully and take into account both the possible benefits and burdens of receiving such information.

Genome-wide tests do not necessarily yield so much information. The analysis of the data set generated by microarray or whole-genome sequencing technologies can be very broad in scope, but it can just as well be restricted to one single disease or to a few abnormalities only. In the public health and clinical context, there are established medical and ethical criteria for determining the scope of a responsible testing or screening offer. ${ }^{7}$ Basically, a test should be "meaningful: the condition screened for must be serious, the test highly predictive, and follow-up actions must be available in terms of healthcare interventions." ${ }^{8}$ Also, testing should be preceded by informed consent. 


\section{Box 8.1 | Explanation of testing techniques}

- Whole-genome sequencing (WGS) refers to technologies for sequencing the whole genome: the ordering of all nucleotide bases that constitute an individual's 'genetic blueprint'. This process generates a data set of roughly three billion base pairs.

- Whole-exome sequencing (WES) focuses 'merely' on the exome, being $1 \%$ of the DNA coding for the construction of proteins. Both WGS and WES require further analysis to enable the deduction of meaningful information. This analysis can be conducted on the whole genome (WGA) or whole exome (WEA), or instead focus on specific areas in the sequence only (targeted analysis).

- Microarray based technologies can simultaneously detect hundreds of thousands or millions of single nucleotide polymorphisms (SNPs, common single-base variants in the DNA molecule) across the genome. This can be done quickly, easily and at a relatively low price. SNPs are associated with genetic susceptibilities to common complex diseases. If assembled in a genetic risk profile, SNPs associated with the risk for a particular disease may indicate an overall increased or decreased personal risk for developing that disease. Personal genome tests based on genome-wide SNPanalysis commonly include a multitude of genetic risk profiles.

- Conventional karyotyping allows for the reliable identification of all numerical and structural chromosome abnormalities that are visible by microscope (abnormality size $>3$ to 5 Mega base). Karyotyping is time-consuming and labour-intensive, because it requires the culturing of foetal cells obtained by amniocentesis or chorionic villus sampling, with the aim of obtaining cells at the metaphase stage.

The aim of informed consent is to gather autonomous authorisation of the person involved for an act that would otherwise be an infringement of that person's rights. ${ }^{9}$ Many medical interventions, including genetic testing and screening, require permission, both legally and morally. Informed consent presupposes adequate information, competence, voluntariness and comprehension. ${ }^{10}$ The traditional model for informed consent in the context of genetic testing is derived from clinical genetics, where the testee is offered extensive and nondirective pre-test counselling to enable autonomous decision-making. The testee has a right to know, but also a right not to know genetic information. Guidelines require that -before giving informed consent- the testee should receive and understand at least the following information: "medical facts of the disorder, risk figures, (possible) benefits and harms of testing, limitations of the test, reliability of the test, implications of testing, familial implications, probabilities of inheritance, prevention and treatment, information on available support and alternative choices." ${ }^{11,12}$ Communication of all this information for one disease usually takes much time and often multiple counselling sessions. It is reasonable to assume that such a meticulous procedure will not be feasible in the context of the new genetics. The enormous quantity of information generally involved in genome-wide testing makes it difficult to meet the requirements of comprehension and competence in 
lay testees. Moreover, children and young minors are often incompetent to give informed consent. Therefore, their parents are allowed to represent them and give or withhold consent for medical interventions. As we will show, the legitimacy of such parental consent is not unlimited, since it may infringe upon the child's present and future autonomy rights, including the right not to know.

In this paper, the (pending) implementation of the new genetics will be discussed for three areas: newborn screening, prenatal screening strategies, and DTC personal genome testing. In all three areas, a carefully designed testing offer and adequate informed consent are considered of paramount importance to respect persons' autonomy, to protect testees' rights, and to guard them from being harmed by testing (non-maleficence). As will be shown, the position of (future) children deserves special attention.

\subsection{Three applications of the new genetics}

\subsubsection{Newborn screening: profiling the newborn}

Newborn screening was first conducted in the USA in 1962 and has since been a routine intervention performed on nearly all newborns in many countries. The aim of newborn screening has traditionally been to discover inborn diseases which manifest early and for which safe and easy treatment is available. ${ }^{13}$ Initially, screening aimed at detecting phenylketonuria (PKU), which is (relatively) common, can be reliably diagnosed and is easy to treat. Since the introduction of newborn screening, the different programmes have come to include increasingly more diseases, some of which are less obvious candidates when traditional criteria of treatability and reliability of the test are applied. ${ }^{14}$ As a result, the screening offer has become more diverse and now includes diseases of varying seriousness, treatability and time of onset. The potential harm associated with such expansions have prompted some authors to insist that mandatory newborn screening or screening with minimal informed consent procedures, are no longer acceptable. ${ }^{15}$ Instead, parents should be offered the option to choose whether or not (and to what extent) to have their newborn tested, at least when screening might generate information which is not of immediate medical benefit to the child.

Recent suggestions to further expand newborn screening by means of microarray based technologies or WGS/WES, raise -with a new urgency- the question of informed consent and the standardisation of the screening offer. These new genetic technologies are likely to routinely generate incidental findings. ${ }^{3}$ Furthermore, it has been suggested that newborn screening should be structured as a continuous process instead of a once-and-for-all affair. Such an approach would be in line with the notion of 'profiling' newborns, which implies the 
possibility of creating a 'health dossier' that could be used for the prevention, diagnosis and treatment of diseases in different stages of a person's life. ${ }^{16}$ When considering these options from the perspective of autonomy, two sets of questions stand out.

The first set of questions relates to the standardisation of the offer. On the one hand, the diversification of possible test outcomes seems to give force to the argument that parents should be offered the option of choice. On the other hand, however, the complexity of the material seems to make autonomous choices with regard to preferred test outcomes practically very difficult. How should this tension be resolved? In order to facilitate understanding and decision-making, different categories of potential outcomes could be distinguished. These categories however would be defined by -perhaps paternalisticauthorities beforehand and may thus also limit the options. Can information justifiably be withheld on the grounds that informed consent would not be possible otherwise? ${ }^{17}$

The second set of questions concerns the future autonomy of the child. These arise when late-onset diseases are concerned or when test results are retained and accessed later on in the child's life. Testing for late-onset diseases has traditionally been considered morally unjustified in view of children's right not to know, because it would deprive them of their right to decide (when competent to do so) whether to be tested for these conditions. ${ }^{18}$ Other questions relate to who has access to the information and when, and for how long it should be stored. If we take seriously the possibility of newborn profiling, the accompanying informed consent procedure should address these issues.

\subsubsection{Prenatal screening: Individualised choice}

Prenatal screening strategies for detecting foetal abnormalities were introduced in the late 1960s, initially to prevent the burden and suffering caused by the birth of children affected with serious chromosomal conditions (notably Down's syndrome) and open neural tube defects. This scope has remained rather constant for decades. Screening consisted of a standard one-step test offer that pregnant women could either accept or decline. In the course of time, the aim of prenatal screening shifted to offering pregnant women (and their partners) the opportunity to obtain information about their foetus that they may want to use for their decision whether or not to continue the pregnancy - in short, to facilitate wellinformed, autonomous, reproductive choice. ${ }^{19,20}$ All this time, conventional karyotyping remained the gold standard for diagnostic testing. This practice, however, is now rapidly changing due to an overall tendency towards broadening the scope of screening and diagnostic testing. ${ }^{2}$ Microarray based techniques are being implemented as diagnostic tests in case of ultrasound abnormalities. Some even propose to offer this technique as a onestep screening test to all pregnant women. ${ }^{18}$ 
This development challenges both the traditional scope of prenatal screening and the aim of facilitating autonomous reproductive choice. Until recently, autonomous choice in this context meant being given the opportunity to decide whether or not to accept a standard prenatal test offer, targeted at a limited number of serious conditions only. But since the scope of a standard offer is becoming less obvious, the question arises whether offering a standard test optimally meets the aim of reproductive choice. At first glance, one might assume that reproductive autonomy is best served by maximising the amount of reproductive options and thus by offering array-based techniques that enable broadscope testing. However, it is well known that preferences regarding the scope of prenatal testing differ considerably between and amongst professionals and pregnant women. ${ }^{21,22}$ Therefore, it may be preferable to differentiate the testing offer in such a way that it meets individual women's interests and wishes. Offering an 'individualised choice' -meaning that pregnant women themselves are allowed to determine whether they would benefit more from a comprehensive or a narrow test- may thus better accord with the aim of prenatal screening. However, the merits and feasibility of such a choice are unclear, because of the associated burdens and the difficulties of informed consent in the context of the new genetics. Whether women are offered one broad array-based standard test or a set of testing options to enable individualised choice, in either case they are confronted with a large quantity of complex information. A new approach to informed consent will thus be needed for prenatal screening.

Another problem arises in case prenatal testing identifies a late-onset disease (especially a disease that is untreatable and possibly severe) while the pregnancy is being continued: one would de facto screen a future child. This raises a similar issue to the one raised in the newborn screening context, for the child's right not to know would then be violated. Thus, a dilemma may arise between the reproductive autonomy of the prospective parents and the future child's right not to know. In contrast with the newborn context, obtaining information about late-onset diseases in the prenatal setting may also serve a reproductive interest: prospective parents may want to use this information to decide about termination of the pregnancy.

These issues in the prenatal context -how to serve reproductive autonomy, how to ensure informed consent and how to respect the autonomy of the future child- necessitate a reconsideration of both the aim and the scope of prenatal screening.

\subsubsection{DTC personal genome testing: bypassing the healthcare system}

Thus far, we have discussed two public health applications, but the new genetics is also confronting the public directly through online DTC marketing by private companies. Targeted genetic tests for specific diseases have been available through online DTC services since the 
early 2000s. ${ }^{23}$ As of 2007 , however, a new generation of companies has been offering genetic testing services for multiple diseases simultaneously. For a few hundred dollars, consumers can now order 'personal genome tests' that map hundreds of thousands of genetic variants across the genome and estimate disease risks for dozens of diseases and other phenotypic traits. Today's testing offers include complex diseases, such as cardiovascular diseases, type 2 diabetes, rheumatoid arthritis, psoriasis, Crohn's disease, psychiatric conditions, and many types of cancer, but also pre-conception carrier screening and tests for monogenic disorders. Most services contain pharmacogenomic tests, and some offer 'entertainment' testing and ancestry testing as well. A complete personal genome test can thus be as elaborate as 243 diseases and other traits, in one single purchase. ${ }^{24}$ Accordingly, the aim of DTC testing has shifted from the prediction of an individual's genetic risk for a single disease to something like 'getting to know as much as possible' on the basis of a genome-wide scan. Personal genome testing is thus no longer exclusively medical in nature but has become multi-purpose, and continues to expand its scope.

As a result, one personal genome test can include many different tests for many different diseases and other traits with corresponding different implications at the medical, personal and social level. The standards of pre-test information provision and informed consent used in clinical genetics can hardly be met in a relatively under-regulated commercial context ${ }^{25,26}$, in which professional knowledge, skills and values are often lacking. ${ }^{27,28}$ Lack of adequate information and informed consent may harm consumers both directly and indirectly: directly through the receipt of unwanted and potentially harmful information (e.g. knowing that one is at increased risk for an untreatable or unpreventable disease, such as Alzheimer's disease), and indirectly through misunderstanding or misinterpretation, and associated personal, social and health risks. ${ }^{29,30}$ The inclusion of potentially harmful tests (e.g. for untreatable conditions) goes against the ethical criteria for a responsible screening offer. $^{14}$

Informed consent is needed not only to help prevent the potential harms associated with personal genome testing, but also to help ensure that genetic testing is the result of an autonomous decision rather than the 'inconsiderate' acceptance of a commercial offer. Given the unequalled quantity, complexity and diversity of the information involved in personal genome testing, however, the construction of adequate informed consent and the enabling of autonomous decision-making will be a major challenge. It could be helpful to differentiate the testing offer, to make the aim(s) of testing explicit to the consumer as part of the pre-test information provision process, and to have the scope of testing correspond with these aims. This means that separate informed consent could be asked for (categories of) tests that are associated with different aims - and preferably also for (categories of) tests that are associated with a higher potential for harm. 
A further issue arises when additional stakeholders are taken into account, namely children. Parents are increasingly interested in ordering (DTC) genetic testing for their children, also for late-onset diseases ${ }^{31}$ and diseases for which there are no treatment options ${ }^{32}$, and providers do indeed perform genetic testing in children and minors. ${ }^{33,34}$ This practice runs against the broad consensus among researchers, clinicians and policymakers that predictive genetic testing of children should not be allowed unless there is clear medical benefit to be obtained through early interventions in childhood, which cannot otherwise be attained. ${ }^{35,36}$ Professional guidelines indicate that testing should be deferred until adulthood. ${ }^{37}$ It would be inconsistent to allow private companies to act differently in this regard.

\subsection{Discussion: informed consent and the new genetics}

We have discussed three contexts of the new genetics and their implications for the principle of respect for autonomy. Although the neonatal, prenatal and DTC testing contexts each raise different sets of questions, common issues can be identified. Three main issues merit further ethical reflection and discussion: first, the original aims of testing and screening are subject to change and tend towards increasing choice while not necessarily increasing wellconsidered, autonomous choice. Second, the notion of individualised choice needs fleshing out in the different contexts, with special attention to the variety of stakeholders involved, including (future) children. And lastly, the interpretation and practice of informed consent needs adjustment to meet the challenges raised by the introduction of new genetics.

Since the scope of genetic testing and of screening offers within and outside healthcare is expanding, the aims of testing and screening are shifting accordingly. In newborn screening, direct medical benefit seems no longer the single aim of screening. Parents may benefit from knowing early that their child will develop a disease in childhood or is carrier of a mutation, because they can use the latter information to decide about future pregnancies. Also in DTC personal genome testing, the aims of testing seem to include broader notions of utility. Testing for incurable diseases such Alzheimer's disease, for example, may help atrisk individuals to prepare for the future. ${ }^{38}$ In all three contexts, however, it holds that more choice is not necessarily better than less, because choices imply costs as well as benefits: they require time and resources, and they entail burdens and responsibilities. ${ }^{39}$ As a result, maximising information or choice is not always beneficial, but may as well undermine comprehension and autonomous decision-making. ${ }^{40}$ Respect for autonomy and adequate informed consent thus seem to demand a trade-off between maximising choice on the one hand, and keeping information relevant and comprehensible on the other hand.

The notion of individualised choice requires serious ethical consideration. Irrespective of whether tests have a narrow or broad scope, a standard offer means that the scope of 
testing is determined by others than testees themselves (with 'testees' we now refer to pregnant women or couples, parents of newborns and/or adult individuals to be tested). On the one hand, standard offers may fail to take into account the different preferences of testees. Ignoring the technological possibilities to enable testees to take some control over the scope of testing and screening, and opting for a traditional 'take it or leave it' approach would be difficult to justify, as it would disregard opportunities to improve autonomy. On the other hand, it will not be feasible nor desirable to give individuals complete control over the testing process. In the prenatal setting, for instance, not all parental wishes regarding genetic testing in their unborn children should be granted, as they may run counter to the principle of respect for the autonomy of the future child. The (legitimate) purpose of prenatal screening is not to offer limitless insight into the genetic make-up of a future child. A similar issue applies to newborn screening programmes: parental control over the screening offer could and should be limited, in cases of harm to the child or disrespect for the autonomy of the adult-to-be. As a general contention, the right to self-determination of the child may trump parental choice.

When considering individualised choice, it is important to acknowledge all stakeholders involved, particularly the future child and the adult to-be. Thus, the principle of respect for autonomy may be best served through a middle way between a standard offer and individualised choice: a differentiation and pre-structuring of the testing or screening offer, a 'menu of options ${ }^{\prime 41,42}$ from which testees may legitimately choose. With regard to (the aim of) prenatal screening this means that testing options should be limited to conditions that meet a clear reproductive interest of the prospective parents ${ }^{18}$, in order to avoid harming the future child's autonomy rights. A form of 'conditional access' would be needed and require thorough genetic counselling. ${ }^{2}$ Pregnant women should be strongly discouraged from having their foetus tested for late-onset disorders if they are not willing to terminate the pregnancy in case a mutation is found. Conditional access would mean that the traditional non-directive character of counselling should be abandoned. Obviously, however, it would not only be difficult, but also undesirable to enforce abortion in case of a positive test result. Ultimately in these matters, voluntariness remains a basic ethical requirement. But it should be clear that testing for (genetic susceptibilities to) late-onset diseases should preferably not be conducted in pregnancies which -regardless of test outcomes- will be carried to term, that is to say: not in future children.

Finally, the notion of informed consent itself may need revision in light of the new genetics. There are important differences between the tests included in broad testing or screening offers, both in terms of clinical validity and utility (some may be highly predictive and have implications for clinical decision-making, others less so) and in terms of characteristics of diseases tested for. ${ }^{43}$ For example, not all persons will want to know their genetic risk 
for diseases for which there are no treatment or preventive options ${ }^{44}$, or for psychiatric diseases. ${ }^{45}$ In the DTC context, such information may come as a terrible surprise for consumers who have purchased a very broad personal genome test without much thought to its precise contents, without having given informed consent, and thus without (mental) preparation for the receiving of such test results. ${ }^{30}$ Differentiation of the testing offer and adequate procedures for informed consent will be indispensable protective shields against the potential harms of expanding genetic testing and screening offers, whether offered within (public) healthcare or outside.

The aim of informed consent in the context of the new genetics should in our opinion be to improve informed and autonomous decision-making with regard to genetic testing and screening. As a consequence of the quantity, complexity and diversity of information possibly involved, detailed and specific consent will simply not be possible. Therefore, informed consent requires a new model. Generic consent, which focuses on general concepts and common-denominator issues ${ }^{46}$, seems a viable and often-mentioned alternative. But ideally -and in line with the proposed differentiation and pre-structuring of the testing offer-a generic consent process should also be differentiated, for if pre-test information is too generic, it may fail to constitute informed consent. The aim is to render pre-test information manageable and comprehensible in order to maximise understanding, without failing to convey important messages about the different versions of testing offers and to enable considered and informed decisions with regard to the scope of testing to be conducted. Generic but differentiated consent should allow persons to opt out of receiving information about themselves or their children that they may not wish to receive or that may harm them. The facilitation of informed consent for an 'individualised' version of a testing or screening offer is a minimal condition for any responsible offer of a genetic (screening) test. Empirical research will be needed to determine effective ways of designing adequate consent procedures in the context of the new genetics.

\subsection{Concluding remarks}

New genetic and genomic technologies such as microarrays and whole-genome or wholeexome sequencing technologies are technical means to generate genetic and genomic data, not medical tests in themselves. They have, however, brought along a tendency to expand the scope of testing and screening. Three areas have been discussed in which new genetics technologies are currently gaining ground - newborn screening, prenatal screening and DTC personal genome testing - and the implications of expansions of testing offers for the principle of respect for autonomy and informed consent. It has been discussed that an expansion of testing offers may yield valuable information and medical benefit, and may enhance autonomous (reproductive) choice. There are however moral limits to 
these expansions. When testing (unborn) children, the right not to know and the right to self-determination of the (future) child should be respected. This means that the scope of newborn screening should be restricted to childhood diseases only, and that access to prenatal testing for late-onset diseases should be conditional. DTC personal genome testing should not be conducted on children or minors.

The new genetics enable testees to have a say in determining the scope of testing and screening offers, and thereby to improve autonomous decision-making with regard to genetic testing or screening. To achieve this, standardised approaches to the design of testing and screening offers may need to be replaced by differentiated or individualised approaches that take into account individual informational preferences. In the context of newborn screening programmes, for instance, this means that there are strong ethical arguments for allowing parents to choose whether or not to have their newborn child tested for childhood diseases for which there are no therapeutic or preventive options.

Still, due to the quantity, complexity and diversity of the information involved in genomewide tests, the new genetics may threaten comprehension of pre-test information and thus hinder informed decision-making. The traditional model of detailed informed consent is no longer tenable for genome-wide genetic tests. Therefore a generic but differentiated approach to informed consent has been supported instead, which aims to convey important information about (categories of) diseases tested for and to enable informed and autonomous decision-making for or against specific versions of the testing offer. By placing limits on the scope of testing and by requiring generic but differentiated consent, a morally responsible design of genetic testing and screening practices -respecting the individual autonomy of both adults and (future) children- may be possible.

\section{Acknowledgements}

This paper is the result of a symposium held at the World Congress of the International Association of Bioethics (IAB) in Rotterdam in June 2012. The research projects of Eline Bunnik (EB), Antina de Jong (AdJ) and Niels Nijsingh (NN) are funded by the CSG Centre for Society and the Life Sciences in The Netherlands, as part of the Netherlands Genomics Initiative. The projects of AdJ (project number: 70.1.061b) and NN (project number: 70.1.070) are supervised by professor Guido de Wert and dr. Wybo Dondorp at Maastricht University. The project of EB (project number: 70.1.053.1e) is supervised by professor A. Cecile J.W. Janssens at Emory University, Atlanta, and professor Maartje Schermer at Erasmus MC, Rotterdam. We would like to express our thanks to Wybo Dondorp, Cecile Janssens and Maartje Schermer, with whom we have had valuable discussions on the topics of this paper. 


\section{References}

1. Davies K: The \$1,000 Genome: The Revolution in DNA Sequencing and the New Era of Personalized Medicine, New York Free Press, 2010.

2. de Jong A, Dondorp W, Frints S, de Die-Smulders C, de Wert G: Advances in prenatal screening: the ethical dimension. Nat Rev Genet 2011;12:657-663.

3. Solomon B, Pineda-Alvarez D, Bear K, Mullikin J, Evans J: Applying Genomic Analysis to Newborn Screening. Mol Syndromol 2012;3:59-67.

4. Tarini B, Goldenberg A: Ethical Issues with Newborn Screening in the Genomics Era. Ann Rev Genom Hum Genet 2012;13:381-393.

5. Collins F: The language of life. DNA and the revolution in personalized medicine. New York: Harper, 2010.

6. 23andme, "http://www.23andme.com"; Navigenics, “http://www.navigenics.com"; deCODEme, "http:// www.decodeme.com"; Pathway Genomics, "http://www.pathway.com".

7. Dondorp W, de Wert G: The 'thousand-dollar genome': an ethical exploration. The Hague: Health Council of the Netherlands, 2010.

8. European Commission: 25 Recommendations on the Ethical, Legal and Social Implications of Genetic Testing. Brussels: European Commission, 2004.

9. Brownsword R, Beyleveld D: Consent in the Law. Oxford: Hart Publishing, 2007.

10. Faden R, Beauchamp T: A History and Theory of Informed Consent, Oxford: Oxford University Press, 1986.

11. Kääriäinen H, Hietala M, Kristoffersson U, Nippert I, Rantanen E, Sequeiros J, Schmidtke J: Recommendations for genetic counselling related to genetic testing. Leuven: EuroGentest, 2008. Available at: http://www. eurogentest.org.

12. Wertz D, Fletcher J, Berg K. On behalf of the World Health Organization: Review of Ethical Issues in Medical Genetics. Geneva: World Health Organization, 2003.

13. Khoury M, Burke W, Thomson E (eds): Genetics and Public Health in the 21st Century: Using Genetic Information to Improve Health and Prevent Disease. Oxford: Oxford University Press, 2000.

14. Wilson J, Jungner G: Principles and practice of screening for disease. Geneve: World Health Organisation, 1968.

15. Ross L: Screening For Conditions that Do Not Meet the Wilson and Jungner Criteria: The Case of Duchenne Muscular Dystrophy: Am J Med Genet 2006;140A:914-922.

16. HGC UKNSC. Human Genetics Commission and the UK National Screening Committee (Joint Working Group): Profiling the newborn: a prospective gene technology? London, UKNSC, 2005

17. Nijsingh N: Informed Consent and the Expansion of Newborn Screening. In: Dawson A, Verweij M (eds): Ethics, Prevention, and Public Health. Oxford: Oxford University Press, 2007, pp 198-213.

18. Dondorp W, Sikkema-Raddatz B, de Die-Smulders C, de Wert G: Arrays in postnatal and prenatal diagnosis: An exploration of the ethics of consent. Hum Mutat 2012;33:916-922.

19. Health Council of the Netherlands: Prenatal Screening: Down's syndrome, neural tube defects, routineultrasonography. Publication no. 2001/11. The Hague: Health Council of the Netherlands, 2001.

20. van El C, Pieters T, Cornel M: Genetic screening and democracy: lessons from debating genetic screening criteria in the Netherlands. J Comm Genet 2012;3:79-89.

21. Bui T-H, Vetro A, Zuffardi O, Shaffer LG: Current controversies in prenatal diagnosis 3: is conventional chromosome analysis necessary in the post-array CGH era? Prenat Diagn 2011;31:235-243.

22. Grimshaw GM, Szczepura A, Hultén M, MacDonald F, Nevin NC, Sutton F, Dhanjal S: Evaluation of molecular tests for prenatal diagnosis of chromosome abnormalities. Health Technol Assess 2003;7:1-146.

23. DNA Direct: http://www.dnadirect.com.

24. 23andme: http://www.23andme.com. 
25. Borry P, van Hellemondt RE, Sprumont D, Jales CF, Rial-Sebbag E, Spranger TM, Curren L, Kaye J, Nys H, Howard H: Legislation on Direct-to-Consumer Genetic Testing in seven European Countries. Eur J Hum Genet 2012;20:715-721.

26. Hogarth S: Myths, Misconceptions and Myopia: Searching for Clarity in the Debate about the Regulation of Consumer Genetics. Public Health Genomics 2010;5:322-326.

27. Bunnik E, Janssens A, Schermer M: The role of informed consent in direct-to-consumer personal genome testing. In press.

28. Lachance C, Erby L, Ford B, Allen VJ, Kaphingst K: Informational Content, Literacy Demands, and Usability of Websites offering Health-Related Genetic Tests directly to Consumers. Genet Med 2010;12:304-312.

29. Leighton J, Valverde K, Bernhardt B: The General Public's Understanding and Perception of Direct-to-Consumer Genetic Test Results. Public Health Genomics 2012;15:11-21.

30. Messner DA: Informed Choice in Direct-to-Consumer Genetic Testing for Alzheimer and Other Diseases: Lessons from Two Cases. New Genet Soc 2011;30:59-72.

31. Tercyak P, Hensley Alford S, Emmons K, Lipkus I, BS W, McBride C: Parents' Attitudes toward Pediatric Genetic Testing for Common Disease Risk. Pediatrics 2011;127:e1288-1295.

32. Tarini B, Singer D, Clark S, Davis M: Parents' interest in predictive genetic testing for their children when a disease has no treatment. Pediatrics 2009;124:e432-438.

33. Borry P, Howard H, Sénécal K, Avard D: Health-related direct-to-consumer genetic testing: a review of companies' policies with regard to genetic testing in minors. Fam Cancer 2010;9:51-59.

34. Howard H, Avard D, Borry P: Are the kids really all right? Direct-to-consumer genetic testing in children: are company policies clashing with professional norms? Eur J Hum Genet 2011;19:1122-1126.

35. de Wert G: Met het oog op de toekomst: Voortplantingstechnologie, Erfelijkheidsonderzoek en Ethiek. Amsterdam Thela Thesis, 1999.

36. Borry P, Evers-Kiebooms G, Cornel M, Clarke A, Dierickx K, on behalf of the Public and Professional Policy Committee (PPPC) of the European Society of Human Genetics (ESHG): Genetic testing in asymptomatic minors: background considerations towards ESHG Recommendations. Eur J Hum Genet 2009;17:711-719.

37. American College of Medical Genetics: Points to Consider: Ethical, Legal, and Psychosocial Implications of Genetic Testing in Children and Adolescents. Am J Hum Genet 1995;57:1233-1241.

38. Rahman B, Meiser B, Sachdev P, Barlow-Stewart K, Otlowski M, Zilliacus E, Schofield P: To know or not to know: an update of the literature on the psychological and behavioral impact of genetic testing for Alzheimer disease risk. Genet Test Mol Biomarkers 2012;16:935-942.

39. Schwartz B: The paradox of choice. Why more is less. New York: HarperCollins Publishers, 2004.

40. Ormond KE, Iris M, Banuvar S, J. Minogue, Annas GJ, Elias S: What do Patients Prefer: Informed Consent Models for Genetic Carrier Testing. J Genet Counsel 2007;16:539-550.

41. Bredenoord A, Onland-Moret N, van Delden J: Feedback of individual genetic results to research participants: in favor of a qualified disclosure policy. Hum Mutat 2011;32:861-867.

42. Rothstein M: Tiered Disclosure Options promote the Autonomy and Well-Being of Research Subjects. Am J Bioeth 2006;6:20-21.

43. Bunnik E, Schermer $M$, Janssens $A$ : The role of disease characteristics in the ethical debate on personal genome testing. BMC Med Genomics 2012;5:4.

44. Morrison P: Accurate Prevalence and Uptake of Testing for Huntington's Disease. Lancet Neurol 2010;9:1147.

45. Laegsgaard MM, Kristensen AS, Mors O: Potential Consumers' Attitudes toward Psychiatric Genetic Research and Testing and Factors Influencing their Intentions to Test. Genet Test Mol Biomarkers 2009;13:57-65.

46. Elias S, Annas G: Generic Consent for Genetic Screening. N Engl J Med 1994;330:1611-1613. 


\section{Chapter \\ 9}

General discussion 



\subsection{Introduction}

In this thesis, I have focused on three developments in prenatal screening: 1) a narrowing of the scope of testing, 2) an increase in the number of heterogeneous prenatal tests, and 3) a broadening the scope of testing by the application of ever more advanced ultrasound scans and genome-wide testing techniques. The possibility to offer a narrow, rapid aneuploidy diagnostic (RAD) test targeted at trisomies 21, 18 and 13 (and mostly $X$ and $Y$ as well) instead of karyotyping allows for earlier test results and avoids unexpected and unclear findings, but reduces the range of possible outcomes that women may consider relevant for their decision-making. Non-invasive prenatal testing (NIPT) has recently been introduced as a second-tier screening test in the testing cascade for the most common trisomies ${ }^{1,2}$, but expectations are that one-step diagnostic NIPT will eventually replace current twostep testing. If so, this also implies a limitation in the diagnostic scope, unless additional testing is offered. Complementary tests however would complicate the testing trajectory and present the question of what exactly to offer as a supplementary: NT-measurement and invasive diagnostics for other aneuploidies and disorders? Another development is the introduction of broad, genome-wide diagnostic testing for various reasons, but primarily to clarify ultrasound abnormalities found by an increasing number of foetal ultrasound scans throughout the pregnancy. Whereas more comprehensive testing allows for the detection of more clinically relevant abnormalities, it also increases the number of unclear and possibly unwanted findings that are difficult to handle in the prenatal situation. Eventually, genome-wide NIPT might be feasible too., ${ }^{3,4}$ All in all, the scope of testing becomes increasingly indistinct because the various diagnostic techniques allow for both a narrowing and a broadening of the traditional scope, and because an increase in the number and a fragmentation of prenatal tests becomes apparent. This development raises the question what to test for and why, and may ultimately challenge the very aim of prenatal screening: is reproductive autonomy promoted by offering more options or is meaningful choice impracticable when offering more and heterogeneous tests? Other questions are whether the offer of the various tests meets the requirements of proportionality and can be justified in terms of justice.

The aim of this thesis was to provide an ethical analysis of possible implications of narrow, more, and broad prenatal testing. I performed this analysis in relation to the existing normative framework for prenatal screening that will be elaborated below. This led to the identification of various tensions that arise between new prenatal tests and the moral framework for prenatal screening. A secondary goal of this thesis was to explore if the notion of autonomous reproductive choice that is traditionally interpreted as the choice to either accept or refuse a standard test offer, can be given the wider interpretation of offering pregnant women opportunity to individually decide what information they wish to receive 
about their foetus: a so-called 'individualised choice'. Furthermore, I conducted an empirical study amongst stakeholders of prenatal testing in order to explore their considerations and opinions on these issues.

In this concluding Chapter, I will recapitulate and more extensively discuss if and how the introduction of new testing techniques may challenge some of the basic assumptions and normative requirements regarding prenatal screening, and how to resolve these. To that end, the general discussion is divided into three parts. In Part I, the development and content of the current normative framework will be discussed (9.2). Then, I will outline in Part II the three developments mentioned and more deeply explore how these relate to different aspects of this framework: standard narrow testing by RAD and NIPT (9.3); an increase in the number of tests (9.4); and standard broad testing by microarray (9.5). Finally, in Part III, I will explore whether individualised choice can be a meaningful and feasible option for rephrasing the concept of reproductive choice in the prenatal context (9.6) and how the concept of reproductive autonomy needs to be qualified (9.7). 


\section{Part I The normative framework for prenatal screening}

\section{Introduction}

In this first part of the general discussion I will discuss how the normative framework for prenatal screening has developed and been adapted in the course of time. Then, two paradigms of prenatal screening, namely that of prevention and of informed choice, will be discussed. I will clarify how these paradigms influence the way that prenatal screening programmes will be presented and evaluated in practice. Finally, the current aim of prenatal screening, to offer opportunity for reproductive choice, will be placed in the context of these developments and paradigms.

\subsection{Prenatal screening: aims, requirements and paradigms}

\subsubsection{The normative framework for population screening in general}

All population screening programs are similar insofar as they regard a health-care initiated and (mostly) collectively funded test offer to persons who neither have symptoms of illness nor another reason to seek medical help for the condition concerned. In order to justify screening, the test offer has to comply with general ethical and legal principles and requirements - the 'normative framework' for screening. The widely accepted framework for responsible population screening was first formulated by Wilson and Jungner in 1968 on behalf of the World Health Organization (WHO) ${ }^{5}$ (See: Box 9.1). Population screening programs are guided by these WHO-conditions and the most important criteria can be summarised as follows: screening is directed at an important health problem, the offer is acceptable to the population addressed, a reliable and valid test is available, an accepted treatment is available and the screening is cost-effective.

\section{Box 9.1 | Wilson and Jungner classic screening criteria}

1. The condition sought should be an important health problem.

2. There should be an accepted treatment for patients with recognized disease.

3. Facilities for diagnosis and treatment should be available.

4. There should be a recognizable latent or early symptomatic stage.

5. There should be a suitable test or examination.

6. The test should be acceptable to the population.

7. The natural history of the condition, including development from latent to declared disease, should be adequately understood.

8. There should be an agreed policy on whom to treat as patients.

9. The cost of case-finding (including diagnosis and treatment of patients diagnosed) should be economically balanced in relation to possible expenditure on medical care as a whole.

10. Case-finding should be a continuing process and not a 'once and for all' project. 
In the course of time, the underlying principles and the WHO-framework itself were further developed. The moral justification of population screening is based on the three basic principles of Western medical ethics (and health law), namely that of beneficence/nonmaleficence, justice, and respect for persons. The latter principle has only later gained more importance in the screening context and is based on a notion of persons as autonomous agents ${ }^{6}$ having the "right to hold views, to make choices, and to take actions based on their personal values and beliefs." ${ }^{\prime 7}$ Autonomy, as understood in this view and in this thesis, recognises that a person does not live in a social vacuum, but is influenced by personal relationships (peers, friends, family) and by his or her cultural, social and political context. Still, a person can be conceived as autonomous insofar as one has the ability and opportunity to choose in an un-coerced way his or her own course of action based on an individual assessment of the options at hand. In the screening context, the principle of respect for persons requires that decisions about participation and about the course of action in case of an adverse test outcome is made voluntarily and based on adequate information: the well-known concept of informed consent. To secure the irrefutability of the requirement of informed consent, it was explicitly included in later adaptations of the normative framework.

Screening programs not only provide benefits in the sense of possible health gains, but can also induce adverse consequences. Examples are the emotional burden of anxiety and decision-making and the impact of false-positive and false-negative outcomes. Therefore, it should be beyond doubt that the benefits of the unsolicited test offer clearly outweigh the disadvantages. This requirement of proportionality stems from the closely connected principles of non-maleficence (to not inflict harm intentionally) and beneficence (to act for the benefit of persons). ${ }^{7,8}$ Whereas this condition initially focused on the balance between benefits and burdens for the participants, proportionality was later approached in a broader way and included the weighing of pros and cons on the societal level too. In this regard possible discriminatory effects of screening on persons living with the targeted disorders and social pressure on potential participants to accept a test offer, have to be accounted for. Finally, the principle of justice requires that a screening program is justified in terms of a fair distribution of benefits and burdens, and a fair allocation of scarce financial resources. If health care resources are spent on prenatal screening, this means that less resources remain for other forms of health care - possibly including the care and treatment of those affected with abnormalities screened for. This issue of what counts as a justified allocation of resources is too extensive to be addressed here, but is also an important consideration when deciding about the scope and extent of prenatal screening. Justice also requires that equity of access to the screening program is ensured. A good survey of the adaptations made to the initial WHO-framework is provided for by the synthesis of screening criteria by Andermann et al. ${ }^{9}$ (See: Box 9.2). 
Box 9.2 | Synthesis of emerging screening criteria proposed over the past $\mathbf{4 0}$ years*

- The screening programme should respond to a recognized need.

- The objectives of screening should be defined at the outset.

- There should be a defined target population.

- There should be scientific evidence of screening programme effectiveness.

- The programme should integrate education, testing, clinical services and programme management.

- There should be quality assurance, with mechanisms to minimize potential risks of screening.

- The programme should ensure informed choice, confidentiality and respect for autonomy.

- The programme should promote equity and access to screening for the entire target population.

- Programme evaluation should be planned from the outset.

- The overall benefits of screening should outweigh the harm.

*Adopted from Andermann et al. (2008) ${ }^{9}$

\subsubsection{The adapted normative framework for prenatal screening}

Although in many respects prenatal screening resembles other screening programs, there are important differences too. The most important one regards the aim of prenatal screening. Whereas other forms of population screening explicitly aim at health gain by means of preventive measures or treatment, prenatal screening does not. Unless, of course, one strives to maximally prevent the birth of affected children and portrays selective abortion as a means to achieve that. This purpose was indeed implied by earlier publications: “(...) the judicious use of therapeutic abortion (...) could help reduce the incidence of human chromosomal abnormalities." ${ }^{10}$ A less explicit formulation was that reduction of the birth prevalence of specific disorders could be achieved "by identifying (....) couples who can have prenatal diagnosis and selective termination of pregnancy." ${ }^{11}$ These views have been met with criticism and concern. Although women were, of course, not legally obliged to have an abortion in case of an adverse test outcome, it was feared that women in practice felt pressured to do so. 12,13

From the outset of prenatal screening, exactly this issue led and still leads to heavy disputes about the officially professed and by some commentators suspected 'real' aim of screening. ${ }^{14-17}$ Various objections can be discerned. First, prenatal screening was objected to because it would be a form of eugenics, meaning that it aimed to extirpate people with certain disorders and characteristics by means of selective abortion. Various motives could lie at the bottom of this aim: either these people were seen as unfit and inferior, or they were deemed to pose too great a financial burden on society due to the care they needed, or both. There were concerns about social pressure on women to screen and act upon test results which might amount to a form of 'collective eugenics'. ${ }^{13}$ Or, as Lippman put it in 1991: "Prenatal diagnosis necessarily involves systematic and systemic selection of foetuses, most 
frequently on genetic grounds. Though the word "eugenics" is scrupulously avoided in most biomedical reports about prenatal diagnosis except when it is strongly disclaimed as a motive for intervention, this is disingenuous." ${ }^{16}$ Second, according to the so-called 'disability rights critique', selective abortion to prevent the birth of an affected child in the prenatal strategy sends the discriminatory message that the lives of people living with the disorder concerned are less worthy than the lives of those living without it. ${ }^{18,19}$ Closely related to this view is the so-called 'expressivist argument' that contends that not only the act of selective abortion per se, but offering women the opportunity to do so already expresses the objectionable message that the world would be better off without people with diseases and disabilities. In this view, the offer of prenatal screening itself is seen as inherently discriminating because it implicitly communicates that one should aim to select against disease and disability. ${ }^{20}$ If prenatal screening would indeed aim to prevent the birth of children with disabilities, this could mean that women are or at least feel pressured to terminate the pregnancy in case of an unfavourable test outcome and that they be held responsible for the (financial) consequences if they fail to do so. ${ }^{15,21}$

Proponents of prenatal screening however, argued that prenatal screening was done for good reasons, because prospective parents themselves were able to determine whether or not to engage in testing and -in case of an adverse test result- to choose selective abortion. Although screening could result in the prevention of suffering caused by serious health problems as experienced by those concerned, this did not represent a collective preventive aim. It was emphasised that the morally controversial and emotionally burdening option of selective abortion should be and remain an autonomous decision of pregnant women and not become a means for achieving a societal preventive goal. ${ }^{22}$ This individual health care perspective, derived from clinical genetic practice, is oriented towards the individual person and his or her autonomous choices. Still, elements of public health can be recognised in the way the prenatal screening program is implemented, namely population wide, and in the focus on major health related problems. In that respect it is not different from other screening programmes, such as for breast cancer. Prenatal screening is offered population wide to a specific group (pregnant women), is generally collectively funded and follows similar logistic procedures as other screening programs. Because of this twofold background (individual health care and public health programs) prenatal screening has a hybrid character and exactly this may cause the controversies and concerns mentioned above. Because even the semblance of prevention should be avoided in prenatal screening policies, the essential conditions, such as the aim of individual reproductive choice and the condition of informed consent, are to be made more explicit. To achieve that, various refinements and adaptations were indeed made to the general normative framework for population screening. ${ }^{12,13,23}$ 
In order to avoid the ethically problematic implications of the aforementioned preventive purpose and to warrant the acceptability of prenatal screening, its aim has been rephrased. It is generally agreed, at least in most Western countries, that prenatal screening does not aim at prevention, but that it aims to offer pregnant women (and their partners) the opportunity to obtain health-related information about their foetus that enables them to have "practical and meaningful courses of action". ${ }^{24}$ These courses include the choice between terminating an affected pregnancy or preparing for the birth of an affected child. In short, the purpose is to provide autonomous reproductive choice. In this autonomous choice-account of prenatal screening, the meaning of the requirement of informed consent that also applies to other screening programs, is more than just a moral precondition. In that regard, 'consent' may not be the appropriate term. Its interpretation is extended in the sense that providing opportunity for individual's well-informed choice is (or should be) the very aim of offering testing. To ensure the actual realisation of this interpretation, informed consent has been specified in more detail: the test offer has to be presented in a very careful way, with well-balanced and adequate information, and the decision-making should be guided by adequate counselling and support. ${ }^{25-27}$ Thus, informed consent serves as both a precondition and as an objective, albeit that in the latter sense it is generally referred to as informed choice.

Like any other screening program, prenatal screening should be proportional in that the benefits clearly outweigh the disadvantages for participants. It is well-recognised that offering worthwhile reproductive options for participants constitutes an important benefit that should be warranted by valid and reliable testing methods. But unlike other programs, prenatal screening programs are feared to have drawbacks for other individuals and groups in society, more particularly, to negatively impact upon people with disorder(s) targeted by the screening. Therefore acceptance of and adequate care for these groups should be given due consideration in this context. Prenatal screening is for the most part collectively funded in the Western world. Therefore, (distributive) justice requires that not only the immaterial gain of worthwhile courses of action but also the financial consequences should be taken into account. These include the costs of initial and follow-up testing and the costs and gains of the ensuing interventions, including the saved life-time costs for those affected. ${ }^{12,28}$ In that regard, financial considerations can also limit the scope of the prenatal screening. For example, expensive tests for rare -although serious- disorders may not be cost-effective and therefore not be included in the screening offer.

The additions above show how the normative framework for prenatal screening provides for a more detailed and context-specific interpretation of the general framework for screening and of the basic principles of health-care ethics. But the moral acceptability of prenatal 
screening can of course not solely be derived from a professed aim in policy documents or by providers. This acceptability just as much depends on how the program is actually implemented: the autonomy view should not only be professed in theory, but also be shown in how the screening program is performed and evaluated. If, for example, the provision of information and counselling is adequate, but the uptake rates or abortion rates are used as the gauge of success, then the program reflects both an autonomy view and a preventive aim, respectively. ${ }^{21}$ But if information is biased and/or minimal and counselling provided in a directive manner, then the program as a whole reflects preventive perspectives despite the officially proclaimed aim of offering autonomous reproductive choice. Practice will seldom if ever show all characteristics of the autonomy perspective. In that regard, it is understandable that critics sometimes suggest that offering informed choice is not genuinely strived for, but only serves as a façade for a testing strategy that actually aims to prevent the birth of affected children. ${ }^{16,19,21}$ It is therefore vital to examine how a screening program is actually presented and implemented. The challenge will be to ensure as much as possible that the requirements of the autonomy view are met in practice.

\subsubsection{Paradigms of prenatal screening: prevention and informed choice}

The difference between what constitutes a morally acceptable or unacceptable provision of prenatal screening can be clarified by the practical features of the program. When evaluating new prenatal tests and discussing how these relate to the aim and requirements of the normative framework, these features will prove to be helpful in identifying the possible conflicts. To make explicit what possible decisions and motives underlie screening practice, Clarke has articulated some specific features as they would appear in a program that aims either at informed choice or at prevention. ${ }^{29}$ These two contrasting paradigms are in literature referred to as "informed choice-paradigm" or "client-centred framework" as opposed to the "prevention-paradigm" or "health-centred framework"29,30, but essentially the features are reasonably similar. Here, I will present my own characterization of these paradigms as two ideal types, typifying two opposed ends on a continuum. As such they do not represent screening practices in all their elements, but they do reflect the assumptions that may underlie actual screening practices. A short overview of both paradigms is presented in Table 9.1.

The prevention-paradigm can be placed in the context of public health which aims to protect and promote the health of a specific group, population or society at large. Those who criticise prenatal screening for its eugenic and discriminatory aim and character, have a stronger claim if the following features present in the screening practice. Prospective parents will be discouraged to get an affected child, refusal of testing or abortion will be seen as deviant, and professionals are directive and influence participants to choose the 
'right' option, namely to accept testing and to abort in case of an adverse test result. In order to maximise the uptake and the number of selective abortions of affected foetuses, testing is portrayed as routine and as a reassurance for timely prevention, and the provision of information is biased. The focus will be on cost-effectiveness of the program, and its success is defined in terms of the number of affected foetuses identified and of selective abortions, while the socio-psychological impact on participants is considered as of minor importance.

The informed-choice paradigm shows contrasting features. Emerging from the context of individual health care, the principle of respect for persons is a core element. To achieve the goal of enabling autonomous reproductive choice, there is a sustained effort to ensure that uptake is based on adequate and well-balanced information, and that the decision is made voluntary. This means that a person is not forced by coercion, deception or any other undue influence. Participants are supported in their decision-making process with regard to accepting or declining testing, terminating or continuing the pregnancy. For that purpose, professionals adopt a non-directive attitude and provide for adequate pre-test and post-test counselling. The burdens of the program itself for participants are monitored, possible side effects such as discrimination and social pressure are precluded, and care and support for affected people are ensured. The program is evaluated by examining if and to what extent prospective parents are actually enabled to make reproductive choices.

Programs will in reality never coincide with all the features of one ideal type as presented in Table 9.1, but always combine characteristics of both paradigms. The evaluation of whether a program represents more an informed choice-paradigm or is inclined toward a preventive aim, therefore depends on if and to what extent the various conditions are met in practice.

Table 9.1 | Features of paradigms for prenatal screening

\begin{tabular}{|c|c|c|}
\hline Paradigm & Choice & Prevention \\
\hline Context & individual health care & public health \\
\hline \multirow{2}{*}{ Aim } & enable autonomous reproductive choice & reduce birth affected children \\
\hline & avoid suffering & reduce social financial costs \\
\hline \multirow{3}{*}{ Individual } & respect for persons & means to achieve preventive aim \\
\hline & voluntariness & encourage testing and abortion \\
\hline & informed consent & test portrayed as routine \\
\hline \multirow{2}{*}{$\begin{array}{l}\text { Test- } \\
\text { program }\end{array}$} & ensure proportionality burdens - benefits & optimise detection affected pregnancies \\
\hline & prevent discrimination and social pressure & ensure cost-effectiveness \\
\hline \multirow[b]{2}{*}{ Professional } & non-directive attitude & directive attitude \\
\hline & adequate information and counselling & $\begin{array}{l}\text { information biased toward preferred } \\
\text { option }\end{array}$ \\
\hline Evaluation & extent of autonomous choices & number of cases identified / aborted \\
\hline
\end{tabular}




\subsubsection{Autonomous reproductive choice and the scope of prenatal screening}

The dominant view, at least in the Western world, is that prenatal screening programs should be designed according to the choice paradigm. This is also the point of departure for the analysis in this thesis. Still, neither the aim to provide reproductive choice nor the requirements of the normative framework as such do determine the extent of 'autonomous reproductive choice' in prenatal screening programs. In general, the right to reproduce or reproductive freedom stipulates the right to autonomously decide whether one wants offspring, and if so, with whom, the number and spacing of one's children. ${ }^{31,32}$ If this freedom is conceived as a negative right, it means that persons have a right to make their own decisions regarding these reproductive matters, without interference or coercion by others, and as long as no substantial harm for others results from it. If, however, this freedom is interpreted as a positive right, it follows that others can be required to do something that enables a person to exercise her or his freedom regarding reproductive interests. Reproductive autonomy as understood in prenatal screening has both negative and positive components: on the one hand, others (such as professionals) should not pressurise or interfere with persons if they want to use genetic information in reproductive decisions, and on the other hand, these others may be required to make important genetic information available. ${ }^{31}$ The concept of reproductive choice in the prenatal screening context can be seen as a specification of the notion of reproductive autonomy in that its focus is beyond the more quantitative aspects (if, when and how many children), directed at the 'qualitative' aspects or traits of one's offspring. As such, it also combines elements of both negative and positive rights. Others should not interfere with the decision whether or not to engage in prenatal screening or how to act in case of an adverse result (negative right), and prospective parents may require, to a certain extent, that they be given access to information about the foetus in order to make an autonomous reproductive choice (positive right). Still, the range of reproductive choice remains to be defined. As most, if not all, rights, reproductive freedom is not absolute and can be limited or restricted when competing moral considerations necessitate doing so. ${ }^{7,31}$ In a maximum interpretation of reproductive autonomy one would have the freedom to choose whatever characteristics of her or his child, including non-health related traits such as eye colour and cognition. However, in prenatal screening reproductive autonomy has always -albeit implicitly- had a weaker and specific interpretation, and been related to the so-called "medical model" 33 that is limited to health-related traits. Therefore, the extent of reproductive choice in the screening context is not unlimited, but confined by its interpretation within this model. ${ }^{23,34}$ This results from the fact that prenatal screening policies originated from two medical spheres, namely clinical genetics and population screening. Clinical genetic practice concentrated on (prenatal) testing in affected families for serious and specific hereditary disorders in order to avoid the suffering caused by the birth of affected children. Population screening strategies were directed at the prevention and 
treatment of conditions that constituted an 'important health problem' and the scope was also limited by reasons of cost-effectiveness, because screening is collectively funded. There have been attempts to define 'serious genetic conditions' for the purpose of screening, but no consensus can be reached about how to define these. Professionals, policy-makers and the public largely disagree about what counts as a serious condition, due to, for example, differences in perception and variable expression of a disease, evolving treatments and personal situation. ${ }^{34}$ This means that the medical model limits the scope of reproductive autonomy in the screening context, but the contours of the this model are left undefined. However, since the traditional scope (common trisomies and neural tube defects), the traditional testing technique (conventional karyotyping) and the traditional way of offering screening (a package deal: women can only choose for or against a well-defined test offer) has long served as a given and as a reference point in prenatal screening, the scope of autonomous choice in prenatal screening was qualified in practice.

The introduction of new testing techniques has challenged this traditional approach, including the interpretation of the notion of 'reproductive choice'. The development of RAD-techniques and NIPT may limit the scope of testing, while concurrently the number of tests is increasing, and genome-wide diagnostic testing expands the range of abnormalities possibly being identified. Thus, new techniques challenge the range of testing and choice and necessitate to reconsider what autonomous reproductive choice actually refers to in the screening context. Do prospective parents have an unqualified right to be informed about all detectable abnormalities that the foetus may be affected with as long as there is a 'recognised need'?9 Or can the provider justifiably limit the scope of the test-offer and if so, to what conditions and on what grounds? It is important to recall that, apart from the medical model, reproductive choice in this context is also determined by the moral principles and requirements that underlie prenatal screening practice. Respect for persons, feasibility of informed consent and autonomous choice, and proportionality are particularly relevant in this regard. But respect for autonomy, in a positive account, does in itself not imply that a maximum amount of reproductive options has always to be favoured and offered. More choice is not necessarily better than less, because choices imply costs as well: not only in the sense of time, but especially in the sense of emotional burden. ${ }^{6,35}$ In order to pursue the aim of offering autonomous reproductive choice, a decision of what tests to offer requires balancing its possible benefits (reproductive options) against its possible burdens (emotional burden) and ensuring that benefits for those involved are clearly positive (proportionality). On the one hand, a narrow (diagnostic) test offer like RAD or NIPT may limit the burdens, but also restricts autonomous reproductive choice. On the other hand, an increased number of tests and a broad scope, as in microarray testing, may promote autonomy insofar as it maximises prospective parents' options for choice. But more and broader tests may also 
undermine autonomy, if prospective parents are confused by the amount and kind of test outcomes, and if the feasibility of adequate information and support for pregnant women in their decision-making process toward a real autonomous reproductive choice is uncertain.

These considerations show that the preferable scope of autonomous reproductive choice in the prenatal screening context is not easy to define. In part II I will explore how new techniques like RAD, NIPT and microarrays relate to the aim of and different requirements regarding the normative framework for prenatal screening, what this means for the interpretation of autonomous reproductive choice, and how prenatal screening should be offered. 


\section{Part II Dynamics of prenatal testing: challenging the normative framework}

\section{Introduction}

When observing the current prenatal screening strategies, three developments can be noticed that affect the traditional scope of prenatal screening for foetal abnormalities. First, there is a trend toward narrowing down the scope of aneuploidy testing, by means of rapid aneuploidy detection (RAD) techniques and by the recent introduction of non-invasive prenatal testing (NIPT) for trisomies 21, 18 and 13. At the same time, an increase in the number and types of prenatal tests can be noticed. Third, there is a tendency to broaden the scope of testing, by ever more detailed foetal ultrasound scans and by the application of broad testing techniques such as microarrays and -in the future- whole genome/exome sequencing and analysis.

In the discussion about narrowing or broadening the scope of prenatal testing, conventional karyotyping still serves as reference point for the amount and type of foetal abnormalities to be identified: the introduction of RAD has led to a debate about the abnormalities that will be missed or avoided by this test, and the increased yield of microarray-based testing compared to karyotyping, is always mentioned as a major advantage. In the past, for lack of alternatives, there was no reason to question the predominance of conventional karyotyping, and its scope may indirectly also have functioned as the standard interpretation of 'reproductive choice' in prenatal screening strategies. But since some propose to offer RAD as the preferred technique in case of an increased risk for chromosomal aneuploidies, and others to establish microarray testing as the standard in this and several other situations, karyotyping is losing its function as reference point for the pursued scope of prenatal testing and for the interpretation of reproductive autonomy in this context. As a result, both are left unresolved amidst the ongoing technological developments. In this second part of the General discussion, I will reflect on the consequences of the aforementioned developments in the prenatal screening strategy and on how these relate to the normative framework for prenatal screening.

\subsection{Standard narrow test offer - RAD and NIPT}

Down's syndrome and some other aneuploidies remain a major target in first trimester prenatal screening strategies. This is visible in the application of RAD in the Netherlands and a few other West-European countries. Providers explicitly intend to limit diagnostic testing to trisomies 21, 18 and 13 (although the probes tend to include the sex-chromosomes as well). Although the aim of NIPT was to make diagnostic testing safe and early, and not to limit its scope, as yet the scope of testing by NIPT de facto is limited as well. NIPT initially 
focussed on trisomy 21 only ${ }^{1,36,37}$, but increasingly includes trisomies 18 and 13 too. . $^{2,38-40}$ Here I will discuss the ethical implications of this narrow scope of RAD and current NIPT, and show its impact on the prenatal testing cascade. Then, I will look ahead at the possibility to apply a broad NIPT in the future.

\subsubsection{Limitation of diagnostic scope}

As shown in Chapter 2, RAD is introduced as a cheap, fast and targeted diagnostic test that allows informed consent and post-test decision-making to be easier because RAD only targets a few severe and clear abnormalities (except when sex-chromosomal abnormalities are included). The drawbacks are that it may miss clinically relevant abnormalities, and its unfavourable detection/miscarriage ratio. It is precisely this latter reason, the iatrogenic miscarriage risk of invasive procedures, that prompted the development of non-invasive prenatal testing techniques and eventually led to the recent introduction of NIPT in the prenatal testing cascade. As soon as NIPT will be used as a follow-up diagnostic test for trisomies 21,18 and 13 , the narrowing of the diagnostic scope will be similar to that of RAD. This seems to be generally overlooked, since the narrow scope of RAD has been criticised repeatedly, whereas the fact that NIPT de facto narrows the focus to some trisomies as well has evokes less criticism. For now, it is important to realise that both RAD and NIPT limit the scope of testing to trisomies 21,18 and $13 .{ }^{41}$

With the limitation of scope, the range of reproductive choices is limited too. This raises the question whether the limitation is compatible with the existing moral framework of prenatal screening. Clearly, these test offers facilitate reproductive decision-making and allow for adequate informed consent, but then for a few specific abnormalities only. If these narrow tests are offered as a standard, this means that not the users of the test (pregnant women, prospective parents) but the providers (professionals, policymakers) determine what constitutes important knowledge for prospective parents and thus to what range reproductive choice extends. As mentioned before (See: Chapters 2 and 6), the decision to offer a narrow diagnostic test is also based on the logic of the screening strategy ('test what you screen for') and takes the initial scope of screening as its point of departure, rather than pregnant women's preferences. Empirical studies, including my own, have clearly shown that pregnant women are interested in knowing about more, primarily severe and hereditary, abnormalities beyond the traditional aneuploidies. If only a standard narrow test is offered, without giving opportunity for broader testing and taking prospective parents' possible other preferences into account, this may not meet the principle of respect for persons, insofar as autonomous reproductive choice is not being facilitated. As for proportionality, the weighing of the essentials of narrow testing (easy to counsel and decide versus limitation of reproductive options) is very difficult and professionals' and prospective parents' views 
considerably differ in that regard. Given these considerations, RAD and NIPT can be deemed to unjustly limit knowledge about the genetic make-up of the future child and thus restrict autonomous reproductive choice. ${ }^{42}$ This is not to say that offering more reproductive options is always to be favoured: the normative framework for prenatal screening leaves room for and can sometimes even necessitate limiting reproductive options for reasons of beneficence, proportionality and -in case of a state-funded test offer- of cost-effectiveness. But reproductive autonomy may require a broader range of options than a standard offer of RAD or NIPT does provide for.

To solve the issue with regard to the choice between RAD and karyotyping, the concept of individualised choice has been proposed by various commentators, including myself. ${ }^{28,43}$ Although this alternative may add to the emotional and cognitive burden of choice, it seems to comply best -at least in theory- with various features of the choice paradigm: pregnant women are allowed to evaluate the burdens and benefits (proportionality) of alternative tests themselves; autonomous reproductive choice is enabled, and in that regard the principle of respect for persons is respected. Of course, this does require that the individualised choice alternative is implemented in a non-directive way and with adequate pre- and post-test counselling. Only then the pitfalls of e.g. information overload and emotional or decisional overcharge are prevented.

\subsubsection{Limitation of screening scope}

NIPT does so far not serve as a safe substitute for invasive diagnostics for aneuploidies, as initially was and still is intended, but as a second-step risk-assessment tool for the major aneuploidies. In case of an adverse result, confirmation by means of invasive testing is still needed. This means that NIPT does not yet fulfil the promise of being early in the sense that a definitive diagnosis can be made early in pregnancy, that women have more time for deliberating about termination or continuation of the pregnancy, or that selective abortion can be performed earlier. However, the current use of NIPT can substantially reduce the number of invasive procedures needed for diagnosing aneuploid foetuses ${ }^{44,45}$, since the specificity of NIPT for the detection of trisomy 21 is considerably higher than that of the generally applied combined screening test (maternal serum screening and foetal nuchal translucency (NT) measurement). As yet, NIPT is neither cheap nor fast, but the cost of this test is expected to drop in the near future, and the reporting time may be reduced to only a few days. If NIPT will replace the current combined screening test for trisomies 21 , 18 and 13, this would mean that this initial screening will be less informative, since the NTmeasurement that may indicate a broad range of other foetal abnormalities, would then be missed. Does the benefit of NIPT, namely less invasive procedures to diagnose the trisomies because of its high prediction rate and low false positive rate ${ }^{1,37,46}$, outweigh this loss of 
findings in providers' and pregnant women's view? In Chapter 4, I have sketched several scenarios, containing complementary tests, that would be able to compensate for the loss of possible findings. But why bother about this decrease in possible relevant findings? The 'traditional' and current scope of the combined screening test didn't and still doesn't explicitly target these other abnormalities after all, and strictly speaking they could be seen as 'incidental findings' of this screening test. From that perspective, complementary testing can be seen as enabling autonomous reproductive choice, but also as a manifestation of the purpose to maximise the detection of any affected pregnancy. The latter would point in the direction of a prevention paradigm. Therefore, the question whether complementary testing would be necessary or advisable in the choice paradigm is not easy to answer. This very much depends on what risks or abnormalities the supplementary tests actually target, whether pregnant women perceive knowledge about the additional findings as beneficial, how they balance this against the possible increased burden of additional testing, and whether adequate informed consent for these different test offers can be achieved. Would individualised choice offer a solution here as well? To answer this question, a proactive evaluation is needed of whether and to what extent this would actually serve reproductive autonomy.

\subsubsection{NIPT as a one-step diagnostic test in the future}

If NIPT will be offered as a general, $100 \%$ reliable, one-step diagnostic test for aneuploidies to all pregnant women, the information and issues to be dealt with will become conceptually easier, because the difficulties of risk-estimation and iatrogenic miscarriage will be absent. ${ }^{47}$ However, the fact that the choice will be more 'pure' does not mean per se that adequate informed consent is easier to guarantee. Several commentators have argued that an easy, safe and early NIPT may be portrayed as a routine test by providers, may result in a rather thoughtless uptake by pregnant women, and may cause trivialisation of both prenatal testing and selective abortion. ${ }^{48,49}$ In fact, similar consequences may occur in the scenario that NIPT is offered as a second-tier screening test, because then the number of invasive procedures also decreases considerably. Trivialisation of testing and selective abortion may become an even more urgent issue if NIPT will (in the future) be offered for a much broader scope by means of a non-invasive whole genome test ${ }^{50}$ to all pregnant women. However, an increase in uptake and abortion does not necessarily indicate trivialisation, but may as well be a result of well-informed choice. ${ }^{51}$

A recent empirical study about attitudes towards termination of pregnancy for trisomy 21 after NIPT suggests that "more women will choose prenatal screening to gain knowledge without the intentions to terminate the pregnancy." ${ }^{\text {" } 7}$ If this attitude is also present in case of broad diagnostic testing that includes late( $r$ )-onset diseases, the interests of future children should be accounted for and may limit either access to or the scope of testing. Still, if the 
feared effects of trivialisation will indeed occur as a result of NIPT, it will be hard to maintain that prenatal screening allows for autonomous decision-making based on voluntariness and informed consent, because such a test offer will result in an ill-considered uptake that does not meet the generally accepted aim of prenatal screening. As shown in Table 9.1, these consequences are illustrative for a shift from offering opportunity for reproductive choice to maximising the number of affected pregnancies detected, and thus for moving toward the prevention paradigm. In that situation the early, easy and safe character of NIPT will become a disadvantage instead of being the long-sought solution for risky procedures. Is it possible that prenatal screening is too easy and safe to be good? As I have stressed in Chapter 3, the possible and unwanted consequences of NIPT should not be taken as a reason for rejecting this new technology, but as a ground for setting conditions aimed at bringing the test-offer in line with the choice-paradigm. This requires ensuring that prospective parents are always aware of what choice may ultimately be at stake here, namely termination or continuation of the affected pregnancy. As I will show in the next Section this means that the timing and way of offering NIPT has to be considered carefully.

\subsection{More and compound prenatal test offers}

Next to the mentioned techniques that either aim at or de facto result in more narrow testing, there is an inclination to intensify testing throughout the pregnancy and to use the same test for different purposes. The first development causes a fragmentation of testing, leading to an overall increase in test moments and test procedures, and to various scopes of testing. Secondly, it is increasingly the case that the same test has coinciding but conflicting goals, namely reproductive decision-making and pregnancy management: formerly I have referred to this as a heterogeneous compound test offer (See: Chapter 4). I will discuss these two developments in the indicated order.

\subsubsection{Increase in number of tests}

In view of recent technological developments it can be expected that prenatal screening strategies will be extended to include more tests. An example is the possible offer of a standalone NT-measurement and/or serum screening to compensate for the loss of findings if the current combined screening test for trisomies will be replaced by NIPT. Deans and Newson (2012) have compared several alternative strategies of implementing NIPT for trisomies 21, 18 and 13. For that purpose, they assumed that NIPT would be $100 \%$ accurate and could serve as a diagnostic tool. They concluded that, from an ethical point of view, the best option would be to offer all pregnant women NIPT with combined screening for other foetal abnormalities and pregnancy-related conditions. ${ }^{52}$ According to them this alternative "would give choice to the greatest number of women, without introducing problems 
associated with very early testing and loss of potential benefits of combined screening."52 Thus, they seem to assume that the potential increased yield of complementary testing does countervail the possible burden associated with additional testing. This, however, is not evident. ${ }^{6,35}$ Empirical research is needed to study the possible impact of fragmented testing, of sequential choices and of prolonged uncertainty and concern for pregnant women, especially if testing is offered throughout the whole pregnancy. Complementary testing for foetal abnormalities may lead to further (invasive) diagnostic testing or ultrasound scans and this may lengthen the period of what Barbara Katz Rothman has formerly called "the tentative pregnancy" 53 - even to the extent that the whole pregnancy becomes 'tentative'. The possible burden and confusion caused by test offers may also be increased if these aim to detect more and different kinds foetal conditions, as will be discussed in Section 9.5. The more tests are offered, the more reason there is to evaluate in advance whether the choice paradigm of prenatal screening can still be kept up and whether the possible benefits do outweigh the possible burdens. It also calls for carefully monitoring the consequences for pregnant women and society in general, in order to evaluate what increased testing brings about in practice.

\subsubsection{Heterogeneous compound test offer}

Apart from the consequences of an increased number of tests, there is a tendency to use one test for several purposes. An example is the use of the combined screening test to detect increased risk for pregnancy-related conditions such as pre-eclampsia, gestational diabetes, intrauterine growth restriction together with foetal abnormalities. ${ }^{54,55}$ Nicolaides proposes to combine early screening for foetal aneuploides with screening for pregnancy complications such as miscarriages and stillbirths, in one integrated prenatal visit at 11-13 weeks of gestation. ${ }^{56}$ Based on the findings, a more "individualised patient and diseasespecific approach" will become possible. ${ }^{57}$ According to Wortelboer one could think of an "a la carte" program facilitating pregnant women to choose what foetal abnormalities or pregnancy complications they do want or do not want to be tested for. ${ }^{54}$ Although such a program may sound plausible and may seem to do justice to the principle that prenatal screening should be a matter of pregnant women's own choice, there are two problems with it.

First, a combined screening test for foetal abnormalities and pregnancy related complications would search for fundamentally different matters in one go: on the one hand, foetal abnormalities that may be a reason for selective abortion or allow to prepare for the birth of an affected child, and on the other hand a test for treatable pregnancy complications that give reason for adjusted prenatal care or health interventions. This issue is not entirely new, since the same set of different test outcomes can be generated by the 
second trimester (and increasingly also various first trimester) foetal ultrasound scans that all pregnant women are offered and that nearly all of them choose to undergo. According to the International Society of Ultrasound in Obstetrics and Gynecology (ISUOG) practice guidelines the objective of a mid-trimester foetal ultrasound scan is twofold: "to provide accurate diagnostic information for the delivery of optimised antenatal care with the best possible outcomes for mother and fetus" and "to detect congenital malformations". 58 Antenatal care may increasingly include treatment of foetuses in utero as well. ${ }^{59,60}$ The distinction between these objectives may in practice not always be made clear to pregnant women. Moreover, because the scan actually reveals information related to these different objectives simultaneously, in the actual provision of test results these objectives may get mixed up too. ${ }^{61}$ Testing for risks in the category 'pregnancy complications' are more or less taken for granted by practitioners and by most pregnant women, as an act of 'good clinical care'. But when testing is offered in the other category (severe abnormalities in the foetus) this should never be portrayed as 'routine' or as 'a matter-of-course'. When both categories are offered in one and the same go, it can easily be forgotten, or at least become blurred, that regarding the latter type of testing other considerations and choices are at stake that need a fundamentally other balancing of interests and values. Screening to ensure adequate prenatal and perinatal care and to achieve health gains for the mother and/or the foetus/ future child seems an obvious choice that may even allow a more directive attitude of clinicians to comply with testing. However, screening for foetal abnormalities should always be offered in a non-directive way and be based on well-informed decision-making in order to achieve an autonomous reproductive choice. When screening for pregnancy-related care and for foetal disorders will be combined, confusion about the different purposes may arise and that the distinction between the frameworks for good prenatal care on the one hand and for prenatal screening on the other hand may fade away. In order to avoid a blurring of these goals, it will be advisable to combine as little as possible the two different categories of screening in one test, at one moment, and in one counselling session. In the case of foetal ultrasound scans, however, this is practically impossible: then, the different categories of possible test outcomes should be made very clear in the pre-test counselling.

A second concern with a heterogeneous test offered for different purposes and various abnormalities is that the complexity of information and choices increases, which challenges both adequate provision of information and informed autonomous decision-making. This tension will manifest itself increasingly as the range of prenatal testing becomes broader. Again, NT-measurement may serve as an example. This test was initially introduced as part of the risk-assessment test for Down's syndrome, but has gradually and more or less unnoticed developed into a test that actually also aims at finding different abnormalities. An NT $\geq 3.5 \mathrm{~mm}$ may indicate congenital heart defects and various genetic syndromes. This 
means that the combined screening test may result in a need for follow-up testing and may eventually necessitate a decision about selective abortion for another reason than women were prepared for, namely one of the trisomies. Pregnant women are hardly or not at all informed about these possible outcomes in the pre-test counselling. ${ }^{62}$ However, based on the principle of respect for autonomy and the standard of informed consent, pregnant women need in the pre-test situation to be counselled about the fact that the combined screening test may indicate risk factors for other abnormalities as well. A similar situation has actually developed with regard to the aforementioned mid-trimester foetal ultrasound; this was -at least in the Netherlands- primarily offered as a test for neural tube defects such as spina bifida, but may indicate other disorders and pregnancy related risk factors as well. From an ethical perspective, it is favourable that pregnant women should be able to decide themselves for what conditions they want their foetus to be examined. But at the same time it is clear that this is actually impossible in case of increasingly advanced ultrasound scans ${ }^{28}$ and may constitute ethical dilemmas for the clinician. This means that the advancement and expansion of prenatal testing capabilities put the feasibility of the ideal of informed choice under pressure, and therefore call for a reflection on both this ideal and prenatal testing practice.

\subsubsection{From prenatal choice to postnatal treatment}

Some propose to include particular abnormalities in prenatal testing for reasons of early detection in order to expedite possible (postnatal) treatment as opposed to the option of reproductive choice. A recent study suggests that experts in the field of counselling and treatment of persons affected with sex chromosomal aneuploidies (SCAs), consider prenatal diagnosis of a SCA to be beneficial, because, according to them, this allows for early postnatal treatment and support. ${ }^{63}$ Therefore, they recommend to include the sex chromosomes in RAD. In their view, the possible parental decision to terminate a pregnancy because of a SCA identified is an adverse consequence, despite the fact that making a reproductive choice is exactly the reason why RAD is being offered in the first place. Following the line of reasoning of these experts, different abnormalities have to be included in RAD for opposite reasons: either to offer reproductive choice, or to allow for early postnatal treatment. As shown in Section 9.3.2, combining various aims in one test(moment) is problematic in principle, because they require a different attitude of the counsellor. A non-directive attitude should be adopted when testing is offered for reproductive decision-making, whereas a directive attitude may be justified if the foetus can be expected to grow into a future child, if that future child will have a great interest in early postnatal treatment and if prenatal detection of the disorder is of paramount importance for that early postnatal treatment. In general, though, it is not evident that the possible benefit of early postnatal clinical care justifies prenatal testing. 
Regarding the possible benefit of early treatment, it is important to notice that symptoms of incidental prenatal SCAs can vary significantly and may show only a mild clinical phenotype only or no symptoms at all ${ }^{64}$ (See also: Chapter 2). A similar pattern can be seen in case of CNVs (See: Chapter 5). Here I take SCAs as an example. Against this background, the suggestion by Pieters (2012) to dismiss prospective parents' moral right not to know about $\mathrm{SCAs}^{65}$ is far from evident. To justify depriving prospective parents of their right not to know firstly requires that the advantage of specific knowledge for the future child is great and beyond doubt. And even if the postnatal advantage for the future child would be obvious, the question still remains if this requires the identification of the SCA prenatally. Does prenatal identification allow prenatal treatment as well? To my knowledge, prenatal treatment of a SCAs is not possible yet, despite ongoing research in the field of foetal therapy for trisomies. ${ }^{66}$ This means that overruling the right not to know of pregnant women during the pregnancy, cannot be justified. Would, in the absence of prenatal treatment, neonatal testing be advisable or even needed then? Again, this would only be so if neonatal or early childhood treatment would obviously benefit the child. Unless proven otherwise, treatment, if necessary, may be early enough when the child, adolescent or adult actually shows symptoms of a SCA.

A more general issue is that, even if there is a medical advantage to prenatal identification and postnatal early treatment in some cases, the question remains whether this (supposed) therapeutic advantage outweighs the possible drawbacks of not respecting prospective parents' right not to know in the context of RAD. Prenatal diagnosis of a SCA may cause "stigmatisation, damage the child's self esteem, and/or distort the family's perception of the child". ${ }^{65}$ Postponement of testing for SCA until symptoms become apparent, would at least have the advantage of not causing this possible negative impact. Instead, the person may live his or her life happily, healthy and unwittingly of this SCA. Moreover, one has to differentiate between the situation that a pregnant women is already having invasive testing, and the situation that she is not. In the latter case, the miscarriage risk of an invasive diagnostic test has to be accounted for as well.

If the benefit of prenatal diagnosis of SCAs or, for that matter, of any other aberration, for the future child would clearly outweigh the possible drawbacks, then pregnant women should perhaps be persuaded to consent to being tested prenatally. A replacement of the aim of reproductive choice by a therapeutic purpose for the future child means that the choice-paradigm no longer applies, and that, for example, a non-directive attitude of the clinician is no longer required. On the contrary, a directive attitude may be more appropriate given the interests of the future child. 


\subsection{Standard broad test offer - microarrays}

The third development to be discussed is the increasing prenatal use of a broad, genomewide test for various indications in the prenatal setting. In this thesis I focused on microarray testing, that is increasingly being applied as a first or second-tier diagnostic tool. Compared to karytoyping, microarrays can detect more abnormalities, can generate results faster (in only a few days) and can be automated - which makes it less amenable for mistakes. ${ }^{67-69}$ However, compared to karyotyping, microarrays identify more copy number variants of unknown clinical significance (VOUS), which is evaluated differently. Some want to avoid these findings because they complicate counselling and reproductive decision-making, whereas others do not want to miss out on possible clinically relevant variants among the VOUS. These opinions are reflected in the choice for applying either a directed or an undirected array, respectively. Earlier I have proposed to use this designation, because the terms 'targeted microarray' and 'genome-wide microarray' blur the ethical discussion (See: Section 5.3): both types of microarrays search the whole genome for CNVs, while the scope of neither of these arrays is specifically targeted to the initial diagnostic indication in the sense that RAD is adjusted to the scope of the prior risk-assessment for trisomies 21,18 and 13. Therefore, I have re-named the two kinds of microarrays as follows: a directed array focuses on regions throughout the genome known to be associated with clinically relevant abnormalities in order to identify all known CNVs; an undirected array searches the entire genome for both known and unknown CNVs. The term targeted I reserved for tests whose scope is attuned to the diagnostic question. If and insofar as a directed array is applied to clarify ultrasound abnormalities that are in themselves indefinable, it can be said to be targeted. An undirected array, however, can never be targeted.

In this Section I want to examine more closely if and how the prenatal implementation of microarrays does or does not comply with the choice-paradigm for prenatal screening. More specifically I will address the ambiguous character of microarrays, the feasibility of adequate informed consent, and the overall proportionality of applying microarrays prenatally. If, in the future, whole exome/genome sequencing and analysis will be introduced in prenatal screening strategies this will raise similar issues, albeit to an even larger extent.

\subsubsection{Moral ambiguity of microarrays: suitability and equal access}

Testing by microarray is usually performed to clarify foetal ultrasound abnormalities and is thus meant to have a diagnostic aim. In Chapter 5 I have argued that this general representation does not adequately describe what actually happens in this situation, because both a directed and an undirected microarray actually screen the whole genome for CNVs either known to be (directed) or possibly being (undirected) clinically relevant. Thus, microarrays have an ambiguous character. Microarrays are performed for their increased 
yield (around $6 \%$ more findings than karyotyping in case of ultrasound aberrations), but it is not clear what \% of this overall extra yield answers the diagnostic question or has to be labelled as 'unexpected' or 'unsought for' findings. This suggests that not the quality of the results, but the quantity of the results possibly gained by screening the whole genome is the main reason to apply a microarray. Ultrasound abnormalities are then a mere occasion to start this genome-wide search for CNVs. If a screening test is used for a diagnostic purpose, this does not necessarily change that purpose into screening as well. However, a choice for an undifferentiated test that results in identifying as much abnormalities as possible, irrespective of their relatedness to the diagnostic question, raises the question whether such a broad test is necessary and in line with the criteria of proportionality and subsidiarity: in short whether it constitutes a 'suitable test' for a diagnostic setting. To better fit those two criteria as well as the diagnostic aim of the test, the design of the microarray may have to be differentiated per type of (ultrasound) indication.

The use of a wider screening test (microarray) for a diagnostic purpose also raises the question of equal access, because it challenges the justification of offering microarray testing to pregnant women with ultrasound abnormalities whose 'increased risk' is not necessarily related to the possible abnormalities found, and not offering it to other women who can also benefit from it. Some commentators state that reserving prenatal microarray testing for the group with ultrasound abnormalities only would "not be the optimal strategy"70, and propose to offer pregnant women with an increased risk for trisomies 21 , 18 and 13 microarray-based testing as well. ${ }^{71}$ It has also been proposed to consider offering microarrays to a priori low-risk groups, since the detection rate of $>1: 100$ in this group is still above the procedure-related miscarriage risk. ${ }^{68,72}$ Moreover, empirical studies, including my own, show that pregnant women themselves may want to have additional testing beyond that of the traditional scope. ${ }^{73-75}$ These women would benefit from broader testing in the sense that their reproductive options would be increased: testing by microarray significantly adds to the finding of abnormalities in low-risk pregnancies as well, namely $>1-1,7: 100 .{ }^{71,76}$ If the finding of all clinically relevant findings is favoured, the question arises, why only an extra yield of $6 \%$ (in case of ultrasound anomalies) would justify applying this test, whereas a surplus of around 1,5\% would not. After all, the general aim of prenatal screening is defined as offering opportunity for autonomous reproductive choice. Would the interest in such a choice be less in case of the $1,5 \%$ than in case of the $6 \%$ ? If offering directed and undirected microarray testing de facto results in screening, and if this is evaluated as being justified and proportional, then the principle of justice necessitates a reconsideration for the current policy of admittance to this test. Of course, financial costs are a point of consideration in a state-funded testing program. Testing by microarray is for now more expensive than karyotyping or $\operatorname{RAD}^{68}$ and only offered to a subgroup of pregnant women. 
But costs of the test are expected to drop in the near future ${ }^{77}$, and the benefit of higher detection and increased reproductive choice for more women, eventually with alternative funding options, has to be accounted for. As for proportionality, important questions are whether the benefits of an increased yield outweigh the burdens of possibly inducing more unclarity to more women. Moreover, would a general offer of microarray based testing still fit in with a choice paradigm or rather represent important elements from the prevention paradigm of screening, such as optimising the detection of any affected pregnancies as a token of success? This depends, among other things, on the question whether, and if so, how the challenges with regard to requirements of adequate information, counselling, and informed consent can be solved. The borderline between a justified or an unjustified test offer in this particular screening context may turn out to be hard to define.

In the discussion about RAD or karyotyping I have proposed to offer an individualised choice between these two test to pregnant women or the couple (See: Chapter 2). In the context of microarrays this may be an option too with regard to a choice between a targeted and a directed array. In cases where the indication allows for appropriate follow-up testing by a targeted array (namely to explain unclear karyotype results or major ultrasound findings), opting for a directed array would in fact no longer be diagnosis but come down to screening. Prospective parents should be made aware of this, if an individualised choice between a targeted and a directed array is being offered. In Chapter 5 it has been explained that whereas a directed microarray can be justified as a suitable test for prenatal screening purposes, this is unlikely for an undirected one.

\subsubsection{Providing adequate information for microarray testing}

Bernardt et al. found that pregnant women experience microarray testing as "too good to pass up."79 This corresponds with results from my own empirical study that potential users feared anticipated decision regret if they would not accept broad testing (See: Chapter 7). These findings give reason to closely monitor possible intrinsic pressure emanating from the test-offer itself, and to guard that the uptake is well-considered. Adequate information and voluntariness are essential aspects in the choice paradigm (See: Section 9.2.3), and the more these requirements are challenged, the more the choice paradigm is challenged too. This means that adequate information provision, including information about potential adverse consequences of broad testing, are essential to justify the prenatal offer of microarray based testing in the screening strategy.

In the Chapters 5 and 6, I have discussed the intrinsic difficulty of achieving adequate informed consent for microarray based testing and have mentioned attempts to determine categories of findings that may be useful for achieving general consent in the prenatal 
context. To achieve a kind of general consent various solutions have been proposed in the context of genetics and genomics research and direct-to-consumer personal testing, varying from offering "packages"80 to "a menu of options"81. These proposals have in common that they cluster similar disorders and mutations and distinguish between heterogeneous ones, in order to make up a convenient arrangement of options where participants and consumers can choose from. For this purpose several types of disorders have been defined ${ }^{82,83}$ I think that the image of "menus of disorders or mutation panels"84 can also be useful in the context of prenatal testing by microarrays. Test providers do in practice already select what findings they do and do not want to generate. To adequately inform pregnant women about these possible outcomes and to allow them to choose what results to receive or not, providers will have to explicate their own pre-selection on a surveyable menu of options offered to pregnant women.

Does this mean that if equal access, adequate provision of information and voluntariness are guaranteed, that offering microarrays is morally sound? Not necessarily. I have proposed to not include VOUS in a microarray if these are merely included for the sake of research and can be precluded, because they do not contribute to well-considered decision making (See: Chapter 5). Be that as it may, other reasons also necessitate to scrutinise and limit the scope of the actual test offer beforehand, namely conflicting interests and competing reasons for testing.

\subsubsection{Looking ahead - broad to what extent? Microarrays and beyond}

Apart from congenital disorders, a prenatal microarray may also generate, albeit infrequently, information about late(r)-onset disease if caused by a major deletion or duplication, and variants of unknown clinical significance - the VOUS. If, in the future, whole genome and whole exome sequencing (WGS/WES) and analysis (WGA/WEA) will be introduced prenatally, it will occur more frequently that, amongst other things, (predispositions for) late(r)-onset diseases, susceptibilities for complex diseases, and unknown abnormalities will be discovered. ${ }^{82,85}$ Such findings are generally referred to as 'unexpected findings ${ }^{\prime 85-87}$, which are in fact misnomers because these findings are known to be found if no measures are taken against it. In Chapter 8, it has been shown that genome-wide testing in different contexts raise similar ethical questions when such categories of findings are generated. Here, I will more particularly address the ethical issues raised if (in the future) WGS/WES and WGA/WEA are applied in the prenatal setting.

In Chapter 6 I have discussed the difficulties related to untreatable, severe late-onset diseases, such as Huntington disease and hereditary Alzheimer disease, and proposed conditional access to these findings in order to preserve the future child's right not to know. ${ }^{88,89}$ Would 
the same procedure be needed for mutations for conditions that are less penetrant, less devastating or amenable to treatment? This primarily depends on the interpretation of the future child's right not to know. Determining factors may for example be the degree of probability that the condition will indeed develop, the degree of burdens associated, how drastic and burdening possible prevention or treatment will be and at what age this should be started. Knowledge can be beneficial, if prevention strategies can be applied and the disease will either not develop or be milder in its consequences. But information can also be harmful, if certain knowledge does not lead to any health gain but does instead lead to, for example, parental confusion and anxiousness, adverse psycho-social effects on the parent-child relationship and/or stigmatisation of the child..$^{85,90}$ In this situation a future child's welfare may be at stake, because the information affects the parents and the future child in a way that may be harmful to that future child. ${ }^{91}$ As a provisional rule, I would propose to not risk infringing a future child's autonomy, if there is no overriding interest for either the prospective parents or the future child in generating certain genetic information about the foetus. Even more restrictively interpreted: if there is no reproductive interest for prospective parents in knowing this information. After all, the foetus is tested as part of a prenatal screening strategy that aims to facilitate reproductive decision-making and not to gain maximal information about the foetus.

Another disputable category is the foetus' carrier status for an autosomal recessive disease or X-linked disease, that is mostly generated as an 'unsought for' finding. Although this foetus/future child will not be affected by this disease, prospective parents possibly have an interest in this knowledge to establish or exclude their own carrier status which is relevant for a possible next pregnancy in which the foetus may be affected with the actual disease. Despite the fact that this did not constitute the primary reason for wanting a prenatal test, it may be an important reason for wanting to be informed about these findings. This subject has already been much discussed in the neonatal context. ${ }^{92}$ Of course, it is relevant and important information. But if it could be avoided, would it not be more appropriate that these prospective parents get themselves tested instead of gaining this information trough testing their foetus? Another complication of genome-wide (in fact of all genetic) testing is that information generated about the foetus or person actually tested, may also have important implications for the (prospective) parents and other relatives. In case of a prenatal microarray parental samples are often taken together with the foetal sample, to determine if specific foetal alterations are inherited or de novo, and thus to enable a better interpretation of the results found in the foetal sample. ${ }^{68,76}$ This practice leads to dissolving the object of testing too: who actually gets tested? The foetus or the family? This question is not new and there have been discussions as to whether genetic information belongs to the individual or the family, and whether there is a legal and/or moral duty for family members 
and/or clinical professionals to distribute relevant genetic information throughout the family. ${ }^{93-95}$ Apart from that, a question in the prenatal context is whether a possible health benefit for prospective parents and/or other relatives is a justified reason for wanting to be informed about certain findings generated by testing the foetus. Again, I would suggest that if information will not be used for reproductive decision-making regarding this pregnancy, it would be more appropriate to have the parents and/or relatives themselves tested, and to exclude, if possible, such information from prenatal testing arrays. Certainly so, if the future child may have an interest in not knowing that information.

Inclusion of the categories mentioned in a broad prenatal test leads to various ethical complications. One way to avoid these difficulties is to design the test in such a way that unwanted findings about late-onset diseases, susceptibilities and VOUS are not -or at least as little as possible- generated, or to 'filter out' these findings in the analysing phase. ${ }^{85}$ This solution seems to be preferable to the alternatives that such outcomes are generated and known in the laboratory but not passed on to the physician, or that the physician is informed about these findings but withholds these from the prospective parents. Both alternatives may bring the professionals in a situation where they see themselves confronted with conflicting interests and the responsibility of either providing or withholding possible relevant information. The option of filtering out specific information in the design or analysis avoids these problems, although it still not answers the question who is to determine the exact range of such a design or filter. Leaving this to professionals may be at odds with the ideal of reproductive autonomy in the sense that women are enabled to decide for themselves what information they find important. As proposed by several commentators, including myself, information about late( $r$ )-onset should, however, only be included if prospective parents have indicated their intention to use that information for terminating the pregnancy in case of a positive result. ${ }^{88,89,96}$ If not, the future child's right not to know is already violated before its birth.

Whether and if so, to what extent, information about susceptibilities for complex diseases and for other than reproductive purposes should be made available has to be evaluated on the basis of the aim and proportionality of prenatal screening strategies. As argued above, I would suggest to, in principle, not include information that will not be used for the intended reproductive decision-making, unless there is an overriding medical advantage for the future child to be tested prenatally for certain conditions. In the latter case, however, the aim of testing is completely different and a shift of paradigm will take place (See: Section 9.3.3). Given the increasing application of microarrays and the pending introduction of WGS and WES in the prenatal context, it has to be decided upon urgently what scope or design of broad tests is favourable from an ethical point of view. 


\subsubsection{Proportionality: the balance between benefits and burdens}

I have discussed various implications of applying microarrays in the prenatal screening strategy and shown that it involves both benefits and burdens. The question whether offering microarrays is proportional has to be evaluated in relation to its purpose: to what degree does it contribute to reproductive autonomous decision-making, and what are the personal, societal and financial costs to achieve that?

With respect to potential participants of screening, the advantage of microarray techniques is that these can detect more clinically relevant abnormalities and that the turnaround time is faster than in case of conventional karyotyping. Disadvantages are that microarrays may cause more anxiety, complicate pre- and post-test counselling and make decision-making more difficult due to more, heterogeneous and more unclear outcomes. A major challenge is to ensure adequate informed consent and pre-test counselling, in order to prevent that the possible follow-up of an ultrasound scan by microarray testing may result in falling into a so-called 'screening trap'. ${ }^{97}$ If the mentioned burdens and challenges of microarrays can be decreased by offering an alternative test that generates less troubling outcomes while still achieving the goal of offering opportunity for meaningful reproductive decision making in this context, such an alternative has to be favoured. Proportionality is closely related to subsidiarity that requires to choose the alternative, in this case the test, that has the least far-reaching and troubling side effects while still reaching its aim. From that perspective, it is necessary to investigate the viability of modifying microarrays in such a way that they are the most suitable and proportional test for the purpose they serve. A well-adapted microarray can best prevent a blurring of the lines between prenatal and postnatal testing, between clinic and research, and between various purposes of prenatal microarray testing. The "rapid assay"78 that has been proposed by Shaffer et al. may serve as an example of an alternative to RAD, karyotyping and microarrays. This assay includes, beside the common aneuploidies of chromosomes $21,18,13, \mathrm{X}$ and $\mathrm{Y}$, selected loci meeting the following criteria: "the selected syndromes are relatively common among chromosomal disorders; the deletions are not detectable, or may be missed, by karyotype analysis; the syndromes result in a known, definable phenotype or outcome that is relatively severe; the syndrome does not usually present with abnormal ultrasound findings; and the deletion is the major mechanism giving rise to the syndrome." ${ }^{\prime 78}$ This rapid assay can be seen as an in-between for karyotyping and microarrays and shows that it is possible to differentiate tests to a wished for scope. The evaluation of what diagnostic yield is suitable and outweighs the possible disadvantages for individual prospective parents in general is difficult to make because this very much depends on how they themselves evaluate and experience the various pros and cons. It may be an option to develop various tests-platforms that allow to differentiate per indication, purpose and desire, while observing the limits set by others' (i.e. the future 
child's) interests and the overall aim of prenatal screening strategies. Thus an individualised choice between the differentiated tests can be offered.

From a societal perspective, the provision of prenatal screening strategies should take into account the benefits and burdens it involves for other persons and society as a whole, including the requirements proportionality, cost-effectiveness and cost-utility. ${ }^{98,99}$ If the scope of microarray testing is not in line with the indication and reasons it is offered for, it may constitute a kind of 'excessive diagnostics' as some physicians in our empirical study characterised both microarray testing and conventional kayotyping, when offered to pregnant women at increased risk for trisomies 21, 18 and 13 only (See: Chapter 7). Insofar as the diagnostic yield of microarrays outranges the ultrasound abnormalities found, the same can be said about microarray testing in this context. 'Overdiagnosis' is a familiar problem in the context of screening and may lead to a waste of resources in health care. ${ }^{100,101}$ Financial cost-effectiveness is an important aspect in state-funded screening strategies, because society contributes to its financial costs. Microarray techniques themselves are (as yet) more expensive than conventional karyotyping, but cost-effectiveness is not determined by means of the costs of separate tests alone. An important part is also to explicate the (saved) incremental costs for live-born children having an abnormality that can be avoided by offering these different tests. To my knowledge, these net costs of both scenarios have not been studied yet while they are an inextricable part of the justification in publicly funded screening. These are also relevant for determining the cost-utility of prenatal screening ${ }^{99,102}$, albeit the merits of prenatal screening may be particularly difficult to quantify in generic measures as this economic technique requires. What exactly does constitute a 'health gain' in this context, given that the extent in which reproductive choices are facilitated should be taken as the measure of success in the choice-paradigm? A cost-utility analysis comparing prenatal screening strategies along with other types of screening or care will encounter even more difficulties than comparisons of other health-care services. Still this issue has to be addressed in view of the increasing possibilities for prenatal screening.

Finally, Shuster (2007) has argued that microarray technologies will probably undermine the values of autonomy, fairness and non-discrimination ${ }^{103}$, because these broad testing techniques may increase discrimination and social pressure to bear a healthy child. Other commentators, however, argue that if only a few conditions are targeted, a possible discriminating effect is more likely to occur than if testing is directed toward a broad range of abnormalities: after all, "we're all mutants" ${ }^{104}$ when taking into account the range of DNA differences between individuals. In that regard, a possible message of not being welcome in society could either hit us all or none of us. In both cases a discriminatory message would be absent, since it would not be targeted at a few groups of people only. ${ }^{105}$ On the other 
hand, it is argued that a broad scope of prenatal screening will result in a general attitude of less acceptance of all abnormalities in children: they will increasingly be seen as having slipped through the prenatal screening net. ${ }^{103}$ This possible adverse consequence is regularly mentioned by several commentators and in the media. It was also mentioned as a threat by participants in several empirical studies, including my own. ${ }^{103,106}$ What consequences broad prenatal testing will have in practice remains to be monitored and especially to be guarded. It is imperative for the justifiability of any prenatal screening strategy that uptake is always the result of autonomous decision making, i.e. that the decision has come about without undue influence of society and/or professionals, and that adequate care is available for those who need it. The reverse of not offering broader testing out of fear for adverse social consequences is that prospective parents are withheld the opportunity for meaningful reproductive decision-making and avoidance of suffering. 


\section{Part III Reproductive autonomy in context}

\section{Introduction}

In Part I, I have sketched the background of the normative framework for prenatal screening. The choice-paradigm was meant to obviate the main objection to the prevention-paradigm of prenatal screening, namely that screening was used as a societal instrument to prevent disease, just as in other screening programmes. Current prenatal screening programmes are based on the view that prenatal screening can be justified if the programme aims at providing prospective parents with what they themselves regard as meaningful reproductive options, and meets the requirements of, amongst other things, proportionality, non-directivity and informed consent. Prenatal screening has been developed in line with its background in public health and clinical genetics, which both focused on the possible identification of a few (severe) conditions only. Severity and prevalence were decisive factors for including disorders in the screening program. As a result, reproductive autonomy in this context was interpreted in a very narrow sense and meant that (a subgroup of) pregnant women were offered a standard test that they could either accept or decline.

In Part II we have seen that this picture has changed recently. New techniques for detecting the (likely) presence of either a small or a broad range of foetal abnormalities find their way into prenatal screening strategies, causing the scope of testing to be far from evident. Although new tests may be implemented for the sake of presumed 'good clinical care' and create new reproductive options for pregnant women, they do not always fit in with the aim and requirements of the normative framework. On the one hand, tests with a narrow scope (RAD, current NIPT), restrict reproductive decision-making to some specific abnormalities only. This means that reproductive choice for prospective parents is limited, irrespective of their own preferences. Is this an adequate way to interpret the concept of reproductive autonomy in this context? Why focus on Down's syndrome and not include other conditions, for example fragile $\mathrm{X}$-syndrome, that may to some extent have similar phenotypic consequences? Can narrow testing be justified, knowing that pregnant women may want to know about a broader range of conditions? And if one thinks there is a discriminating effect, would this not be stronger if testing focuses on a few abnormalities than if testing includes a broader range of aberrations? On the other hand, broad risk-assessment and diagnostic tests (ultrasound scans and microarray based tests, respectively) for a (genome-) wide range of abnormalities are provided as a standard to (specific groups of) pregnant women. Although a broad scope of testing may be welcomed by some, others may prefer testing to be limited to some serious and clear abnormalities only, in order to reduce the burden of decisionmaking and choice. Since broad tests may lead to many heterogeneous and sometimes unclear findings, it is difficult -if not impossible- to obtain informed consent as traditionally 
understood. Can broad testing then still be said to promote reproductive autonomy, or does it lead to an information overload and undermine reproductive autonomy instead? Moreover, the scope of microarrays often seems rather arbitrarily and not always tailored to the indication pregnant women present with. This leads to unequal access to testing as well.

If, in principle, prenatal testing for both a narrow and a broad scope is feasible, who is then to decide what to test for and why? On what grounds, if at all, can a preconceived test offer be justified? What was meant by the aim of promoting reproductive autonomy, and do earlier interpretations of this concept still hold in the context of current and possible future technological developments? The offer of one standard test has been replaced by the alternative of an individualised choice in one specific situation: women at increased risk for trisomies 21, 18 and 13 are given the opportunity in a few North-West European countries to choose between RAD and karyotyping. By offering this option, women can choose less than the traditional test. But why should reproductive autonomy not equally require that pregnant women are enabled to choose more than what is traditionally provided for in screening strategies? In that scenario, women could be offered a choice between karyotyping and microarrays. Can or should tests be individualised in such a way that the scope is determined by what prospective parents themselves find relevant for their reproductive decision-making?

In this final part III, I will briefly outline why, in my opinion, individualised choice may be a justifiable way to translate the notion of reproductive autonomy in the prenatal screening context. At the same time, I will suggest to further qualify reproductive autonomy in order to do justice to the aim and health care context of prenatal screening, to ensure the feasibility of autonomous choice and to guarantee the future child's interests. I will round off with some concluding remarks.

\subsection{From a standard to an individualised test offer}

The introduction of new techniques in prenatal screening strategies has led to a certain degree of arbitrariness in what abnormalities are included and to whom tests are offered. Moreover, the current cascade of tests does not always meet the preferences of women - and professionals themselves prefer to offer different tests too. An offer of RAD limits pregnant women's autonomous choice and may not correspond with the trade off between benefits and burdens as evaluated by these women themselves (See: Chapter 2). A broad diagnostic test, like microarrays, may neither correspond with pregnant women's preferences, nor suit the purpose of informed decision-making. I have argued earlier that the option of an individualised choice between RAD and karyotyping would be in line with 
the general aim of offering opportunities for autonomous reproductive choice (See: Chapter 2). Likewise, Ganesamoorthy et al. recently found with regard to microarrays that "the issue of balancing the use of the highest resolution arrays to maximise detection against the drawbacks of novel or uncertain findings may best be managed by giving parents the option of high-resolution or low-resolution, targeted, prenatal analysis." ${ }^{\prime 107}$ I think this proposal also comes down to an offer of individualised choice (between an undirected and directed microarray, respectively), although this concept is not mentioned explicitly. Both situations have in common that they concern diagnostic tests -at least theoretically- offered to a preselected group of pregnant women. However, it has become clear in this thesis that current risk-assessment tests may lead to unequal access to diagnostic follow-up testing. Since the aim of facilitating reproductive autonomy is meant to hold for the whole prenatal strategy, this inequality is hard to justify. If we take seriously the classical account of the aim of prenatal screening, it seems that pregnant women themselves should also have a say in what disorders their foetus is to be tested for. Offering an individualised choice may meet this intention. That way, providers and pregnant women can be seen as partners who both contribute to the decision of what test best fits the individual situation and preferences. To some extent this may resemble a form of 'personalised medicine', conceptualised as designating care and tests tailored to the individual concerned. ${ }^{108}$ Applied to the prenatal testing cascade, this would mean that prenatal screening no longer has a system-based approach, taking some targeted abnormalities or techniques as the point of departure, but a more individual-driven approach, in which the choice of the individual pregnant woman (and her partner) are guiding instead.

An individualised-choice scenario means replacing a 'one size fits all'-view for a more patient-specific approach. I propose such a patient-specific, individualised approach to prenatal screening because it better meets a person's wants and preferences, and in that regard contributes to promoting autonomous reproductive choice. In this scenario, pregnant women are made aware that they can be confronted with two different paths of testing throughout the pregnancy: one directed at pregnancy management, the other aimed towards generating information that may be relevant for reproductive decision-making in the sense of termination or continuation of the pregnancy. Regarding the latter path, the preliminary question will be whether pregnant women want to be offered this type of testing at all. In case of a confirmative answer, the follow-up strategy will be to find out for what abnormalities they want their foetus to be tested in order to be allowed a reproductive choice. Can such an approach still be considered prenatal screening in the traditional sense of being a health care initiated test offer to (a specific group in) the population? I think it does, since the initiative to raising the issue of prenatal testing still rests with public health authorities or professionals. But the concept of individualised choice would mean a major 
change in practice, insofar as women themselves are allowed to indicate what (scope of) test they prefer. This can be considered an inverse of the current testing cascade, insofar as the preferred diagnostic scope instead of a risk-assessment for pre-sorted abnormalities becomes leading for the decision of what test to offer. For that purpose, several test options with a varying scope have to be developed and to be made available. For now, an invasive test would be needed to generate a final diagnosis. In the future, one may think of offering NIPT-tests with an alternate scope.

\subsection{Shaping reproductive autonomy in prenatal screening}

Does the concept of an individualised choice mean that 'anything goes' and that prospective parents have to be offered whatever test they wish for? The answer is "no". From an ethical perspective, several factors are relevant with regard to the question what interpretation of reproductive autonomy can be justified in this specific prenatal context. This interpretation subsequently co-determines the possible scope of an individualised choice. A first factor is that promoting opportunity for reproductive choice as such can hardly be seen as a justified aim of a public health program. If the possibility for choice is provided by society, it seems that it should concern a serious health problem and not include trivial health related or non-health related features. Therefore, reproductive autonomy is limited to serious health related features beforehand. Second, the concept of individualised choice sounds great and seems to correspond fine with the aim of promoting reproductive autonomy in theory. But giving pregnant women the opportunity to determine themselves what they want their foetus to be tested for, may in practice undermine rather than promote their autonomy, because of the complexity of that choice. This renders another reason to limit the concept of reproductive autonomy in this context. Third, it has been shown that the future child's right not to know may be violated if prenatal testing is offered without a proviso. Finally, the shifting aims of prenatal screening may necessitate a further restriction. Below, I will address in more detail these aspects on the interpretation of reproductive autonomy.

\subsubsection{The qualified nature of reproductive autonomy}

The two traditions of clinical genetics and public health underlie the scope of prenatal screening and the interpretation of reproductive autonomy in this context. Clinical genetics focused primarily on serious heritable diseases, and the initial WHO-criteria for screening included that "the condition sought should be an important health problem". ${ }^{5}$ In later interpretations the object of screening is described less specific: "The screening programme should respond to a recognised need." 9 If prenatal screening is funded publicly or collectively, as it indeed is in most Western countries, then it should be restricted in such a way that it does meet a state's duty of care and can produce health gains or, in case of prenatal 
screening, options to act on that are not only regarded as worthwhile by those concerned but also by most people in society. ${ }^{12}$ In the prenatal context it can of course be debated what exactly constitutes a worthwhile option, because this is to a great extent determined by the persons concerned. Still, the scope of prenatal screening is at least always connected with health-related features, because of its public health character. This rests on financial considerations too. The principle of distributive justice requires a "fair, equitable and appropriate distribution"7 of financial means. From that perspective, inclusion of more and marginal abnormalities may be hard to justify if this is more expensive than testing for a few severe abnormalities only. This reasoning has played an important part in the traditional and current limitation of prenatal test offers. Advancing technology may in the future allow for diagnostic testing for a wide and heterogeneous range of foetal abnormalities, for example by a broad NIPT. Although the test itself may be relatively cheap, the costs for counselling are likely to increase if adequate informed consent and autonomous decision-making are taken seriously.

Restraint against broadening the scope of prenatal screening to minor abnormalities may also be influenced by the consideration that selective abortion is a possible consequence of this publicly initiated test offer. Abortion is a morally sensitive issue, because of the moral status of the foetus. The generally accepted gradualist view in Western countries is that the status of the embryo/foetus is initially relatively low, but increases with its development. This means that abortion is never a morally indifferent act, and that the interests put forward to justify abortion should be of sufficient importance. In this regard, selective abortion, because of the expected major burden of severe abnormalities is easier to justify than abortion because of milder conditions that would only marginally affect the parents' and future child's life.

In short, the public health character of prenatal screening is likely to retain a limiting effect on the scope of testing and may justify confinement to serious health-related features only. Although it is notoriously difficult to find agreement on what constitutes a serious enough health problem for prenatal screening purposes, there is no getting away from this aspect in the discussion about the scope of prenatal screening.

\subsubsection{Restrict and adapt choices for the sake of autonomy}

In this thesis it has been mentioned several times that it is problematic to demarcate the scope of prenatal screening based on reasons of severity and prevalence of disorders. Severity is evaluated very differently, phenotypes may vary and prospective parents differ considerably in what risk they are willing to accept and what burden they are able or willing to bear. Does this mean that it is not professional societies that should define what conditions are serious enough to screen and abort for, but that this should be left to the actual pregnant woman 
and her individual doctor, as Wertz and Knoppers have suggested a decade ago ${ }^{34}$ This partly holds true, and constitutes a major reason to favour an individualised choice. But I also think that for organisational reasons and for the feasibility of an adequately informed and autonomous choice, some prior limitations to the scope of testing are inevitable. Otherwise, the choice would become too complex to make. The question of what autonomy in the prenatal context means has come up regularly: should the emphasis be on maximising the amount of information and reproductive options or on optimizing and easing the process of decision-making? In the preceding part I have shown that maximising information or options per se may counteract autonomous decision-making, while confining the domain of choice concerned may contribute to the aim of achieving autonomous reproductive choice. One could object that constraining the scope of prenatal screening does always constitute a form of paternalism because it limits reproductive autonomy as such. To a certain extent it does indeed. But I suggest that it may be justified to act paternalistically and limit the scope of prenatal screening beforehand, in order to enable prospective parents to make an autonomous reproductive choice at all.

In this context it is important to realise that the concept of autonomy as an ideal does not necessarily mean that more information leads to a more autonomous choice as well. Not only the amount of information, but also the quality of the decision-making process is relevant in this regard. Although it may be contra-intuitive, one may have to offer less information to enable more opportunity for choice. Phrased otherwise: decision-making may be enhanced by restraining information.

The drawbacks of information overload and difficult decision-making have been mentioned regularly throughout this thesis. Persons may get overwhelmed and confused by the information and decisions they face, and this may impair their capacity to make an autonomous choice. This means that the options and choices offered should not exceed persons' capacities. Dworkin (1988) was one of the first to argue that, from a moral point of view, more is not always preferable to less. However, he also indicates that "(a) decent respect for autonomy of individuals will lead us to be very wary of limiting choices even when it is in the rational self-interest of the individuals concerned." ${ }^{6}$ Therefore, not any restriction of choice is to be welcomed. A justified and appropriate limitation of choices can in his view only be determined by giving due consideration to, amongst other things, the particular purpose, choices, persons, benefits and costs at hand. ${ }^{6} \mathrm{~A}$ similar picture has been drawn by Schwartz in his book 'The paradox of choice. Why more is less'. He describes how people can get lost in the burden and amount of choices they are confronted with and concludes that "we should learn to view limits on the possibilities we face as liberating not constraining." 35 Finally, the discourse of Sunstein and Thaler about so-called "libertarian paternalism" is informative in this regard. ${ }^{109}$ They claim that it is possible to influence behaviour, while also 
respecting freedom of choice. In their view, persons are always influenced somehow by how the context and dilemmas are framed. In that sense, persons do not always make a wellconsidered autonomous choice. Especially not, if it concerns a complicated and unfamiliar domain and the decision has to be made infrequently. I think that prenatal screening can be seen as one of these domains where most prospective parents are confronted with inherently complex and rare decision-making. Of course, persons can still make good choices if they receive adequate information, but "(s)o long as people are not choosing perfectly, it is at least possible that some policy could make them better off by improving their decisions." ${ }^{109}$ Just to be clear, this notion of 'improvement' means setting the conditions for improving their own decisions. From this perspective, paternalism does not always have to involve unjustified pressure or coercion: it may as well determine policies that do not make individual choices impossible, but on the contrary enable and even promote autonomous decision-making. Applied to our prenatal screening case, this means that if providers and/or professionals are allowed to take part in deciding the scope of abnormalities to be included in a prenatal test, the ideal of reproductive autonomy per se need not be limited in an unjustified way.

A challenge is still how to reach adequate informed consent if the test offer would include several test options where prospective parents are supposed to choose from. The need for categorising types of test-outcomes and reshaping the traditional interpretation of informed consent by a model of general consent has been mentioned as a possible solution (See: Chapters 5 and 6). The image of a menu of options has been mentioned in case of microarrays (See: Section 9.5.2) but may be just as useful in this context, when looking for ways to enable individualised choice: while the test providers select what's on the menu, prospective parents are enabled to choose à la carte.

To ensure that prospective parents' views and preferences are taken into account with regard to the scope of testing, the pre- and post-test counselling has to satisfy more than the requirements of adequate information and non-directiveness alone. As proposed in Chapter 7, the 'interpretive model' of the professional-patient relationship as introduced by Emanuel and Emanuel ${ }^{110}$ seems to comply best with what is needed in this situation. This model allows for a collaboration of the professional and the -in our case- pregnant woman to choose the test option that suits the woman's situation and preferences best. To reach that, the professional helps the woman to clarify her own wants and values, and to reach the decision that best fits her. But, as we will see below, the professional is also obliged to complete the moral assessment by making clear that there may be other moral issues that need to be accounted for. In that regard, the woman's own agenda alone is not indicative for the decision-making process. Ethical considerations that have a limiting effect on the available options may need to be discussed. From that perspective, considerations 
put forward by the professional are not noncommittal. They may for example include information and explanation of why certain options cannot or can only conditionally be included in the test offer - for example to safeguard the future child's interests and rights. The professional has a duty to provide this kind of information and considerations that the woman herself is either unaware of or prone to depreciate. In that regard, elements of the 'deliberative model'110 are included as well in this counselling situation.

\subsubsection{Interests of the future child}

An important limiting factor for the interpretation of reproductive autonomy in the prenatal screening context is the interest of the future child. I have discussed earlier the problems that arise if late-onset diseases are included in the test offer (See: Chapters 5 and 6 ). If the predisposition for such a finding is found in the foetus and the pregnancy is continued, the future child's right not to know would be violated. To avoid that, I have proposed (in Chapter 6 and in part II of this Chapter) to not include such findings in a prenatal test if prospective parents do not intend to abort in case of an adverse test result. However, if they want to use this information for their reproductive decision-making, conditional access may be given. This reasoning may apply to other findings as well. I have discussed the case of sex chromosomal aneuploidies (SCAs). As long as the consequences for the future child are unknown but possibly adverse (e.g. emotional harm or burden, negative influence on the parent-child relationship, stigmatisation), would it not be preferable to design the test in such a way that this information will not be generated? In the neonatal and postnatal context it is generally accepted that neonates and children are not tested for (late-onset) diseases that cannot be prevented or treated early in childhood. Similarly, reproductive autonomy as promoted in prenatal screening should not be at the cost of the informational privacy and integrity of the future child.

\subsubsection{The purport of reproductive autonomy}

In policy documents and also in this thesis, reproductive choice is sometimes phrased in terms of 'choosing to continue or terminate the pregnancy'. Currently, prospective parents often choose to terminate a pregnancy if the foetus turns out to be affected by an abnormality. Others want to be tested and informed to be able to prepare themselves for the birth of an affected child. Both options are generally understood as being part of prospective parents' reproductive autonomy. According to a recent study by Verweij et al (2013), the introduction of NIPT is likely to "cause a shift in decision-making in which more women will choose prenatal screening to gain knowledge without the intention to terminate the pregnancy." ${ }^{47}$ 
Reproductive autonomy presupposes that pregnant women are entitled to information about their foetus. Having this information at one's disposal is a necessary condition to realise one's reproductive autonomy. This does however not mean that pregnant women have a right to obtain such information per se: access to information is explicitly for the purpose of one's reproductive autonomy. As reported in the preceding Section, access may be limited for reasons of the interest of the future child. Are there also other reasons to limit the provision of information about the foetus? What exactly is the purport of reproductive autonomy in this regard? It seems to be accepted that obtaining information for the sake of reassurance during pregnancy is part of one's reproductive autonomy. The same goes for preparing oneself for the birth of an affected child. But is the wish to be informed for reasons of curiosity only, part of it too? In view of the ever broadening scope, and the possible increasing ease and safety of (future NIPT) prenatal testing, there is reason to contemplate what exactly should be understood as belonging to one's reproductive autonomy. Would it be reasonable to favour a more narrow interpretation of the aim of prenatal screening, namely that the foetus is only to be tested and prospective parents are only to be informed insofar this is relevant for their reproductive decision to abort or not?

This question is also relevant from the perspective of proportionality and opportunity costs. Will there be a turning point in the scenario described by Verweij et $a /$ ? $^{47}$ If more women only want to be informed about possible health-related peculiarities of their foetus without considering termination of the pregnancy, how should this 'gain of knowledge' on the collective level be balanced against the health gains that can be reached by other types of screening or health-care services? Will it be proportional to continue the prenatal testing cascade, whatever the partition between continuation or termination of pregnancies will be? In view of the developments ahead, there is a need to discuss and examine more closely what can be justified by the aim of reproductive autonomy and what not.

\subsubsection{A compound prenatal test offer}

A specific complication with regard to the aim of prenatal screening is the fact that in practice tests are offered for two colliding reasons simultaneously. On the one hand, testing may aim to identify foetal abnormalities that are relevant for reproductive decision making - the kind of testing that has dominated the discussion in this thesis. On the other hand, testing may be offered to identify pregnancy related problems, either with the mother or the foetus, that need to be treated in order optimise pregnancy outcomes (pregnancy management). I have earlier referred to this situation of combining divergent aims in one test as a 'compound test offer' (See: Chapter 4). The first trimester combined test and NIPTtesting are examples of tests that can indicate and are actually offered for both kinds of reasons. ${ }^{54,58,111}$ Although it may be practical and efficient to combine testing for these two 
purposes in one test and one test-moment, from a moral point of view it is necessary to conceptually distinguish between these different purposes of testing. Professionals' attitude can and should be different in these situations. Whereas non-directivity is a major value in the normative framework for prenatal screening for foetal abnormalities ${ }^{22}$, professionals may have a directive attitude in persuading women to consent in testing that benefits the pregnant woman, the foetus (and future child) or both. It seems that things become confusing if both kinds of tests, requiring a different attitude and leading to different test-outcomes and decision-making consequences, are offered simultaneously. To avoid any misconception in this regard, it seems morally preferable to carry out the conceptual distinction between the two purposes in practice as well: in pre-test counselling, in the actual test offer and in the post-test situation when informing testees about the test results.

The (ever more detailed) ultrasound scans, however, do not allow for a clear distinction between the two purposes and the two kinds of findings in practice. Whether it be NTmeasurement or the extended second trimester foetal ultrasound scan, both identify abnormalities and markers that indicate foetal aberrations and pregnancy complications simultaneously. If, in this situation, the woman has indicated that she does not want to know about foetal abnormalities, but wants to be tested for reasons of pregnancy management, it is impossible to respect her right not to know. The actual ultrasound scan and the interpretation of the image happen in the proximity of the pregnant woman. Professionals cannot help noticing abnormalities, and their (nonverbal) reactions may already reveal that they have discovered 'something'. Moreover, the professional may be in a difficult situation if he or she detects an abnormality that requires adapted prenatal or perinatal care in the interest of the future child. In the future this may also include options for foetal therapy. The only solution then seems to inform the women beforehand about the fact that one aim (pregnancy management) does not come without the other (detecting foetal abnormalities relevant for reproductive decision making), and that in that sense testing by ultrasound scan is an 'all or nothing' deal. Insofar prenatal testing may clearly benefit the future child and does not imply a disproportionate burden to the woman herself, it cannot be considered a noncommittal test offer either. In that regard, shaping reproductive autonomy is not only about making choices, but may involve having duties as well.

\subsubsection{Some final remarks}

With regard to prenatal testing in order to promote reproductive autonomy, an inclination to pursue maximising the yield of testing may run counter to the choice-paradigm. Ever broader testing may render adequate informed or generic consent infeasible, and thus cross the line between a justified and unjustified prenatal screening strategy. For that reason, reproductive autonomy should be qualified. I have outlined some of the qualifying 
aspects. The list above may not be complete and there may be other factors that need to be accounted for when setting out the scope of reproductive autonomy in this particular context. Still, the factors mentioned may serve as elements to consider when contemplating how the normative framework for prenatal screening needs to be supplemented: the aim of prenatal screening needs to be specified, its relation with the medical model needs to be upheld, the traditional account of informed consent has to be adjusted, and the medical and informational interests of future children have to be accounted for. The screening practice is in need for some changes too: one standard test offer seems no longer appropriate, various test options that better accord with women's preferences are to be developed, and the counselling of pregnant women to reach an individualised choice has to be adapted. In the near future, further ethical analysis and empirical research (for instance in the form of pilots exploring specific forms of 'individualised choice') are needed to study whether that way prenatal test strategies can better achieve what they aim for. 


\section{References}

1. Palomaki GE, Kloza EM, Lambert-Messerlian GM, Haddow JE, Neveux LM, Ehrich M, van den Boom D, Bombard AT, Deciu C, Grody WW, Nelson SF, Canick JA: DNA sequencing of maternal plasma to detect Down syndrome: an international clinical validation study. Genet Med 2011;13:913-920.

2. Nicolaides K, Syngelaki A, Ashoor G, Birdir C, Touzet G: Noninvasive prenatal testing for fetal trisomies in a routinely screened first-trimester population. AJOG 2012:374.e371-376.

3. Lo YM, Chan KC, Sun H, Chen EZ, Jiang P, Lun FM, Zheng YW, Leung TY, Lau TK, Cantor CR, Chiu RW: Maternal plasma DNA sequencing reveals the genome-wide genetic and mutational profile of the fetus. Sci Trans/ Med 2010;2:61ra91.

4. Kitzman JO, Snyder MW, Ventura M, Lewis AP, Qiu R, Simmons LE, Gammill HS, Rubens CE, Santillan DA, Murray JC, Tabor HK, Bamshad MJ, Eichler EE, Shendure J: Noninvasive Whole-Genome Sequencing of a Human Fetus. Sci Transl Med 2012;4:137ra176.

5. Wilson J, Jungner G. Principles and practice of screening for disease. Geneve: World Health Organisation, 1968.

6. Dworkin G: The theory and practice of autonomy. Cambridge: Cambridge University Press, 1988.

7. Beauchamp TL, Childress JF: Principles of Biomedical Ethics. New York/Oxford: Oxford University Press Inc, 2009.

8. Chervenak F, McCullough L: Ethical issues in perinatal genetics. Semin Fetal Neonatal Med 2011;16:70-73.

9. Andermann A, Blancquaert I, Beauchamp S, Déry V: Revisiting Wilson and Jungner in the genomic age: a review of screening criteria over the past 40 years. Bulletin of the World Health Organization 2008;86:317319.

10. Steele M, Breg WJ: Chromosome analysis of human amniotic-fluid cells. Lancet 1966;1:383-385.

11. Murray J, Cuckle H, Taylor G, Littlewood J, Hewison J: Screening for cystic fibrosis. Health Technol Assess 1999;3:i-104.

12. Health Council of the Netherlands: Screening: between hope and hype. Publication no. 2008/05. The Hague: Health Council of the Netherlands, 2008.

13. van El C, Pieters T, Cornel M: Genetic screening and democracy: lessons from debating genetic screening criteria in the Netherlands. J Comm Genet 2012;3:79-89.

14. Flessel M, Lorey F: The California Prenatal Screening Program: "options and choices" not "coercion and eugenics". Genet Med 2011;13:711-713.

15. Williams P: Should we prevent Down's syndrome? Br J Learn Disab 1995;23:46-50.

16. Lippman A: Prenatal genetic testing and screening: constructing needs and reinforcing inequities. Am J Law Med 1991;17:15-50.

17. McCabe L, McCabe E: Down syndrome: coercion and eugenics. Genet Med 2011;13:708-710.

18. Parens E, Asch A (eds): Prenatal testing and disability rights. Georgetown: Georgetown University Press, 2000.

19. Reinders SJ: Moeten wij gehandicapt leven voorkomen? Ethische implicaties van beslissingen over kinderen met een aangeboren of erfelijke afwijking. Utrecht: Nederlandse Vereniging voor Bioethiek, 1996.

20. Wilkinson S: Choosing tomorrow's children. The ethics of selective reproduction. New York: Oxford University Press Inc., 2010.

21. Clarke A: Is non-directive genetic counselling possible? Lancet 1991;338:998-1001.

22. de Wert G, Dondorp W: Ethical issues. In: van Vugt M, Shulman K (eds): Prenatal medicine. New York/London: Taylor \& Francis, 2006, pp 575-604.

23. Council of Europe: Recommendation No. R (90)13 of the Committee of Ministers to Member States on prenatal genetic screening, prenatal genetic diagnosis and associated genetic Counselling. 1990.

24. Health Council of the Netherlands: Genetic Screening. The Hague: Health Council of the Netherlands, 1994. 
25. Health Council of the Netherlands: Prenatal Screening: Down's syndrome, neural tube defects, routineultrasonography. Publication no. 2001/11. The Hague: Health Council of the Netherlands, 2001.

26. UK National Screening Committee: NHS Fetal Anomaly Screening Programme - Screening for Down's syndrome. Policy recommendations 2007-2010. Model of Best Practice. 2008.

27. World Health Organisation: Proposed international guidelines on ethical issues in medical genetics and genetic services. Geneva: WHO, 1997.

28. de Jong A, Dondorp W, De Wert G: Ethische reflectie. In: Wildschut H, van Goudoever J, den Hollander N, Keirse E, De Wert G (eds): Foetale en neonatale screening op aangeboren afwijkingen. Leidraad voor besluitvorming. Amsterdam: Reed Business, 2011, pp 405-437.

29. Clarke AJ: Prenatal genetic screening: paradigms and perspectives. In: Harper PS, Clarke AJ (eds): Genetics, Society and Clinical Practice. Oxford: BIOS Scientific Publishers, 1997, pp 119-140.

30. Nordgren A: Prenatal genetic counselling: conceptual and ethical issues. In: Leuzinger-Bohleber M, Engels E-M, Tsiantis J (eds): The Janus Face of Prenatal Diagnostics. A European Study Bridging Ethics, Psycholanalysis, and Medicine. London: Karnac Books, 2008, pp 307-325.

31. Buchanan A, Brock D, Daniels N, Wikler D: From chance to choice. Genetics and justice. Cambridge: Cambridge University Press, 2000.

32. Cook R, Dickens B, Fathalla M: Reproductive health and human rights. Oxford: Clarendon Press, 2003.

33. de Wert G: Prenatal testing and selection: proceed with caution. In: Galjaard H, Noor LHW (eds): Prenatal testing. New developments and ethical dilemmas. Amsterdam: Royal Netherlands Academy of Arts and Sciences, 2003, pp 61-68.

34. Wertz D, Knoppers B: Serious genetic disorders: can or should they be defined? Am J Med Genet 2002;108:2935.

35. Schwartz B: The paradox of choice. Why more is less. New York: HarperCollins Publishers, 2004.

36. Lo YMD, Chiu RWK: Non-invasive prenatal diagnosis of Down's syndrome. Lancet 2007;369:1997.

37. Verweij E, van den Oever J, de Boer M, Boon E, Oepkes D: Diagnostic accuracy of noninvasive detection of fetal trisomy 21 in maternal blood: a systematic review. Fetal Diagn Ther 2012;31:81-86.

38. Ashoor G, Syngelaki A, Wang E, Struble C, Oliphant A, Song K, Nicolaides KH: Trisomy 13 detection in the first trimester of pregnancy using a chromosome-selective cell-free DNA analysis method. Ultrasound Obstet Gynecol 2013;41:21-5.

39. Dan S, Wang W, Ren J, Li Y, Hu H, Xu Z, Lau TK, Xie J, Zhao W, Huang H, Xie J, Sun L, Zhang X, Wang W, Liao S, Qiang R, Cao J, Zhang Q, Zhou Y, Zhu H, Zhong M, Guo Y, Lin L, Gao Z, Yao H, Zhang H, Zhao L, Jiang F, Chen F, Jiang H, Li S, Li Y, Wang J, Wang J, Duan T, Su Y, Zhang X: Clinical application of massively parallel sequencingbased prenatal noninvasive fetal trisomy test for trisomies 21 and 18 in 11,105 pregnancies with mixed risk factors. Prenat Diagn 2012;32:1225-1232.

40. Chen EZ, Chiu RW, Sun H, Akolekar R, Chan KC, Leung TY, Jiang P, Zheng YW, Lun FM, Chan LY, Jin Y, Go AT, Lau ET, To WW, Leung WC, Tang RY, Au-Yeung SK, Lam H, Kung YY, Zhang X, van Vugt JM, Minekawa R, Tang MH, Wang J, Oudejans CB, Lau TK, Nicolaides KH, Lo YM: Noninvasive Prenatal Diagnosis of Fetal Trisomy 18 and Trisomy 13 by Maternal Plasma DNA Sequencing. PLoS ONE 2011;6:e21791.

41. de Jong A, Dondorp WJ, Frints SG, de Die-Smulders CE, de Wert GM: Non-invasive prenatal diagnosis for aneuploidy: toward an integral ethical assessment. Hum Reprod 2011;26:2915-2917.

42. Leung WC, Lau ET, Lau WL, Tang R, Wong SF, Lau TK, Tse KT, Wong SF, To WK, Ng LK, Lao TT, Tang MH: Rapid aneuploidy testing (knowing less) versus traditional karyotyping (knowing more) for advanced maternal age: what would be missed, who should decide? Hong Kong Med J 2008;14:6-13.

43. Boormans EM, Birnie E, Oepkes D, Boekkooi PF, Bonsel GJ, van Lith JM; MAKE study groupMembers of the the MAKE study group: Individualized choice in prenatal diagnosis: the impact of karyotyping and standalone rapid aneuploidy detection on quality of life. Prenat Diagn 2010;30:928-936.

44. Bianchi D, Platt L, JD G, Abuhamad A, Sehnert A, Rava R: Genome-Wide Fetal Aneuploidy Detection by Maternal Plasma DNA Sequencing. Obstet Gynecol 2012;119: 890-901. 
45. Swanson A, Sehnert AJ, Bhatt S: Non-invasive Prenatal Testing: Technologies, Clinical Assays and Implementation Strategies for Women's Healthcare Practitioners. Curr Genet Med Rep 2013;1:113-121.

46. Ehrich M, Deciu C, Zwiefelhofer T, Tynan JA, Cagasan L, Tim R, Lu V, McCullough R, McCarthy E, Nygren AO, Dean J, Tang L, Hutchison D, Lu T, Wang H, Angkachatchai V, Oeth P, Cantor CR, Bombard A, van den Boom D: Noninvasive detection of fetal trisomy 21 by sequencing of DNA in maternal blood: a study in a clinical setting. Am J Obstet Gynecol 2011;204:205.e201-211.

47. Verweij E, Oepkes D, de Boer M: Changing attitudes towards termination of pregnancy for trisomy 21 with non-invasive prenatal trisomy testing: a population-based study in Dutch pregnant women. Prenat Diagn 2013;33:397-399.

48. Benn PA, Chapman AR: Practical and Ethical Considerations of Noninvasive Prenatal Diagnosis. JAMA 2009;301:2154-2156.

49. Wright C. Cell-free fetal nucleic acids for non-invasive prenatal diagnosis. Report of the UK expert working group. PHG Foundation, 2009.

50. Srinivasan A, Bianchi D, Huang H, Sehnert A, Rava R: Noninvasive Detection of Fetal Subchromosome Abnormalities via Deep Sequencing of Maternal Plasma. Am J Hum Genet 2013;92:167-176.

51. de Jong A, Dondorp W, de Die-Smulders C, Frints S, de Wert G: Non-invasive prenatal testing: ethical issues explored. Eur J Hum Genet 2010;18:272-277.

52. Deans Z, Newson A: Ethical considerations for choosing between possible models for using NIPD for aneuploidy detection. J Med Ethics 2012;38:614-618.

53. Rothman BK: The Tentative Pregnancy. Prenatal Diagnosis and the Future of Motherhood, London: Viking Penguin Inc, 1986.

54. Wortelboer E: Screening in early pregnancy; more than Down syndrome alone. PhD thesis. Utrecht: Utrecht University, 2011.

55. Kuc S, Wortelboer E, van Rijn B, Franx A, Visser G, Schielen P: Evaluation of 7 serum biomarkers and uterine artery Doppler ultrasound for first-trimester prediction of preeclampsia: a systematic review. Obstet Gynecol Surv 2011;66:225-239.

56. Nicolaides K: Turning the pyramid of prenatal care. Fetal Diagn Ther 2011;29:183-196.

57. Nicolaides K: A model for a new pyramid of prenatal care based on the 11 to 13 weeks' assessment. Prenat Diagn 2011;31:3-6.

58. Salomon LJ, Alfirevic Z, Berghella V, Bilardo C, Hernandez-Andrade E, Johnsen SL, Kalache K, Leung KY, Malinger G, Munoz H, Prefumo F, Toi A, Lee W; ISUOG Clinical Standards Committee: Practice guidelines for performance of the routine mid-trimester fetal ultrasound scan. Ultrasound Obstet Gynecol 2011;37:116-126.

59. Diemert A, Diehl W, Glosemeyer P, Deprest J, Hecher K: Intrauterine surgery-choices and limitations. Dtsch Arztebl Int 2012;109:603-638.

60. Deprest J, Nicolaides K, Gratacos E: Fetal surgery for congenital diaphragmatic hernia is back from never gone. Fetal Diagn Ther 2011;29:6-17.

61. Getz L, Kirkengen A: Ultrasound screening in pregnancy: advancing technology, soft markers for fetal chromosomal aberrations, and unacknowledged ethical dilemmas. Soc Sci Med 2003;56:2045-2057.

62. Bilardo C, Timmerman E, Pajkrt E, van Maarle M: Increased nuchal translucency in euploid fetuses-what should we be telling the parents? Prenat Diagn 2010;30:93-102.

63. Pieters J, Verhaak CM, Braat D, van Leeuwen E, Smits A: Experts' opinions on the benefit of an incidental prenatal diagnosis of sex chromosomal aneuploidy: a qualitative interview survey. Prenat Diagn 2012;32:11511157.

64. Pieters J, Kooper A, van Kessel A, Braat D, Smits A: Incidental prenatal diagnosis of sex chromosome aneuploidies: health, behavior, and fertility. ISRN Obstet Gynecol 2011;2011:807106.

65. Pieters J: Incidental findings of sex chromosome aneuploidies in routine prenatal diagnostic procedures. PhD Thesis, Radboud Universiteit Nijmegen. Rotterdam: Optima Grafische Communicatie, 2012. 
66. Bianchi D: From prenatal genomic diagnosis to fetal personalized medicine: progress and challenges. Nat Med 2012;18:1041-1051.

67. Savage M, Mourad M, Wapner R: Evolving applications of microarray analysis in prenatal diagnosis. Curr Opin Obstet Gynecol 2011;23:103-108.

68. Armengol L, Nevado J, Serra-Juhé C, Plaja A, Mediano C, García-Santiago FA, García-Aragonés M, Villa O, Mansilla E, Preciado C, Fernández L, Ángeles Mori M, García-Pérez L, Lapunzina PD, Pérez-Jurado LA: Clinical utility of chromosomal microarray analysis in invasive prenatal diagnosis. Hum Genet 2012;131:513-523.

69. Rajcan-Separovic E: Chromosome microarrays in human reproduction. Hum Reprod Update 2012;18:555-567.

70. van den Veyver I, Beaudet AL: Comparative genomic hybridization and prenatal diagnosis. Curr Opin Obstet Gynecol 2006;18:185-191.

71. Maya I, Davidov B, Gershovitz L, Zalzstein Y, Taub E, Coppinger J, Shaffer LG, Shohat M: Diagnostic utility of array-based comparative genomic hybridization (aCGH) in a prenatal setting. Prenat Diagn 2010;30:11311137.

72. Fiorentino F, Napoletano S, Caiazzo F, Sessa M, Bono S, Spizzichino L, Gordon A, Nuccitelli A, Rizzo G, Baldi M: Chromosomal microarray analysis as a first-line test in pregnancies with a priori low risk for the detection of submicroscopic chromosomal abnormalities. Eur J Hum Genet 2013;21:725-30.

73. Lumley M, Zamerowski S, Jackson L, Dukes K, Sullivan L: Psychosocial correlates of pregnant womens attitudes toward prenatal maternal serum screening and invasive diagnostic testing: beyond traditional risk status. Genet Test 2006;10:131-138.

74. Hathaway F, Burns E, Ostrer H: Consumers' desire towards current and prospective reproductive genetic testing. J Genet Couns 2009;18:137-146.

75. de Jong A, Dondorp W, Krumeich A, Boonekamp J, van Lith J, de Wert G: The scope of prenatal diagnosis for women at increased risk for aneuploidies: views and preferences of professionals and potential users. $J$ Community Genet 2013;4:125-35.

76. Wapner RJ, Martin CL, Levy B, Ballif BC, Eng CM, Zachary JM, Savage M, Platt LD, Saltzman D, Grobman WA, Klugman S, Scholl T, Simpson JL, McCall K, Aggarwal VS, Bunke B, Nahum O, Patel A, Lamb AN, Thom EA, Beaudet AL, Ledbetter DH, Shaffer LG, Jackson L: Chromosomal microarray versus karyotyping for prenatal diagnosis. N Engl J Med 2012;367:2175-2184.

77. Hillman S, McMullan D, Maher E, Kilby M: Clinical utility of array comparative genomic hybridisation for prenatal diagnosis: a cohort study of 3171 pregnancies. BJOG 2012;119:1281-1282.

78. Shaffer LG, Coppinger J, Morton SA, Alliman S, Burleson J, Traylor R, Walker C, Byerly S, Lamb AN, Schultz R, Ravnan JB, Kashork CD, Torchia BS, Sulpizio S, Sundin K, Schermer M, Adler K, Dallaire S, Ballif BC: The development of a rapid assay for prenatal testing of common aneuploidies and microdeletion syndromes. Prenat Diagn 2011;31:778-787.

79. Bernhardt B, Soucier D, Hanson K, Savage M, Jackson L, Wapner R: Women's experiences receiving abnormal prenatal chromosomal microarray testing results. Genet Med 2013;15:139-145.

80. Bredenoord A, Onland-Moret N, van Delden J: Feedback of individual genetic results to research participants: in favor of a qualified disclosure policy. Hum Mutat 2011;32:861-7.

81. Rothstein MA: Tiered disclosure options promote the autonomy and well-being of research subjects. Am J Bioethics 2006;6:20-21.

82. Donley G, Hull S, Berkman B: Prenatal whole genome sequencing. Just because we can, should we? Hastings Cent Rep 2012;42:28-40.

83. Bunnik E, Schermer M, Janssens A: The role of disease characteristics in the ethical debate on personal genome testing. BMC Med Genomics 2012;5:4.

84. International Prenatal Screening Group (IPSG). US Professional Guidelines. PSP 2011;16:9. Available at: www. ipsgroup.org.uk

85. Dondorp W, de Wert G. The 'thousand-dollar genome': an ethical exploration. The Hague: Health Council of the Netherlands, 2010. 
86. Reiff M, Ross K, Mulchandani S, Propert KJ, Pyeritz RE, Spinner NB, Bernhardt BA: Physicians' perspectives on the uncertainties and implications of chromosomal microarray testing of children and families. Clin Genet 2013;83:23-30.

87. van Zwieten $M$, Willems D, Litjens L, Schuring-Blom $H$, Leschot $N$ : How unexpected are unexpected findings in prenatal cytogenetic diagnosis? A literature review. Eur J Obstet Gynecol Reprod Biol 2005;120:15-21.

88. Dondorp W, Sikkema-Raddatz B, de Die-Smulders C, de Wert G: Arrays in postnatal and prenatal diagnosis: An exploration of the ethics of consent. Hum Mutat 2012;33:916-922.

89. de Jong A, Dondorp W, Frints S, de Die-Smulders C, de Wert G: Advances in prenatal screening: the ethical dimension. Nat Rev Genet 2011;12:657-663.

90. Lakes K, Vaughan E, Lemke A, Jones M, Wigal T, Baker D, Swanson JM, Burke W: Maternal perspectives on the return of genetic results: Context matters. Am J Med Genet 2012;161A:38-47.

91. Juth $\mathrm{N}$, Munthe $\mathrm{C}$ : The ethics of screening in health care and medicine. Serving society or serving the patient? Dordrecht: Springer, 2012.

92. Wilfond B: Ethical and policy implications of conducting carrier testing and newborn screening for the same condition. In: Baily M, Murray T (eds): Ethics and newborn genetic screening. New technologies, new challenges. Baltimore: The John Hopkins University Press, 2009, pp 292-311.

93. Offit K, Groeger E, Turner S, Wadsworth E, Weiser M: The "duty to warn" a patient's family members about hereditary disease risks. JAMA 2004;292:1469-1473.

94. Liao S: Is there a duty to share genetic information? J Med Ethics 2009;35:306-309.

95. Parker M, Lucassen A: Genetic information: a joint account? BMJ 2004;29:165-167.

96. de Wert G: Ethical aspects of prenatal testing and preimplantation genetic diagnosis for late onset neurogenetic disease: the case of Huntington's disease. In: Evers-Kiebooms G, Zoetewij M, Harper P (eds): Prenatal Testing for Late-Onset Neurogenetic Diseases. Oxford: Bios Scientific Publishers, 2002, pp 129-157.

97. de Wert G, Dondorp W: Ethiek van voortplantingsgeneeskunde. In: Heineman M, Evers J, Massuger L, Steegers E (eds): Obstetrie en gynaecologie. Maarssen: Elsevier, 2012, pp 19-64.

98. Sanderson S, Zimmern R, Kroese M, Higgins J, Patch C, Emery J: How can the evaluation of genetic tests be enhanced? Lessons learned from the ACCE framework and evaluating genetic tests in the United Kingdom. Genet Med 2005;7:495-500.

99. de Neeling J. Kostenutiliteitsanalyse. Publicatie nr A03/01. Den Haag: Gezondheidsraad, 2003.

100. Burke W, Tarini B, Press N, Evans J: Genetic screening. Epidemiol Rev 2011;33:148-164.

101. Moynihan R, Doust J, Henry D: Preventing overdiagnosis: how to stop harming the healthy. BMJ 2012;28:e3502.

102. de Neeling J: Cost-utility analysis; uncertainties restrict applicability. Ned Tijdschr Geneeskd 2004;148:11061110.

103. Shuster E: Microarray genetic screening: a prenatal roadblock for life? Lancet 2007;369:526-529.

104. Paddock C. We're All Mutants, According To New Gene Sequencing Research: Medical News Today, 03 Sep 2009. http://www.medicalnewstoday.com/articles/162809.php.

105. Boyle R, Savulescu J: Prenatal Diagnosis for "Minor" Genetic Abnormalities is Ethical. Am J Bioeth 2003;3:W60-W65.

106. de Cock Buning T, Broerse JE, Bunders JF: Public Perception of Prenatal Genetic Testing: Arguments Put forward by the Public during a Participatory Policy Project in the Netherlands. Community Genet 2008;11:5262.

107. Ganesamoorthy D, Bruno DL, McGillivray G, Norris F, White SM, Adroub S, Amor DJ, Yeung A, Oertel R, Pertile MD, Ngo C, Arvaj AR, Walker S, Charan P, Palma-Dias R, Woodrow N, Slater HR: Meeting the challenge of interpreting high-resolution single nucleotide polymorphism array data in prenatal diagnosis: does increased diagnostic power outweigh the dilemma of rare variants? BJOG 2013;120:594-606.

108. PHG Foundation. Public health in an era of genome-based and personalised medicine. PHG Foundation, 2010. Available at: http://www.phgfoundation.org 
109. Sunstein C, Thaler R: Libertarian Paternalism Is Not an Oxymoron. University of Chicago Law Review 2003;70:1159-1201.

110. Emanuel E, Emanuel L: Four models of the physician-patient relationship. JAMA 1992;267:2221-2226.

111. Sayres L, Cho M: Cell-free fetal nucleic acid testing: a review of the technology and its applications. Obstet Gynecol Surv 2011;66:431-442. 



\section{Summary}





\section{Summary}

\section{Chapter 1}

Prenatal screening for foetal abnormalities was introduced in the $1970 \mathrm{~s}$ in most Western countries. At the time, this only concerned screening for neural tube defects and chromosomal abnormalities, especially Down's syndrome. As initially screening for chromosomal abnormalities was only possible using costly and not entirely risk-free invasive tests, this screening was offered only to pregnant women of advanced maternal age ( $\geq 36-38$ years), because of their a priori increased risk of having a child with aneuploidy. Foetal material was obtained by means of amniocentesis (at 15-18 weeks of gestation) or chorionic villus sampling (at 10-14 weeks gestation). Both invasive procedures hold a small but significant risk of iatrogenic miscarriage. This risk was initially estimated to be about $1.0 \%$, currently estimations are $0.3-0.5 \%$. The development of methods for riskassessment resulted in a prenatal screening program for Down's syndrome (and other chromosomal abnormalities) that was offered to all pregnant women and included a twostep testing cascade: risk-assessment and invasive diagnostic testing for those at increased risk ( $\geq 1: 200-250$ ) for having a child with aneuploidy. From the 1990s onward, a second trimester foetal ultrasound scan was offered to all pregnant women to detect neural tube defects and other major congenital anomalies. Conventional karyotyping, identifying major numerical or structural chromosomal abnormalities that are visible by microscope, was the gold standard of diagnostic testing. The testing techniques and the scope of testing have remained rather constant for decades, and the screening strategy consisted of a limited set of standard test offers that pregnant women could either accept or decline. Recent technological developments have challenged the obviousness of these standards and are reason to deliberate upon what tests to offer, to whom to offer them and why. These are not only practical questions, but they bear moral relevance as well. In this thesis, I focus on three recent developments in prenatal screening: 1) a narrowing of the scope of testing, 2) a broadening of the scope of testing, and 3) an increase in the number and a diversification of the purpose of prenatal tests. Regarding the first development, the introduction of socalled rapid aneuploidy detection (RAD) molecular techniques is relevant. These techniques enable faster, cheaper and targeted testing for a few selected abnormalities only. Generally they focus on trisomies 21, 18, 13 and sex chromosomal abnormalities. For now, noninvasive prenatal testing (NIPT) ${ }^{1}$, enabling early, easy and safe testing on foetal DNA/RNA circulating in the blood of pregnant women, also focuses on the most common trisomies, but this may change in the future. A broadening of the scope is effectuated by microarray-

\footnotetext{
${ }^{1}$ In the chapters 3, 4, and 6 the abbreviation NIPD (non-invasive prenatal diagnosis) is used, because these chapters consist of papers that were written and published some time ago. Recently, however, the terminology has internationally changed into NIPT (non-invasive prenatal testing). To be in keeping with this international usage, I also use this latter term in the chapters 1 and 9.
} 
based techniques that allow for detecting a much wider range of foetal defects than can be revealed by karyotyping. In the future, a broad NIPT may be feasible too. Finally, the number and moments of testing tend to be increased to ensure optimal identification of possible abnormalities. Moreover, a single test is increasingly being used for two purposes, namely prenatal screening for foetal abnormalities and pregnancy management. All in all, the scope of prenatal screening becomes increasingly indistinct.

From the beginning, the aim of prenatal screening policies was much debated. Its initial preventive goal was criticized and soon replaced by a so-called 'autonomy view'. Facilitating autonomous reproductive choice became the generally accepted aim of prenatal screening in Western countries, but current dynamics in prenatal screening challenges this account of reproductive autonomy. It is no longer clear what a standard test offer should include and the question arises what the notion of autonomous choice in the prenatal screening context exactly means.

The main objective of this thesis is to map out the moral landscape of prenatal screening, more specifically to identify and systematically evaluate the moral pros and cons of the main developments in current prenatal screening strategies. This evaluation will be performed in relation to two paradigms of prenatal screening, namely prevention and choice. For this purpose theoretical and empirical methods are used. The ethical method used is the wide reflective equilibrium and the data generated by the empirical research are integrated in this ethical process of deliberation.

The second goal is to explore whether the alternative of a so-called individualised choice, one that allows pregnant women to individually decide what information they wish to receive about their foetus, can replace the traditional standard test offer and can be an adequate translation of the notion of reproductive autonomy in this context.

\section{Chapter 2}

In this chapter, the ethical implications of offering a narrow diagnostic test (RAD) instead of conventional karyotyping to women at increased risk for trisomies 21,18 and 13, are examined. RAD has some clear advantageous features: it is fast, relatively cheap and produces only clear test results. The latter may ease pre- and post-test counselling and decision-making and fast test results have short term psychological benefits over later results. The latter does however not lead to an overall psychological benefit. A drawback of RAD is that it may also miss clinically relevant abnormalities. Women have to be informed about this limitation of RAD and this diminishes the counselling advantages of the targeted scope of RAD. Moreover, the relevance of these missed abnormalities is evaluated differently between and among professionals and pregnant women. For these reasons, RAD is not evidently more in line 
with the requirement of respect for autonomy than karyotyping. Whether the case for RAD is regarded as convincing seems to depend mainly on one's implicit view of what prenatal screening is about. Those who think that prenatal screening is about testing for trisomy 21 and a few other serious conditions may find the arguments for limiting the test offer to RAD convincing. The more so if the consistency in scope throughout the screening strategy, i.e. between the risk-assessment and diagnostic test, is taken into account. But others may find that there are good grounds to at least include a wider range of conditions in the diagnostic test offer. Since professionals and pregnant women have different views about this, the best approach may be to offer women a choice between RAD and karyotyping: a so-called individualised choice. This approach would at least have the benefit of being most in line with the general aim of prenatal screening: providing opportunities for autonomous reproductive choice.

\section{Chapter 3}

In this chapter the ethical implications of introducing non-invasive prenatal diagnosis (NIPD) in prenatal screening strategies are explored. NIPD can be performed easily, safely and early in pregnancy. It is feared that these features will lead to an uninformed and thoughtless uptake and to normalisation of testing and selective abortion. However, pregnant women may clearly profit from the features of NIPD and there are ethically favourable consequences as well: absence of iatrogenic miscarriage, earlier reassurance, a longer period for decisionmaking and the possibility of an early abortion, which may be physically and psychologically less burdening and ethically less problematic because of the lower moral status generally ascribed to the foetus in its earlier developmental stages. Moreover, since NIPD is conceptually easier than the current two-step procedure, informed consent may become easier to obtain. An increase in uptake and more selective abortions need not in itself be taken to signal a thoughtless acceptance of NIPD.

The real moral challenge of NIPD testing seems to consist in the possibility of linking up this safe and early technique with new genomic technologies that allow broad (genomewide) prenatal diagnostic testing. In case of a broad NIPD, informed consent will become more difficult -if attainable at all- and this will challenge the notion of prenatal screening as serving reproductive autonomy. The debate about the ethical challenges of broad genetic testing is primarily conducted in the contexts of neonatal screening and invasive prenatal testing, but the same issues will present themselves even more forcefully should broad NIPD become possible. This also includes the issue of the 'right not to know' of the future child, in case NIPD includes later-onset diseases as well. 


\section{Chapter 4}

This chapter also regards NIPD, but then focuses on the question of what the introduction of a narrow NIPD for trisomies 21, 18 and 13 means for the screening strategy as a whole. If NIPD is going to replace current two-step testing, this means a loss of information as compared with current practice. More in general, a routine offer of NIPD for these trisomies requires decisions about its timing, and about the scope and strategy of the remaining testing cascade. Given the aim of prenatal screening, to facilitate autonomous reproductive decision-making, a decision is needed whether complementary (invasive) testing should be offered in order to maintain the current array of options for reproductive choice. However, an accumulation of tests may negatively impact upon the requirements of informed consent and proportionality. If additional testing needs to be offered, the general opinion that NIPD allows prenatal testing to become easier, safe and earlier in pregnancy, needs to be adjusted. Therefore, decisions regarding NIPD need to address choices regarding the whole prenatal screening strategy and require a proactive ethical evaluation to find out which approach is most in line with the normative framework for prenatal screening.

\section{Chapter 5}

In this chapter, the use of microarrays as a diagnostic tool in prenatal screening strategies will be evaluated from an ethical point of view. Genomic microarray analysis enables searching the genome at a higher resolution and with higher sensitivity than conventional karyotyping and can therefore indentify more clinically significant abnormalities. This is usually seen as a benefit, also in the prenatal context. As yet, no clear guidelines exist when microarrays should be applied prenatally, nor whether a targeted or genome-wide array has to be favoured. This lack of clarity has motivated the discussion about the character and application of microarrays in prenatal screening strategies. First, the general distinction between a targeted and a genome-wide microarray is scrutinised. This leads to distinguishing between a targeted, a directed and an undirected array, describing respectively a test that only seeks the aberrations indicated by the diagnostic question; a test that seeks all known and clear (benign or pathogenic) aberrations, and a test that seeks all (both clear and unclear) aberrations. From the perspective of medical ethics, it would seem that the indications women present with determine what can be seen as a 'suitable diagnostic test'. If this indication is clear, diagnostic testing by a targeted microarray, focussing on associated copy number variants (CNVs), has to be preferred. If such an array is not and cannot be made available or if the indication is unclear, a broader microarray may be used. Then a directed microarray identifying known CNVs has to be favoured over an undirected microarray that generates variants of unclear significance (VOUS) as well. This choice is based on the evaluation of the emotional and decisional burdens of VOUS versus the benefit of possibly identifying yet unknown but possibly clinically relevant CNVs. It is suggested that including 
VOUS serves a research purpose rather than directly contributing to the aim of autonomous reproductive decision making - although it may do so in the long run when proper studies have revealed their either benign or pathogenic character.

Second, the question is whether, and if so how, adequate information about the heterogeneous findings possibly generated by (both directed and undirected) microarrays can be provided to pregnant women in order to obtain adequate informed consent. The model of generic consent may be helpful here. Furthermore, the 'interpretive model' of the professional-patient relationship is suggested for this situation. Finally, if microarrays or other future genome-wide testing techniques like whole genome/exome sequencing and analysis will also reveal information about a late(r)-onset disease, the future child's right not to know may be violated. Suggestions of how to address this issue are provided.

\section{Chapter 6}

This chapter presents an overview of technological developments discussed so far: RAD, foetal ultrasound scans, genome-wide molecular testing and NIPT. It shows how these advances in prenatal screening challenge the aim and requirements of prenatal screening. The application of RAD could result in an unjustified limitation of meaningful reproductive choice. To keep in line with the aim of prenatal screening it is suggested to offer pregnant women the choice between conventional karyotyping and RAD. Regarding broad, heterogeneous testing like foetal ultrasound scans and microarrays the aim to offer opportunity for reproductive choice is endangered too, albeit for the inability to provide information in the traditional way. Therefore, the feasibility of alternative models of informed consent are explored and the option to categorise the possible outcomes of testing beforehand is presented. It seems inevitable that filters have to be used to avoid findings that are unwanted, either by prospective parents themselves or to protect future children's interests. The latter implies that the right of pregnant women to obtain information about their future child is not unlimited, nor unconditional. This still leaves open the question who should define the exact scope of testing and on what grounds. The overall tendency towards more, additional and ever-broader testing challenges the requirements of equal access and proportionality. The latter regards not only the assessment between the benefits (enabling reproductive choice) and the emotional and decisional burdens of test offers on the individual level. The societal impact of prenatal test offers, including the financial costs and gains and possible discriminatory effects, have to be addressed as well. This shows that the choices to be made in prenatal screening strategies are as much about ethics as they are about technology. 


\section{Chapter 7}

In this chapter the main findings of the empirical research are described. This qualitative study investigated the views and preferences of professionals and potential users regarding four diagnostic test options for women at increased risk for common aneuploidies. These options included three standard test offers: RAD, conventional karyotyping or microarrays that represent a narrow, traditional and broad test respectively. Fourth was the option of individualised choice. Seven focus group sessions were conducted including various categories of participants $(n=55)$ : professionals engaged in prenatal testing and potential users of the tests (pregnant women and parents of young children). All these participants were invited to first individually evaluate the four options. After that, a semi-structured group interview was conducted. The data were analysed by the constant comparative method. Two major themes emerged in the focus groups, showing two levels of deliberation: classification of test features and reflection on the concepts of informed choice and autonomy. Participants first focused on the features of the test options, such as test outcomes, wait for results, costs and familiarity with particular tests. In general, they all identified similar test features and classified these as test-specific pros and cons. But when asked what option should be offered to pregnant women, they showed different preferences. Professionals, except the midwives, for the most part preferred option 1 (RAD), whereas the pregnant women, parents and midwives mainly chose option 4 (individualised choice). This difference was mainly influenced by their opinion on the second theme: the meaning and feasibility of informed choice and autonomy in the prenatal screening context. On a theoretical level, participants agreed that users should be enabled to make an informed choice about what test to apply. Thus they shared the ideal of an individualised choice. But when discussing the feasibility of such a choice, views differed. Whereas some considered it fairly impossible to provide women with adequate information and to ensure adequate counselling to enable an individual carefully thought-out choice, others were convinced that women's reproductive options should not be constrained by others despite the possible informational and decisional problems. The latter group emphasised that, to reach the aim of individualised choice, counselling should not only ensure adequate information and non-directivity, but also support counselees in reflecting on their wants and values and in finding ways to realise these.

The results of the empirical research confirm the finding in other studies that the question of what test option best complies with the aim of prenatal screening is answered differently by both professionals and users, and suggests that a 'one-size fits-all' approach fails to take into account the different views and preferences of prospective parents. Furthermore, estimated personal bearing capacity led some users to give a different answer with regard to what they would choose for themselves and to what choices should be offered to pregnant women in general. 


\section{Chapter 8}

This chapter focuses on new genetic and genomic technologies (the 'new genetics') and the challenge they entail for the requirement of informed consent in three different contexts: newborn screening, prenatal screening and commercial direct-to-consumer (DTC) personal testing. Technologies such as whole genome/exome sequencing and microarray based analysis enable genome-wide testing for many and heterogeneous abnormalities and predispositions simultaneously. The advantage is that they increase the chance of identifying relevant disorders. However, they may also reveal so-called incidental and possibly unwanted findings. This may cause friction with the principle of respect for autonomy and demands a rethinking of traditional interpretation of the concept of informed consent. The discussion takes the existing ethical framework for responsible screening and clinical care as its point of departure. This means that the scope of a responsible test or screening offer has to be consistent with the purpose(s) of testing and with the principle of respect for autonomy for all stakeholders involved, including -in the prenatal scenario future- children. Informed consent is a prerequisite in all three contexts. The traditional interpretation of informed consent in the context of genetic testing is that the testee is offered extensive and non-directive pretest counselling to enable an informed, autonomous choice. In the light of the new genetics, however, informed consent requires a new approach. A renewed interpretation has to take into account the aim of testing, the possibility for individual differentiation and the feasibility of informed consent in the various contexts. The overall conclusion is that standardised approaches to the design of testing and screening offers are no longer appropriate, but need to be replaced by differentiated or individualised approaches that enable tailoring the tests to individual informational needs and preferences. The principle of respect for persons may be best served through differentiating and pre-structuring the testing or screening offer into a 'menu of options' from which testees may choose. By differentiating choice, autonomy can be preserved.

\section{Chapter 9}

This final chapter is divided into three parts. In Part I, the normative framework for prenatal screening is extensively discussed. The objective of prenatal screening, initially understood in terms of prevention, has soon been specified as offering opportunity for autonomous reproductive decision-making. These different aims are related to two opposite paradigms of prenatal screening, prevention and choice, of which the latter currently dominates screening practice in Western countries. The two paradigms entail various features and influence the way prenatal screening programmes are presented and evaluated in practice. When confronting the generally shared aim to offer opportunity for reproductive choice with the introduction of new testing techniques, it becomes clear that the choice paradigm is challenged. Given the opposite developments of a narrowing and a broadening of the 
scope of testing, it is necessary to reconsider what autonomous reproductive choice actually refers to in the prenatal screening context. The three basic principles that underlie the normative framework for prenatal screening are respect for persons, beneficence/ non-maleficence, and justice. But these principles are not unequivocal when asking what scope has to be preferred from an ethical point of view. Respect for autonomy, in a positive account, may dismiss the suggestion of limiting a person's options but does not necessarily imply that a maximum amount of reproductive choices has to be preferred. More and broader tests may also undermine autonomy if prospective parents are overwhelmed by the amount and kind of possible test outcomes. It is difficult to determine whether offering more narrow or broader testing benefits participants most, since this very much depends on personal capabilities and preferences too. Finally, equal access and proportionality are both important requirements if prenatal screening is publicly funded.

In Part II, the consequences of the three developments in prenatal screening are more deeply explored in relation to the two paradigms. If narrow tests (RAD, narrow NIPT) are offered as a standard, this means that not the users of the test, but the providers determine what constitutes important knowledge for prospective parents. This does not meet the principle of respect for persons insofar as autonomous reproductive choice is not being facilitated. Therefore, offering standard narrow tests can be deemed to unjustly limit possibly relevant knowledge and thus restrict autonomous reproductive choice. This does not mean that more reproductive options are always to be favoured, but the question what is beneficial and proportional in view of the adhered benefits and burdens, is difficult to solve on an abstract level and is in need of an individual evaluation too. The alternative of an individualised choice, that allows pregnant women to choose themselves what test best suits their personal situation and preferences, can solve the dilemma but is not easy to implement. The major pitfalls of this concept are information overload and emotional or decisional overcharge, and these drawbacks have to be prevented. Similar issues arise when broad and compound tests (microarrays, foetal ultrasound scans, future whole genome and whole exome sequencing and analysis) are offered in the prenatal screening cascade. Inclusion of specific categories of findings are a matter of concern in case of genome-wide testing. This regards late(r)-onset diseases, susceptibilities and VOUS. To avoid the ethical complications of such findings, the test may be designed in such a way that these findings will not be generated, or these findings may be 'filtered out' in the analysing phase. However, this solution still does not answer the question of who is to determine the exact range of such a design or filter. Another ethical problem is that the prenatal use of genome-wide techniques for a diagnostic aim leads in practice to screening the foetus for any genetic aberration, irrespective of the initial indication. This challenges the justification of using that technique as a 'suitable test' and raises the question of equal access: if any indication suffices, why would not every women be eligible for this kind of testing? 
Part III discusses why individualised choice may be a justifiable way to translate the notion of reproductive autonomy in the prenatal screening context. If the classical account of the aim of prenatal screening is taken seriously, it seems that pregnant women themselves should also have a say in the range of conditions their foetus is tested for. This leads to a individual-driven approach in which the choice of individual pregnant women is guiding, instead of following a system-based approach that charges professionals with offering standard tests to particular groups of women. The concept of individualised choice does not mean that 'anything goes' and that prospective parents have to be offered whatever they ask for. Reproductive autonomy, and thus individualised choice, in the prenatal screening context is limited by three factors. First, if prenatal screening is funded publicly, it should be restricted in such a way that it meets a state's duty of care and regards worthwhile options as understood by most people in society. Moreover, the scope of screening may be influenced by the consideration that selective abortion is a possible consequence of this publicly initiated test offer. Second, prenatal testing has to promote autonomous choice and should not undermine it due to information overload or complexity of choice. This calls for a surveyable menu of test options. Third, the future child's right not to know has to be protected and this requires not including findings in the testing array that may violate this right. Providers have to make a pre-selection of test options that meets the qualified interpretation of reproductive autonomy. When offered this well-balanced menu, prospective parents can choose themselves what serves their personal situation, values and preferences best. 



\section{Samenvatting}





\section{Samenvatting}

\section{Hoofdstuk 1}

Prenatale screening op foetale aandoeningen is in de meeste westerse landen in de jaren '70 van de vorige eeuw geïntroduceerd. Het ging toen uitsluitend om screening op neuralebuisdefecten en chromosoomafwijkingen, met name downsyndroom. Omdat voor screening op chromosoomafwijkingen toen nog alleen gebruik gemaakt kon worden van kostbare en niet geheel risicovrije invasieve testen, werd die screening aanvankelijk alleen aangeboden aan zwangere vrouwen van 38 jaar (later: 36 jaar) en ouder, vanwege hun $a$ priori verhoogd risico op een kind met aneuploïdie (chromosomale afwijking veroorzaakt door een afwijkend aantal chromosomen). Hiervoor werd gebruik gemaakt van foetaal materiaal dat verkregen werd via een vruchtwaterpunctie (bij 15-18 weken zwangerschap) of een vlokkentest (bij 10-14 weken zwangerschap). Beide invasieve testen brengen een miskraamrisico met zich mee dat aanvankelijk werd geschat op ongeveer 1,0\% (tegenwoordig gaat men uit van $0,3-0,5 \%$ ). De ontwikkeling van niet-invasieve risicoschattende testen resulteerde vanaf de jaren ' 80 in een prenataal screeningsprogramma voor alle zwangere vrouwen en bestond uit een traject met twee opeenvolgende testen: eerst werd een risicoschatting gedaan en alleen degenen met verhoogd risico ( $\geq 1: 200-250)$ op het krijgen van een kind met aneuploïdie kregen de invasieve diagnostische testen aangeboden. Vanaf de jaren '90 kwam het structureel echoscopisch onderzoek (SEO) naar neurale buisdefecten en andere ernstige aangeboren afwijkingen in zwang. Deze screeningsecho wordt meestal rond de 20e zwangerschapsweek gedaan. Conventionele karyotypering, waarmee alle microscopisch zichtbare chromosomale afwijkingen kunnen worden gevonden, gold als de 'gouden standaard' van de prenatale diagnostiek. De reikwijdte van prenatale screening en de technieken die daarvoor werden ingezet zijn decennialang vrij constant gebleven. Dit betekende dat het screeningstraject bestond uit een beperkte set van standaardtesten, die zwangere vrouwen konden accepteren of afwijzen.

Recente technologische ontwikkelingen hebben ertoe geleid dat het testaanbod niet langer vanzelfsprekend is en dit doet de vragen rijzen welke test moet worden aangeboden, aan wie en waarom. Dit zijn niet louter praktische vragen, ze zijn ook ethisch relevant. In dit proefschrift richt ik me op drie recente ontwikkelingen in prenatale screening: 1) een versmalling van de reikwijdte van het testen, 2 ) een verbreding van de reikwijdte van het testen, en 3 ) een toename van het aantal prenatale testen en een wisselend doel van die testen.

Wat betreft de eerste ontwikkeling, is de introductie van zogenoemde rapid aneuploidy detection (RAD) technieken relevant. Deze moleculaire technieken maken het mogelijk snel, goedkoop en gericht op een paar geselecteerde afwijkingen te testen. In het algemeen richten RAD-testen zich op trisomie 21 (downsyndroom), trisomie 18 (patausyndroom), 
trisomie 13 (edwardssyndroom) en geslachtschromosomale afwijkingen. Voorlopig richt ook de zogenoemde 'niet-invasieve prenatale test' (NIPT) zich op de drie genoemde trisomieën. NIPT is een techniek die het mogelijk maakt om al vroeg in de zwangerschap testen uit te voeren op foetaal DNA/RNA dat in het bloed van de zwangere vrouw circuleert. Dit betekent dat NIPT in principe vroeg, veilig en makkelijk kan worden uitgevoerd.

Een verbreding van de reikwijdte van prenatale screening is te zien in de toepassing van zogenoemde 'microarray'- technieken (mircroarrays). Deze kunnen een veel breder scala aan foetale afwijkingen ontdekken dan karyotypering. De verwachting is dat in de toekomst NIPT ook voor een brede reikwijdte kan worden aangeboden.

Tenslotte bestaat de tendens om gedurende de hele zwangerschap meer testen aan te bieden en zo alle mogelijke foetale afwijkingen te identificeren. Daarnaast wordt een en dezelfde test steeds vaker gebruikt voor twee doelen, namelijk voor prenatale screening op foetale afwijkingen en voor het vaststellen van zwangerschapscomplicaties. Al met al wordt de reikwijdte van prenatale screening dus steeds onduidelijker.

Vanaf het begin is er veel discussie geweest over het doel van prenatale screening. De aanvankelijke doelstelling, die gericht was op preventie en gezondheidswinst, werd fel bekritiseerd en al snel vervangen door het doel om reproductieve autonomie te faciliteren. Dit hield in dat prenatale screening zwangere vrouwen (en hun partners) in staat moest stellen om, middels het verschaffen van zinvolle handelingsopties, reproductieve keuzes te maken. In de westerse landen is dit laatste nog steeds het algemeen aanvaarde doel van prenatale screening, dat ook in beleidsdocumenten terug te vinden is. Echter, de huidige dynamiek in prenatale screening stelt deze reproductieve autonomie opnieuw ter discussie. Nu niet meer duidelijk wat een standaard testaanbod moet omvatten, rijst de vraag wat het begrip 'autonome reproductieve keuze' in de prenatale screening context precies betekent.

Het primaire doel van dit proefschrift is om de morele vragen rond prenatale screening in kaart te brengen, meer specifiek om de morele voor- en nadelen van de belangrijkste ontwikkelingen in de hedendaagse praktijk van prenatale screening te identificeren en te evalueren. In deze evaluatie zullen twee paradigma's van prenatale screening worden betrokken, namelijk die van preventie en van autonome keuze. Hiertoe worden theoretische en empirische methoden gebruikt. De gehanteerde ethische methode is het wide reflective equilibrium. Dit is een redeneermethode waarin wordt gestreefd naar coherentie tussen verschillende opvattingen, intuïties, algemene ethische principes, oordelen en (praktijk-) ervaringen. De data uit het empirisch onderzoek worden in deze methode geïntegreerd.

Het tweede doel is om te onderzoeken of het alternatief van een zogenoemde geïndividualiseerde keuze (individualised choice), dat inhoudt dat zwangere vrouwen individueel kunnen bepalen welke informatie ze over hun foetus willen ontvangen, het 
traditionele standaard testaanbod kan vervangen en een adequate operationalisering van het begrip reproductieve autonomie in deze context kan zijn.

\section{Hoofdstuk 2}

In dit hoofdstuk wordt onderzocht wat de ethische implicaties zijn van het aanbieden van een smalle diagnostische test (RAD) in plaats van karyotypering aan vrouwen met een verhoogd risico op trisomie 21,18 of 13 . RAD heeft een aantal evidente voordelen: het is snel, relatief goedkoop en genereert duidelijke testresultaten. Dit laatste kan de pre- en posttest counseling en besluitvorming vergemakkelijken. Snelle testresultaten leveren op de korte termijn een psychologisch en emotioneel voordeel op, maar op de lange termijn lijkt het voor het emotionele welbevinden van vrouwen niet uit te maken of ze een paar dagen of een paar weken op de testuitslag hebben moeten wachten. Een nadeel van RAD is dat het klinisch relevante afwijkingen kan missen. Ervan uitgaande dat vrouwen vooraf moeten worden geïnformeerd over de beperkte reikwijdte van RAD is het niet evident dat de informatieverstrekking omtrent RAD eenvoudiger is. Een ander belangrijk punt is dat de relevantie van de afwijkingen die door RAD gemist worden door professionals en zwangere vrouwen verschillend wordt beoordeeld. Tegen de achtergrond van deze voor- en nadelen kan niet zonder meer gezegd worden dat een aanbod van RAD meer in overeenstemming is met het beginsel van respect voor personen dan een aanbod van karyotypering. Of een pleidooi voor RAD overtuigend wordt gevonden, lijkt voornamelijk af te hangen van iemands visie op de reikwijdte van prenatale screening als zodanig. Degenen die vinden dat prenatale screening vooral gaat over testen voor trisomie 21 en een paar andere ernstige aandoeningen, vinden de argumenten voor het beperken van het testaanbod tot RAD waarschijnlijk overtuigend. Dit geldt des te meer als men vindt dat de reikwijdte van het testaanbod gedurende het hele screeningstraject gelijk moet zijn. Een dergelijke 'screeningslogica' betekent dat de risicoschattende test en de diagnostische test op dezelfde aandoeningen gericht moeten zijn. Anderen kunnen evenwel vinden dat er goede gronden zijn om een breder scala aan afwijkingen in de diagnostische test op te nemen, temeer daar een invasieve test het risico op een miskraam met zich meebrengt. Breder testen leidt tot een gunstiger detectie-miskraam ratio. Omdat professionals en zwangere vrouwen ook onderling over deze kwesties van mening verschillen, is een alternatief om zwangere vrouwen zelf te laten kiezen tussen RAD en karyotypering. Dit komt neer op een zogenoemde geïndividualiseerde keuze. Het geven van deze keuze zou tenminste beter dan een standaardaanbod aansluiten bij het algemene doel van prenatale screening: het bieden van mogelijkheden voor autonome reproductieve keuze. 


\section{Hoofdstuk 3}

In dit hoofdstuk wordt onderzocht wat de ethische implicaties zijn van het invoeren van nietinvasieve prenatale diagnostiek (NIPD) ${ }^{1}$ in prenatale screening scenario's. Er wordt hier vanuit gegaan dat NIPD een $100 \%$ betrouwbare diagnostische test is. De belangrijkste voordelen van NIPD zijn dat deze veilig is om te doen, dat wil zeggen dat er geen miskraamrisico aan verbonden is, dat deze vroeg in de zwangerschap en op tamelijk eenvoudige wijze kan worden uitgevoerd - er is namelijk slechts een klein beetje bloed van de zwangere vrouw voor nodig. De vrees bestaat dat deze eigenschappen van NIPD ertoe zullen leiden dat zwangere vrouwen ondoordacht en zonder adequate voorafgaande informatie deze test zullen laten doen en dat het in het algemeen zal leiden tot een normalisatie van het ondergaan van zowel prenatale testen als selectieve abortus.

Echter, zwangere vrouwen profiteren ook van de eigenschappen van NIPD en deze hebben bovendien ethische voordelen. Ten eerste is het iatrogene miskraamrisico afwezig. Ten tweede kan vroege NIPD een eerdere geruststelling betekenen, of een langere termijn voor de besluitvorming over afbreken of voortzetten van de zwangerschap. Voorts maakt NIPD een vroege abortus mogelijk die zowel fysiek als psychologisch minder belastend is. Ook ethisch gezien is een vroege abortus minder problematisch vanwege de veronderstelde lagere morele status van de foetus eerder in de zwangerschap. Ten derde, omdat NIPD conceptueel eenvoudiger is dan de huidige getrapte procedure van eerst een risico-schatting en daarna invasieve diagnostiek, kan geïnformeerde toestemming (informed consent) ook makkelijker worden. Als dit al tot een toename van het aantal testen en het aantal selectieve abortussen leidt, hoeft dit op zichzelf niet te duiden op een achteloze aanvaarding van NIPD: evenzeer kan dit een uiting zijn van een toename van autonome reproductieve keuzes.

Indringender morele vragen rond NIPD lijken vooral te ontstaan als het mogelijk wordt deze veilige en vroege test te koppelen aan nieuwe technieken die (genoom-)brede prenatale diagnostiek mogelijk maken. Bij een brede NIPD zal het moeilijker worden te voldoen aan de eis van informed consent en dit zal ook het doel van prenatale screening, reproductieve autonomie, op de proef stellen. Het debat over de ethische vragen rond brede genetische testen wordt voornamelijk gevoerd in de context van neonatale screening en invasieve prenatale testen. Dezelfde vragen zullen zich nog nadrukkelijker voordoen als een brede NIPD mogelijk wordt. In geval NIPD ook later in het leven optredende (late-onset) ziektes bestrijkt, kan daarbij bovendien de kwestie van het 'recht op niet-weten' van het toekomstige kind aan de orde zijn.

\footnotetext{
${ }^{1}$ In de hoofdstukken 3, 4 en 6 wordt de afkorting NIPD (niet-invasieve prenatale diagnositiek) gebruikt, omdat deze hoofdstukken bestaan uit artikelen die enige tijd geleden geschreven en gepubliceerd zijn. Recent is de term internationaal gewijzigd in NIPT (niet-invasieve prenatale test). Om bij deze internationale terminogie aan te sluiten, gebruik ik deze laatste term in de hoofdstukken 1 en 9.
} 


\section{Hoofdstuk 4}

Dit hoofdstuk gaat ook over NIPD, maar betreft dan de vraag wat de introductie van een smalle NIPD, gericht op trisomie 21, 18 en 13, voor de prenatale screening als geheel betekent. Als NIPD het huidige testtraject voor deze trisomieën gaat vervangen, betekent dit dat een deel van de informatie die met de huidige opzet gegenereerd wordt, niet meer verkregen zal worden. Meer in het algemeen vereist een routine aanbod van NIPD voor de trisomieën een beslissing over de timing, over de reikwijdte en over eventuele aanvullende testen in het screeningstraject. Gezien het doel van prenatale screening, autonome reproductieve besluitvorming faciliteren, is een beslissing nodig of aanvullende (invasieve) testen moeten worden aangeboden, zodat het huidige scala aan reproductieve opties gehandhaafd blijft. Echter, een opeenstapeling van testen kan negatief uitwerken voor de eisen van informed consent en proportionaliteit. Als aanvullende testen moeten worden aangeboden, zou dit de voordelen van NIPD (veilig, vroeg, gemakkelijk) grotendeels teniet doen. Beslissingen over de invoering van NIPD vereisen daarom ook keuzes ten aanzien van het hele prenatale screeningstraject. Een proactieve ethische evaluatie is nodig om te beoordelen welke aanpak het beste strookt met het normatieve kader voor prenatale screening.

\section{Hoofdstuk 5}

In dit hoofdstuk zal de implementatie van microarrays als diagnostisch middel in het prenatale screeningstraject worden geëvalueerd vanuit ethisch gezichtspunt. Microarrays doorzoeken het genoom met een hogere resolutie en een hogere gevoeligheid dan karyotypering doet. Daardoor kunnen meer klinisch significante afwijkingen gevonden worden. Meestal wordt dit als een voordeel gezien, ook in de prenatale context. Vooralsnog bestaan er geen eenduidige richtlijnen wanneer microarrays prenataal moet worden ingezet, noch of deze gericht of genoombreed moeten zijn. Over het karakter en de toepassing van microarrays in de prenatale context kan het volgende worden gezegd. Om te beginnen wordt het algemeen gehanteerde onderscheid tussen een gerichte en genoombrede microarray onder de loep genomen. Dit leidt er toe dat we drie verschillende soorten microarrays onderscheiden: 1) een test die enkel beoogt de diagnostische vraag te beantwoorden en de reikwijdte daartoe beperkt (een targeted microarray); 2) een test die alle bekende (benigne en pathogene) afwijkingen opspoort (een directed microarray), 3) een test die er naar streeft alle (zowel duidelijke als onduidelijke) aberraties aan het licht te brengen (een undirected microarray). Vanuit medisch-ethisch perspectief lijkt het logisch dat de indicatie van zwangere vrouwen medebepalend is voor wat als een geschikte diagnostische test kan gelden. Als de indicatie helder is, verdient het aanbeveling de diagnostische test toe te spitsen op de variaties in het genoom die met deze indicatie geassocieerd zijn. Als de indicatie minder helder is, zoals vaak wanneer bij het SEO afwijkingen worden gevonden, kan een bredere -een directedmicroarray worden gebruikt. Deze verdient de voorkeur boven een undirected microarray, 
omdat de laatste ook variaties in het genoom detecteert waarvan de betekenis onduidelijk is. Deze aanbevelingen zijn gebaseerd op de afweging van de emotionele last die het kennisnemen van en de besluitvorming op basis van onduidelijke variaties veroorzaken, versus het voordeel dat een directed test enkel bekende variaties aan het licht brengt. Waarschijnlijk ligt aan de keuze voor een undirected microarray mede een onderzoeksmotief ten grondslag: immers, op die manier kunnen thans nog onbekende variaties door follow-up monitoring toch gerelateerd worden aan een bepaald genotype - en daardoor als benigne of pathogeen worden gecategoriseerd. Dit onderzoeksdoel dient echter niet de doelstelling van autonome reproductieve besluitvorming in het concrete geval, hoewel het op de langere termijn natuurlijk wel kan bijdragen aan kennis over de betekenis van bepaalde variaties in het genoom.

Ten tweede is de vraag of, en zo ja hoe, voorafgaand aan de test adequate informatie aan zwangere vrouwen kan worden verstrekt, aangezien zowel directed als undirected microarrays heterogene bevindingen kunnen genereren. Categorisering van eventuele bevindingen geeft mogelijk een antwoord op dit probleem. Tevens wordt voorgesteld in deze situatie het 'interpretive model' van de art-patiënt relatie toe te passen.

Tenslotte, als microarrays of andere genoom-brede testtechnieken zoals whole genome/ exome sequencing en analyse ook informatie over late(r)-onset ziektes kunnen onthullen, dan kan het recht-op-niet-weten van het toekomstige kind worden geschonden. Er worden enkele suggesties gegeven hoe dit (zoveel mogelijk) kan worden voorkómen.

\section{Hoofdstuk 6}

Dit hoofdstuk geeft een overzicht van de tot nog toe genoemde technologische ontwikkelingen: RAD, het SEO, microarrays en NIPD en laat zien hoe deze ontwikkelingen het doel van en de voorwaarden voor prenatale screening onder druk zetten. Het toepassen van RAD kan leiden tot een ongerechtvaardigde beperking van zinvolle reproductieve keuzes. In lijn met het doel van prenatale screening wordt voorgesteld om zwangere vrouwen de keuze te bieden tussen karyotypering en RAD. Ten aanzien van brede, heterogene testen, zoals het SEO en microarrays, wordt het doel van de reproductieve keuze ook op de proef gesteld, omdat het onmogelijk is om informatie tot op detailniveau te verstrekken. Dit werd wel beoogd in de traditionele opvatting van informed consent. Het is daarom nodig alternatieve modellen van informed consent te onderzoeken. Een optie is om de mogelijke uitkomsten van prenatale testen te categoriseren en informatie op dit categorie-niveau te verstrekken. Daarnaast lijkt het onvermijdelijk om filters te gebruiken, die ervoor kunnen zorgen dat ongewenste bevindingen vermeden of niet bekend worden. Dit draagt ertoe bij om de belangen van hetzij aspirant-ouders zelf, hetzij toekomstige kinderen te waarborgen. We komen tot de conclusie dat het recht van zwangere vrouwen op informatie over hun toekomstig kind niet onbeperkt, noch onvoorwaardelijk is. Wie de precieze omvang van breder testen moet definiëren en op welke gronden, is vooralsnog niet duidelijk. 
De algemene tendens naar meer, aanvullende en steeds bredere testen heeft ook zijn weerslag op de voorwaarden van gelijke toegang en proportionaliteit. Dat laatste betreft niet alleen de afweging tussen de voordelen (waaronder reproductieve keuze) en nadelen (emotionele last van vereiste besluitvorming) van het testaanbod op individueel niveau. De maatschappelijke impact van het prenatale testaanbod, waaronder de financiële baten en lasten en mogelijke discriminerende effecten, moeten ook worden verdisconteerd. Dit alles laan zien dat de keuzes die ten aanzien van prenatale screening moeten worden gemaakt, niet alleen over technologie, maar ook over ethiek gaan.

\section{Hoofdstuk 7}

In dit hoofdstuk worden de belangrijkste resultaten van het empirisch onderzoek weergegeven. In deze kwalitatieve studie zijn de opvattingen en voorkeuren van professionals en potentiële gebruikers ten aanzien van vier diagnostische testmogelijkheden onderzocht. Concreet ging het daarbij om de volgende opties: 1) een standaard smal testaanbod (RAD), 2) een standaard traditioneel testaanbod (karyotypering) of 3) een standaard breed testaanbod (microarrays). De vierde optie was die van een geïndividualiseerde keuze. Er werden zeven focusgroepen gehouden, met verschillende categorieën deelnemers ( $n=55)$ : professionals die zich bezighouden met prenatale testen en potentiële gebruikers van prenatale testen, te weten zwangere vrouwen en ouders van jonge kinderen (0-3 jaar). Aan deze deelnemers werd gevraagd om eerst individueel alle voor- en nadelen van de vier testopties te evalueren en hun voorkeur te bepalen. Daarna werd een semi-gestructureerd groepsinterview gehouden. De data werden geanalyseerd volgende de constant comparative method. In de focusgroepen kwamen twee centrale thema's naar boven, die op twee verschillende niveaus lagen: 1 ) een classificatie van testkenmerken en 2 ) een reflectie op de concepten van geïnformeerde keuze en autonomie. Deelnemers waren in eerste instantie gericht op het benoemen van de kenmerken van de testopties, zoals het soort testresultaten, de termijn tot de testuitslag en de financiële kosten. In het algemeen benoemden de deelnemers soortgelijke kenmerken bij iedere testoptie en classificeerden deze als testspecifieke voorof nadelen. Maar toen hun gevraagd werd welke optie aan zwangere vrouwen zou moeten worden aangeboden, bleek dat ze verschillende voorkeuren hadden. Professionals, behalve de verloskundigen, kozen overwegend voor optie 1 (RAD), terwijl de zwangeren, ouders en verloskundigen vooral optie 4 (geïndividualiseerde keuze) kozen. Dit verschil werd vooral beïnvloed door hun mening over het tweede thema: de betekenis en de haalbaarheid van geïnformeerde keuze en autonomie in de prenatale screening context. Op een theoretisch niveau waren deelnemers het erover eens dat testgebruikers (zwangere vrouwen en hun partners) in staat moesten worden gesteld om een weloverwogen keuze te maken ten aanzien van het soort test dat ze wilden ondergaan. Het ideaal van een geïndividualiseerde keuze werd dus gedeeld. Maar over de haalbaarheid van een dergelijke keuze waren de 
meningen verdeeld. Sommigen achten het onmogelijk om zwangere vrouwen van adequate informatie te voorzien en om vrouwen zodanig te begeleiden dat zij een individuele en goed doordachte keuze konden maken. Anderen waren ervan overtuigd dat de reproductieve mogelijkheden van vrouwen niet door anderen beperkt mochten worden en dat alles in het werk moest worden gesteld om de vereiste informatie en ondersteuning te geven. Deze laatste groep benadrukte tevens dat, om het doel van geïndividualiseerde keuze te realiseren, betrokkenen ook ondersteund moesten worden in hun denkproces over hun waarden en wensen en hoe deze het best gerealiseerd konden worden.

Tot slot leidde de inschatting van de persoonlijke draagkracht ertoe dat sommige potentiële gebruikers voor zichzelf een andere testoptie kozen, dan zij voor zwangere vrouwen in het algemeen hadden gedaan. Daarmee werd het belang van het zélf kunnen kiezen nog eens onderstreept.

De resultaten van het empirisch onderzoek bevestigen de bevindingen in andere studies die laten zien dat het antwoord op de vraag welke testoptie het beste voldoet aan het doel van prenatale screening door professionals en gebruikers verschillend wordt beantwoord. Dit duidt erop dat een 'one size fits all' benadering ten onrechte geen rekening houdt met de verschillende standpunten en voorkeuren van toekomstige ouders.

\section{Hoofdstuk 8}

Dit hoofdstuk richt zich op de inzet van nieuwe genetische technologieën (de 'new genetics') in drie verschillende contexten: neonatale screening, prenatale screening en commerciële direct-to-consumer (DTC) persoonlijke testen. Technologieën zoals whole genome/exome exome sequencing en microarrays kunnen genoombreed testen op vele en heterogene afwijkingen en predisposities tegelijk. Het voordeel hiervan is dat ze de kans op het identificeren van de mogelijke aandoeningen verhogen. Echter, ze kunnen ook zogenoemde incidentele en mogelijk ongewenste bevindingen genereren. Dit is in tegenspraak met het beginsel van respect voor autonomie en is reden om de traditionele interpretatie van het concept informed consent te heroverwegen. In de discussie wordt het bestaande ethisch kader voor verantwoorde screening en klinische zorg als uitgangspunt genomen. Dit betekent dat de reikwijdte van een verantwoord test- of screeningsaanbod in overeenstemming moet zijn met de doelstelling(en) van het testen en met het beginsel van respect voor personen, waaronder (in het prenatale scenario ook toekomstige) kinderen. Informed consent is een vereiste in alle drie contexten. De traditionele interpretatie van informed consent in de context van genetisch testen luidt dat de te testen persoon een uitgebreide en niet-directieve pre-test counseling moet krijgen om een weloverwogen, autonome keuze mogelijk te maken. In het licht van de new genetics, vereist het concept van informed consent een nieuwe aanpak. Deze nieuwe interpretatie dient rekening te houden 
met het doel van testen, de mogelijkheid van individuele differentiatie en de haalbaarheid van informed consent in de verschillende contexten. De algemene conclusie is dat een standaardaanbod van testen en screening niet langer voldoet, maar moet worden vervangen door een gedifferentieerde of geïndividualiseerde benadering, die een betere afstemming van de testen op individuele behoeften en voorkeuren mogelijk maakt. Het beginsel van respect voor personen kan het best worden gediend door het test- of screeningsaanbod te differentiëren en voor te structureren en dit aan te bieden als een 'menu met opties' waaruit betrokkenen kunnen kiezen.

\section{Hoofdstuk 9}

Dit laatste hoofdstuk is verdeeld in drie delen. In Deel I wordt het normatieve kader voor prenatale screening besproken. Het doel van prenatale screening, aanvankelijk begrepen in termen van preventie en gezondheidswinst, is al snel gespecificeerd als het aanbieden van mogelijkheden voor autonome reproductieve besluitvorming. Deze doelstellingen zijn gerelateerd aan twee tegenovergestelde paradigma's van prenatale screening, namelijk preventie en autonome keuze. Het laatste wordt in de meeste westerse landen als uitgangspunt genomen voor prenatale screening. De twee paradigma's hebben verschillende kenmerken en beïnvloeden de manier waarop prenatale screening programma's in de praktijk worden gepresenteerd en geëvalueerd. Als de introductie van nieuwe prenatale testtechnieken wordt bekeken in het licht van het algemeen onderschreven doel, namelijk het faciliteren van reproductieve keuze, dan wordt duidelijk dat het keuze-paradigma niet langer vanzelfsprekend is. Gezien de tegengestelde ontwikkelingen van enerzijds een versmalling en anderzijds een verbreding van de reikwijdte van prenatale testen, is het nodig om opnieuw te bezien wat autonome reproductieve keuze in de context van prenatale screening eigenlijk betekent.

Er liggen drie fundamentele principes aan het normatieve kader van prenatale screening ten grondslag. Dit zijn 1) respect voor personen, 2) goed doen / niet-schaden, en 3) rechtvaardigheid. Maar deze principes zijn niet eenduidig als het gaat om de vraag welke testopties de voorkeur hebben vanuit een ethisch gezichtspunt. Respect voor personen/ autonomie kan betekenen dat de (reproductieve keuze-) mogelijkheden van een persoon niet mogen worden beperkt, maar dit betekent niet noodzakelijkerwijs dat een maximale hoeveelheid aan reproductieve keuzes de voorkeur verdient. Meer en bredere tests kunnen ook afbreuk doen aan autonomie, namelijk als toekomstige ouders overweldigd worden door de hoeveelheid en het soort mogelijke testresultaten. Het is moeilijk om te bepalen of het aanbieden van smallere of bredere testen voor deelnemers het beste uitpakt, omdat dit ook sterk afhankelijk is van persoonlijke capaciteiten en voorkeuren. Tot slot zijn gelijke toegang en proportionaliteit belangrijke voorwaarden als prenatale screening collectief gefinancierd wordt. 
In Deel II worden de gevolgen van de drie ontwikkelingen in prenatale screening vanuit de twee paradigma's nader onderzocht. Als standaard een smalle test (RAD, smalle NIPT) wordt aangeboden, betekent dit dat de aanbieders en niet de aanstaande ouders zelf bepalen wat belangrijke informatie voor hen is. In zoverre autonome reproductieve keuze hiermee niet gefaciliteerd wordt, voldoet deze benadering niet aan het beginsel van respect voor personen. Een standaard aanbod met alleen een smalle test kan de mogelijk relevante informatie en dus autonome reproductieve keuze ten onrechte te beperken. Dit betekent niet dat het bieden van meer reproductieve opties altijd de voorkeur heeft. De vraag wat nuttig en proportioneel is, gelet op de voor- en nadelen van de verschillende testopties, is moeilijk op een abstract niveau te bepalen en vergt in essentie ook een individuele beoordeling. Het alternatief van een geïndividualiseerde keuze, die het zwangere vrouwen mogelijk maakt zelf te kiezen welke testen het beste bij hun persoonlijke situatie en voorkeuren passen, zou dit dilemma kunnen oplossen. Maar de uitvoering van dit alternatief is niet gemakkelijk. De belangrijkste valkuilen van dit concept zijn een teveel aan informatie (information overload) en een emotionele en/of cognitieve overbelasting vanwege de te maken keuze. Het is zaak deze nadelen te voorkomen. Vergelijkbare problemen ontstaan wanneer brede en heterogene testen (microarrays, SEO, toekomstige whole genome/exome sequencing en analyse) worden aangeboden in het prenatale screeningstraject. Een bijzonder punt van zorg is het includeren van specifieke categorieën (mogelijke) bevindingen in genoombrede testen: dit betreft late(r)-onset ziekten, predisposities en variaties waarvan de klinische betekenis onduidelijk is. Om de ethische complicaties van dergelijke bevindingen te voorkomen, kan de test zodanig worden ontworpen dat deze bevindingen niet worden gegenereerd, of kunnen deze in de analyse-fase 'uitgefilterd' worden. Deze oplossing biedt echter nog geen antwoord op de vraag wie de exacte reikwijdte van een dergelijk ontwerp of filter bepaalt. Een ander ethisch probleem is dat het gebruik van prenatale genoombrede technieken voor diagnostische doeleinden in de praktijk leidt tot het screenen van de foetus op elke mogelijke genetische afwijking, onafhankelijk van de aanvankelijke indicatie waarmee de zwangere vrouw zich meldt. Hierdoor kan worden betwijfeld of het gebruik van een zodanige techniek als een 'geschikte test' te rechtvaardigen is. Ook wordt het recht op gelijke toegang mogelijk geschonden: als iedere indicatie volstaat, waarom zou dan niet elke zwangere vrouw in aanmerking komen voor dit soort testen?

Deel III laat zien waarom het alternatief van een geïndividualiseerde keuze een goede operationalisering van reproductieve autonomie in de prenatale screening context kan zijn. Het betekent dat zwangere vrouwen ook zelf zeggenschap hebben in de reikwijdte van aandoeningen waarvoor hun foetus getest wordt. Als dit uitgangspunt wordt doorgevoerd, dan zal dat leiden tot een individuele benadering waarbij de vraag of wens van de individuele zwangere vrouw leidend is, in plaats van een systeembenadering waarin de aanbieder 
of professional bepaalt welke test aan welke groep zwangere vrouwen standaard wordt aangeboden. Het concept van geïndividualiseerde keuze betekent niet dat alles mag en dat aanstaande ouders alles moeten krijgen wat ze vragen. Reproductieve autonomie en dus een geïndividualiseerde keuze in de prenatale screening context worden beperkt door drie factoren. Ten eerste, als prenatale screening publiek gefinancierd wordt, moet het aanbod zodanig worden beperkt dat dit voldoet aan de zorgplicht van de staat en valt onder datgene wat de meeste mensen in de samenleving als waardevolle opties beschouwen. Bovendien wordt de reikwijdte van de screening beïnvloed door de overweging dat selectieve abortus een mogelijk gevolg is van dit publiek geïnitieerde testaanbod. Ten tweede, prenatale testen worden aangeboden om autonome reproductieve keuze te bevorderen en niet om deze te ondermijnen door bijvoorbeeld een overdaad aan informatie of door de complexiteit van de keuze. Dit vereist een overzichtelijk aanbod van testopties. Ten derde, het recht op nietweten van het toekomstige kind moet beschermd worden, hetgeen vereist dat de testen geen bevindingen (kunnen) genereren die met dit recht in strijd zijn. Dit alles betekent dat aanbieders bij het opstellen van een 'menu met testopties' slechts die mogelijkheden includeren die voldoen aan de gekwalificeerde interpretatie van reproductieve autonomie. Als aanstaande ouders een dergelijk uitgebalanceerd testaanbod krijgen, kunnen ze uiteindelijk zelf kiezen wat het beste aansluit bij hun persoonlijke situatie, waarden en voorkeuren. 



\section{Curriculum Vitae}





\section{Curriculum Vitae}

Antina de Jong werd geboren op 8 mei 1967 te Gaast. In 1985 haalde zij haar VWO-diploma aan het Bogerman College te Sneek en ging theologie studeren aan de Rijksuniversiteit te Groningen. Daar studeerde zij af in de richting sociale ethiek (1991). Vervolgens ging zij een jaar reizen en werken in Indonesië en Australië (1992). Na terugkeer in Nederland werkte zij bij het toenmalige accountants- en belastingkantoor Moret, Ernst \& Young en bij de Belastingdienst (1993). In de daaropvolgende periode was zij achtereenvolgens patiëntenvertrouwenspersoon bij de Stichting Patiëntenvertrouwenspersoon Geestelijke Gezondheidszorg te Utrecht (1994-1996) en secretaris van de klachtencommissie en functionaris klachtenbemiddeling in een algemeen ziekenhuis (1997-1999). Daarna deed zij wetenschappelijk onderzoek bij het Instituut voor Gezondheidsethiek te Maastricht (1999-2002). Haar onderzoek had betrekking op de ethische vragen bij screening op dragerschap van het fragiele-X-syndroom. Gedurende de jaren 1995-2001 volgde zij tevens de deeltijdopleiding Nederlands Recht aan de Erasmus Universiteit te Rotterdam, waar zij afstudeerde in het staats- en strafrecht. Aansluitend ging zij als wetgevingsjurist bij de afdeling Wetgeving van de Raad van State werken (2002-2008). Daar concentreerde zij zich op de beleidsterreinen van Volksgezondheid, Welzijn en Sport en Onderwijs, Cultuur en Wetenschap. Voorts ontwikkelde zij zich daar tot specialist op het terrein van privacy. In het kader daarvan was zij geruime tijd gedetacheerd als senior beleidsmedewerker bij het College Bescherming Persoonsgegevens (2006). Eind 2008 begon zij aan haar promotieonderzoek op het gebied van ethiek en prenatale screening aan de Universiteit Maastricht (UM), bij de vakgroep Metamedica (Health Ethics \& Society, HES). Vanaf maart 2013 werkt zij als senior stafmedewerker/adviseur bij de Onderwijsraad te Den Haag. Daarnaast voert zij op projectbasis werkzaamheden uit op het gebied van de medische ethiek. 

List of publications 



\section{List of publications}

de Jong A, Dondorp WJ, Macville MV, de Die-Smulders CEM, van Lith JMM, de Wert GMWR: Microarrays as a diagnostic tool in prenatal screening strategies. Ethical reflection. Human Genetics (in press)

Bunnik EM, de Jong A, Nijsingh N, de Wert GMWR: The new genetics and informed consent: differentiating choice to preserve autonomy. Bioethics 2013;27:348-355.

de Jong A, Dondorp WJ, Krumeich A, Boonekamp J, van Lith JM, de Wert GM: The scope of prenatal diagnosis for women at increased risk for aneuploidies: views and preferences of professionals and potential users. J Community Genet 2013;4:125-135.

de Jong A, Dondorp WJ, de Wert GMWR: Ethische reflectie. In: Wildschut HIJ, van den Goudoever JB, den Hollander NS, Keirse E, de Wert G (eds): Foetale en neonatale screening op aangeboren afwijkingen. Amsterdam: Reed Business, 2011, pp 405-439.

de Jong A, Dondorp WJ, Frints SGM, de Die-Smulders CEM, de Wert GMWR: Advances in prenatal screening: the ethical dimension. Nat Rev Genet 2011;12:657-663.

de Jong A, Dondorp WJ, Frints SGM, de Die-Smulders CEM, de Wert GMWR: Non-invasive prenatal diagnosis for aneuploidy: toward an integral ethical assessment. Hum Reprod 2011;26:2915-2917.

de Jong A, Dondorp WJ, Timmermans DRW, van Lith JMM, de Wert GMWR: Rapid aneuploidy detection or karyotyping? Ethical reflection. Eur J Hum Genet 2011;19:1020-1025.

de Jong A, Dondorp WJ, de Wert GM: Rapid aneuploidy screening. Hong Kong Med J 2011;17(2):165.

de Jong, A: Non-invasive prenatal diagnosis: pending possibilities and moral challenges. J Nucleic Acids Investigation 2011;2(suppl 1):4-5.

de Jong A, Dondorp WJ, de Die-Smulders CEM, Frints SGM, de Wert GMWR: Non-invasive prenatal testing: ethical issues explored. Eur J Hum Genet 2010;18:272-277.

de Jong A, Dondorp WJ, de Wert GMWR: Prenatale chromosoomdiagnostiek: breed of smal? Ethische overwegingen bij het testaanbod. Tijdschr voor Verloskundigen 2010;35(2):24-27. 
de Jong A, Dondorp WJ, de Die-Smulders CEM, de Wert GMWR: De dynamiek van prenatale screening. Steeds breder testaanbod maakt morele keuzes noodzakelijk. Medisch Contact 2010;65:39.

de Jong A, Teeuw M, Janssens ACJW: 'Whole genome sequencing'. Nieuwe mogelijkheden voor de gezondheidszorg? Ned Tijdschr Geneeskd 2010;154:A2753.

de Jong A, Dondorp WJ, de Wert GMWR: Prenatale chromosoomdiagnostiek: breed of smal? Ethische overwegingen bij het testaanbod. Ned Tijdschr Geneeskd 2009;153:A1060.

de Jong A, Berghmans R, de Wert G: Bescherming van de zwakkeren. Maandblad Geestelijke Volksgezondheid 2009;64:1056-1058.

de Jong A, de Wert G: Screening op dragerschap van het fragiele-X-syndroom; ethische verkenning. Ned Tijdschr Geneeskd 2002;146:611-615.

de Jong A, de Wert G: Van gen naar ziekte; van hemoglobinegenen naar thalassemie en sikkelcelanemie. Ned Tijdschr Geneeskd 2000;144:2480-2481. 